\title{
PROBABILIDADE DE PATERNIDADE Uma proposta metodológica para seu cálculo
}

\section{Luis Eduardo Montoya Delgado}

\author{
TESE APRESENTADA \\ $\mathrm{AO}$ \\ INSTITUTO DE MATEMÁTICA E ESTATÍSTICA \\ DA \\ UNIVERSIDADE DE SÃO PAULO \\ PARA OBTENÇÃO DO GRAU \\ $\mathrm{DE}$ \\ DOUTOR EM ESTATÍSTICA
}

\author{
Área de Concentração: Estatística \\ Orientador: Prof. Dr. Carlos Alberto de Bragança Pereira
}

-São Paulo, Setembro de 1998-

Apoio Financeiro: $\mathrm{CNPq}$ 


\section{PROBABILIDADE DE PATERNIDADE \\ Uma proposta metodológica \\ para seu cálculo}

Este exemplar corresponde à redação

final da tese, devidamente corrigida, apresentada por Luis Eduardo Montoya Delgado e aprovada pela Comissào Julgadora.

São Paulo, 03 de Novembro de 1998.

\section{Banca Examinadora}

-Prof. Dr. Carlos Alberto de Bragança Pereira (Presidente)

IME-USP

-Prof. Dr. Sergio Wechsler

IME-USP

-Prof. Dr. Paulo Alberto Otto

IB-USP

-Prof. Dr. Fernando de Castro Reinach

IQ-USP

-Profa. Dra. Nancy Lopes Garcia

IMECC-UNICAMP 


\section{Agradecimentos}

Ao Prof. Dr. Carlos Alberto de Bragança Pereira, pela amizade, as idéias e orientação transmitidas durante o desenvolvimento deste trabalho. Pelo apoio que sempre me ofereciou e a confiança que em mim depositou.

Ao Prof. Dr. Sérgio Wechsler, pelas sugestões e oportunos comentários em diferentes aspectos da vida.

Aos professores do IME, aqueles, com os que teve a oportunidade de aprender, compartilhar experiências e trocar idéias.

A minha amiga e colega, Rosângela Helêna Loschi, pela paciência que teve, na revisão de algumas partes deste trabalho.

À Dra. Nazareth Rabello-Gay, pela leitura e valiosos comentários sobre uma grande parte deste trabalho.

Aos meus amigos e colegas, pela amizade e companherismo.

À Universidad del Cauca, por ter-me liberado durante meus estudos de doutorado.

Ao $\mathrm{CNPq}$, pelo apoio financiero.

A minha família, que soube suportar a solidão. 


\section{Resumo}

Neste trabalho se apresenta uma proposta metodológica para calcular a probabilidade de paternidade, quando não é possível analisar ou obter o DNA do indivíduo acusado de ser o pai e, os genótipos dos outros indivíduos considerados no estudo, são determinados sem erro. Para cada conjunto de parentes do acusado - pais, irmãos e/ou filhos - a metodologia proposta permite determinar, exactamente, a distribuição de probabilidade $a$ posteriori para o genótipo do acusado, após ter observado os genótipos de seus parentes. Com esta distribuição, a probabilidade a posteriori de paternidade pode ser calculada. Consideramos a lei de equilíbrio populacional de Hardy-Weinberg, apresentando un teste exato e não-condicional. O teste é desenvolvido, separadamente, para ambos os casos, o de dois alelos e o de alelos múltiplos. Baseándonos no conceito de informação esperada de um experimento (Smith e Bernardo, 1994), estabelecemos uma ordem de preferência entre todas las classes de parentes. Para obter essa ordem, analisamos os diferentes conjuntos de parentes do acusado. Além disso, alguns locos, usados pelo laboratório Genomic, em suas análises de DNA, são classificados em termos da informação esperada obtida para os diferentes experimentos aqui considerados. 


\section{Abstract}

This thesis presents a methodologic proposal for calculating a probability of paternity when it is not possible to analyze or to obtain the DNA of the putative father and when the genotypes of the other individuals, considered in the study, are determinated whithout error. For each set of relatives of the accused - parents, brothers, and/or sons - the methodology proposed permittes to obtain, exactly, the posterior probability distribution for the genotype of the accused, after the genotypes of the relatives have been observated. With this distribution, the posterior probability of paternity can be calculated. We consider the Hardy-Weinberg equilibrium law and present an exact and not conditional test. The test is developed, separetly, to both, the two alleles and the multiple alleles cases. Taking in account the concept of expected information of an experiment (Smith and Bernardo, 1994), we stablish an order of preference between all kinds of relativeness. To obtain this order, we analyze the different sets of relatives of the accused. Further, some loci, used by the Genomic Laboratory, in its DNA analysis, are classified according to the expected information obtained for the alternative experiments considered to be performed. 


\section{Notações}

Ao longo deste trabalho usaremos a seguinte notação.

- Seja $B$ um conjunto qualquer. O conjunto $\mathcal{A}_{B}$ denota a $\sigma$-álgebra de todos os subconjuntos de $B$.

- $\mathcal{B}_{L}$ é o conjunto de alelos observáveis no loco $L$.

- $G_{L}$ é o conjunto dos genótipos diferentes, associados aos alelos do conjunto $\mathcal{B}_{L}$.

- Consideremos $n$ alelos diferentes, $a_{1}, \cdots, a_{n}$ no conjunto $\mathcal{B}_{L}$. Para cada $i=$ $1, \cdots, n$, denotamos por $\left(a_{i},(\underbrace{x \cdots x}_{n \text { vezes }})^{c}\right)$ o conjunto constituído por todos os possíveis genótipos $\left(a_{i}, b\right)$, onde $b$ pertence a $\mathcal{B}_{L}$ e $b \neq a_{j}, j=1, \cdots, n$.

- Todas as funções, exceto as três permutações definidas a seguir, são denotadas na seguinte forma: $f[\cdot]$, onde $f$ é a função considerada.

- As permutações $\sigma(\cdot), \tau(\cdot)$ e $\gamma(\cdot)$, dos conjuntos $\{1,2\},\{2,3\}$ e $\{3,4\}$, respectivamente, são definidas da seguinte forma:

$$
\begin{aligned}
& \sigma:\{1,2\} \quad \longrightarrow \quad\{1,2\} \\
& i \quad \longmapsto \quad \sigma(i)=\left\{\begin{array}{l}
2 \text { se } i=1 \\
1 \text { se } i=2
\end{array}\right. \\
& \tau:\{2,3\} \longrightarrow\{2,3\} \\
& i \quad \tau(i)=\left\{\begin{array}{l}
3 \text { se } i=2 \\
2 \text { se } i=3
\end{array}\right.
\end{aligned}
$$




$$
\begin{aligned}
\gamma:\{3,4\} & \longrightarrow\{3,4\} \\
i & \longmapsto \gamma(i)=\left\{\begin{array}{l}
4 \text { se } i=3 \\
3 \text { se } i=4
\end{array}\right.
\end{aligned}
$$

- Para cada número natural $r$ e cada número real $t$ pertencente ao intervalo $[0,1]$, definimos $H[r, t]$ pela seguinte expressão

$$
H[r, t]=1+\left(2^{r-1}-1\right) t .
$$





\section{Sumário}

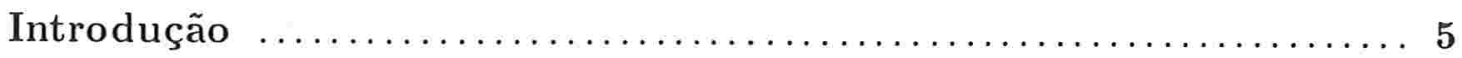

1 Conceitos genéticos e a probabilidade de paternidade $\quad 7$

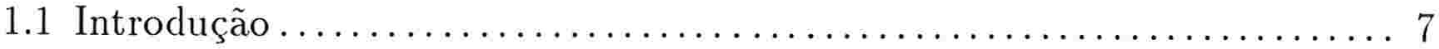

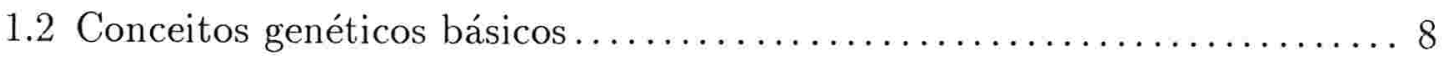

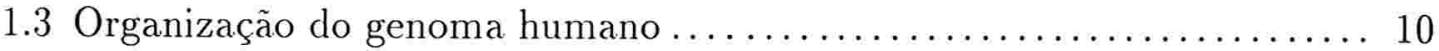

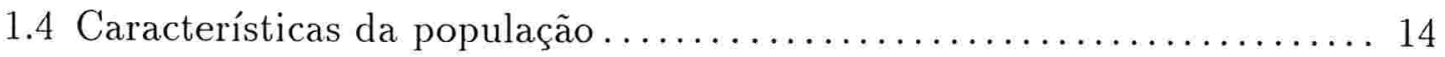

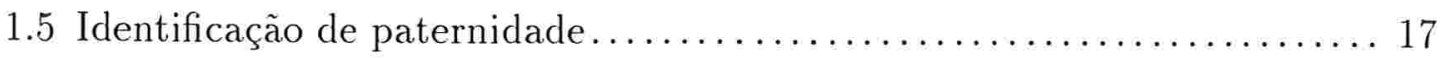

2 O teste exato não-condicional para a lei de equilíbrio de Hardy-Weinberg

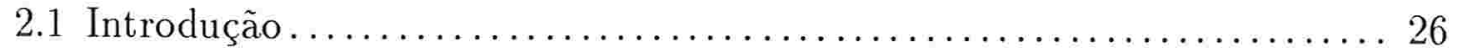

2.2 Definição e apresentação do Teste exato não-condicional .............. 28

2.3 Comparação do Teste exato não-condicional com o teste exato de Fisher 33

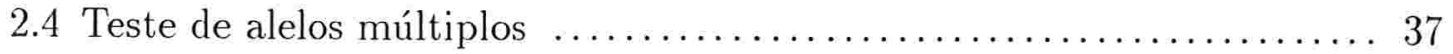


2.5 Exemplos . . . . . . . . . . . . . . . . . . . 46

3 Análise para irmãos $\quad 49$

3.1 Introdução . . . . . . . . . . . . . . . . . 49

3.2 Descrição geral da metodologia . . . . . . . . . . . . . 50

3.3 Análise dos casos . . . . . . . . . . . . . . . . . 56

$\begin{array}{lll}4 & \text { Análise para esposa e filhos } & 75\end{array}$

4.1 Introdução . . . . . . . . . . . . . . . . . . . . . . 75

4.2 Descrição geral da metodologia . . . . . . . . . . . . . 76

4.3 Análise dos casos . . . . . . . . . . . . . . . . . . . 81

5 Análise para filhos $\quad 99$

5.1 Introdução . . . . . . . . . . . . . . . . . . . . . . . . 99

5.2 Descrição geral da metodologia . . . . . . . . . . . . . 100

5.3 Análise dos casos . . . . . . . . . . . . . . . . . . 105

$\begin{array}{llr}6 & \text { Análise para pais do demandado } & 119\end{array}$

6.1 Introdução . . . . . . . . . . . . . . . . . . . . . 119

6.2 Descrição geral da metodologia I . . . . . . . . . . . . . . 120 
6.3 Análise dos casos . . . . . . . . . . . . . . . . . . . . 122

6.4 Descrição geral da metodologia II . . . . . . . . . . . . . . . 127

6.5 Análise dos casos . . . . . . . . . . . . . . . . . . . . . . . . . . 129

7 Análise para um pai e irmãos do demandado 136

7.1 Introdução . . . . . . . . . . . . . . . . . . . . 136

7.2 Descrição geral da metodologia . . . . . . . . . . . . . 137

7.3 Análise dos casos . . . . . . . . . . . . . . . . . . . . . . . . 141

8 Análise para um pai e filhos do demandado $\quad 170$

8.1 Introdução . . . . . . . . . . . . . . . . . . . 170

8.2 Descrição geral da metodologia . . . . . . . . . . . . . . 171

8.3 Análise dos casos . . . . . . . . . . . . . . . . . . . 174

9 Análise para irmãos e filhos do demandado 192

9.1 Introdução . . . . . . . . . . . . . . . . . . . . . . . 192

9.2 Descrição geral da metodologia . . . . . . . . . . . . . . . . . 193

9.3 Análise dos casos . . . . . . . . . . . . . . . . . . . 197

10 Ordem de preferência entre parentes do demandado 


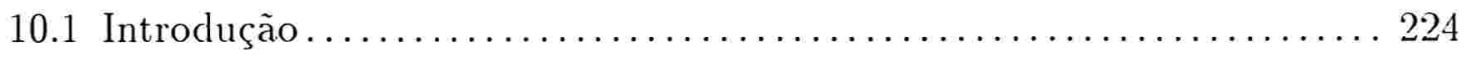

10.2 Medidas de informaçào.................................. 225

10.3 Cálculo da informação esperada de um experimento .............. 229

10.4 Informação esperada, por experimento, nos diferentes locos ......... 235

10.5 Informação esperada, por loco, nos diferentes experimentos ......... 239

$\begin{array}{ll}\text { Conclusões } & 243\end{array}$

$\begin{array}{ll}\text { Referências Bibliográficas } & \mathbf{2 4 5}\end{array}$ 


\section{Introdução}

A medicina genética serve-se da análise do $\mathrm{ADN}$ (ácido desoxirribonucleico) para, dentre outras coisas, prevenir e detectar algumas doenças, determinar o sexo de um feto e identificar vínculo genético, também chamado de teste de paternidade. As ciências forenses utilizam a análise do ADN na identificação de esqueletos e, mais geralmente, na comparação de amostras biológicas tais como manchas de sêmen ou sangue, fios de cabelo, etc.

Em vários países do mundo, a justiça utiliza as análisis do ADN para avaliar a probabilidade de um suspeito ter cometido um crime, ou para determinar relaçōes familiares em disputas de paternidade e casos de imigração.

Geralmente, nos casos de disputas de paternidade, é analisado o ADN da pessoa para quem se está solicitando o reconhecimento da paternidade (o demandante ) - embora muitas vezes não seja ele mesmo a pessoa que estabeleceu a demanda de paternidade - e os ADN da mãe do demandante e do indivíduo acusado de ser o verdadeiro pai do demandante (o demandado).

As análises apresentadas por diferentes autores são baseadas na comparação entre o ADN da mãe do demandante, do demandante e do demandado (vide, por exemplo, Gjertson et al. (1988), Berry (1991), Pena e Chakraborty (1994), Robertson e Vignaux (1995), Weir (1996)). No entanto, nenhum desses trabalhos apresenta uma metodologia que possa ser usada quando o ADN do demandado não esteja disponível.

Neste trabalho, propomos metodologias para calcularmos a probabilidade de paternidade quando não é possível analisar o $\mathrm{ADN}$ do demandado. Neste caso, naturalmente, é necessário considerar os parentes do demandado - pais, irmãos e/ou filhos - como fontes de informação genética sobre uma possivel estrutura genética do demandado. 
Procuramos estabelecer, também, uma ordem de preferência na escolha do(s) parente(s) do demandado quando, por diferentes razôes, não seja possível efetuar a análise do $\mathrm{ADN}$ de alguns deles.

Além disso, como em nosso trabalho supòe-se que, na população da qual provêm os indivíduos aqui considerados, a lei de equilíbrio populacional de Hardy e Weinberg (vide, por exemplo, Emigh e Lientz (1980)) é válida, desenvolvemos um teste exato nãocondicional para tal hipótese de equilíbrio.

No capítulo 1, apresentamos os conceitos genéticos básicos, necessários para o entendimento da linguagem própria do problema de identificação de paternidade e da probabilidade de paternidade, cujo método de cálculo será exibido, também. nesse capítulo.

O teste exato não-condicional, para a lei de equilíbrio populacional de Hardy e Weinberg, tanto para o caso de dois alelos quanto para o caso de alelos múltiplos, é apresentado no capítulo 2.

A metodologia, a ser usada para calcular a probabilidade de paternidade, segundo o(s) parente(s) do demandado que seja(m) considerado(s), é apresentada do capítulo 3 ao 9 , contendo, respectivamente, as análises quando são observados alguns irmãos do demandado, a "esposa" e alguns filhos do demandado, somente filhos do demandado, um ou ambos os pais do demandado, alguns irmãos e a mãe do demandado, alguns filhos e a mãe do demandado e, finalmente, irmãos e filhos do demandado.

No capítulo 10, apresentamos o conceito de informação esperada de um experimento. Este conceito é usado como critério de comparação entre os experimentos considerados nos capítulos 2-8. Além disso, exibimos a ordem - em termos de informação esperada - estabelecida entre alguns dos locos utilizados pela empresa Genomic em suas análises de ADN. 


\section{Capítulo 1}

\section{Conceitos genéticos e a probabilidade de paternidade}

\subsection{Introdução}

Para melhor compreensão deste trabalho, faz-se necessário o conhecimento de alguns conceitos genéticos e do problema de identificação de paternidade, os quais serão apresentados aqui.

A seção 1.2 contém os conceitos genéticos fundamentais que serão utilizados neste trabalho. A organização do genoma humano, junto com algumas considerações a respeito da utilização das seqüências de ADN na comparação de amostras biológicas, é mostrado na seção 1.3. Na seção 1.4 apresentamos as características que a população de indivíduos à qual pertencem as pessoas consideradas no estudo genético deve ter.

Na seção 1.5 é apresentado o problema de identificação de paternidade, sendo definida. nessa mesma seção, a chamada probabilidade de paternidade. Também, na seção 1.5 , será exibido o método de cálculo da probabilidade de paternidade.

As definições apresentadas nas seções 1.2, 1.3 e 1.4, foram obtidas de Cavalli-Sforza e Bodmer (1971), Farah (1997), Pavan e Da Cunha (1966), Weir (1996) e Whittle (1998). 


\subsection{Conceitos genéticos básicos}

O material genético dos seres humanos (ADN - ácido dexoxirribonucléico), que está presente no núcleo de todas as células do organismo, define a constituição genética de cada pessoa e especifica, nos mínimos detalhes, a função a ser realizada por cada uma das células que constituem o organismo. Na constituição genética estão determinadas todas as características do indivíduo as quais podem ou não manifestar-se ao longo de sua vida.

Os ácidos nucléicos, dos quais o $\mathrm{ADN}$ faz parte, são constituídos por unidades moleculares chamadas de nucleotídeos que sào compostos por um grupo fosfato, um açúcar e uma base nitrogenada. O açúcar e o fosfato são componentes invariáveis nos nucleotídeos e apenas fazem parte da estrutura da molécula de ADN. Já as bases nitrogenadas - citosina (C), timina (T), adenina (A) e guanina (G) - são responsáveis por armazenar toda a informação importante para a síntese proteica.

As proteínas, por sua vez, são macromoléculas formadas pela união de duas ou mais cadeias polipeptídicas lineares sintetizadas separadamente. Cada cadeia polipeptídica linear é uma mistura de centenas ou milhares dos vinte diferentes tipos de aminoácidos existentes. Esta mistura de aminoácidos, necessária para formar uma certa cadeia polipeptídica linear, é determinada pela informação específica contida numa seqüência de bases que está localizada numa porção do $\mathrm{ADN}$ e que é conhecida por gene. Diferentes genes são responsáveis pela codificaçào de distintas cadeias polipeptídicas lineares, e diferentes genes podem codificar a mesma proteína.

A molécula de ADN é constituída, em parte, por duas cadeias de nucleotídeos que se enrolam formando uma dupla hélice. A estrutura dessa molécula tem sido comparada a uma escada enrolada sobre si mesma em forma de espiral, sendo os corrimãos formados pela parte invariável da molécula - ou seja, o grupo fosfato e o açúcar - e cada degrau por duas bases nitrogenadas ligadas por pontes de hidrogênio. No caso humano, os únicos pares de bases possíveis são A-T e C-G, já que a adenina sempre se liga à timina e a citosina sempre se liga à guanina. Desta maneira, as duas cadeias de nucleotídeos que fazem parte da molécula de $\mathrm{ADN}$ são complementares. Por exemplo, se numa cadeia aparece a seqüência de bases A.ATCCGGT, na cadeia complementar aparecerá a seqüência TTAGGCCA.

O ADN de uma célula humana apresenta um comprimento total de quase dois (2) me- 
tros e, provavelmente, para facilitar sua organizaçào dentro do núcleo de cada célula. é dividido em vários elementos distintos chamados cromossomos. Existem 46 cromossomos na espécie humana, formando 23 pares, dos quais 44 são chamados autossomos e dois chamados cromossomos sexuais, por estarem envolvidos na determinação do sexo. $\mathrm{Na}$ mulher, o par sexual é formado por dois cromossomos iguais, os cromossomos $\mathrm{X}$; no homem, esse par é constituído por um X e um cromossomo menor. denominado $Y$. Os dois $\mathrm{X}$ da mulher e os 44 não -sexuais formam, nos dois sexos, pares de homólogos, e provêm um do pai e outro da mãe. No caso de um indivíduo de sexo masculino, o $\mathrm{X}$ foi herdado da mãe e o $\mathrm{Y}$, do pai.

Em cada cromossomo existem regiões específicas contendo seqüências de nucleotídeos denominadas locos. Em cada loco podem ser encontrados um gene ou uma seqüencia de nucleotídeos não codificadora. Posições ou locos correspondentes em cromossomos homólogos contêm genes responsáveis pela mesma característica genética, embora muitas vezes as seqüências de bases que os constituem não sejam necessariamente idênticas. Estes genes são considerados genes alelos ou simplesmente alelos. Também sào denominados alelos as seqüências não codificadoras que ocupam locos correspondentes nos cromossomos homólogos. Quando um indivíduo possui alelos diferentes para um dado loco, dizemos que ele é heterozigoto com respeito àquela característica genética ou para aquele particular gene. Se tais alelos são idênticos dizemos que ele é homozigoto.

Nos cromossomos homólogos, os alelos presentes em um determinado loco são o genótipo deste loco. O termo genótipo é também utilizado para designar o conjunto de todos os alelos presentes em um conjunto de locos de um mesmo indivíduo. A manifestação morfológica ou bioquímica de qualquer genótipo é denominada fenótipo. Quando genótipos diferentes manifestam-se como fenótipos diferentes dizemos que os alelos sào co-dominantes.

Como nosso sistema de reprodução é sexuado, a formação de um indivíduo provém da fusão de um gameta feminino (óvulo) com um gameta masculino (espermatozóide). Para manter o número cromossômico da espécie humana, cada um dos gametas deve contribuir com a metade do número de cromossomos presentes nas outras células. Por esta razão os gametas são células haplóides - isto é, são células que possuem somente um cromossomo de cada par de cromossomos homólogos e apresentam apenas um alelo em cada loco. Este loco é dito monomórfico. O conjunto formado pelos alelos de um ou mais locos, transferidos a um indivíduo por um de seus pais, é chamado de haplótipo. As outras células de nosso corpo são as chamadas células somáticas e todas elas são diplóides por possuirem dois conjuntos dos cromossomos presentes nos gametas. 
Assim, em cada par cromossômico encontrado em um individuo adulto, cada genótipo de cada loco, é formado por um alelo proveniente da màe e outro do pai. Constituído desta maneira, o ADN representa todo o material genético que um indivíduo herda de seus pais e por isto é chamado de material genético ou hereditário da célula.

Na próxima seção abordaremos suscintamente a forma em que está organizada a informação genética humana.

\subsection{Organização do genoma humano.}

A palavra genoma é usada para designar o conjunto de genes ou seqüências de nucleotídeos não codificadoras presentes em uma célula, em um indivíduo ou em uma espécie. A informação genética nas células humanas está organizada em dois grandes genomas: mitocondrial e nuclear.

O genoma mitocondrial é constituído por alguns genes extranucleares e tem herança exclusivamente materna. Este tipo de genoma é, em geral, idêntico e as vezes é usado na identificação de indivíduos - por exemplo, quando somente é possível obter um perfil de ADN da mãe da pessoa que se deseja identificar. Algumas doenças genéticas transmitidas somente pelas mães podem ocorrer por causa de mutações nos genes mitocondriais.

O genoma nuclear de uma célula humana haplóide contém um total de $3 \times 10^{9}$ pares de bases que aparecem distribuídos nos 23 cromossomos e onde cada cromossomo consiste de uma única molécula de ADN de tamanho variado. Aproximadamente $75 \%$ do genoma nuclear está constituído por seqüências de nucleotídeos que não se repetem ou que aparecem poucas vezes representadas no genoma humano, as quais são chamadas seqüências simples de $\mathrm{ADN}$. O ADN restante é composto de seqüências que se repetem de centenas a milhões de vezes no genoma, compondo o ADN repetido ( $r A D N)$. Apesar da grande maioria dos genes codificarem um polipeptídio específico, existe uma minoria destes que codificam RN. De qualquer maneira, o total de ADN codificador (genes) compõe somente cerca de $2.5 \%$ do genoma humano e encontra-se principalmente entre as seqüências de nucleotídeos que não se repetem na molécula de ADN. Estima-se que, no genoma humano, existem aproximadamente 100000 genes.

O ADN simples não codificador pode ser encontrado dentro dos genes ou formando os íntrons, ou como genes que, se acredita, foram um dia ativos mas que perderam 
sua atividade ao longo da evolução (os pseudogenes), ou ainda podem ser seqüências dispersas entre os genes - o ADN extragênico.

O ADN repetido, que compõe aproximadamente $25 \%$ do genoma nuclear, pode ser classificado em ADN codificador, formador das famílias de multigenes, e em ADN não codificador que compõe $\mathrm{ADN}$ extragênico. Este último tipo de $\mathrm{ADN}$ não inclui genes funcionais e é composto por seqüências que se repetem em tandem (ou seja, uma após a outra) e por seqüências dispersas no genoma que se repetem individualmente. As seqüências que se repetem em tandem sào classificadas de acordo com o tamanho médio das unidades de repetição. Segundo este critério podem ser classificadas como ADN satélite, minissatélite ou microssatélite.

O ADN satélite compreende seqüências relativamente grandes - mais de 60 nucleotídeos - e sem atividade de transcrição. Ainda pouco se sabe sobre este tipo de ADN. No ADN minissatélite, a seqüência repetida é de tamanho moderado - entre 20 e 60 nucleotídeos - e assume comprimento entre 15 e 20 mil pares de bases. As famílias de ADN microssatélites incluem seqüências muito pequenas, repetidas em tandem, contendo entre 1 e 4 pares de bases que aparecem distribuídas ao longo do genoma.

As seqüências de ADN minissatélites e microssatélites são o tipo de ADN de maior interesse para nosso trabalho, por terem estas se constituído em importantes ferramentas da Biologia Molecular. Através do estudo destas seqüências, algumas áreas da genética como a localização de genes, o diagnóstico de doenças genéticas, a identificação de indivíduos e a determinação do vínculo genético, têm-se beneficiado enormemente já que podemos identificar o perfil ou fingerprinting molecular de cada indivíduo utilizando uma amostra qualquer de tecido. Esta identificação só é possível porque, salvo em casos de gêmeos idênticos, não existem dois indivíduos com o mesmo genótipo e também por que o ADN de um indivíduo é igual em qualquer célula de seu organismo.

Os perfis de ADN humano fornecem uma poderosa ferramenta na comparação de amostras biológicas tais como manchas de sêmen ou sangue, fios de cabelo, etc. - que aparecem como possíveis provas na cena de um crime. Também são utilizados os perfis de ADN para determinar relações familiares em disputas de paternidade e casos de imigração, assim como na identificação de esqueletos. Para estes casos, os perfis de ADN são geralmente obtidos utilizando marcadores genéticos discretos entre os quais mencionamos o polimorfismo no comprimento do fragmento de restrição (RFLP - restriction fragment length polymorphisms), a reação em cadeia de polimerasa (PCR - polymerase chain reaction), o número variável de repetições em tandem (VNTR - variable number of tandem repeats) correspondente às seqüências de ADN minissatélite e as pequenas re- 
petições em tandem (STR - short tandem repeats) correspondentes às seqüências de ADN microssatélite. Uma breve descrição destes marcadores pode ser encontrada em Weir (1996) e Farah (1997).

Usualmente, a comparação de amostras biológicas, tais como manchas de sêmen ou sangue, fios de cabelo, etc., é feita para identificar indivíduos envolvidos em algum crime. Quando um crime ocorre, o delinqüente pode deixar no cenário do crime alguma quantidade de fluido corporal - chamada amostra evidenciária - a qual pode posteriormente ser usada para incriminar ou não um certo suspeito. Para isto, retira-se uma amostra de sangue do suspeito e se compara com a amostra evidenciária colhida no local do crime, fazendo-se um perfil de ADN.

Para o caso descrito no parágrafo anterior, quando o marcador RFLP é usado para a obtenção dos perfis em um loco, Berry (1991) havia proposto uma medida da evidência genética de que a amostra evidenciária provém do suspeito, supondo que os erros de medição em cada uma das bandas do perfil são independentes e lognormalmente distribuídos. Estas suposições conduzem também ao julgamento de independência sobre o comprimento das bandas. Neste mesmo artigo, o autor estende a proposta feita ao caso de identificação de paternidade. Neste caso, dado o perfil de ADN da pessoa para quem se está solicitando o reconhecimento da paternidade (o demandante ) - embora muitas vezes não seja ele mesmo a pessoa que estabeleceu a demanda de paternidade - e os perfis da mãe do demandante e do indivíduo acusado de ser o verdadeiro pai do demandante (o demandado), a razão entre a probabilidade da evidência genética - constituída neste caso pelos três perfis de ADN - supondo que o demandado é o verdadeiro pai do demandante e a probabilidade da evidência genética supondo que o verdadeiro pai do demandante não é o demandado, é considerada como uma medida da evidência genética a favor da hipótese de que o demandado é o verdadeiro pai do demandante. Esta razão de verossimilhanças também é chamada índice de paternidade.

Um tratamento Bayesiano para o problema de identificar suspeitos criminosos pode ser encontrado em Berry et al. (1992), também para o caso quando o marcador RFLP é usado na obtenção dos perfis em um loco. Estes autores consideram a importância da correlação entre os erros de medição no comprimento dos fragmentos em cada banda do perfil. Sob a suposição de normalidade para estes erros, Berry et al. (1992) utilizam a razão de verossimilhança normal (entre a probabilidade condicional da evidência genética supondo que a amostra evidenciária provém do suspeito e a probabilidade condicional da evidência genética supondo que a amostra evidenciária provém de outra pessoa) para concluir sobre a hipótese de que a amostra evidenciária vem do suspeito. Um método mais simples do que o proposto por Berry tt al. (1992) para calcular a razão 
de verossimilhança normal é apresentado por Evett et al. (1992).

Recentemente, Foreman et al. (1997) desenvolveram algumas idéias e metodologias sob uma perspectiva bayesiana, fundamentalmente, para analisar dados e avaliar a razão de verossimilhança quando a evidência genética está baseada em perfis de ADN obtidos em locos STR. A razão de verossimilhança considerada pelos autores fornece apenas uma medida da evidência genética a favor da hipótese de que a amostra de ADN retirada do cenário do crime provém do suspeito - ou seja, eles não examinam, por exemplo, o caso de identificação de paternidade.

Em casos de identificação de esqueletos, os perfis de ADN dos esqueletos são comparados com perfis de membros da família à qual supostamente pertencem. Neste caso particular, geralmente são utilizados os locos STR que são mais informativos quando o ADN disponível está parcialmente degradado ou é muito limitado (Hammond et al. (1994)). Um caso histórico e famoso que ilustra esta situação é o da identificação dos restos da família Romanov. O desaparecimento desta família aconteceu em meados de 1918 e em Julho de 1991 foram descobertos nove esqueletos em um túmulo. Estes esqueletos foram identificados - sem muita certeza - pelas autoridades forenses russas como pertencentes ao último Czar russo, sua esposa, três de seus cinco filhos, o médico da família e três empregados. Uma vez analisados os perfis de ADN obtidos destes esqueletos, os resultados obtidos levam à aceitação da hipótese que cinco deles, de fato, pertencem à família Romanov. Maiores detalhes podem ser vistos em Gill et al. (1994).

Apesar da identificação de alelos nos locos VNTR ser mais passivel de erro, estes locos têm sido preferencialmente usados por serem mais polimórficos - isto é, possuem uma grande quantidade de alelos. $\mathrm{O}$ uso de locos polimórficos permite discriminar com mais precisão indivíduos falsamente acusados - ou seja, conduz a uma maior probabilidade de exclusão. Ver, por exemplo Hammmond et al. (1994) para maiores detalhes.

Quando utilizamos locos STR, os alelos ocorrem em menor número e são identificados sem erro de medição, desde que se tenha um bom controle nos processos laboratoriais. Esta e outras vantagens da utilização dos locos STR estão descritas em Hammond et al. (1994), Gill e Evett (1995) e Foreman et al. (1997).

Na próxima seção apresentaremos mais algumas considerações sobre os indivíduos cujos perfis são fruto de análise neste trabalho. 


\subsection{Características da população}

Antes de entrarmos em maiores detalhes sobre o problema que abordaremos neste trabalho - a saber, a determinação da probabilidade de paternidade - forneceremos alguns aspectos importantes a respeito do conjunto de indivíduos do qual provém as pessoas cujos perfis genéticos serão analisados.

Ao longo de todo este trabalho, suporemos que os indivíduos considerados no estudo genético provém de uma população $\mathcal{P}$ supostamente infinita (ou suficientemente grande), onde todos os cruzamentos ocorrem completamente ao acaso - isto é, os indivíduos considerados farão parte de uma população pan-mítica que satisfaz as leis mendelianas. ${ }^{1}$ Por exemplo, $\mathcal{P}$ pode estar constituída por todos os individuos de uma mesma raça ou de um determinado grupo étnico.

Consideraremos também um sistema monogênico, autossômico, polialélico e codominante - isto é, um sistema constituído por um loco $(L)$ não situado nos cromossomos sexuais, com múltiplos alelos e onde genótipos distintos definem fenótipos diferentes.

Também denotaremos por $\mathcal{B}_{L}$ o conjunto $\left\{b_{1}, \cdots, b_{c}\right\}(c \geq 2)$ formado por todos os possiveis alelos observáveis no loco L. A freqüência alélica populacional do alelo $b_{i}$ na população $\mathcal{P}$, denotada por $f_{b_{i}}$, será considerada como a proporção de indivíduos desta população que possuem, no loco $\mathrm{L}$ e seu homólogo, o alelo $b_{i}$ para todo $i=1, \cdots, c$, e satisfazendo a relação $\sum_{i=1}^{c} f_{b_{i}}=1$. Suporemos que, na população $\mathcal{P}$, tanto homens quanto mulheres têm as mesmas freqüências alélicas.

Denotaremos por $g_{k_{i}}$ ou por $\left(b_{i}, b_{j}\right)$ o genótipo relacionado aos alelos $b_{i}$ e $b_{j}{ }^{2}$ para $i \leq j, i, j=1, \cdots, c$ e consideraremos o conjunto $G_{L}=\left\{g_{1}, g_{2}, \cdots, g_{N}\right\}$ formado pelos $N$ genótipos diferentes associados aos alelos do conjunto $\mathcal{B}_{L}$, onde

$$
k_{i j}=\frac{(i-1)(2 c-i)+2 j}{2} \text { e } N=\frac{c(c+1)}{2} .
$$

A freqüência genotípica populacional do genótipo $\left(b_{i}, b_{j}\right)$ (ou $g_{k_{i j}}$ ) na populaçào $\mathcal{P}$ será denotada por $p_{i j}$ (ou $p_{k_{i j}}$ ) e representará a proporção de indivíduos desta população

\footnotetext{
${ }^{1}$ Estas suposições são consideradas razoáveis pois todos os grandes laboratórios que realizam testes de ADN possuem grandes bases de dados as quais são usadas como populações de referência (Roeder (1994)).

${ }^{2}$ Não faremos distinção alguma entre os genótipos $\left(b_{i}, b_{j}\right)$ e $\left(b_{j}, b_{i}\right)$.
} 
que. no loco L, possuem o genótipo $\left(b_{i}, b_{j}\right)$ (ou $g_{k_{i}}$ ) para $i=1 . \cdots, c ; j=i, \cdots, c$ e $\sum_{i=1}^{c} \sum_{j=i}^{c} p_{i j}=1$.

Chamaremos de $n_{i j}$ o número de indivíduos na amostra que possuem o genótipo $\left(b_{i}, b_{j}\right)$. Se da população $\mathcal{P}$ retiramos uma amostra de tamanho $n$ entào, a freqüencia relativa amostral do genótipo $\left(b_{i}, b_{j}\right)$ e a freqüência relativa amostral do alelo $b_{i}$ serão dadas respectivamente por:

$$
\begin{aligned}
& \tilde{p}_{i j}=\frac{n_{i j}}{n}, \quad i \leq j, \quad i, j=1, \cdots, c \\
& \tilde{f}_{b_{\mathrm{r}}}=\frac{\sum_{j=1}^{i} n_{j i}+\sum_{j=i}^{c} n_{i j}}{2 n}, \quad i=1, \cdots, c .
\end{aligned}
$$

Um conceito de enorme importância e sob o qual estará baseado nosso trabalho é o conceito de equilíbrio populacional. Para as considerações que aqui faremos adotaremos a definição de equilíbrio fornecida por Hardy e Weinberg em 1908, a qual é conhecida na literatura como o princípio ou a lei de equilíbrio populacional de HardyWeinberg. Esta lei, que será enunciada a seguir, estabelece que em uma população pan-mítica e suficientemente grande, desde que as migrações, mutações e escolhas naturais não afetem um loco, as freqüências alélicas e as freqüências genotípicas neste loco permanecem estáveis.

No capítulo 2, consideraremos a lei de equilíbrio populacional de Hardy-Weinberg em maiores detalhes, apresentando um teste exato para verificar a conhecida lei das freqüências de Hardy-Weinberg - enunciada a seguir.

\section{Lei das freqüências de Hardy-Weinberg}

Em uma população pan-mítica, que não se afasta das leis mendelianas, o equilíbrio é obtido em uma etapa da reprodução e existem $z_{1}, z_{2}, \cdots, z_{c}$ em $(0,1) \operatorname{com} \sum_{j=1}^{c} z_{j}=1$, tais que a seguinte relaçâo é satisfeita:

$$
p_{\frac{(i-1)(2 n-i)+2 j}{2}}=\left\{\begin{array}{lr}
z_{i}^{2} & \text { se } j=i, i=1, \cdots, c \\
2 z_{i} z_{j} & \text { se } i=1, \cdots, c-1, \\
& j=i+1, \cdots, c
\end{array}\right.
$$

A lei anterior permite caracterizar as freqüências genotípicas populacionais em termos das freqüências alélicas populacionais. Se a lei de equilíbrio de Hardy-Weinberg 
é válida no loco $L$, para a populaçào $\mathcal{P}$, entào, dadas as freqüências alélicas $z_{1}, \cdots, z_{c}$ $\operatorname{com} \sum_{j=1}^{c} \tilde{\sim}_{j}=1$, as freqüências genotípicas são dadas pela expressão 1.1.

Geralmente, um perfil do ADN de uma pessoa é obtido analisando-se vários locos. Por este motivo, é necessário considerarmos um conceito de equilíbrio populacional relacionado com o conjunto de locos que serão usados na determinação deste perfil. Este conceito de equilíbrio, apresentado a seguir, tem sido estudado por Jeffreys et al. (1991), Gjertson e Morris (1995), Weir (1996), Lazzeroni e Lange (1997), entre outros.

Dizemos que a população $\mathcal{P}$ está em equilíbrio com respeito ao conjunto formado pelos locos $L_{1}, \cdots, L_{m}$, se os dois haplótipos, correspondentes a este conjunto de locos, transmitidos pelos pais (não parentes) ao seu filho são independentes e identicamente distribuidos. Ou seja, considerando $\mathcal{B}_{L_{j}}=\left\{b_{j 1}, \cdots, b_{j c}\right\}$ o conjunto de alelos observáveis no loco $L_{j}$ para cada $j=1, \cdots, m$ e denotando por $\left[b_{1 k_{1}}, b_{2 k_{2}}, \cdots, b_{m k_{m}}\right]$ um haplótipo para este conjunto de $m$ locos, onde o alelo $b_{j k}$, pertence a $\mathcal{B}_{L_{j}}$ e $k_{j}=1, \cdots, c_{j}$. então a população $\mathcal{P}$ está em equilíbrio, com respeito a esse conjunto de locos, se a freqüência populacional do genótipo

$$
\left(\left[b_{1 k_{1}}, b_{2 k_{2}}, \cdots, b_{m k_{m}}\right],\left[b_{1 k_{1}^{\prime}}, b_{2 k_{2}^{\prime}}, \cdots, b_{m k_{m}^{\prime}}\right]\right)
$$

for dada pelo produto das freqüências populacionais de cada um dos haplótipos

$$
\left[b_{1 k_{1}}, b_{2 k_{2}}, \cdots, b_{m k_{m}}\right] \text { e }\left[b_{1 k_{1}^{\prime}}, b_{2 k_{2}^{\prime}}, \cdots, b_{m k_{m}^{\prime}}\right]
$$

e se, para cada haplótipo, sendo ele proveniente do pai ou da mãe, sua freqüência populacional é a mesma.

Quando a freqüência populacional de cada haplótipo é dada pelo produto das freqüências populacionais dos alelos que o constituem, dizemos que a população $\mathcal{P}$ está em equilíbrio de ligação com respeito ao conjunto formado pelos locos em consideração.

Em casos de identificação forense e de determinação de paternidade, geralmente são considerados quatro ou mais locos localizados em cromossomos diferentes e assumese que estes locos encontram-se em equilíbrio de ligação. Lazzeroni e Lange (1997) desenvolveram uma metodologia para testar equilíbrio de Hardy-Weinberg e equilíbrio de ligação a qual utiliza cadeias de Markov na estimação do valor de signicancia em um teste exato condicional.

Até aqui apresentamos alguns conceitos genéticos, cujo conhecimento, mesmo que pouco profundo, será de grande importância na compreensão das idéias que desenvolveremos 
daqui em diante, ao abordarmos o problema de identificaçào de paternidade. A seguinte seçào será dedicada à apresentação e definição deste problema.

\subsection{Identificação de paternidade}

Os trabalhos disponíveis na literatura referentes à determinação de paternidade de um indivíduo partindo de perfis do $\mathrm{ADN}$, geralmente, consideram a disponibilidade de informação sobre os perfis genotípicos do demandante, da mãe do demandante e do demandado. Geralmente, considera-se como pai alternativo um indivíduo qualquer da população; podendo, algumas vezes, ser este pai alternativo um parente do demandado - por exemplo, o pai, um irmão ou um sobrinho do demandado. (Para maiores detalhes veja Evett (1992), Curnow e Wheeler (1993), Weir (1996)).

As análises apresentadas por diferentes autores sào baseadas na comparação entre os perfis do ADN da mãe do demandante, do demandante e do demandado. Segundo o marcador genético utilizado na determinação dos perfis de ADN - RFLP (veja, Gjertson ct al. (1988), Berry (1991)), VNTR (ver, Devlin et al. (1992), Curnow e Wheeler (1993), Pena e Chakraborty (1994)), STR (veja, Evett et al. (1996), Ranjan et al. (1995), Foreman et al. (1997)), etc., estão disponíveis várias metodologias para calcular a probabilidade de que o demandado seja o verdadeiro pai do demandante, denominada probabilidade de paternidade. Outros autores consideram unicamente o índice de paternidade - a razão entre as probabilidades dos perfis, supondo que o demandado seja ou não o verdadeiro pai do demandante (veja, por exemplo, Jeffreys et al (1991)).

Contudo, nenhum desses trabalhos apresenta uma metodologia que possa ser usada quando o demandado esteja morto e seja impossível obter um perfil de seu ADN, ou simplesmente quando essa pessoa esteja desaparecida. Neste caso, devemos considerar os parentes do demandado como fontes de informação genética sobre um possível perfil do demandado, ou seja, consideraremos pessoas sobre as quais não existe dúvida sobre sua relação de parentesco com o demandado, por exemplo, os pais, irmãos e filhos, se existirem.

Aqui. desenvolvemos algumas idéias e propomos metodologias para calcularmos a probabilidade de paternidade quando não é possivel obter o perfil genotípico do demandado. Os dados correspondentes aos perfis genéticos das pessoas consideradas no estudo de paternidade - a mãe do demandante, o demandante e os parentes do demandado - são 
determinados sem erro, por exemplo usando locos microssatélites (STR).

Formalmente, o problema básico de paternidade pode especificar-se da seguinte maneira:

Consideremos as hipóteses

$H_{0}$ : o demandado é o verdadeiro pai do demandante.

$H_{1}$ : o verdadeiro pai do demandante é uma outra pessoa, que não é parente do demandado mas pertence à mesma população.

Seja $\theta$ o parâmetro indicador de hipótese; isto é, $\theta=i$ se $H_{i}$ é verdadeira para $i=0,1$. As preferências a priori do analista pelas hipóteses estão descritas pela distribuição de probabilidade $\pi$ onde

$$
\pi_{i}=\pi[\theta=i] ; \quad i=0,1 \text { com } \pi_{0}+\pi_{1}=1 .
$$

Ou seja, para $i=0,1$ temos que $\pi_{i}=\pi[\theta=i]$ é a probabilidade a priori de que o demandado seja ou não seja o verdadeiro pai do demandante, respectivamente. Isto é, $\pi[\theta=0]$ é a probabilidade a priori de paternidade.

Nosso objetivo é determinar a distribuição de probabilidade a posteriori de paternidade $\pi[\cdot \mid D]$, onde $D$ é o conjunto de dados obtidos ao observarmos o genótipo da mãe do demandante, do demandante e dos parentes do demandado. Isto é, queremos estabelecer qual é a probabilidade de que o demandado seja ou não o verdadeiro pai do demandante - uma vez que foram observados o genótipo da mãe do demandante, do demandante e dos parentes do demandado.

Sejam $\mathcal{B}_{L}$ e $G_{L}$ os conjuntos de alelos e genótipos respectivamente - no loco $L$ - como definidos na seção anterior.

Consideremos o espaço mensurável $\left(G_{L}, \mathcal{A}_{G_{L}}\right)$, onde $\mathcal{A}_{G_{L}}$ é a $\sigma$-álgebra das partes do conjunto $G_{L}$ e seja $Z$ a variável aleatória $\mathcal{A}_{G_{L}}$ mensurável que denota o genótipo de um indivíduo qualquer da população. Se todos os cruzamentos ocorrerem ao acaso e se, além disto, a lei de equilíbrio populacional de Hardy-Weinberg é satisfeita, as frequências genotípicas populacionais serão dadas pela expressão $1.1 \mathrm{ou}$, equivalentemente, por

$$
P\left[\left\{g_{\frac{(i-1)(2 c-i)+23}{2}}\right\}\right]= \begin{cases}f_{b_{i}}^{2} & \text { se } i=j, i=1, \cdots, c \\ 2 f_{b_{i}} f_{b_{j}} & \text { se } i=1, \cdots, c-1 ; j=i+1, \cdots, c,\end{cases}
$$

e, conseqüentemente, teremos que a medida $P$ definida sobre o espaço mensurável $\left(G_{L}, \mathcal{A}_{G_{L}}\right)$, é uma medida de probabilidade. Esta distribuição de probabilidade será 
chamada de distribuição a priori para o genótipo de um indivíduo qualquer da populaçào e entenderemos $P\left[\left\{g_{k}\right\}\right]$ como sendo a probabilidade de que $Z$ assuma o valor $g_{k}$. isto é, é a probabilidade $P\left[Z=g_{k}\right]$.

Suponhamos que estejam disponíveis dados do demandante e de sua mãe, além de dados referentes a alguns parentes do demandado. Isto é, as árvores genealógicas que estudaremos são subárvores da que apresentamos a seguir.

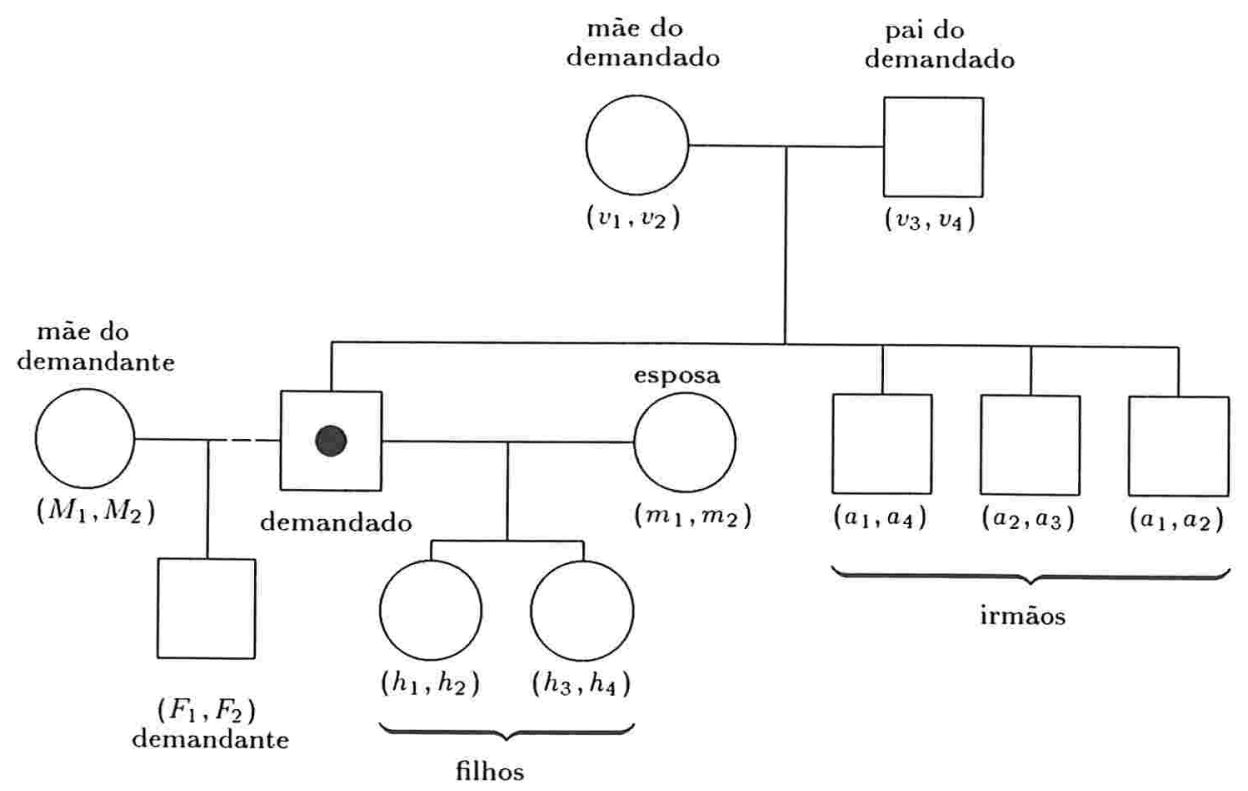

Sejam $M, F$ e $X$ variáveis aleatórias $\mathcal{A}_{G_{L}}$ mensuráveis que denotam, respectivamente, o genótipo da mãe do demandante, do demandante e do demandado, e consideremos $U$ como sendo o vetor aleatório dos genótipos dos parentes do demandado constituído por componentes $\mathcal{A}_{G_{L}}$ mensuráveis.

Se os valores observados de $M, F$ e $U$ são respectivamente $\left(M_{1}, M_{2}\right),\left(F_{1}, F_{2}\right)$ e u, o conjunto dos dados $D$ correspondente a este experimento é formado por

$$
D=\left\{\left(M_{1}, M_{2}\right),\left(F_{1}, F_{2}\right), \mathrm{u}\right\} .
$$


Dado que os genótipos $\left(M_{1}, M_{2}\right)$ e $\left(F_{1}, F_{2}\right)$ devem ter pelo menos um alelo em comum, sem perda de generalidade podemos supor que $M_{1}=F_{1}$. Se $F_{2} \neq M_{i}, i=1,2$ ou se $F_{1}=F_{2}$ então, o pai do demandante necessariamente deve ter o alelo $F_{2}$, o qual chamamos de alelo de interesse. Quando $M_{i}=F_{i}, i=1,2$ e $M_{1} \neq M_{2}$ o pai do demandante pode ter qualquer um dos alelos $F_{i}, i=1,2$; nesse caso, estes dois alelos são chamados de alelos de interesse.

Utilizando o Teorema de Bayes como mecanismo de atualização de probabilidades temos que a distribuição de probabilidade a posteriori de paternidade $\pi[\cdot \mid D]$ é dada pela seguinte expressão

$$
\pi[\theta=i \mid D]=\frac{P[D \mid \theta=i] \pi[\theta=i]}{\sum_{j=0}^{1} P[D \mid \theta=j] \pi[\theta=j]}, \quad i=0,1,
$$

onde, para $i=0,1$ a probabilidade condicional $P[D \mid \theta=i]$ é dada por

$$
\begin{aligned}
P[D \mid \theta=i] & =P\left[M=\left(M_{1}, M_{2}\right), F=\left(F_{1}, F_{2}\right), U=\mathbf{u} \mid \theta=i\right] \\
& =V_{i}[D] P\left[M=\left(M_{1}, M_{2}\right), U=\mathbf{u} \mid \theta=i\right], \quad i=0,1
\end{aligned}
$$

e a probabilidade condicional $V_{i}[D]$ é dada pela expressão

$$
V_{i}[D]=P\left[F=\left(F_{1}, F_{2}\right) \mid M=\left(M_{1}, M_{2}\right), U=\mathbf{u}, \theta=i\right], \quad i=0,1 .
$$

Ou seja,

$$
\begin{aligned}
V_{0}[D]= & \sum_{i=1}^{c} \sum_{j=i}^{c} P\left[F=\left(F_{1}, F_{2}\right) \mid M=\left(M_{1}, M_{2}\right), X=\left(b_{i}, b_{j}\right)\right] \\
\times & P\left[X=\left(b_{i}, b_{j}\right) \mid D\right] \\
V_{1}[D]= & \sum_{i=1}^{c} \sum_{j=i}^{c} P\left[F=\left(F_{1}, F_{2}\right) \mid M=\left(M_{1}, M_{2}\right), Z=\left(b_{i}, b_{j}\right)\right] P\left[Z=\left(b_{i}, b_{j}\right)\right]
\end{aligned}
$$

onde $P[\cdot \mid D]$ é a distribuição de probabilidade a posteriori para o genótipo do demandado, uma vez que foram observados os genótipos das pessoas consideradas no estudo e $c$ é o número de alelos no loco L. A determinação desta distribuição de probabilidade será explicitada nos capítulos 3-9, por dependerem dos parentes do demandado que foram observados. 
Também, ao longo deste trabalho. as probabilidades condicionais $P[D \mid \theta=0]$ e $P[D \mid \theta=$ 1] serào denotadas respectivamente, por $I P[D]$ (verossimilhança de pai) e $\ln P[D]$ (verossimilhança de não pai).

Percebamos que $V_{0}[D]$ e $V_{1}[D]$ fornecem as probabilidades condicionais de que o demandante apresente o genótipo $\left(F_{1}, F_{2}\right)$ dado que sua mãe tem o genótipo $\left(M_{1}, M_{2}\right)$, os parentes do demandado possuem o(s) genótipo(s) u e supondo, respectivamente, que o demandado é ou não o pai do demandante.

Usando as expressões 1.6 e 1.7 e o fato que a probabilidade do genótipo da mãe do demandante e dos parentes do demandado não dependem do estado $\theta$, obtemos que a probabilidade a posteriori de paternidade $\pi[\theta=0 \mid D]$ é dada pela seguinte expressão

$$
\pi[\theta=0 \mid D]=\frac{\bigvee_{0}[D] \pi[\theta=0]}{\sum_{j=0}^{1} V_{j}[D] \pi[\theta=j]}
$$

Como a priori não temos certeza se o demandado é ou não pai do demandante, temos que $0<\pi[\theta=0]<1$ e, se a probabilidade condicional $V_{0}[D]$ for positiva, a expressão 1.8 pode ser escrita da seguinte forma

$$
\pi[\theta=0 \mid D]=\left\{1+\frac{1-\pi_{0}}{\pi_{0}} R V[D]\right\}^{-1},
$$

onde a razão de verossimilhanças, $R V[D]$, é dada por

$$
R V[D]=\frac{V_{1}[D]}{V_{0}[D]}=\frac{V n P[D]}{V P[D]} .
$$

Em resumo, temos que a probabilidade a posteriori de paternidade $\pi[\theta=0 \mid D]$, estabelecida após ser observada a informação fornecida pelos dados $D$, pode ser determinada utilizando a probabilidade a priori de paternidade $\pi[\theta=0]$ e as verossimilhanças de não pai $V n P[D]$ e de pai $V P[D]$. Quando $V P[D]$ é positiva, esta distribuição a posteriori dependerá de $V n P[D]$ e $V P[D]$ apenas através de $R V[D]$ como pode ser visto na expressão 1.9. Ainda mais, das expressões 1.4 e 1.5 podemos concluir que para calcular $R V[D]$ é suficiente calcularmos as probabilidades condicionais $V_{i}[D]$ para $i=0,1$.

Particularmente, quando o demandado nào é o pai do demandante, a probabilidade $V_{1}[D]$ é exibida no seguinte resultado. 
Proposição 1.5.1 A probabilidade condicional de que o demandante possua o genótipo $\left(F_{1}, F_{2}\right)$, dado que sua màe tem o genótipo $\left(M_{1}, M_{2}\right)$, os parentes do demandado apresentam o(s) genótipo(s) u $\epsilon$ supondo que o demandado nào $\dot{\epsilon}$ o pai do demandante, $\dot{\epsilon}$ dada por

$$
V_{1}[D]=\gamma_{\left(M_{1}, M_{2}\right)} \sum_{b_{k} \in I} f_{b_{k}},
$$

onde $\gamma_{\left(M_{1}, M_{2}\right)}$ é definido por

$$
\gamma_{\left(M_{1}, M_{2}\right)}=\left\{\begin{array}{cl}
1 & \text { se } M_{1}=M_{2} \\
1 / 2 & \text { se } M_{1} \neq M_{2}
\end{array}\right.
$$

e I é o conjunto do(s) alelo(s) de interesse.

Prova: Da expressão 1.7 temos que a probabilidade condicional $V_{1}[D]$ é dada por

$$
V_{1}[D]=\sum_{i=1}^{c} \sum_{j=i}^{c} P\left[F=\left(F_{1}, F_{2}\right) \mid M=\left(M_{1}, M_{2}\right), Z=\left(b_{i}, b_{j}\right)\right] P\left[Z=\left(b_{i}, b_{j}\right)\right] \text {. }
$$

Como os alelos $F_{1}$ e $F_{2}$ pertencem ao conjunto $\mathcal{B}$ existem $k_{1}$ e $k_{2}$ em $\{1, \cdots, c\}$ tais que $F_{i}=b_{k_{i}}$ para $i=1,2 \mathrm{e}$, sem perda de generalidade, podemos supor que $k_{1}<k_{2}$.

Consideremos $b_{k_{1}}$ como sendo o único alelo de interesse. Então a probabilidade condicional $V_{1}[D]$ pode ser escrita como

$$
\begin{aligned}
V_{1}[D]= & P\left[F=\left(b_{k_{1}}, b_{k_{2}}\right) \mid M=\left(b_{k_{1}}, M_{2}\right), Z=\left(b_{k_{1}}, b_{k_{1}}\right)\right] P\left[Z=\left(b_{k_{1}}, b_{k_{1}}\right)\right]+ \\
& \sum_{i \neq k_{1}} P\left[F=\left(b_{k_{1}}, F_{2}\right) \mid M=\left(b_{k_{1}}, M_{2}\right), Z=\left(b_{k_{1}}, b_{i}\right)\right] P\left[Z=\left(b_{b_{k_{1}}}, b_{i}\right)\right] \\
= & \gamma_{\left(b_{k_{1}}, M_{2}\right)}\left(f_{b_{k_{1}}}^{2}+\frac{1}{2} 2 f_{b_{k_{1}}}\left(1-f_{b_{k_{1}}}\right)\right) \\
= & \gamma_{\left(b_{k_{1}}, M_{2}\right)} f_{b_{k_{1}}} .
\end{aligned}
$$

Quando os alelos de interesse são $b_{k_{i}}$ para $i=1,2$, a probabilidade condicional $V_{1}[D]$ é dada por

$$
V_{1}[D]=P\left[F=\left(b_{k_{1}}, b_{k_{2}}\right) \mid M=\left(b_{k_{1}}, b_{k_{2}}\right), Z=\left(b_{k_{1}}, b_{k_{1}}\right)\right] P\left[Z=\left(b_{k_{1}}, b_{k_{1}}\right)\right]+
$$




$$
\begin{aligned}
& P\left[F=\left(b_{k_{1}}, b_{k_{2}}\right) \mid M=\left(b_{k_{1}}, b_{k_{2}}\right), Z=\left(b_{k_{1}}, b_{k_{2}}\right)\right] P\left[Z=\left(b_{k_{1}}, b_{k_{2}}\right)\right]+ \\
& \sum_{j \neq k_{1}, k_{2}} P\left[F=\left(b_{k_{1}}, b_{k_{2}}\right) \mid M=\left(b_{k_{1}}, b_{k_{2}}\right) . Z=\left(b_{k_{1}}, b_{j}\right)\right] P\left[Z=\left(b_{k_{1}}, b_{j}\right)\right]+ \\
& P\left[F=\left(b_{k_{1}}, b_{k_{2}}\right) \mid M=\left(b_{k_{1}}, b_{k_{2}}\right), Z=\left(b_{k_{2}}, b_{k_{2}}\right)\right] P\left[Z=\left(b_{k_{2}}, b_{k_{2}}\right)\right]+ \\
& \sum_{j \neq k_{1}, k_{2}} P\left[F=\left(b_{k_{1}}, b_{k_{2}}\right) \mid M=\left(b_{k_{1}}, b_{k_{2}}\right) . Z=\left(b_{k_{2}}, b_{j}\right)\right] P\left[Z=\left(b_{k_{2}}, b_{j}\right)\right] \\
= & \gamma_{\left(b_{k_{1}}, b_{k_{2}}\right)}\left(f_{b_{k_{1}}}^{2}+2 f_{b_{k_{1}}}, f_{b_{k_{2}}}+\left(f_{b_{k_{1}}}+f_{b_{k_{2}}}\right)\left(1-f_{b_{k_{1}}}-f_{b_{k_{2}}}\right)+f_{b_{k_{2}}}^{2}\right) \\
= & \gamma_{\left(b_{k_{1}}, b_{k_{2}}\right)}\left(f_{b_{k_{1}}}+f_{b_{k_{2}}}\right) .
\end{aligned}
$$

Note que a probabilidade condicional $V_{1}[D]$, obtida na proposição 1.5 .1 , a menos de uma constante, é a soma das freqüências dos alelos de interesse.

O cálculo da probabilidade condicional $V_{0}[D]$ é muito mais complexo, já que envolve a distribuição de probabilidade a posteriori para o genótipo do demandado $P[\cdot \mid D]$ à qual depende de quais dos parentes do demandado foram observados. No entanto, podemos estabelecer o seguinte resultado.

Proposição 1.5.2 A probabilidade condicional de que o demandante possua o genótipo $\left(F_{1}, F_{2}\right)$, dado que sua mâe tem o genótipo $\left(M_{1}, M_{2}\right)$. os parentes do demandado apresentam o(s) genótipo(s) u e supondo que o demandado é o verdadeiro pai do demandante, é dada por

$$
V_{0}[D]=\gamma_{\left(M_{1}, M_{2}\right)} \sum_{b_{i} \in I} \sum_{r=1}^{N} \delta_{\left(b_{i}, g_{r}\right)} P\left[g_{r} \mid D\right],
$$

onde $\delta_{\left(b_{i}, g_{r}\right)}$ é definido por

$$
\delta_{\left(b_{i}, g_{r}\right)}=\left\{\begin{array}{l}
1 \quad \text { se } g_{r}=\left(b_{i}, b_{i}\right) \\
\frac{1}{2} \quad \text { se } g_{r}=\left(b_{i}, b_{w}\right) \text { ou } g_{r}=\left(b_{u} . b_{i}\right), \text { com } i \neq w \\
0 \quad \text { caso contrário, }
\end{array}\right.
$$

$\gamma_{\left(M_{1}, M_{2}\right)}$ é como o definido em 1.12 e P[·|D] é a distribuiçào de probabilidade a posteriori para o genótipo do demandado, uma vez que $D$ tenha sido observado. 
Prova: Da expressão 1.6 temos que a probabilidade condicional $V_{0}[D]$ é dada por

$$
\begin{aligned}
& V_{0}[D]=\sum_{i=1}^{c} \sum_{j=i}^{c} P\left[F=\left(F_{1}, F_{2}\right) \mid M=\left(M_{1}, M_{2}\right), X=\left(b_{i}, b_{j}\right)\right] P\left[X=\left(b_{i}, b_{j}\right) \mid D\right] \\
& =\sum_{r=1}^{N} P\left[F=\left(F_{1}, F_{2}\right) \mid M=\left(M_{1}, M_{2}\right), X=g_{r}\right] P\left[g_{r} \mid D\right]
\end{aligned}
$$

Considerando $F_{1}=b_{k_{1}}$ como o único alelo de interesse e utilizando a identidade

$$
P\left[F=\left(b_{k_{1}}, b_{k_{2}}\right) \mid M=\left(b_{k_{1}}, M_{2}\right), X=g_{r}\right]=\gamma_{\left(b_{k_{1}}, M_{2}\right)} \delta_{\left(b_{k_{1}}, g_{r}\right)},
$$

onde $\gamma_{\left(b_{k_{1}}, M_{2}\right)}$ é dado pela expressão 1.12 e $\delta_{\left(b_{k_{1}}, g_{r}\right)}$ é definido por

$$
\delta_{\left(b_{k_{1}}, g_{r}\right)}= \begin{cases}1 & \text { se } g_{r}=\left(b_{k_{1}}, b_{k_{1}}\right) \\ \frac{1}{2} & \text { se } g_{r}=\left(b_{k_{1}}, b_{w}\right) \text { ou } g_{r}=\left(b_{u}, b_{k_{1}}\right), \text { com } k_{1} \neq w \\ 0 & \text { caso contrário, }\end{cases}
$$

para $r=1, \cdots, N$ e $w=1, \cdots, c$, a expressão 1.16 pode ser escrita da seguinte forma

$$
V_{0}[D]=\gamma_{\left(b_{k_{1}}, M_{2}\right)} \sum_{r=1}^{N} \delta_{\left(b_{k_{1}}, g_{r}\right)} P\left[g_{r} \mid D\right] .
$$

Quando os alelos de interesse são $F_{i}=b_{k_{i}}$ para $i=1,2$, a expressào 1.14 é obtida equivalentemente por

$$
V_{0}[D]=\gamma_{\left(M_{1}, M_{2}\right)} \sum_{i=1}^{2} \sum_{r=1}^{N} \delta_{\left(b_{k_{i}}, g_{r}\right)} P\left[g_{r} \mid D\right] .
$$

O resultado segue das expressões 1.17 e 1.18 .

Finalmente, no caso em que consideramos $K$ locos diferentes em que a hipótese de equilíbrio de ligação seja válida, podemos determinar - como se mostra a seguir - a probabilidade a posteriori de que o demandado seja o verdadeiro pai do demandante, 
uma vez que foram observados. nos $K$ locos, os genótipos da mãe do demandante. do demandante e dos parentes do demandado.

Para cada $j=1, \cdots, K$ seja $D_{j}$ o conjunto dos dados correspondentes ao loco $L_{j}$. Suponhamos que os $K$ locos sào observados seqüencialmente, por exemplo, na ordem $L_{1}, L_{2}, \cdots, L_{K}$ e para cada $j=2, \cdots, K$ a probabilidade a posteriori de paternidade - após termos observado $D_{j}$, denotada $\pi^{(j)}\left[\theta=0 \mid D_{j}\right]$, é obtida, pela fórmula de Bayes usando como probabilidade a priori de paternidade a probabilidade a posteriori de paternidade - após termos observado $D_{j-1}$. Assim, por exemplo,

$$
\begin{aligned}
\pi^{(2)}\left[\theta=0 \mid D_{2}\right] & =\frac{\pi\left[\theta=0 \mid D_{1}\right] P\left[D_{2} \mid \theta=0\right]}{\sum_{i=0}^{1}\left(\pi\left[\theta=i \mid D_{1}\right] P\left[D_{2} \mid \theta=i\right]\right)} \\
\pi^{(K)}\left[\theta=0 \mid D_{K}\right] & =\frac{\pi^{(K-1)}\left[\theta=0 \mid D_{K-1}\right] P\left[D_{K} \mid \theta=0\right]}{\sum_{i=0}^{1}\left(\pi^{(K-1)}\left[\theta=i \mid D_{K-1}\right] P\left[D_{K} \mid \theta=i\right]\right)}
\end{aligned}
$$

Portanto, a probabilidade a posteriori de paternidade após termos observado os conjuntos $D_{1}, \cdots, D_{K}$ é dada por $\pi^{(K)}\left[\theta=0 \mid D_{K}\right]$.

Uma outra expressão para calcular $\pi^{(K)}\left[\theta=0 \mid D_{K^{\prime}}\right]$ é dada por

$$
\begin{aligned}
\pi^{(K)}\left[\theta=0 \mid D_{K}\right] & =\frac{\pi[\theta=0] \prod_{k=1}^{K} P\left[D_{k} \mid \theta=0\right]}{\sum_{i=0}^{1}\left(\pi[\theta=i] \prod_{k=1}^{K} P\left[D_{k} \mid \theta=i\right]\right)} \\
& =\left\{1+\frac{1-\pi[\theta=0]}{\pi[\theta=0]} \prod_{k=1}^{K} R V\left[D_{k}\right]\right\}^{-1}
\end{aligned}
$$

onde $\pi[\theta=0]$ é a probabilidade a priori de paternidade antes de qualquer observação nos locos $L_{1}, \cdots, L_{K}$. 


\section{Capítulo 2}

\section{O teste exato não-condicional para a lei de equilíbrio de Hardy - Weinberg}

\subsection{Introdução}

Desde o seu descobrimento, no início deste século, a lei de Hardy - Weinberg tem sido intensamente estudada por ser uma poderosa ferramenta em pesquisas genéticas. Esta lei estabelece que em uma população muito grande, desde que as migrações, mutações e escolhas naturais não afetem um loco, as freqüências alélicas e as freqüências genotípicas neste loco permanecem estáveis.

Atualmente, por causa dos grandes avanços obtidos em genética, a lei de Hardy Weinberg tem sua importância ressaltada por ser uma ferramenta valiosa na análise de evidências do DNA, cujo uso tem sido explorado, por exemplo, em casos de identificação forense, identificação de paternidade e de criminosos. As conclusões tiradas com base nas evidências do DNA dependem da avaliação probabilística que o pesquisador declara para tais evidências e esta avaliação de probabilidades pode ser simplificada se a lei de Hardy-Weinberg é declarada válida.

Em estatística, o teste de equilíbrio de Hardy-Weinberg é usualmente feito utilizando 
os testes qui-quadrado, exato de Fisher e da razão de verossimilhança. Uma ampla discussão e comparação entre estes testes pode ser vista por exemplo. em Hernandez e Weir (1989), Maiste (1993) e Weir (1996).

O teste qui-quadrado é altamente dependente de resultados assintóticos e pode levarnos algumas vezes a rejeitar ou aceitar erroneamente a hipótese de equilíbrio de HardyWeinberg. Basicamente, estes erros nas conclusões ocorrem quando o tamanho da amostra não é suficientemente grande e/ou aparecem pontos que apresentam freqüências muito baixas. No problema que abordaremos, estes pontos pouco frequentes ocorrem em grande número devido à própria estrutura genética. Nào é raro encontrarmos no banco de dados um alelo que aparece apenas uma ou duas vezes, mesmo quando este banco apresenta um número considerável de casos (ao redor de 5000).

Já o teste exato de Fisher é útil quando são consideradas pequenas amostras, por não ser um teste assintótico. Este teste depende da distribuição multinomial e requer a ordenação de todas as possíveis amostras com as mesmas freqüências dos genes e mesmo tamanho amostral. No entanto, a ordenação das possíveis amostras é problemática quando aumentamos o tamanho da amostra. Uma outra desvantagem deste teste é que ele impõe probabilidades não realistas a pontos cujas probabilidades já haviam sido determinadas pelo condicionamento.

Naqueles casos onde o número de alelos por loco ou o tamanho da amostra são grandes, é utilizada a técnica de gerar cadeias de Markov para estimar $p$-values de testes exatos condicionais (ver Guo e Thompson (1992), Lazzeroni e Lange (1997)).

O objetivo deste capítulo é apresentar o teste exato baseado na comparação entre as verossimilhanças ponderadas (Dickey e Lientz (1970)) sob as hipóteses nula e alternativa. A distribuição nula da razào destas verossimilhanças define uma ordem natural no espaço amostral. Portanto, o teste é exato, não-condicional e não é dependente de resultados assintóticos. Além disso, é um ótimo teste sob o ponto de vista da Teoria da Decisão uma vez que minimiza alguma combinação linear dos erros de tipo I e II (Pereira (1985)).

O peso escolhido para calcular a verossimilhança ponderada sob cada uma das hipóteses está baseado nas preferências a priori, provenientes da escolha de uma distribuição a priori sobre o espaço paramétrico. A dimensão do subespaço definido pela hipótese de equilíbrio de Hardy-Weinberg é menor do que a dimensão do espaço paramétrico original. Conseqüentemente, para calcularmos a verossimilhança ponderada sob a hipótese nula fazemos uso de integrais de linha ou de superfície. Igualmente. os erros de tipo I e II 
são erros médios ponderados. (Veja Pereira (1985), Irony e Pereira (1995)).

Na seção 2.2 apresentamos o teste exato não-condicional baseado na comparação entre as verossimilhanças ponderadas sob as hipóteses nula e alternativa. Além disso, nessa mesma seção é apresentado o teste exato não-condicional para o caso de dois alelos e na seção 2.3 faremos uma comparação entre o teste proposto e o teste exato de Fisher. A seção 2.4 destina-se a apresentação do teste para o caso de alelos múltiplos e de um procedimento seqüêncial para testar a lei de equilíbrio de Hardy-Weinberg. Finalmente, na seção 2.5 mostraremos exemplos que ilustram a aplicabilidade do teste proposto para o caso de alelos múltiplos.

\subsection{Definição e apresentação do Teste exato não- condicional}

A seguir, apresentaremos de maneira geral a construção do teste exato, não condicional, baseado na comparação entre as verossimilhanças ponderadas sob as hipóteses nula e alternativa, seguindo as idéias de Dickey e Lientz (1970) e Pereira (1985).

Sejam $D$ os dados obtidos como resultado de um experimento, $f[D \mid \omega]$ a função de densidade de probabilidade amostral aplicada aos dados observados, dado $\omega, \omega$ o parâmetro relacionado a $D$ pela função de verossimilhança $v[\omega \mid D]$ e $\Omega$ o espaço paramétrico.

Antes da observação de $D$, as incertezas do pesquisador sobre eventos de $\Omega$ são descritas através de uma distribuição de probabilidades a priori $P$ à qual está associada uma função densidade de probabilidade $g[\cdot]$.

Seja $\left\{\Omega_{0}, \Omega_{1}\right\}$ uma partição de $\Omega$ e considere as seguintes hipóteses:

$$
H_{0}: \omega \in \Omega_{0} \text { e } H_{1}: \omega \in \Omega_{1} \text {. }
$$

Defina $\theta$ como o parâmetro indicador de hipótese - isto é, $\theta=i$ se $\omega \in \Omega_{i}$ (ou equivalentemente se $H_{i}$ é verdadeira), $i=0,1$. Suponha que a distribuição a priori do pesquisador para as hipóteses é dada por

$$
\xi_{i}=P[\theta=i], \quad i=0,1 \text { com } \xi_{0}+\xi_{1}=1 .
$$


Assim, a razão de Bayes $R_{01}=\frac{\xi_{0}}{\xi_{1}}$ indica a vantagem a priori, percebida pelo pesquisador. de $H_{0}$ em relaçào a $H_{1}$.

Uma vez que não temos necessariamente $P\left[\Omega_{i}\right]>0, i=0,1$, introduzimos uma modificação sobre $g[\cdot]$, a densidade a priori sobre $\Omega$, com o objetivo de garantir probabilidades positivas para cada conjunto $\Omega_{i}$.

Seja $g_{i}[\cdot]$ a função de densidade a priori para os eventos em $\Omega_{i}$ ao considerarmos a hipótese $H_{i}: \theta=i, \quad i=0,1$ definida por

$$
g_{i}[\omega]=\frac{g[\omega] I_{\Omega_{i}}[\omega]}{\int g[\omega] d \Omega_{i}}, \quad i=0,1,
$$

onde $I_{\Omega_{i}}$ é a função indicadora do conjunto $\Omega_{i}$ e $\int g[\omega] d \Omega_{i}$ é a integral de linha ou de superfície de $g[\omega]$ sobre $\Omega_{i}, \quad i=0,1$.

Se $f_{i}[D]$ é a função definida sob $H_{i}: \theta=i, \quad i=0,1$ pela expressão

$$
f_{i}[D]=\int g_{i}[\omega] v[\omega \mid D] d \Omega_{i}=\frac{\int g[\omega] v[\omega \mid D] d \Omega_{i}}{\int g[\omega] d \Omega_{i}}, \quad i=0,1
$$

então $f_{i}[D]$ é a média ponderada da função de verossimilhança sob $H_{i}, \quad i=0,1$.

Portanto, a probabilidade a posteriori para o evento $\{\theta=i\}$ dado $D$ e a razão de probabilidades a posteriori são dadas respectivamente por

$$
\begin{gathered}
\xi_{i}[D]=P[\theta=i \mid D]=\frac{\xi_{i} f_{i}[D]}{\xi_{0} f_{0}[D]+\xi_{1} f_{1}[D]}, i=0,1 \mathrm{e} \\
R_{01}[D]=\frac{\xi_{0}[D]}{\xi_{1}[D]}=\frac{\xi_{0}}{\xi_{1}} \frac{f_{0}[D]}{f_{1}[D]} .
\end{gathered}
$$

Um teste Bayesiano favorecerá $H_{0}$ se $R_{01}[D]>c$, onde $c$ é uma constante escolhida considerando-se os erros de primeira e segunda espécies. 
C'omo $g_{i}[\cdot]$ é um sistema ponderado determinado por uma medida de probabilidade $\Pi_{H_{i}}$ definida sobre o conjunto dos pontos do espaço paramétrico que caraterizam $H_{i}, \quad i=0,1$ e $f_{i}[D]$ é a média ponderada da função de verossimilhança sob $H_{i}, \quad i=0,1$ então, o teste exato não-condicional proposto está baseado na razão das verossimilhanças ponderadas. (Dickey e Lientz (1970)).

Vejamos, a seguir, como podemos utilizar o teste descrito acima se desejamos testar a lei de equilíbrio de Hardy-Weinberg em um sistema com dois alelos.

Consideremos um sistema monogênico, dialélico e autossômico - isto é, um sistema constituído por um loco com dois alelos, $b_{1}$ e $b_{2}$, não localizado nos cromossomos sexuais e, além disto, suponhamos que não ocorrem mutações. Sejam

$$
\left(b_{1}, b_{1}\right) \cdot\left(b_{1}, b_{2}\right) \text { e }\left(b_{2}, b_{2}\right)
$$

os genótipos relacionados aos alelos $b_{1}$ e $b_{2}$ e denotemos por $p_{1}, p_{2}$ e $p_{3}$ as correspondentes proporções na população destas classes genotípicas. Suponha ainda que o sistema é codominante - isto é, classes genotípicas distintas definem classes fenotípicas distintas. Desta maneira, em uma amostra de tamanho $n$, a freqüência de elementos em cada classe $n_{1}, n_{2}$ e $n_{3}$, satisfazendo a condição $\sum_{i=1}^{3} n_{i}=n$, podem ser identificadas.

Como em uma população pan-mítica que não se afasta das leis mendelianas, o equilíbrio é obtido em uma etapa da reprodução e garante-se a existência de um número real $p \in(0,1)$ tal que as proporções genotípicas satisfazem a relação

$$
p_{1}=p^{2}, \quad p_{2}=2 p(1-p), \quad p_{3}=(1-p)^{2}
$$

(Ver Pereira (1985)), para decidir-se sobre a existência ou não de equilíbrio, deve-se testar a hipótese nula, $H_{0}: \omega=\left(p_{1}, p_{2}, p_{3}\right) \in \Omega_{0}$, onde

$$
\Omega_{0}=\left\{\left(x_{1}, x_{2}, x_{3}\right) \mid 0 \leq x_{1} \leq 1 ; x_{2}=2 \sqrt{x_{1}}\left(1-\sqrt{x_{1}}\right) ; x_{3}=\left(1-\sqrt{x_{1}}\right)^{2}\right\},
$$

contra a hipótese alternativa, $H_{1}: \omega \in \Omega_{1}=\Omega-\Omega_{0}$, onde

$$
\Omega=\left\{\left(x_{1}, x_{2}, x_{3}\right) \mid x_{i} \geq 0, i=1,2,3 ; \quad \sum_{j=1}^{3} x_{j}=1\right\} .
$$

Logo, o problema estatístico de interesse é a construção de um teste para confrontar as seguintes hipóteses:

$$
H_{0}: \omega \in \Omega_{0}
$$


$\mathrm{e}$

$$
H_{1}: \omega \in \Omega_{1}=\Omega-\Omega_{0},
$$

onde $\Omega$ e $\Omega_{0}$ são como definidos anteriormente (veja figura 2.1).

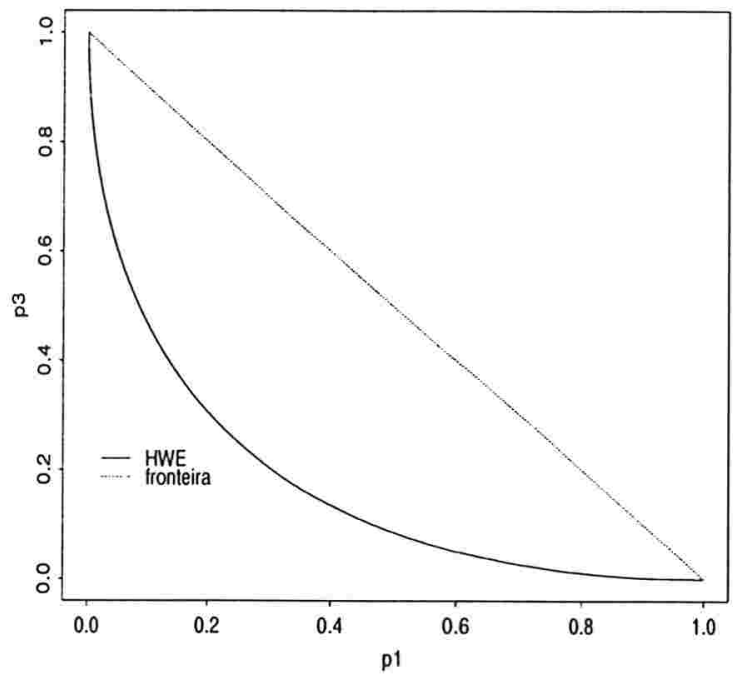

Figura 2.1: Espaço paramétrico

Supondo que os elementos amostrais são obtidos independentemente, através de um processo de Bernoulli multivariado, prefixando o tamanho da amostra $n$ e representando os dados $D$ por $D=\left(n_{1}, n_{2}, n_{3}\right)$ temos que a função de verossimilhança é dada por

$$
v[\omega \mid D]=n ! \prod_{i=1}^{3} \frac{p_{i}^{n_{i}}}{n_{i} !},
$$

onde $\omega \in \Omega$.

Suponhamos que as incertezas a priori do pesquisador sobre eventos em $\Omega$ estão representadas pela distribuição Dirichlet multivariada com parâmetros $\alpha_{1}, \alpha_{2}$ e $\alpha_{3}-D_{3}\left(\alpha_{1}, \alpha_{2}, \alpha_{3}\right)$ - $\operatorname{com} \alpha_{i}>0, i=1,2,3$. Isto é, se $\Gamma[\cdot]$ representa a função Gamma, a função $g[\cdot]$

$$
g[\omega]=\Gamma\left[\sum_{i=1}^{3} \alpha_{i}\right] \prod_{i=1}^{3} \frac{p_{i}^{\alpha_{i}-1}}{\Gamma\left[\alpha_{i}\right]}
$$

define as preferências a priori dos possíveis valores do parâmetro $\omega=\left(p_{1}, p_{2}, p_{3}\right)$. Sob o ponto de vista Bayesiano, a escolha desta densidade é equivalente à escolha de uma 
distribuição a priori conjugada e, conseqüentemente, temos que, após observarmos os dados $D=\left(n_{1}, n_{2}, n_{3}\right)$, a distribuição de probabilidade a posteriori sobre eventos em $\Omega$ é Dirichlet multivariada com parâmetros $\beta_{1}=\alpha_{1}+n_{1}, \beta_{2}=\alpha_{2}+n_{2}$ e $\beta_{3}=\alpha_{3}+n_{3}$. Então, a verossimilhança ponderada sobre $\Omega_{1}$ é dada por

$$
\begin{aligned}
f_{1}[D] & =\frac{\int_{\Omega_{1}} v[\omega \mid D] g[\omega] d \omega}{\int_{\Omega_{1}} g[\omega] d \omega} \\
& =\frac{n !}{\prod_{i=1}^{3} n_{i} !} \frac{\int_{\Omega_{1}} \prod_{i=1}^{3} p_{\Omega_{1}}^{\beta_{i}-1} d \omega}{\prod_{i=1}^{3} p_{i}^{\alpha_{i}-1} d \omega} \\
& =\frac{n !}{\prod_{i=1}^{3} n_{i} !} \frac{\Gamma\left[\sum_{i=1}^{3} \alpha_{i}\right]}{\Gamma\left[\sum_{i=1}^{3} \beta_{i}\right]} \prod_{i=1}^{3} \frac{\Gamma\left[\beta_{i}\right]}{\Gamma\left[\alpha_{i}\right]} .
\end{aligned}
$$

Analogamente, a verossimilhança ponderada sobre $\Omega_{0}$ é dada por

$$
\begin{aligned}
f_{0}[D] & =\frac{\int_{\Omega_{0}} v[\omega \mid D] g[\omega] d \omega}{\int_{\Omega_{0}} g[\omega] d \omega} \\
& =\frac{n !}{\prod_{i=1}^{3} n_{i} !} \frac{\int_{\Omega_{0}} \prod_{i=1}^{3} p_{i}^{\beta_{i}-1} d \omega}{\int_{\Omega_{0}} \prod_{i=1}^{3} p_{i}^{\alpha_{i}-1} d \omega} \\
& =\frac{n ! 2^{n_{2}}}{\prod_{i=1}^{3} n_{i} !} \frac{\int_{0}^{1} \sqrt{1-3 x(1-x)} x^{2 \beta_{1}+\beta_{2}-3}(1-x)^{2 \beta_{3}+\beta_{2}-3} d x}{\int^{1-3 x(1-x)} x^{2 \alpha_{1}+\alpha_{2}-3}(1-x)^{2 \alpha_{3}+\alpha_{2}-3} d x}
\end{aligned}
$$

Suponhamos que a densidade a priori sobre $\Omega$ é uniforme. Então, fazendo $\alpha_{i}=1$ para $i=1,2,3$ nas expressões 2.3 e 2.4 , temos que o valor exato das verossimilhanças ponderadas sobre $\Omega_{1}$ e $\Omega_{0}$ são dadas respectivamente por

$$
\begin{aligned}
& f_{1}[D]=\frac{2}{(n+1)(n+2)} \\
& f_{0}[D]=\frac{n ! 2^{n_{2}}}{\prod_{i=1}^{3} n_{i} !} \frac{\int_{0}^{1} \sqrt{1-3 x(1-x)} x^{2 n_{1}+n_{2}}(1-x)^{2 n_{3}+n_{2}} d x}{\int_{0}^{1} \sqrt{1-3 x(1-x)} d x}
\end{aligned}
$$

Conseqüentemente, se suposermos que a distribuição a priori do pesquisador para as hipóteses é uniforme - isto é, $\xi_{0}=\xi_{1}=1 / 2$, a razão de probabilidades a posteriori 
$R_{01}[D]$ é dada pela seguinte expressão

$$
R_{01}[D]=2^{n_{2}-1} \frac{(n+2) !}{\prod_{i=1}^{3} n_{i} !} \frac{\int_{0}^{1} \sqrt{1-3 x(1-x)} x^{2 n_{1}+n_{2}}(1-x)^{2 n_{3}+n_{2}} d x}{\int_{0}^{1} \sqrt{1-3 x(1-x)} d x} .
$$

Um teste para a hipótese de equilíbrio de Hardy-Weinberg consiste em comparar $R_{01}[D]$ com a unidade. Neste caso, temos um teste que minimiza a soma das médias dos erros de primeira e segunda espécies (Para maiores detalhes, ver Pereira (1985)).

Algumas vezes, o cálculo exato da expressão 2.7 pode não ser factível. Por isso é interessante apresentarmos aproximações para sua determinação. Um valor aproximado da expressão 2.7, após usarmos uma aproximação em série de Taylor para a função $h[x]=\sqrt{1-3 x(1-x)}$ em uma vizinhança do ponto $x=1 / 2$, é dado pela seguinte expressão

$$
\begin{aligned}
R_{01}[D]= & \frac{(n+2) !}{n_{1} ! n_{2} ! n_{3} !} \frac{\left(2 n_{1}+n_{2}\right) !\left(2 n_{3}+n_{2}\right) ! 2^{n_{2}-1}}{(2 n+1) ! 3} \\
& \times\left[5-12 \frac{\left(2 n_{1}+n_{2}+1\right)\left(2 n_{3}+n_{2}+1\right)}{(2 n+2)(2 n+3)}\right] .
\end{aligned}
$$

Na próxima seção apresentaremos a comparação desta proposta para testar o equilíbrio de Hardy-Weinberg com o teste exato de Fisher. Outras comparações do teste exato de Fisher com outros testes, usualmente empregados no teste de equilíbrio para o caso de dois alelos, podem ser vistas, por exemplo, em Levene (1949), Emigh e Lientz (1980) e Singer et al. (1996)

\subsection{Comparação do teste exato não condicional com o teste de Fisher.}

Nesta seção, vamos comparar o teste exato não condicional proposto na seção anterior com o teste exato de Fisher, considerando todas as possíveis amostras de tamanho $n=10$ e calculando o $P$ - value para cada uma destas amostras. A tabela 2.1 apresenta as razòes das verossimilhanças ponderadas e o $\boldsymbol{P}$ - value do teste não condicional. 
Para o cálculo do $\boldsymbol{P}$ - value consideramos a estatística razão de verossimilhanças ponderadas

$$
\underline{R}=R[D]=\frac{f_{1}[D]}{f_{0}[D]}
$$

a qual toma o valor $r$ no ponto $d$. Assim, o valor do $P$-value no ponto $r$ (ou no ponto d) é dado por

$$
P[r]=\operatorname{Pr}\left\{\underline{R} \geq r \mid H_{0}\right\}=\int I_{r}[x] f_{0}[x] d x,
$$

onde $I_{r}[x]$ é a função indicadora do conjunto $\{x: R[x] \geq r\}$. (Ver Pereira e Wechsler (1993)).

Tabela 2.1 Razões de verossimilhança e $P$ - value do teste proposto

\begin{tabular}{|r|r|r|l||r|r|r|l|}
\hline$R V P$ & $n_{1}$ & $n_{3}$ & $P$-value & $R V P$ & $n_{1}$ & $n_{3}$ & $P$-value \\
\hline 0.003294 & 5 & 5 & 0.000050 & 0.668971 & 1 & 2 & 0.114822 \\
0.004180 & 4 & 6 & 0.000177 & 0.681555 & 2 & 5 & 0.135475 \\
0.008585 & 3 & 7 & 0.000437 & 0.878364 & 3 & 3 & 0.148784 \\
0.013385 & 0 & 0 & 0.000640 & 0.944451 & 1 & 7 & 0.177404 \\
0.029514 & 2 & 8 & 0.001534 & 0.961614 & 0 & 4 & 0.206543 \\
0.036584 & 4 & 5 & 0.002642 & 1.003370 & 2 & 4 & 0.236949 \\
0.056796 & 3 & 6 & 0.004364 & 1.054040 & 2 & 2 & 0.252919 \\
0.074330 & 0 & 1 & 0.006616 & 1.070260 & 1 & 3 & 0.285351 \\
0.137487 & 2 & 7 & 0.010782 & 1.170700 & 2 & 3 & 0.320827 \\
0.164693 & 4 & 4 & 0.013278 & 1.283220 & 1 & 6 & 0.359712 \\
0.193783 & 1 & 9 & 0.0191499 & 1.363110 & 1 & 4 & 0.401019 \\
0.200674 & 3 & 5 & 0.025231 & 1.442420 & 1 & 5 & 0.444728 \\
0.229342 & 0 & 2 & 0.032181 & 1.539860 & 0 & 5 & 0.491391 \\
0.301153 & 1 & 1 & 0.036744 & 2.203720 & 0 & 6 & 0.558170 \\
0.360605 & 2 & 6 & 0.047671 & 2.879690 & 0 & 7 & 0.645433 \\
0.487797 & 3 & 4 & 0.062453 & 3.488090 & 0 & 8 & 0.751133 \\
0.519280 & 0 & 3 & 0.078188 & 3.960460 & 0 & 9 & 0.871147 \\
0.539942 & 1 & 8 & 0.094550 & 4.252150 & 0 & 10 & 1. \\
\hline
\end{tabular}

As tabelas 2.2 e 2.3 apresentam os valores do $P$-value, multiplicado por 100 , para o teste exato não - condicional e o teste exato de Fisher, respectivamente. 
Tabela 2.2P $\times 100$ - value não - condicional: caso bi-caudal

\begin{tabular}{|c|c|c|c|c|c|c|c|c|c|c|c|}
\hline$n_{3}$ & & & & & & & & & & & \\
\hline 10 & 100 & & & & & & & & & & \\
\hline 9 & 87 & 3 & & & & & & & & & \\
\hline 8 & 75 & 9 & 0 & & & & & & & & \\
\hline 7 & 65 & 18 & 1 & 0 & & & & & & & \\
\hline 6 & 56 & 36 & 5 & 0 & 0 & & & & & & \\
\hline 5 & 49 & 44 & 14 & 3 & 0 & 0 & & & & & \\
\hline 4 & 21 & 40 & 24 & 6 & 1 & 0 & 0 & & & & \\
\hline 3 & 8 & 29 & 32 & 15 & 6 & 3 & 0 & 0 & & & \\
\hline 2 & 3 & 11 & 25 & 32 & 24 & 14 & 5 & 1 & 0 & & \\
\hline 1 & 1 & 4 & 11 & 29 & 40 & 44 & 36 & 18 & 9 & 2 & \\
\hline \multirow[t]{2}{*}{0} & 0 & 1 & 3 & 8 & 21 & 49 & 56 & 65 & 75 & 87 & 100 \\
\hline & 0 & 1 & 2 & 3 & 4 & 5 & 6 & 7 & 8 & 9 & 10 \\
\hline
\end{tabular}

Tabela $2.3 p \times 100$-value condicional - Teste exato de Fisher

\begin{tabular}{|c|c|c|c|c|c|c|c|c|c|c|c|}
\hline$n_{3}$ & & & & & & & & & & & \\
\hline 10 & 100 & & & & & & & & & & \\
\hline 9 & 100 & $\bar{j}$ & & & & & & & & & \\
\hline 8 & 100 & 16 & 1 & & & & & & & & \\
\hline 7 & 100 & 31 & 5 & 0 & & & & & & & \\
\hline 6 & 100 & 48 & 13 & 2 & 0 & & & & & & \\
\hline 5 & 100 & 100 & 48 & 8 & 2 & 0 & & & & & \\
\hline 4 & 47 & 100 & 57 & 25 & 8 & 2 & 0 & & & & \\
\hline 3 & 22 & 100 & 100 & 56 & 25 & 8 & 2 & 0 & & & \\
\hline 2 & 17 & 52 & 100 & 100 & 57 & 48 & 13 & 5 & 1 & & \\
\hline 1 & 5 & 20 & 52 & 100 & 100 & 100 & 48 & 31 & 16 & 5 & \\
\hline \multirow[t]{2}{*}{0} & 0 & 5 & 17 & 22 & 47 & 100 & 100 & 100 & 100 & 100 & 100 \\
\hline & 0 & 1 & 2 & 3 & 4 & 5 & 6 & 7 & 8 & 9 & 10 \\
\hline
\end{tabular}

Das tabelas 2.2 e 2.3 se deduz que o teste exato (condicional) de Fisher é mais conservativo que o teste exato não-condicional. Percebe-se que, se o teste por nós apresentado minimiza a soma das médias dos erros de primeira e segunda espécies e se em uma 
amostra de tamanho $n=10$ forem observados os valores $n_{1}=1, n_{2}=8 \cdot n_{3}=1$, entào o teste exato nào-condicional rejeita a hipótese de equilíbrio $(P=0.0367437 \approx 0.04)$. No entanto, o teste exato de Fisher não rejeitaria tal hipótese $(P=0.20)$.

O $P$-value do teste exato de Fisher pode ser obtido a partir das razões de verossimilhanças ponderadas. Por exemplo, fixando o tamanho da amostra em $n=10$ e supondo que o número total de elementos observados que apresentam o alelo $b_{1}$ (dado por $\left.n_{b_{1}}=2 n_{1}+n_{2}\right)$ é 9 , basta considerarmos todas as possíveis amostras com esta característica. Para determinarmos a probabilidade condicional em $n$ e $n_{b_{1}}$ da amostra $\left(n_{1}, n_{2}, n_{3}\right)$, dividimos a $R V P$ correspondente a esta amostra pela soma das $R V P$ de todos os pontos amostrais $\left(m_{1}, m_{2}, m_{3}\right)$ com $2 m_{1}+m_{2}=n_{b_{1}}$. Uma vez realizado este procedimento com todas as possíveis amostras que satisfazem as condições dadas acima é simples calcular o $p$-value para o teste exato (condicional) de Fisher. A tabela 2.4 apresenta os resultados correspondentes ao exemplo em consideração.

Tabela 2.4 Obtenção do $p$-value condicional a partir da razão de verossimilhanças ponderadas para o caso $n=10$ e $n_{b_{1}}=9$.

\begin{tabular}{|c|c|c|c|c|}
\hline$\left(m_{1}, m_{2}, m_{3}\right)$ & $R V P[\cdot]$ & $\operatorname{Pr}\left[\cdot \mid n_{b_{1}}\right]$ & $\frac{R V P[\cdot]}{\sum}$ & $p$-value \\
\hline$(0,9,1)$ & 0.074330 & 0.030483 & 0.030483 & 0.045487 \\
$(1,7,2)$ & 0.668971 & 0.274351 & 0.274351 & 0.519886 \\
$(2,5,3)$ & 1.170700 & 0.480114 & 0.480114 & 1.000000 \\
$(3,3,4)$ & 0.487797 & 0.200048 & 0.200048 & 0.245535 \\
$(4,1,5)$ & 0.036584 & 0.015004 & 0.015004 & 0.015004 \\
$\sum$ & 2.438382 & & & \\
\hline
\end{tabular}

No caso geral, fixemos o tamanho da amostra em $n$ e o número total de elementos observados que apresentam o alelo $b_{1}$ em $n_{b_{1}}$. Considerando a estatística $T$ definida por $T=2 N_{1}+N_{2}$, sendo $N_{1}$ e $N_{2}$ as variáveis aletórias que denotam o número de indivíduos observados na amostra que possuem o genótipo $\left(b_{1}, b_{1}\right)$ e $\left(b_{1}, b_{2}\right)$, respectivamente, temos que para cada $D=\left(n_{1}, n_{2}, n_{3}\right)$ com $2 n_{1}+n_{2}=n_{b_{1}}$ e $\sum_{i=1}^{3} n_{i}=n$, qualquer que seja o valor de $p$ em $(0,1)$ a probabilidade condicional $\operatorname{Pr}\left[D \mid T=n_{b_{1}}\right]$ é dada pela expressão

$$
\begin{aligned}
\operatorname{Pr}\left[D \mid T=n_{b_{1}}\right] & =\frac{n !\left(2 n_{1}+n_{2}\right) !\left(2 n_{3}+n_{2}\right) !}{(2 n) ! n_{1} ! n_{2} ! n_{3} !} 2^{n_{2}} \\
& =\frac{R V P[d]}{\sum_{u \in \mathcal{D}} R V P[u]},
\end{aligned}
$$


onde

$$
\mathcal{D}=\left\{u=\left(m_{1}, m_{2}, m_{3}\right) \mid m_{i} \in N, i=1,2,3, \sum_{i=1}^{3} m_{i}=n \text { e } 2 m_{1}+m_{2}=n_{b_{1}}\right\} .
$$

\subsection{Teste de alelos múltiplos.}

Sejam $\mathcal{B}_{L}$ e $G_{L}$ como definidos na seção 2.2 .

Denotemos por $p_{k_{i}}$ a proporção da classe genotípica $g_{k_{\imath}}$ na população, onde

$$
p_{k_{i j}}, \quad k_{i, j}=\frac{(i-1)(2 c-i)+2 j}{2}, \quad i=1, \cdots, c ; j=i, \cdots, c .
$$

No caso geral, de maneira análoga ao caso de dois alelos, a condição de equilíbrio expressa em 2.1, é caracterizada pela expressão 2.8 apresentada na seguinte proposição:

Proposição 2.4.1 Sob as condiçôes dadas acima temos que, em uma populaçâo panmítica, que nâo se afasta das leis mendelianas, o equilíbrio é obtido em uma etapa da reprodução e existem $u_{1}, u_{2}, \cdots, u_{c} \in(0,1)$ com $\sum_{j=1}^{c} u_{j}=1$, tais que a relação abaixo é satisfeita

$$
p_{k_{i j}}=\left\{\begin{array}{lr}
u_{i}^{2} & \text { se } j=i, i=1, \cdots, c \\
2 u_{i} u_{j} & \text { se } i=1, \cdots, c-1, \\
& j=i+1, \cdots, c
\end{array}\right.
$$

Agora, como o sistema é codominante, em uma amostra de tamanho $m$ as freqüências dos elementos em cada classe genotípica, $m_{1}, m_{2}, \cdots, m_{N}$, com $\sum_{i=1}^{N} m_{i}=m$, podem ser identificadas.

Supondo que os elementos amostrais são obtidos independentemente, através de um processo de Bernoulli (multivariado), temos que a função de verossimilhança é dada pela expressão

$$
v[\omega \mid D]=m ! \prod_{i=1}^{N} \frac{p_{i}^{m_{i}}}{m_{i} !}
$$


onde $D=\left(m_{1}, \cdots, m_{N}\right)$ e $\omega=\left(p_{1}, \cdots, p_{N}\right)$ pertence ao simplex $\Omega$ dado por

$$
\Omega=\left\{\left(p_{1}, \cdots, p_{N}\right) \mid p_{i} \geq 0, i=1, \cdots, N \text { e } \sum_{i=1}^{N} p_{i}=1\right\} .
$$

Portanto, para decidir sobre a existência ou não de equilíbrio, deve-se testar a hipótese nula. $H_{0}: \omega \in \Omega_{0}$, onde $\left(x_{1}, \cdots, x_{N}\right) \in \Omega_{0}$ se, e somente se,

i) $\quad x_{k_{i i}} \in(0,1)$, para $k_{i i}=\frac{(i-1)(2 c-i)+2 i}{2}, \quad i=1, \cdots, c$

ii) $\quad \sum_{i=1}^{c} x_{k_{i i}}=1$

iii) $\quad x_{k_{i j}}=2 \sqrt{x_{k_{i i}}} \sqrt{x_{k_{\jmath \jmath}}}$ para $k_{i j}=\frac{(i-1)(2 c-i)+2 j}{2}$

contra a alternativa, $H_{1}$, de que $\omega$ pertença ao complemento de $\Omega_{0}$ em relação ao simplex $\Omega$.

Assumamos que as preferências a priori do pesquisador sobre eventos em $\Omega$ são representadas pela distribuição Dirichlet multivariada com parâmetros $\alpha_{1}, \cdots, \alpha_{N}$, denotada $D_{N}\left(\alpha_{1}, \cdots, \alpha_{N}\right)$, onde $\alpha_{i}>0$ para $i=1, \cdots, N$. Isto é, a função densidade $g[\cdot]$ dada pela expressão

$$
g[\omega]=\Gamma\left[\sum_{i=1}^{N} \alpha_{i}\right] \prod_{i=1}^{N} \frac{p_{i}^{\alpha_{i}-1}}{\Gamma\left[\alpha_{i}\right]}
$$

define as preferệncias a priori dos possíveis valores do parâmetro $\omega$. Como no caso de dois alelos, sob o ponto de vista Bayesiano, a escolha desta densidade é equivalente à escolha de uma distribuição a priori conjugada e conseqüentemente temos que, após observarmos os dados $D=\left(m_{1}, \cdots, m_{N}\right)$ a distribuição de probabilidade a posteriori sobre eventos em $\Omega$ é Dirichlet multivariada com parâmetros $\beta_{i}=\alpha_{i}+m_{i}$ para $i=$ $1, \cdots, N$. Portanto, a verossimilhança ponderada sobre $\Omega_{1}$ é dada por

$$
f_{1}[D]=\frac{\int_{\Omega_{1}} v[\omega \mid D] g[\omega] d \omega}{\int_{\Omega_{1}} g[\omega] d \omega}
$$




$$
\begin{aligned}
& =\frac{m !}{\prod_{i=1}^{N} m_{i} !} \frac{\int_{\Omega_{1}} \prod_{i=1}^{N} p_{i}^{\beta_{i}-1} d \omega}{\int_{\Omega_{1}} \prod_{i=1}^{N} p_{i}^{\alpha_{i}-1} d \omega} \\
& =\frac{m !}{\prod_{i=1}^{N} m_{i} !} \frac{\Gamma\left[\sum_{i=1}^{N} \alpha_{i}\right]}{\Gamma\left[\sum_{i=1}^{N} \beta_{i}\right]} \prod_{i=1}^{N} \frac{\Gamma\left[\beta_{i}\right]}{\Gamma\left[\alpha_{i}\right]} .
\end{aligned}
$$

De forma análoga, obtem-se que a verossimilhança ponderada sobre $\Omega_{0}$ é dada por

$$
\begin{aligned}
f_{0}[D] & =\frac{\int_{\Omega_{0}} v[\omega \mid D] g[\omega] d \omega}{\int_{\Omega_{0}} g[\omega] d \omega} \\
& =\frac{m !}{\prod_{i=1}^{N} m_{i} !} \frac{\int_{\Omega_{0}} \prod_{i=1}^{N} p_{i}^{\beta_{i}-1} d \omega}{\int_{\Omega_{0}} \prod_{i=1}^{N} p_{i}^{\alpha_{i}-1} d \omega}
\end{aligned}
$$

Suponhamos que a densidade a priori sobre $\Omega$ é uniforme. Então, fazendo $\alpha_{i}=1$ para $i=1, \cdots, N$ nas expressões 2.10 e 2.11 , temos que o valor exato das verossimilhanças ponderadas sobre $\Omega_{1}$ e $\Omega_{0}$ são dadas, respectivamente, por

$$
\begin{aligned}
& f_{1}[D]=\prod_{i=1}^{m} \frac{i}{N+m-i}=\frac{m !(N-1) !}{(N+m-1) !} \\
& f_{0}[D]=\frac{m !}{\prod_{i=1}^{N} m_{i} !} \frac{\int_{\Omega_{0}} \prod_{i=1}^{N} p_{i}^{m_{i}} d \omega}{\int_{\Omega_{0}} d \omega}
\end{aligned}
$$

$O$ valor exato da verossimilhança ponderada sobre $\Omega_{0}$ depende do cálculo das integrais de superfície - ou de linha -

$$
\begin{aligned}
& I_{0}=\int_{\Omega_{0}} d \omega \mathrm{e} \\
& I_{1}=\int_{\Omega_{0}} \prod_{i=1}^{N} p_{i}^{m_{i}} d \omega
\end{aligned}
$$

as quais podem ser transformadas em integrais múltiplas como se mostra a seguir (veja Courant e John (1974) para maiores detalhes). 
Ao considerarmos o fato de que os pontos em $\Omega_{0}$ estào determinados pela expressào 2.8 ou, equivalentemente, pelas equaçòes

$$
p_{k_{i j}}=\left\{\begin{array}{lr}
u_{i}^{2} & \text { se } i=1, \cdots, c-1, \quad j=i, \\
2 u_{i} u_{j} & \text { se } i=1, \cdots, c-2, \\
& j=i+1, \cdots, c-1, \\
2 u_{i}\left(1-\sum_{r=1}^{c-1} u_{r}\right) & \text { se } i=1, \cdots, c-1, j=c, \\
\left(1-\sum_{r=1}^{c-1} u_{r}\right)^{2} & \text { se } j=i=c,
\end{array}\right.
$$

obtemos que o sistema de equações 2.16 é uma parametrização da superfície $\Omega_{0}$. A matriz de derivadas parciais de $2.16, \Delta=\left[\delta_{\left(k_{i j}, s\right)}\right]$ com $N$ linhas e $c-1$ colunas, é definida pela expressão

$$
\delta_{\left(k_{i j}, s\right)}=\frac{\partial p_{k_{i j}}}{\partial u_{s}}, \quad k_{i j}=\frac{(i-1)(2 c-i)+2 j}{2}, i=1, \cdots, c, j=i, \cdots, c, s=1, \cdots, c-1
$$

A matriz $\Delta$ pode ser escrita da seguinte forma

$$
\Delta=\left[Q_{1}^{T} \cdots Q_{i}^{T} \cdots Q_{c}^{T}\right]^{T},
$$

onde $Q_{1}$ é a matriz de tamanho $c \times(c-1)$ dada pela expressão

$$
Q_{1}=\left[\begin{array}{ccccc}
2 u_{1} & 0 & 0 & \cdots & 0 \\
2 u_{2} & 2 u_{1} & 0 & \cdots & 0 \\
\vdots & \vdots & & \ddots & \vdots \\
2 u_{c-1} & 0 & 0 & \cdots & 2 u_{1} \\
2\left(1-u_{1}-\sum_{t=1}^{c-1} u_{t}\right) & -2 u_{1} & -2 u_{1} & \cdots & -2 u_{1}
\end{array}\right] \text {, }
$$

e para cada $i=2, \cdots, c-1$, se $c>2$, a submatriz $Q_{i}$ é uma matriz de tamanho $(c+1-i) \times(c-1)$ com a seguinte estrutura

$$
Q_{i}=\left[\begin{array}{lll}
Q_{i_{11}} & Q_{i_{12}} & Q_{i_{13}} \\
Q_{i_{21}} & Q_{i_{22}} & Q_{i_{23}}
\end{array}\right],
$$


onde $Q_{i_{11}}$ e $Q_{i_{13}}$ sào matrizes zero de tamanhos $(c-i) \times(i-1)$ e $1 \times(c-1-i)$ respectivamente; $Q_{i_{12}}$ é a matriz coluna de tamanho $(c-i)$ dada por

$$
Q_{i_{12}}=2\left[u_{i}, \cdots, u_{c-1}\right],
$$

para $j=1,2,3$ as matrizes $Q_{i_{2}}$ e a matriz $Q_{c}$ são matrizes linha de tamanhos $i$ $1,1, c-i-1$ e $c-1$ respectivamente, dadas pelas seguintes expressões

$$
\begin{aligned}
Q_{i_{21}} & =-2 u_{i} \mathbb{1}_{1 \times(i-1)} \\
Q_{i_{22}} & =2\left(1-u_{i}-\sum_{t=1}^{c-1} u_{t}\right) \\
Q_{i_{23}} & =-2 u_{i} \mathbb{1}_{1 \times(c-i-1)} \\
Q_{c} & =-2 \sum_{t=1}^{c-1} u_{t} \mathbb{1}_{1 \times(c-1)},
\end{aligned}
$$

sendo $\mathbb{1}_{r \times s}$ a matriz de uns de tamanho $r \times s$.

O próximo passo - uma vez calculada a matriz $\Delta$ - é determinar, para cada um dos $K$ diferentes subconjuntos de $c-1$ linhas desta matriz, uma nova matriz, dizemos a matriz $D_{i}$ para o $i$-ésimo subconjunto de linhas, onde $K=\left(\begin{array}{c}N \\ c-1\end{array}\right)$.

Seja $\phi=\phi\left[u_{1}, \cdots, u_{c-1}\right]$ a função definida pela expressão

$$
\phi\left[u_{1}, \cdots, u_{c-1}\right]=\sqrt{\sum_{i=1}^{K}\left(\operatorname{det}\left[D_{i}\right]\right)^{2}}
$$

onde $\operatorname{det}[\cdot]$ é a função determinante.

Assim, o valor da integral de superfície

$$
I=\int_{\Omega_{0}} \prod_{i=1}^{N} p_{i}^{\theta_{i}-1} d \omega
$$

pode determinar-se calculando a seguinte integral múltipla

$$
I=\int_{0}^{1} \int_{0}^{1-u_{1}} \cdots \int_{0}^{1-\sum_{r=1}^{c-2}} 2^{\lambda_{0}}\left(1-\sum_{t=1}^{c-1} u_{t}\right)^{\lambda_{c}} \prod_{t=1}^{c-1} u_{t}^{\lambda_{t}} \phi d u_{n-1} \cdots d u_{1}
$$


onde

$$
\begin{aligned}
& \lambda_{0}=\sum_{j=1}^{N} \theta_{j}-\sum_{i=1}^{c} \frac{\theta_{(i-1)(2 c-i)+2 i}}{2}-(N-c) \\
& \lambda_{k}=\sum_{j=k}^{c} \theta_{\frac{(k-1)(2 c-k)+2 j}{2}}+\sum_{i=1}^{k} \theta_{\frac{(i-1)(2 c-i)+2 k}{2}}-(c+1) .
\end{aligned}
$$

Para obtermos os valores de $I_{0}$ e $I_{1}$ é suficiente substituir, para cada $i=1, \cdots, N$, o valor de $\theta_{i}$ por 1 e $m_{i}+1$ respectivamente, nas expressões 2.17, 2.18 e 2.19. Conseqüentemente, os valores de 2.14 e 2.15 são dados pelas seguintes expressões

$$
\begin{aligned}
& I_{0}=\int_{0}^{1} \int_{0}^{1-u_{1}} \cdots \int_{0}^{1-\sum_{r=1}^{c-2}} \phi d u_{n-1} \cdots d u_{1}, \\
& I_{1}=2^{\lambda_{0}} \int_{0}^{1} \int_{0}^{1-u_{1}} \cdots \int_{0}^{1-\sum_{r=1}^{c-2}}\left(1-\sum_{t=1}^{c-1} u_{t}\right)^{\lambda_{c}} \prod_{t=1}^{c-1} u_{t}^{\lambda_{t}} \phi d u_{n-1} \cdots d u_{1},
\end{aligned}
$$

onde

$$
\begin{aligned}
& \lambda_{0}=m-\sum_{i=1}^{c} \frac{m_{\frac{(i-1)(2 c-i)+2 i}{2}}}{\lambda_{k}=\sum_{j=k}^{c} m_{\frac{(k-1)(2 c-k)+2 \jmath}{2}}+\sum_{i=1}^{k} m_{\frac{(i-1)(2 c-i)+2 k}{2}}}
\end{aligned}
$$

Percebe-se que as dificuldades que surgem no cálculo das integrais de superfície, ou as correspondentes integrais múltiplas, envolvidas neste caso são muito grandes. Por isso, vamos considerar um caminho alternativo - apresentado a seguir - para testar a hipótese de equilíbrio de Hardy-Weinberg no caso de alelos múltiplos.

Apartir da caracterização de equilíbrio populacional de Hardy-Weinberg dado pela expressão 2.8, podemos provar que os dois fatos seguintes são verdadeiros. Estes fatos constituem a base do procedimento que vamos propor para testar a hipótese de equilíbrio no caso de alelos múltiplos.

Se o sistema com $c$ alelos, $\mathcal{B}_{L}=\left\{b_{1}, b_{2}, \cdots, b_{c}\right\}$, satisfaz a condição de equilíbrio de Hardy-Weinberg dada na expressão 2.8 esta condição é satisfeita por 'qualquer sistema' 
obtido particionando $\mathcal{B}_{L}$ em pelo menos dois subconjuntos não vazios e considerando cada elemento desta partiçào como 'um alelo', este resultado pode ser formalizado como segue

Proposição 2.4.2 Seja $\mathcal{B}_{L}=\left\{b_{1}, \cdots, b_{c}\right\}$ o conjunto dos $c$ alelos em consideração. Para cada inteiro positivo $2 \leq r \leq c$, seja $\Pi=\left\{B_{1}, B_{2}, \cdots, B_{r}\right\}$ uma partiçáo do conjunto $\mathcal{B}_{L}$. Suponhamos que existem $u_{1}, u_{2}, \cdots, u_{c}$ números reais não negativos tais que $\sum_{i=1}^{c} u_{i}=1$ e a expressâo 2.8 é válida. Então, existem $w_{1}, w_{2}, \cdots, w_{r}$ números reais não negativos tais que $\sum_{j=1}^{r} w_{j}=1 e$

$$
q_{k_{s y}}= \begin{cases}u_{s}^{2} & \text { se } y=s, s=1, \cdots, r \\ 2 w_{s} w_{y} & \text { se } s=1, \cdots, r-1 y=s+1, \cdots, r\end{cases}
$$

onde $k_{s y}=((s-1)(2 r-s)+2 y) / 2$ e q $k_{s y}$ é a freqüência de todos os genótipos obtidos pelos cruzamentos entre os alelos do conjunto $B_{s}$ com os alelos do conjunto $B_{y}$ para $s=1, \cdots, r ; y=s, \cdots, r$.

\section{Demonstração}

Sem perda de generalidade podemos supor que existem inteiros positivos $n_{1}, n_{2}, \cdots, n_{r}$ tais que $\sum_{k=1}^{r} n_{k}=c$ e os elementos da partição $\Pi$ são dados por

$$
\begin{aligned}
& B_{1}=\left\{b_{1}, \cdots, b_{n_{1}}\right\}, \\
& B_{i}=\left\{b_{l_{i}}, \cdots, b_{l_{i+1}}\right\},
\end{aligned}
$$

onde $l_{i}=1+\sum_{j=1}^{i-1} n_{j}$ e $l_{i+1}=\sum_{j=1}^{i} n_{j}$ para cada $i=2, \cdots, r$.

Consideremos os conjuntos de números inteiros consecutivos $N_{1}=\left\{1, \cdots, n_{1}\right\}$ e $N_{i}=$ $\left\{l_{i}, \cdots, l_{i+1}\right\}$ para $i=2, \cdots, r$. Definindo

$$
w_{s}=\sum_{i \in N_{s}} u_{i}, \quad s=1, \cdots, r
$$

obtemos que

$$
\begin{aligned}
& \text { i) } \quad w_{s} \geq 0, \quad s=1, \cdots, r \\
& \text { ii) } \quad \sum_{s=1}^{r} w_{s}=\sum_{s=1}^{r} \sum_{i \in N_{s}^{\prime}} u_{i}=\sum_{i=1}^{c} u_{i}=1
\end{aligned}
$$




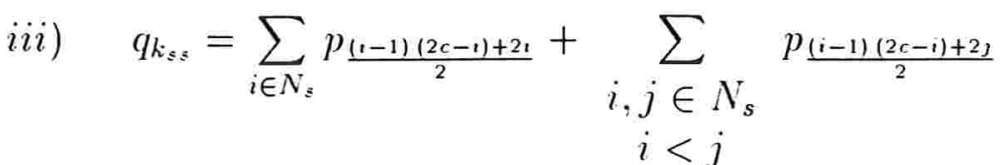

$$
q_{k_{s s}}=\sum_{i \in N_{s}} u_{i}^{2}+2 \sum_{\substack{i, j \in N_{s} \\ i<j}} u_{i} u_{j}=w_{s}^{2} \text {, se } s=1, \cdots, r
$$

iv) $\quad q_{k_{s y}}=\sum_{i \in N_{s}} \sum_{j \in N_{y}} p_{\frac{(i-1)(2 c-i)+2 \jmath}{2}}=2 \sum_{i \in N_{s}} \sum_{j \in N_{y}} u_{i} u_{j}$

$$
q_{k_{s y}}=2 w_{s} w_{y}, \text { se } s=1, \cdots, r-1 \quad y=s+1, \cdots, r
$$

O resultado se segue de $i)-i v$ ).

O fato 2, visto a seguir, é importante, pois permite definir, junto com o resultado apresentado na proposição 2.4 .2 , um procedimento seqüencial para testar a hipótese de equilíbrio.

Proposição 2.4.3 Seja $\mathcal{B}_{L}=\left\{b_{1}, \cdots, b_{c}\right\}$ o conjunto dos alelos observáveis no loco $L$. Se para qualquer $i_{1}=1, \cdots, c$ a condiçâo de equilíbrio de Hardy-Weinberg - dada na expressãon 2.1 - é satisfeita pelo sistema dialélico $b_{i_{1}}, B_{I_{1}}$ onde

$$
I_{1}=\{1,2, \cdots, n\}-\left\{i_{1}\right\}, \quad B_{I_{1}}=\mathcal{B}_{L}-\left\{b_{i_{1}}\right\},
$$

e se para cada $j=2, \cdots, c-1$ a condição de equilíbrio de Hardy-Weinberg é satisfeita pelo sistema dialélico $b_{i_{j}}, B_{I_{j}}$, qualquer que seja $i_{j}$ em $I_{j-1}$, onde

$$
I_{j}=I_{j-1}-\left\{i_{j}\right\}, \quad \text { e } B_{I_{j}}=B_{I_{j-1}}-\left\{b_{i j}\right\} \text {, }
$$

então, o sistema com os alelos $b_{1}, b_{2}, \cdots, b_{c}$ satisfaz a condiçâo de equilíbrio de HardyWeinberg dada na expressão 2.8 .

\section{Demonstração}


Sem perda de generalidade, podemos supor que para cada $j=1, \cdots, c-1$ o alelo escolhido no passo $j$ é $b_{j}$ - isto é, $i_{j}=j$. Além disso, pela hipótese temos que para cada $j=1, \cdots, c-1$, no sistema 'dialélico' $b_{j}, B_{j}$ existem números reais não negativos $u_{j 1} \mathrm{e}$ $u_{j 2}$ tais que

$$
\begin{aligned}
\text { i) } & u_{j 1}+u_{j 2}=u_{j-1,2} \\
\text { ii) } & p_{\left(b_{\jmath}, b_{\jmath}\right)}=u_{j 1}^{2} \\
\text { iii) } & p_{\left(b_{\jmath}, B_{\jmath}\right)}=2 u_{j 1} u_{j 2} \\
\text { iv) } & p_{\left(B_{\jmath}, B_{\jmath}\right)}=u_{j 2}^{2},
\end{aligned}
$$

onde $u_{02}=1, p_{\left(b_{j}, B_{j}\right)}$ denota a freqüência de todos os genótipos da forma $\left(b_{j}, b_{k}\right)$ para $k=j, \cdots, c$ e $p_{\left(B_{\jmath}, B_{\jmath}\right)}$ é a freqüência de todos os genótipos da forma $\left(b_{t}, b_{s}\right)$ para $t, s=$ $j, \cdots, c ; t \leq s$.

Da parte $i$ ) em 2.20 obtemos que existem $u_{11}, \cdots, u_{c, 1}$ números reais não-negativos tais que

$$
\sum_{j=1}^{c} u_{j 1}=1
$$

onde $u_{c 1}=u_{c-1,2}$.

Das partes $i i)$ e $i v$ ) na expressão 2.20 obtemos imediatamente que, para cada $i=1, \cdots, c$ a freqüência do genótipo $\left(b_{i}, b_{i}\right)$ é dada por $p_{k_{i i}}=u_{i 1}^{2}$, onde $k_{i i}=((i-1)(2 c-i)+2 i) / 2$.

Finalmente, das partes $i$ ) e $i i i)$ na expressão 2.20 determinarmos que, para cada $i, j=$ $1, \cdots, c, i<j$ a freqüência do genótipo $\left(b_{i}, b_{j}\right)$ é dada por $p_{k_{i j}}=2 u_{i 1} u_{j 1}$, onde $k_{i j}=$ $((i-1)(2 c-i)+2 j) / 2$.

Utilizando conjuntamente os resultados apresentados nas proposições 2.4 .2 e 2.4 .3 definimos o seguinte procedimento seqüencial para testar a hipótese de equilíbrio de HardyWeinberg.

\section{PROCEDIMENTO}


Faça $m=1$ e considere $I_{0}=\{1,2, \cdots, c\}$ e $B_{0}=\left\{b_{1}, b_{2}, \cdots, b_{c}\right\}$.

Passo 1. Procure $b_{i_{m}} \in B_{m-1}$ tal que para todo $t \in I_{m}=I_{m-1}-\left\{i_{m}\right\}$ (ou para todo $\left.b_{t} \in B_{I_{m}}=B_{I_{m-1}}-\left\{b_{i_{m}}\right\}\right)$ se tenha

$$
n_{b_{i_{m}} b_{i_{m}}}+\sum_{j \neq i_{m}} n_{b_{i_{m}} b_{j}} \leq n_{b_{t} b_{t}}+\sum_{j \neq t} n_{b_{t} b_{j}}
$$

Passo 2. Se, sobre o sistema dialélico $b_{i_{m}}, B_{I_{m}}$ a condição de equilíbrio de HardyWeinberg - dada na expressão 2.1 - nào é satisfeita, então vá para o Passo 4. Caso contrário, substitua $m$ por $m+1$ e vá para o Passo 3 .

Passo 3. Se $m<c$, vá para o Passo 1; caso contrário, vá para o Passo 4.

Passo 4. Se $m(<)=c$ o sistema com os alelos $b_{1}, b_{2}, \cdots, b_{c}$ (não) satisfaz a condição de equilíbrio de Hardy-Weinberg dada na expressãon 2.8 .

\subsection{Exemplos}

Nos exemplos que vamos considerar apresentaremos a seqüência em que foram realizados os testes de equilíbrio, segundo o procedimento definido na seção anterior.

Seja $n_{a}$ o número de alelos no loco considerado. Para cada $i=1, \cdots, n_{a}-1$ definimos

$b_{i} \quad$ alelo selecionado para efetuar o $i$-ésimo teste

$\left(b_{i}\right)^{c} \quad$ conjunto formado pelos alelos restantes ao efetuar o $i$-ésimo teste

$n_{i 1} \quad$ número de genótipos $\left(b_{i}, b_{i}\right)$

$n_{i 2} \quad$ número de genótipos $\left(b_{i},\left(b_{i}\right)^{c}\right)$

$n_{i 3} \quad$ número de genótipos $\left(\left(b_{i}\right)^{c},\left(b_{i}\right)^{c}\right)$

$R V P_{i}$ razão de verossimilhança ponderada, correspondente ao $i$-ésimo teste

\section{Exemplo 1}

Os dados seguintes correspondem à informação disponivel sobre o loco STR, MYC, com 
19 alelos e $n_{a}=5714$. (Whittle (1997)).

\begin{tabular}{|c|r|r|r|r|r|}
\hline $\mathrm{i}$ & $\mathrm{b}_{\mathrm{i}}$ & $n_{i 1}$ & $n_{i 2}$ & $n_{i 3}$ & $R V P_{i}$ \\
\hline \hline 1 & 91 & 0 & 2 & 5712 & 2587 \\
2 & 85 & 0 & 3 & 5709 & 2585 \\
3 & 93 & 0 & 3 & 5706 & 2583 \\
4 & 95 & 0 & 5 & 5701 & 2579 \\
5 & 123 & 0 & 5 & 5696 & 2577 \\
6 & 97 & 0 & 6 & 5690 & 2573 \\
7 & 99 & 0 & 7 & 5683 & 2569 \\
8 & 89 & 0 & 12 & 5671 & 2553 \\
9 & 87 & 0 & 22 & 5649 & 2505 \\
10 & 101 & 2 & 21 & 5626 & 0.74 \\
11 & 121 & 7 & 35 & 5584 & $9.6 \times 10^{-9}$ \\
\hline
\end{tabular}

Portanto, neste loco deve rejeitar-se a hipótese de equilíbrio de Hardy-Weinberg.

\section{Exemplo 2}

Os dados seguintes correspondem a informação disponível sobre o loco STR, D17S250, com 21 alelos e $n_{a}=5592$. (Whittle (1997)). 


\begin{tabular}{|c|r|r|r|r|r|}
\hline $\mathrm{i}$ & $\mathrm{b}_{\mathrm{i}}$ & $n_{i 1}$ & $n_{i 2}$ & $n_{i 3}$ & $R V P_{i}$ \\
\hline \hline 1 & 131 & 0 & 4 & 5588 & 2529.7 \\
2 & 139 & 0 & 5 & 5583 & 2526.4 \\
3 & 137 & 0 & 6 & 5577 & 2522.5 \\
4 & 171 & 0 & 8 & 5569 & 2515.7 \\
5 & 135 & 0 & 10 & 5559 & 2507.2 \\
6 & 133 & 0 & 11 & 5548 & 2499.9 \\
7 & 145 & 0 & 21 & 5527 & 2454.9 \\
8 & 169 & 0 & 31 & 5496 & 2384.2 \\
9 & 143 & 1 & 107 & 5388 & 773.2 \\
10 & 141 & 1 & 111 & 5276 & 788.5 \\
11 & 147 & 1 & 134 & 5141 & 857 \\
12 & 167 & 2 & 183 & 4956 & 599.8 \\
13 & 165 & 9 & 402 & 4545 & 278.7 \\
14 & 163 & 18 & 506 & 4021 & 158.7 \\
15 & 161 & 21 & 511 & 3489 & $6.6 \times 10^{160}$ \\
16 & 159 & 19 & 502 & 2968 & $2.2 \times 10^{155}$ \\
17 & 149 & 31 & 498 & 2439 & 53.5 \\
18 & 157 & 56 & 544 & 1839 & 6.63 \\
19 & 155 & 105 & 709 & 1025 & 11.1 \\
20 & 151 & 286 & 477 & 292 & $1.1 \times 10^{148}$ \\
\hline
\end{tabular}

Logo, neste loco não se rejeita a hipótese de equilíbrio de Hardy-Weinberg. 


\section{Capítulo 3}

\section{Análise para irmãos}

\subsection{Introdução}

Neste capítulo, primeiramente apresentamos em detalhes a metodologia proposta para determinar a distribuição de probabilidade a posteriori para o genótipo do demandado, uma vez que foi observada uma determinada estrutura genotípica em alguns de seus irmãos. Esta distribuiçâo de probabilidade a posteriori é a base para determinar a probabilidade de paternidade após terem sido observados os genótipos dos irmãos do demandado, da mãe do demandante e do próprio demandante - isto é, a probabilidade a posteriori de paternidade - cujo método de cálculo será exibido na seção 3.2 .

Na seção 3.3, utilizamos a metodologia desenvolvida na seção anterior para calcular tanto a distribuição de probabilidade a posteriori para o genótipo do demandado quanto a razão entre as verossimilhanças do demandado não ser o pai do demandante, $\operatorname{Vn} P[\cdot]$, e do demandado ser o pai do demandante, $V P[\cdot]$, para cada um dos possíveis casos determinados pelos dados referentes aos genótipos dos irmãos do demandado. Estes dois elementos são fundamentais no cálculo da probabilidade a posteriori de paternidade, a qual é obtida substituindo - na expressão 1.18 - os valores encontrados aqui para estes elementos. 


\subsection{Descrição geral da metodologia}

Consideremos um sistema monogênico, autossômico, polialélico e codominante - isto é, um sistema constituído por um loco $(L)$, nào situado nos cromossomos sexuais, com múltiplos alelos $(c \geq 2)$ e onde classes genotípicas distintas definem classes fenotípicas distintas.

Definamos $\mathcal{B}_{L}$ como sendo o conjunto $\left\{b_{1}, \cdots . b_{c}\right\}$ formado por todos os possiveis alelos observáveis no loco L e $f_{b_{i}}$ a freqüência alélica populacional do alelo $b_{i}, \quad i=1, \cdots, c$ tal que $\sum_{i=1}^{c} f_{b_{i}}=1$.

Denotemos por $g_{k_{i}}$ ou por $\left(b_{i}, b_{j}\right)$ o genótipo relacionado aos alelos $b_{i}$ e $b_{j}, i=1, \cdots, c ; j=$ $i, \cdots, c$ e consideremos

$$
G_{L}=\left\{g_{1}, g_{2}, \cdots, g_{N}\right\}
$$

o conjunto dos $N$ genótipos diferentes associados aos alelos do conjunto $\mathcal{B}_{L}$, onde

$$
k_{i j}=\frac{(i-1)(2 c-i)+2 j}{2} \text { e } \quad N=\frac{c(c+1)}{2},
$$

para $i \leq j, i, j=1, \cdots, c$.

Consideremos o espaço mensurável $\left(G_{L} \cdot \mathcal{A}_{G_{L}}\right)$ e seja $Z$ a variável aleatória $\mathcal{A}_{G_{L}}$ mensurável que denota o genótipo de um indivíduo qualquer da população. Se todos os cruzamentos ocorrerem ao acaso e se, além disto, a lei de equilíbrio populacional de Hardy-Weinberg é satisfeita, as freqüências genotípicas populacionais serão dadas pela seguinte expressão.

$$
P\left[\left\{g_{\frac{(i-1)(2 c-i)+2 j}{2}}\right\}\right]= \begin{cases}f_{b_{i}}^{2} & \text { se } i=j, i=1, \cdots, c \\ 2 f_{b_{i}} f_{b_{j}} & \text { se } i=1, \cdots, c-1 ; j=i+1, \cdots, c\end{cases}
$$

e, conseqüentemente, teremos que a medida $P$ definida sobre o espaço mensurável $\left(G_{L}, \mathcal{A}_{G_{L}}\right)$, é uma medida de probabilidade. Esta distribuição de probabilidade será chamada de distribuição a priori para o genótipo de um indivíduo qualquer da população e entenderemos $P\left[\left\{g_{k}\right\}\right]$ como sendo a probabilidade de que $Z$ assuma o valor $g_{k}$, ou seja, é a probabilidade $P\left[Z=g_{k}\right]$.

As considerações acima foram feitas na seção 1.4 , no entanto, são incluídas aqui para facilitar a leitura dos próximos sete capítulos. 
Suponhamos que estejam disponíveis dados do demandante e de sua mãe, além de dados referentes a alguns irmàos do demandado. Isto é. a árvore genealógica que estudaremos apresenta a seguinte estrutura:

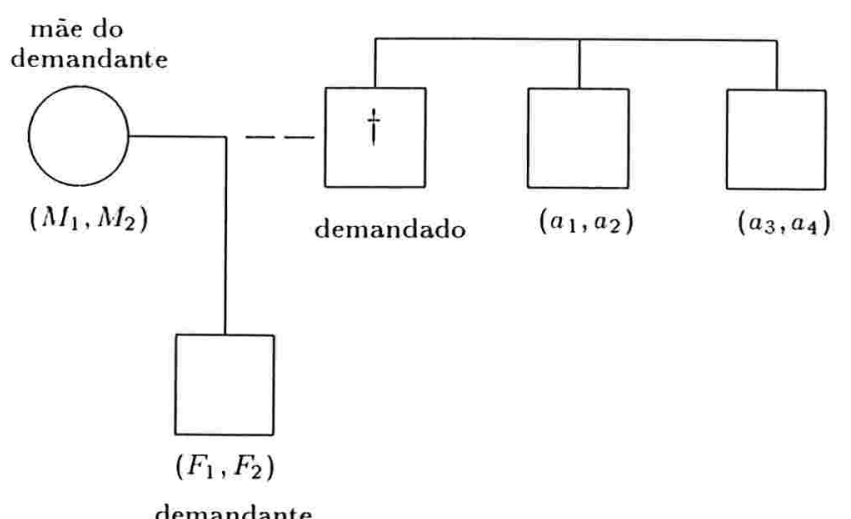

Árvore genealógica correspondente ao caso irmãos do demandado

Sejam $M, F$ e $X$ variáveis aleatórias $\mathcal{A}_{G_{L}}$ mensuráveis que denotam respectivamente os genótipos da mãe do demandante, do demandante e do demandado, e consideremos $U$ como sendo o vetor aleatório dos genótipos dos irmãos do demandado constituído por componentes $\mathcal{A}_{G_{L}}$ mensuráveis. Se os valores observados de $M, F$ e $U$ são respectivamente $\left(M_{1}, M_{2}\right),\left(F_{1}, F_{2}\right)$ e $\mathbf{u}$, o conjunto dos dados $D$ correspondente a este experimento é formado por

$$
D=\left\{\left(M_{1}, M_{2}\right),\left(F_{1}, F_{2}\right), \mathbf{u}\right\} .
$$

Inicialmente, o interesse é determinar a distribuição de probabilidade para o genótipo do demandado, após observar os genótipos de seus irmãos e o(s) alelo(s) de interesse isto é, queremos obter a distribuição de probabilidade a posteriori $P[\cdot \mid D]$ da variável aleatória $X$. Para determinarmos esta distribuição de probabilidade propomos o seguinte procedimento.

Primeiramente, consideremos o conjunto $G_{L}^{*}$ formado por todos os cruzamentos diferentes entre genótipos dos pais do demandado, isto é

$$
G_{L}^{*}=\bigcup_{k=1}^{N}\left(\left\{g_{k}\right\} \times G_{L}^{(k)}\right)
$$


onde

$$
G_{L}^{(1)}=G_{L} \text { e } G_{L}^{(k)}=G_{L}^{(k-1)}-\left\{g_{k-1}\right\}, k=2, \cdots, N
$$

Sobre o espaço mensurável $\left(G_{L}^{*}, \mathcal{A}_{G_{L}^{*}}\right)$ consideremos a medida $P^{\star}$ definida por

$$
P^{\star}\left[\left\{\left(g_{i}, g_{j}\right)\right\}\right]= \begin{cases}P^{2}\left[\left\{g_{i}\right\}\right] & \text { se } i=j \text { e } i=1, \cdots, N \\ 2 P\left[\left\{g_{i}\right\}\right] P\left[\left\{g_{j}\right\}\right] & \text { se } i=1, \cdots, N-1 \mathrm{e} \\ j & =i+1, \cdots, N\end{cases}
$$

onde $P$ é a medida de probabilidade definida em 3.1 .

Como está definida, $P^{*}$ é a distribuição de probabilidade que descreve a incerteza sobre os cruzamentos entre os genótipos dos pais do demandado, antes de serem observados genótipos de alguns irmaōs do demandado e o(s) alelo(s) de interesse - isto é, $P^{*}$ é a distribuição de probabilidade a priori para os cruzamentos entre os genótipos dos pais do demandado.

Agora, suponhamos que foram observados independentemente o genótipo da mãe do demandante, do demandante e os genótípos de $s$ irmãos do demandado, e sejam $\left(M_{1}, M_{2}\right)$, $\left(F_{1}, F_{2}\right)$ e $\mathbf{u}$ os genótipos observados respectivamente. Consideremos $D_{\mathbf{u}}$ como o conjunto formado por todos os elementos $(x, y)_{q}$ onde $(x, y)$ é o genótipo observado em um dos irmãos do demandado e $q$ representa o número de vezes que este genótipo foi observado nos $s$ irmãos - isto é, $q$ representa o número de vezes que o genótipo $(x, y)$ ocorre no vetor $\mathbf{u}$. Na verdade $D_{\mathbf{u}}$ é uma outra representação do vetor u. Por exemplo, se

$$
D_{\mathbf{u}}=\left\{\left(a_{1}, a_{1}\right)_{n} .\left(a_{1}, a_{2}\right)_{m},\left(a_{2}, a_{2}\right)_{r}\right\},
$$

se entende que os genótipos $\left(a_{1}, a_{1}\right),\left(a_{1}, a_{2}\right)$ e $\left(a_{2}, a_{2}\right)$ foram observados em $n, m$ e $r$ irmãos do demandado, respectivamente. onde $n+m+r=s$ e $a_{1}, a_{2}$ pertencem a $\mathcal{B}_{L}$.

Supondo que os pais do demandado não são parentes e sob a hipótese de que a lei de equilíbrio populacional de Hardy-Weinberg, no loco L, é satisfeita temos que os dois alelos que uma pessoa herda de seus pais. neste loco, são independentes e identicamente distribuídos (Veja Cavalli-Sforza e Bodmer (1971) para maiores detalhes).

Como poderemos observar neste capítulo e subseqüentes, em muitas ocasiões será necessário calcularmos a probabilidade condicional de um indivíduo ter um dado genótipo dados os genótipos dos pais deste indivíduo. 
Suponhamos que os pais de uma pessoa possuam os genótipos $g_{i}$ e $g_{j}$. Seja $V\left[g_{k} \mid\left(g_{i}, g_{j}\right)\right]$ a probabilidade condicional de que o genótipo $g_{k}$ provenha do cruzamento entre os genótipos $g_{i}$ e $g_{j}$. Esta probabilidade condicional pode ser obtida da seguinte tabela:

Tabela 2.1 Probabilidade condicional do indivíduo possuir um dado genótipo dados os genótipos de seus pais.

\begin{tabular}{|c|c|c|c|}
\hline Genótipo & \multicolumn{3}{|c|}{ Genótipo } \\
\hline $\mathrm{pai}_{1} \quad \mathrm{pai}_{2}$ & & do filho & $V[\cdot \mid(\cdot, \cdot)]$ \\
\hline$\left(b_{i}, b_{i}\right) \quad\left(b_{j}, b_{j}\right)$ & & $\left(b_{i}, b_{j}\right)$ & 1 \\
\hline$\left(b_{i}, b_{i}\right) \quad\left(b_{k}, b_{r}\right)$ & $k \neq r$ & $\begin{array}{l}\left(b_{i}, b_{k}\right) \\
\left(b_{i}, b_{r}\right)\end{array}$ & $\begin{array}{l}1 / 2 \\
1 / 2\end{array}$ \\
\hline$\left(b_{i}, b_{j}\right) \quad\left(b_{i}, b_{j}\right)$ & $i \neq j$ & $\begin{array}{l}\left(b_{i}, b_{i}\right) \\
\left(b_{i}, b_{j}\right) \\
\left(b_{j}, b_{j}\right)\end{array}$ & $\begin{array}{l}1 / 4 \\
1 / 2 \\
1 / 4\end{array}$ \\
\hline$\left(b_{i}, b_{j}\right) \quad\left(b_{k}, b_{r}\right)$ & $\begin{array}{c}i \neq j \\
k \neq r \\
(i, j) \neq(k, r)\end{array}$ & $\begin{array}{l}\left(b_{i}, b_{k}\right) \\
\left(b_{i}, b_{r}\right) \\
\left(b_{j}, b_{k}\right) \\
\left(b_{j}, b_{r}\right)\end{array}$ & $\begin{array}{l}1 / 4 \\
1 / 4 \\
1 / 4 \\
1 / 4\end{array}$ \\
\hline
\end{tabular}

Dado que estamos considerando $s$ irmãos do demandado, independentemente, para cada elemento $\left(g_{i}, g_{j}\right)$ em $G_{L}^{*}$ com $i \leq j, i, j=1, \cdots, N$ calculamos a probabilidade condicional $V\left[D_{\mathbf{u}} \mid\left(g_{i}, g_{j}\right)\right]$ a qual fornece a probabilidade de ocorrência do conjunto $D_{\mathbf{u}}$. supondo que o cruzamento entre os genótipos dos pais do demandado tenha sido $\left(g_{i}, g_{j}\right)$. Esta probabilidade será utilizada no cálculo da probabilidade a posteriori para o genótipo do demandado, como podemos ver nas expressões 3.5 e 3.6 , a seguir.

A forma como calculamos $V\left[D_{\mathbf{u}} \mid\left(g_{i}, g_{j}\right)\right]$ será ilustrada considerando o conjunto $D_{\mathbf{u}}$ dado na expressão 3.3 , onde, sem perda de generalidade, podemos supor que $a_{k}=b_{k}$ para $k=1,2$. Para este caso,

$$
\begin{aligned}
V\left[D_{\mathbf{u}} \mid\left(g_{i}, g_{j}\right)\right] & =\left(V\left[\left(a_{1}, a_{1}\right) \mid\left(g_{i}, g_{j}\right)\right]\right)^{n}\left(V\left[\left(a_{1}, a_{2}\right) \mid\left(g_{i}, g_{j}\right)\right]\right)^{m}\left[V\left(\left(a_{2}, a_{2}\right) \mid\left(g_{i}, g_{j}\right)\right]\right)^{r} \\
& =\left\{\begin{array}{cl}
\frac{1}{2^{2 n}} \frac{1}{2^{m}} \frac{1}{2^{2 r}} & \text { se } \left.g_{i}=g_{j}=\left(a_{1}, a_{2}\right) \quad \text { ou } i=j=2\right) \\
0 & \text { caso contrário. }
\end{array}\right.
\end{aligned}
$$


Geralmente, quando percorremos todo o conjunto $G_{L}^{*}$ algumas - às vezes muitas - das probabilidades condicionais $V\left[D_{\mathbf{u}} \mid\left(g_{i}, g_{j}\right)\right]$ serão zero. Em particular, serão nulas todas as probabilidades cujo cruzamento condicionante não permitir gerar algum dos genótipos considerados em $D_{\mathbf{u}}$. Assim, para efeitos práticos, bastaria considerar desde o início cruzamentos que gerem os elementos de $D_{\mathbf{u}}$ e os cruzamentos que permitem gerar filhos cujo genótipo inclua o(s) alelo(s) de interesse.

O próximo passo é a atualização da distribuição de probabilidade a priori $P^{*}$. Para isto usamos a informação obtida da observação dos irmãos do demandado, a qual é traduzida no conjunto $D_{\text {u }}$ e utilizamos o Teorema de Bayes como mecanismo de atualização de probabilidade.

Seja

$$
\delta=\sum_{k=1}^{N} \sum_{l=k}^{N}\left(V\left[D_{\mathbf{u}} \mid\left(g_{k}, g_{l}\right)\right] P^{*}\left[\left(g_{k}, g_{l}\right)\right]\right) .
$$

Das expressões 3.2 e 3.4 obtemos que a distribuição de probabilidade $P^{*}\left[\cdot \mid D_{\mathbf{u}}\right]$, após ser observado $D_{\mathrm{u}}$, é

$$
\begin{aligned}
P^{*}\left[\left(g_{i}, g_{j}\right) \mid D_{\mathbf{u}}\right] & =\frac{V\left[D_{\mathbf{u}} \mid\left(g_{i}, g_{j}\right)\right] P^{*}\left[\left(g_{i}, g_{j}\right)\right]}{\delta} \\
& =\frac{V\left[D_{\mathbf{u}} \mid\left(g_{i}, g_{j}\right)\right] P^{*}\left[\left(g_{i}, g_{j}\right)\right]}{\sum_{k=1}^{N} \sum_{l=k}^{N}\left(V\left[D_{\mathbf{u}} \mid\left(g_{k}, g_{l}\right)\right] P^{*}\left[\left(g_{k}, g_{l}\right)\right]\right)},
\end{aligned}
$$

para todo elemento $\left(g_{i}, g_{j}\right)$ pertencente a $G_{L}^{*}$.

Feito isto, podemos determinar a distribuição de probabilidade a posteriori $P\left[\cdot \mid D_{\mathbf{u}}\right]$ para o genótipo do demandado - uma vez que foram observados $s$ irmãos cujos genótipos estejam descritos no conjunto $D_{\mathbf{u}}$ - da seguinte forma

$$
P\left[g_{i} \mid D_{\mathbf{u}}\right]=\sum_{k=1}^{N} \sum_{l=k}^{N} V\left[g_{i} \mid\left(g_{k}, g_{l}\right)\right] P^{*}\left[\left(g_{k}, g_{l}\right) \mid D_{\mathbf{u}}\right], \quad i=1, \cdots, N .
$$

Em resumo, considerando a variável aleatória $X, \mathcal{A}_{G_{L}}$ mensurável, que denota o genótipo do demandado, $P$ como a medida de probabilidade definida sobre o espaço $\left(G_{L}, \mathcal{A}_{G_{L}}\right)$ definida na expressão 3.1 , a qual descreve a incerteza a priori sobre $X$, e u o vetor dos genótipos observados nos irmãos do demandado representado no conjunto $D_{\mathbf{u}}$, ficou provado o seguinte resultado. 
Teorema 3.2.1 Se u é obtido ao observarmos independentemente sirmâos do demandado, entâo a distribuiçào de probabilidade a posteriori $P\left[\cdot \mid D_{\mathrm{u}}\right]$ para $X^{\prime}$ é dada pela expressào

$$
P\left[g_{i} \mid D_{\mathbf{u}}\right]=\sum_{k=1}^{N} \sum_{l=k}^{N} V\left[g_{i} \mid\left(g_{k}, g_{l}\right)\right] P^{*}\left[\left(g_{k}, g_{l}\right) \mid D_{\mathbf{u}}\right], \quad i=1, \cdots, N,
$$

onde $V\left[\cdot \mid\left(g_{k}, g_{l}\right)\right]$ e $P^{*}\left[\cdot \mid D_{\mathbf{u}}\right]$ sâo dadas, respectivamente, pelas expressões da tabela 2.1 e 3.5 (a ser vista na próxima seçào).

Finalmente, a probabilidade a posteriori de paternidade $\pi[\theta=0 \mid D]$ estabelecida após ser observada a informação fornecida pelos dados $D$, pode ser determinada utilizando as expressões 1.8 ou 1.9 .

$\mathrm{Na}$ próxima seçâo, aplicaremos a metodologia introduzida aqui considerando todos os diferentes conjuntos $D_{\mathbf{u}}$ que trazem informação sobre os genótipos observados nos irmãos do demandado. Para facilitarmos a apresentação dos resultados correspondentes aos conjuntos $D_{\mathbf{u}}$ que determinam diferentes distribuições de probabilidade a posteriori para o genótipo do demandado, estes serão referenciados ao longo deste capítulo pelo código caso c.i.j a ser dado na primeira coluna da tabela 3.2 , onde c indica o número do capítulo, i o número de alelos diferentes que aparecem em $D_{\mathbf{u}}$ e $\mathbf{j}$ enumera as diferentes associações com igual número de alelos.

Tabela 3.2 Dados relevantes ao observarmos irmãos do demandado.

caso genótipos observados

3.1.1

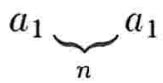

3.2 .1
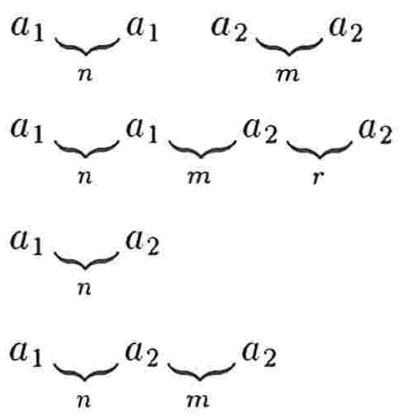

3.3 .1

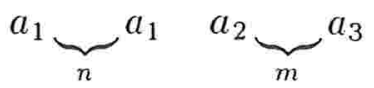




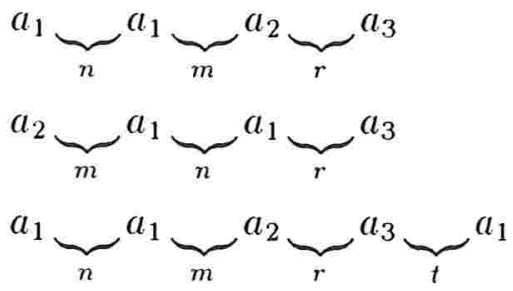

3.3 .2

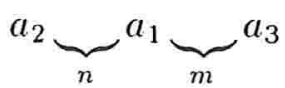

3.3.3

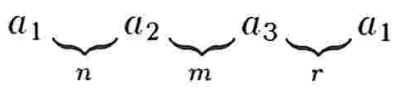

3.4 .1

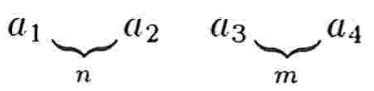

3.4 .2

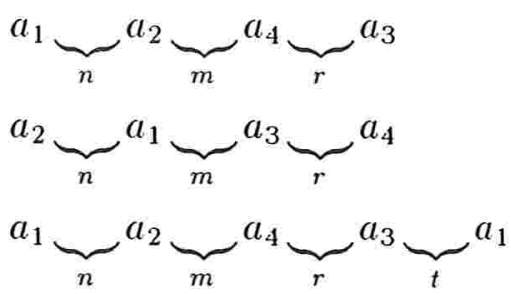

\subsection{Análise dos casos}

Nesta seção, aplicamos a metodologia desenvolvida na seção 3.2 para determinar a distribuição de probabilidade a posteriori para o genótipo do demandado. considerando cada um dos casos relacionados na tabela 3.2, exibida no final da seção anterior. Além disso, pelos argumentos fornecidos na capítulo anterior, exibiremos apenas a probabilidade condicional $V_{0}[D]$ - ou $R V[D]$ quando possível - necessária ao cálculo da probabilidade a posteriori de paternidade. Quanto à outra probabilidade condicional $V_{1}[D]$, também necessária ao cálculo desta probabilidade a posteriori, será omitida por ser diretamente obtida da proposição 1.5.1.

Ao longo desta seção não tornaremos explícitos aqueles genótipos e cruzamentos de genótipos cujas probabilidades a posteriori sejam nulas.

Consideremos $n$ alelos diferentes, $a_{1}, \cdots, a_{n}$ no conjunto $\mathcal{B}_{L}$. Para cada $i=1, \cdots, n$, denotamos por $\left(a_{i},(\underbrace{x \cdots x}_{n \text { vezes }})^{c}\right)$ o conjunto constituído por todos os possíveis genótipos 
$\left(a_{i}, b\right)$, onde $b$ pertence a $\mathcal{B}_{L}$ e $b \neq a_{j}, j=1, \cdots, n$. Além disso, para cada número natural $n$ e cada número real $t$ pertencente ao intervalo $[0,1]$, definimos $H[n, t]$ pela seguinte expressão

$$
H[n, t]=1+\left(2^{n-1}-1\right) t
$$

\section{Caso 3.1.1}

Sejam $a_{1}, F_{1}$ e $F_{2}$ três alelos diferentes. Suponhamos que, ao considerarmos $n$ irmãos do demandado, independentemente, observamos em cada um deles o genótipo $\left(a_{1}, a_{1}\right)$ isto é, $D_{\mathbf{u}}=\left\{\left(a_{1}, a_{1}\right)_{n}\right\}$.

Para abranger todas as situaçòes em que o(s) alelo(s) de interesse não incluem o alelo $a_{1}$, consideremos todos os cruzamentos que permitem gerar genótipos da forma $\left(a_{1}, \alpha\right)$, ou, equivalentemente, $\left(F_{i}, \alpha\right)$ para $i=1,2$, onde $\alpha$ é um alelo qualquer no loco $L$.

Sob essas considerações, as probabilidades $P^{*}[\cdot]$ e $V\left[D_{\mathbf{u}} \mid \cdot\right]$ podem ser obtidas a seguir

$$
\begin{array}{rlc}
\text { cruzamento }(\cdot) & \multicolumn{1}{c}{P^{*}[\cdot]} & V\left[D_{\mathbf{u}} \mid \cdot\right] \\
\left(\left(a_{1}, a_{1}\right),\left(a_{1}, a_{1}\right)\right) & f_{a_{1}}^{4} & 1 \\
\left(\left(a_{1}, a_{1}\right),\left(a_{1}, F_{i}\right)\right) & 2^{2} f_{a_{1}}^{3} f_{F_{i}}, i=1,2 & (1 / 2)^{n} \\
\left(\left(a_{1}, a_{1}\right),\left(a_{1},(x x x)^{c}\right)\right) & 2^{2} f_{a_{1}}^{3}\left(1-f_{a_{1}}-\sum_{i=1}^{2} f_{F_{i}}\right) & (1 / 2)^{n} \\
\left(\left(a_{1}, F_{i}\right),\left(a_{1}, F_{i}\right)\right) & 2^{2} f_{a_{1}}^{2} f_{F_{i}}^{2}, i=1,2 & (1 / 4)^{n} \\
\left(\left(a_{1}, F_{2}\right),\left(a_{1}, F_{1}\right)\right) & 2^{3} f_{a_{1}}^{2} \prod_{i=1}^{2} f_{F_{i}} & (1 / 4)^{n} \\
\left(\left(a_{1}, F_{i}\right),\left(a_{1},(x x x)^{c}\right)\right) & 2^{3} f_{a_{1}}^{2} f_{F_{i}}\left(1-f_{a_{1}}-\sum_{i=1}^{2} f_{F_{i}}\right), i=1,2 & (1 / 4)^{n} \\
\left(\left(a_{1},(x x x)^{c}\right),\left(a_{1},(x x x)^{c}\right)\right) & 2^{2} f_{a_{1}}^{2}\left(1-f_{a_{1}}-\sum_{i=1}^{2} f_{F_{i}}\right)^{2} & (1 / 4)^{n}
\end{array}
$$

Conseqüentemente, para obtermos a distribuição $P^{*}\left[\cdot \mid D_{\mathbf{u}}\right]$ é necessário apenas calcular o valor de $\delta$ definido na expressão 3.4. Para o caso que consideramos aqui, $\delta$ torna-se

$$
\delta=\left\{\frac{f_{a_{1}} H\left[n, f_{a_{1}}\right]}{2^{n-1}}\right\}^{2},
$$

e a distribuição de probabilidade a posteriori para os cruzamentos entre os genótipos dos pais do demandado é dada no seguinte resultado. 
Proposição 3.3.1 A distribuiçâo de probabilidade a posteriori para os cruzamentos entre os genótipos dos pais do demandado $P^{\times}\left[\cdot \mid D_{\mathbf{u}}\right]$, uma vez que em $n$ dos irmàos do demandado foi observado o genótipo $\left(a_{1}, a_{1}\right)$ é a seguinte.

$$
\begin{aligned}
\text { cruzamento }(\cdot) & \multicolumn{1}{c}{P^{\times}\left[\cdot \mid D_{\mathbf{u}}\right]} \\
\left(\left(a_{1}, a_{1}\right),\left(a_{1}, a_{1}\right)\right) & \frac{2^{2 n-2} f_{a_{1}}^{2}}{H^{2}\left[n, f_{a_{1}}\right]} \\
\left(\left(a_{1}, a_{1}\right),\left(a_{1}, F_{i}\right)\right) & \frac{2^{n} f_{a_{1}} f_{F_{i}}}{H^{2}\left[n, f_{a_{1}}\right]}, i=1,2 \\
\left(\left(a_{1}, a_{1}\right),\left(a_{1},(x x x)^{c}\right)\right) & \frac{2^{n} f_{a_{1}}\left(1-f_{a_{1}}-\sum_{j=1}^{2} f_{F_{j}}\right)}{H^{2}\left[n, f_{a_{1}}\right]} \\
\left(\left(a_{1}, F_{i}\right),\left(a_{1}, F_{i}\right)\right) & \frac{f_{F_{i}}^{2}}{H^{2}\left[n, f_{a_{1}}\right]}, i=1,2 \\
\left(\left(a_{1}, F_{1}\right),\left(a_{1}, F_{2}\right)\right) & \frac{2 \prod_{j=1}^{2} f_{F_{J}}}{H^{2}\left[n, f_{a_{1}}\right]} \\
\left(\left(a_{1}, F_{i}\right),\left(a_{1},(x x x)^{c}\right)\right) & \frac{2 f_{F_{i}}\left(1-f_{a_{1}}-\sum_{j=1}^{2} f_{F_{j}}\right)}{H^{2}\left[n, f_{a_{1}}\right]} \\
\left(\left(a_{1},(x x x)^{c}\right),\left(a_{1},(x x x)^{c}\right)\right) & \frac{\left(1-f_{a_{1}}-\sum_{j=1}^{2} f_{F_{J}}\right)^{2}}{H^{2}\left[n, f_{a_{1}}\right]}
\end{aligned}
$$

Como vimos na expressão 3.6 , a distribuição de probabilidade a posteriori $P\left[\cdot \mid D_{\mathbf{u}}\right]$ para o genótipo do demandado é imediatamente obtida utilizando-se a distribuição $P^{\times}\left[\cdot \mid D_{\mathbf{u}}\right]$. Como ilustração do procedimento de obtenção de $P\left[\cdot \mid D_{\mathbf{u}}\right]$ derivamos a seguir a probabilidade do demandado possuir o genótipo $\left(a_{1}, a_{1}\right)$, uma vez que em $n$ de seus irmãos foi observado este mesmo genótipo.

onde

$$
P\left[\left(a_{1}, a_{1}\right) \mid D_{\mathbf{u}}\right]=\frac{\phi\left[n, f_{a_{1}}\right]}{H^{2}\left[n, f_{a_{1}}\right]},
$$

$$
\phi\left[n, f_{a_{1}}\right]=2^{2 n-2} f_{a_{1}}^{2}+\frac{1}{2}\left(2^{n} f_{a_{1}} \sum_{j=1}^{2} f_{F_{j}}+2^{n} f_{a_{1}}\left(1-f_{a_{1}}-\sum_{j=1}^{2} f_{F_{j}}\right)\right)
$$




$$
\begin{aligned}
& +\frac{1}{4}\left(\sum_{j=1}^{2} f_{F_{j}}^{2}+2 \prod_{j=1}^{2} f_{F_{j}}+2\left(1-f_{a_{1}}-\sum_{j=1}^{2} f_{F_{j}}\right) \sum_{j=1}^{2} f_{F_{j}}\right) \\
& +\frac{1}{4}\left(1-f_{a_{1}}-\sum_{j=1}^{2} f_{F_{j}}\right)^{2} \\
& =\frac{\left(1+\left(2^{n}-1\right) f_{a_{1}}\right)^{2}}{4}=\frac{H^{2}\left[n+1, f_{a_{1}}\right]}{4} .
\end{aligned}
$$

Procedendo de maneira similar, derivamos as demais probabilidades a posteriori para o genótipo do demandado $P\left[\cdot \mid D_{\mathbf{u}}\right]$, as quais são apresentadas no seguinte resultado.

Proposição 3.3.2 A distribuiçâo de probabilidade a posteriori para o genótipo do demandado $P\left[\cdot \mid D_{\mathbf{u}}\right]$, uma vez que em $n$ de seus irmãos foi observado o genótipo $\left(a_{1}, a_{1}\right)$ é a seguinte.

$$
\begin{aligned}
\text { genótipo }(\cdot) & P\left[(\cdot) \mid D_{\mathbf{u}}\right] \\
\left(a_{1}, a_{1}\right) & \frac{H^{2}\left[n+1, f_{a_{1}}\right]}{4 H^{2}\left[n, f_{a_{1}}\right]} \\
\left(a_{1}, F_{i}\right) & \frac{2 f_{F_{i}} H\left[n+1, f_{a_{1}}\right]}{4 H^{2}\left[n, f_{a_{1}}\right]}, i=1,2 \\
\left(a_{1},(x x x)^{c}\right) & \frac{2\left(1-f_{a_{1}}-\sum_{i=1}^{2} f_{F_{i}}\right) H\left[n+1, f_{a_{1}}\right]}{4 H^{2}\left[n, f_{a_{1}}\right]} \\
\left(F_{i}, F_{i}\right) & \frac{f_{F_{i}}^{2}}{4 H^{2}\left[n, f_{a_{1}}\right]}, i=1,2 \\
\left(F_{1}, F_{2}\right) & \frac{2 \prod_{j=1}^{2} f_{F_{j}}}{4 H^{2}\left[n, f_{a_{1}}\right]} \\
\left(F_{i},(x x x)^{c}\right) & \frac{2 f_{F_{i}}\left(1-f_{a_{1}}-\sum_{j=1}^{2} f_{F_{j}}\right)}{4 H^{2}\left[n, f_{a_{1}}\right]}, i=1,2 \\
\left((x x x)^{c},(x x x)^{c}\right) & \frac{\left(1-f_{a_{1}}-\sum_{j=1}^{2} f_{F_{j}}\right)^{2}}{4 H^{2}\left[n, f_{a_{1}}\right]}
\end{aligned}
$$


Como visto na proposição 1.5 .2 , da distribuição de probabilidade a posteriori para o genótipo do demandado obtemos a probabilidade condicional do demandante ter recebido do demandado o(s) alelo(s) de interesse após termos observado $D$. Consideremos, como antes, o conjunto $I$ como sendo o conjunto formado pelo(s) alelo(s) de interesse.

Corolário 3.3.1 A probabilidade condicional $V_{0}[D]$ do demandante ter recebido do demandado o(s) alelo(s) de interesse após termos observado $D$ é dada por

$$
\begin{aligned}
& I \quad V_{0}[D] \\
& a_{1} \quad \gamma\left(M_{1}, M_{2}\right) \frac{H\left[n+1, f_{a_{1}}\right]}{2 H\left[n, f_{a_{1}}\right]} \\
& F_{i} \quad \gamma\left(M_{1}, M_{2}\right) \frac{f_{F_{i}}}{2 H\left[n, f_{a_{1}}\right]} i=1,2 \\
& a_{1} \text { e } F_{i} \quad \gamma\left(M_{1}, M_{2}\right) \frac{H\left[n+1, f_{a_{1}}\right]+f_{F_{i}}}{2 H\left[n, f_{a_{1}}\right]} i=1,2 \\
& F_{1} \text { e } F_{2} \quad \gamma\left(M_{1}, M_{2}\right) \frac{f_{F_{1}}+f_{F_{2}}}{2 H\left[n, f_{a_{1}}\right]} \text {. }
\end{aligned}
$$

Prova: Consideremos o caso onde $I=\left\{a_{1}, F_{1}\right\}$. Queremos calcular a probabilidade condicional do demandante possuir o genótipo $\left(a_{1}, F_{1}\right)$ sabendo que sua mãe tem o genótipo $\left(a_{1}, F_{1}\right)$, que em $n$ dos irmãos do demandado observamos o genótipo $\left(a_{1}, a_{1}\right)$ e supondo que o demandado é o verdadeiro pai do demandante. Da proposição $1.5 .2 \mathrm{e}$ da expressão 1.14 obtemos que a probabilidade $V_{0}[D]$ é dada por

$$
\begin{aligned}
V_{0}[D]= & \frac{1}{2}\left\{P\left[\left(a_{1}, a_{1}\right) \mid D_{\mathbf{u}}\right]+P\left[\left(F_{1}, F_{1}\right) \mid D_{\mathbf{u}}\right]+\frac{1}{2}\left(\sum_{i=1}^{2} P\left[\left(a_{1}, F_{i}\right) \mid D_{\mathbf{u}}\right]+P\left[\left(a_{1}, F_{1}\right) \mid D_{\mathbf{u}}\right]\right)\right. \\
& \left.+\frac{1}{2}\left(P\left[\left(a_{1},(x x x)^{c}\right) \mid D_{\mathbf{u}}\right]+P\left[\left(F_{1}, F_{2}\right) \mid D_{\mathbf{u}}\right]+P\left[\left(F_{1},(x x x)^{c}\right) \mid D_{\mathbf{u}}\right]\right)\right\} .
\end{aligned}
$$

Substituindo na expressão anterior os correspondentes resultados dados na proposição 3.7 temos que a probabilidade $V_{0}[D]$ é

$$
\begin{aligned}
V_{0}[D] & =\frac{1}{2} \frac{H\left[n+1, f_{a_{1}}\right]+f_{F_{1}}}{2 H\left[n, f_{a_{1}}\right]} \\
& =\gamma\left(M_{1}, M_{2}\right) \frac{H\left[n+1, f_{a_{1}}\right]+f_{F_{1}}}{2 H\left[n, f_{a_{1}}\right]},
\end{aligned}
$$


como desejávamos provar.

As outras probabilidades condicionais sào calculadas similarmente.

Dos resultados apresentados no corolário 3.3 .1 e na proposição 1.5.1 obtemos a razão $R V[D]$ para cada conjunto $I$, a qual exibimos na tabela a seguir.

Tabela 3.3 Razão de verossimilhanças - Caso 2.1.1

$$
\begin{array}{cl}
I & \multicolumn{1}{c}{R V[D]} \\
a_{1} & \frac{2 f_{a_{1}} H\left[n, f_{a_{1}}\right]}{H\left[n+1, f_{a_{1}}\right]} \\
F_{i} & 2 H\left[n, f_{a_{1}}\right] i=1,2 \\
a_{1} \text { е } F_{i} & \frac{2 H\left[n, f_{a_{1}}\right]\left(f_{a_{1}}+f_{F_{i}}\right)}{H\left[n+1, f_{a_{1}}\right]+f_{F_{i}}} i=1,2 \\
F_{1} \text { е } F_{2} & 2 H\left[n, f_{a_{1}}\right]
\end{array}
$$

Daqui em diante, apresentaremos os resultados de maior relevância para os diferentes casos, dispensando os detalhes que conduzem às diferentes distribuições de probabilidade a posteriori, à probabilidade condicional $V_{0}[D]$ e à razão $R V[D]$. Além disso, na apresentação dos valores de $V_{0}[D]$ omitiremos o fator $\gamma_{\left(M_{1}, M_{2}\right)}$, entendendo que o valor verdadeiro de $V_{0}[D]$ é o produto entre o valor apresentado e $\gamma_{\left(M_{1}, M_{2}\right)}$.

\section{Caso 3.2.1}

Sejam $a_{1}, a_{2}$ e $F_{1}$ três alelos diferentes e suponhamos que, ao observarmos independentemente $s$ irmãos do demandado, ocorra uma das seguintes situações:

$$
\begin{aligned}
& D_{\mathbf{u}}=\left\{\left(a_{1}, a_{1}\right)_{n},\left(a_{2}, a_{2}\right)_{m}\right\}, \text { onde } s=n+m \text {, ou } \\
& D_{\mathbf{u}}=\left\{\left(a_{1}, a_{1}\right)_{n},\left(a_{1}, a_{2}\right)_{m},\left(a_{2}, a_{2}\right)_{r}\right\}, \text { com } s=n+m+r .
\end{aligned}
$$

Em qualquer uma dessas situações temos que a distribuição de probabilidade a posteriori $P^{*}\left[\cdot \mid D_{\mathrm{u}}\right]$ para os cruzamentos entre os genótipos dos pais do demandado é a distribuição

$$
P^{*}\left[\left(g_{i}, g_{j}\right) \mid D_{\mathbf{u}}\right]= \begin{cases}1 & \text { se } g_{i}=g_{j}=\left(a_{1}, a_{2}\right) \\ 0 & \text { caso contrário, }\end{cases}
$$


da qual derivamos a distribuição a posteriori $P\left[\cdot \mid D_{\mathbf{u}}\right]$ que é exibida no seguinte resultado.

Proposição 3.3.3 Sob as condiçôes dadas acima, a distribuição de probabilidade a posteriori para o genótipo do demandado $P\left[\cdot \mid D_{\mathbf{u}}\right]$ é dada por

$$
\begin{aligned}
\text { genótipo }(\cdot) & P\left[\cdot \mid D_{\mathbf{u}}\right] \\
\left(a_{i}, a_{i}\right) & 1 / 4, \quad i=1,2 \\
\left(a_{1}, a_{2}\right) & 1 / 2,
\end{aligned}
$$

onde $D_{\mathbf{u}}$ é como definido $\mathrm{em} 3.9$ ou bem 3.10 .

A razão de verossimilhança $R V[D]$ e a probabilidade condicional $V_{0}[D]$, que é obtida da proposição 3.3 .3 , estão dadas na seguinte tabela.

Tabela 3.4 Probabilidade condicional $V_{0}[D]$ e razão de verossimilhanças $R V[D]$ - Caso 2.2.1

$$
\begin{array}{ccl}
I & V_{0}[D] & R V[D] \\
a_{i} & 1 / 2 & 2 f_{a_{i}}, \quad i=1,2 \\
a_{1} \text { е } a_{2} & 1 & f_{a_{1}}+f_{a_{2}} \\
a_{i} \text { e } F_{1} & 1 / 2 & 2\left(f_{a_{i}}+f_{F_{1}}\right) i=1,2
\end{array}
$$

\section{Caso 3.2.2}

Sejam $a_{i}$ e $F_{i}$ para $i=1,2$ quatro alelos diferentes. Suponhamos que, ao considerarmos $n$ irmãos do demandado, independentemente, observamos em cada um deles o genótipo $\left(a_{1}, a_{2}\right)$ - isto é, $D_{\mathbf{u}}=\left\{\left(a_{1}, a_{2}\right)_{n}\right\}$.

Neste caso, as probabilidades $P^{*}[\cdot]$ e $V\left[D_{\mathbf{u}} \mid \cdot\right]$ podem ser assim obtidas: 


$$
\begin{aligned}
& \text { cruzamento }(\cdot) \quad P^{*}[\cdot] \quad V\left[D_{\mathbf{u}} \mid \cdot\right] \\
& \left(\left(a_{1}, a_{1}\right),\left(a_{1}, a_{2}\right)\right) \quad 2^{2} f_{a_{1}}^{3} f_{a_{2}} \quad(1 / 2)^{n} \\
& \left(\left(a_{1}, a_{1}\right),\left(a_{2}, a_{2}\right)\right) \quad 2 \prod_{k=1}^{2} f_{a_{k}}^{2} \quad 1 \\
& \left(\left(a_{1}, a_{1}\right),\left(a_{2}, F_{i}\right)\right) \quad 2^{2} f_{a_{1}}^{2} f_{a_{2}} f_{F_{1}}, i=1,2 \quad(1 / 2)^{n} \\
& \left(\left(a_{1}, a_{1}\right),\left(a_{2},(x x x x)^{c}\right)\right) \quad 2^{2} f_{a_{1}}^{2} f_{a_{2}}\left(1-\sum_{j=1}^{2}\left(f_{a_{j}}+f_{F_{j}}\right)\right) \quad(1 / 2)^{n} \\
& \left(\left(a_{1}, a_{2}\right),\left(a_{1}, a_{2}\right)\right) \quad 2^{2} \prod_{k=1}^{2} f_{a_{k}}^{2} \quad(1 / 2)^{n} \\
& \left(\left(a_{1}, a_{2}\right),\left(a_{2}, a_{2}\right)\right) \quad 2^{2} f_{a_{1}} f_{a_{2}}^{3} \quad(1 / 2)^{n} \\
& \left(\left(a_{1}, a_{2}\right),\left(a_{2}, F_{i}\right)\right) \quad 2^{3} f_{a_{1}} f_{a_{2}}^{2} f_{F_{i}}, i=1,2 \quad(1 / 4)^{n} \\
& \left(\left(a_{1}, a_{2}\right),\left(a_{2},(x x x x)^{c}\right)\right) \quad 2^{3} f_{a_{1}} f_{a_{2}}^{2}\left(1-\sum_{j=1}^{2}\left(f_{a_{j}}+f_{F_{j}}\right)\right) \quad(1 / 4)^{n} \\
& \left(\left(a_{1}, F_{i}\right),\left(a_{1}, a_{2}\right)\right) \quad 2^{3} f_{a_{1}}^{2} f_{a_{2}} f_{F_{i}}, i=1,2 \quad(1 / 4)^{n} \\
& \left(\left(a_{1}, F_{i}\right),\left(a_{2}, a_{2}\right)\right) \quad 2^{2} f_{a_{1}} f_{a_{2}}^{2} f_{F_{i}}, i=1,2 \quad(1 / 2)^{n} \\
& \left(\left(a_{1}, F_{i}\right),\left(a_{2}, F_{i}\right)\right) \quad 2^{3} f_{F_{i}}^{2} \prod_{k=1}^{2} f_{a_{k}}, i=1,2 \quad(1 / 4)^{n} \\
& \left(\left(a_{1}, F_{i}\right),\left(a_{2}, F_{j}\right)\right) \quad 2^{3} f_{F_{i}} f_{F_{j}} \prod_{k=1}^{2} f_{a_{k}}, i \neq j, i, j=1,2 \quad(1 / 4)^{n} \\
& \left(\left(a_{1}, F_{i}\right),\left(a_{2},(x x x x)^{c}\right)\right) \quad 2^{3} f_{F_{i}} \prod_{k=1}^{2} f_{a_{k}}\left(1-\sum_{j=1}^{2}\left(f_{a_{j}}+f_{F_{\jmath}}\right)\right), i=1,2 \quad(1 / 4)^{n} \\
& \left(\left(a_{1},(x x x x)^{c}\right),\left(a_{1}, a_{2}\right)\right) \quad 2^{3} f_{a_{1}}^{2} f_{a_{2}}\left(1-\sum_{j=1}^{2}\left(f_{a_{j}}+f_{F_{j}}\right)\right) \quad(1 / 4)^{n} \\
& \left(\left(a_{1},(x x x x)^{c}\right),\left(a_{2}, a_{2}\right)\right) \quad 2^{2} f_{a_{1}} f_{a_{2}}^{2}\left(1-\sum_{j=1}^{2}\left(f_{a_{j}}+f_{F_{j}}\right)\right) \quad(1 / 2)^{n} \\
& \left(\left(a_{1},(x x x x)^{c}\right),\left(a_{2}, F_{i}\right)\right) \quad 2^{3} f_{F_{i}} \prod_{k=1}^{2} f_{a_{k}}\left(1-\sum_{j=1}^{2}\left(f_{a_{j}}+f_{F_{j}}\right)\right), i=1,2 \quad(1 / 4)^{n} \\
& \left(\left(a_{1},(x x x x)^{c}\right),\left(a_{2},(x x x x)^{c}\right)\right) \quad 2^{3} \prod_{k=1}^{2} f_{a_{k}}\left(1-\sum_{j=1}^{2}\left(f_{a_{j}}+f_{F_{j}}\right)\right)^{2} \quad(1 / 4)^{n}
\end{aligned}
$$

Prescindindo da expressão explícita para a distribuição a posteriori $P^{\star}\left[\cdot \mid D_{\mathbf{u}}\right]$ e considerando a função

$$
w=w\left[n, f_{a_{1}}, f_{a_{2}}\right]=1+\left(2^{n-1}-1\right)\left(f_{a_{1}}+f_{a_{2}}+2^{n-1} f_{a_{1}} f_{a_{2}}\right),
$$

fornecemos a distribuição de probabilidade a posteriori para o genótipo do demandado $P\left[\cdot \mid D_{\mathbf{u}}\right]$ no seguinte resultado.

Proposição 3.3.4 A distribuição de probabilidade a posteriori para o genótipo do demandado $P\left[\cdot \mid D_{\mathbf{u}}\right]$, uma vez que em $n$ de seus irmâos foi observado o genótipo $\left(a_{1}, a_{2}\right)$ é 
a seguinte.

$$
\begin{aligned}
\text { genótipo }(\cdot) & P\left[\cdot \mid D_{\mathbf{u}}\right] \\
\left(a_{i}, a_{i}\right) & f_{a_{i}}\left(H\left[n+1, f_{a_{1}}\right]+\left(2^{n-1}-1\right) f_{a_{\sigma(i)}}\right) / 4 w, \quad i=1,2 \\
\left(a_{1}, a_{2}\right) & \left(1+\left(2^{n}-1\right)\left(f_{a_{1}}+f_{a_{2}}+2^{n} f_{a_{1}} f_{a_{2}}\right)\right) / 4 w \\
\left(a_{i}, F_{j}\right) & \left(1+2^{n} f_{a_{\mathbf{t}}}\right) f_{F_{j}} / 4 w, \quad i, j=1,2 \\
\left(a_{i},(x x x x)^{c}\right) & \left(1+2^{n} f_{a_{i}}\right)\left(1-\sum_{j=1}^{2}\left(f_{a_{j}}+f_{F_{j}}\right)\right) / 4 w, \quad i=1,2 \\
\left(F_{i}, F_{i}\right) & f_{F_{i}}^{2} / 4 w, i=1,2 \\
\left(F_{1}, F_{2}\right) & \prod_{k=1}^{2} f_{F_{k}} / 2 w \\
\left(F_{i},(x x x x)^{c}\right) & f_{F_{i}}\left(1-\sum_{j=1}^{2}\left(f_{a_{3}}+f_{F_{j}}\right)\right) / 2 w, \quad i=1,2 \\
\left((x x x x)^{c},(x x x x)^{c}\right) & \left(1-\sum_{j=1}^{2}\left(f_{a_{j}}+f_{F_{j}}\right)\right)^{2} / 4 w,
\end{aligned}
$$

onde w é a funçâo definida na expressão 3.11 e $\sigma(\cdot)$ é a função definida a seguir

$$
\begin{aligned}
\sigma:\{1,2\} & \longrightarrow\{1,2\} \\
i & \longmapsto \sigma(i)=\left\{\begin{array}{l}
2 \text { se } i=1 \\
1 \text { se } i=2
\end{array}\right.
\end{aligned}
$$

Como conseqüência do resultado anterior surge, naturalmente, o seguinte corolário.

Corolário 3.3.2 Sob as condições da proposição 3.3.4, temos que a razâo de verossimilhanças $R V[D]$ e a probabilidade condicional $V_{0}[D]$, do demandante ter recebido do demandado o(s) alelo(s) de interesse após termos observado $D$, são:

$$
V_{0}[D]
$$




$$
\begin{array}{cll}
a_{i} & \frac{v_{i}\left[n, f_{a_{1}}, f_{a_{2}}\right]}{4 w\left[n, f_{a_{1}}, f_{a_{2}}\right]} & \frac{4 f_{a_{1}} w\left[n, f_{a_{1}}, f_{a_{2}}\right]}{v_{i}\left[n, f_{a_{1}}, f_{a_{2}}\right]}, i=1,2 \\
F_{j} & \frac{f_{F} \sum_{i=1}^{2} H\left[n, f_{a_{i}}\right]}{4 w\left[n, f_{a_{1}}, f_{a_{2}}\right]} & \frac{4 w\left[n, f_{a_{1}}, f_{a_{2}}\right]}{\sum_{i=1}^{2} H\left[n, f_{a_{i}}\right]}, j=1,2 \\
a_{1} e a_{2} & \frac{v_{3}\left[n, f_{a_{1}}, f_{a_{2}}\right]}{4 w\left[n, f_{a_{1}}, f_{a_{2}}\right]} & \frac{4\left(f_{a_{1}}+f_{a_{2}}\right) w\left[n, f_{a_{1}}, f_{a_{2}}\right]}{v_{3}\left[n, f_{a_{1}}, f_{a_{2}}\right]} \\
a_{i} \in F_{j} & \frac{v_{i j}\left[n, f_{a_{i}}, f_{a_{\sigma(i)}}, f_{F}\right]}{4 w\left[n, f_{a_{1}}, f_{a_{2}}\right]} & \frac{4\left(f_{a_{i}}+f_{F_{j}}\right) w\left[n, f_{a_{1}}, f_{a_{2}}\right]}{v_{i j}\left[n, f_{a_{1}}, f_{a_{\sigma(1)}}, f_{F_{j}}\right]}, i, j=1,2 \\
F_{1} \in F_{2} & \frac{\sum_{i=1}^{2}, f_{F_{1}} \sum_{i=1}^{2} H\left[n, f_{a_{i}}\right]}{4 w\left[n, f_{a_{1}}, f_{a_{2}}\right]} & \frac{4 w\left[n, f_{a_{1}}, f_{a_{2}}\right]}{\sum_{i=1}^{2} H\left[n, f_{a_{i}}\right]},
\end{array}
$$

onde $v_{i}=v_{i}\left[n, f_{a_{1}}, f_{a_{2}}\right], \quad i=1,2,3, e v_{i j}=v_{i j}\left[n, f_{a_{1}}, f_{a_{2}}, f_{F_{3}}\right], \quad i, j=1,2$, são dadas por

$$
\begin{aligned}
v_{i}= & \left(1+f_{a_{i}}\right) H\left[n, f_{a_{i}}\right]+2^{n-1} f_{a_{i}} H\left[n+1, f_{a_{\sigma(i)}}\right]+\left(2^{n-1}-1-f_{a_{i}}\right) f_{a_{\sigma(i)}}, \quad i=1,2 \\
v_{3}= & 2+\left(3 \times 2^{n-1}-1\right)\left(f_{a_{1}}+f_{a_{2}}\right)+\left(2^{n-1}-1\right)\left(f_{a_{1}}^{2}+f_{a_{2}}^{2}\right)+\left(2^{2 n}-2^{n}-2\right) f_{a_{1}} f_{a_{2}} \\
v_{i j}= & \left(2^{n-1}-1-f_{a_{i}}\right) f_{a_{\sigma(i)}}+f_{F_{j}} H\left[n, f_{a_{\sigma(i)}}\right]+2^{n-1} f_{a_{i}} H\left[n+1, f_{a_{\sigma(i)}}\right] \\
& +\left(1+f_{a_{i}}+f_{F_{\jmath}}\right) H\left[n, f_{a_{i}}\right], \quad i, j=1,2 .
\end{aligned}
$$

\section{Caso 3.2.3}

Consideremos quatro alelos diferentes $a_{i}$ e $F_{i}, i=1,2$. Suponhamos que foram observados $n+m$ irmãos do demandado, independentemente, encontrando em $n$ deles o genótipo $\left(a_{1}, a_{2}\right)$ e nos outros $m$ irmãos o genótipo $\left(a_{2}, a_{2}\right)$ - isto é,

$$
D_{\mathbf{u}}=\left\{\left(a_{1}, a_{2}\right)_{n},\left(a_{2}, a_{2}\right)_{m}\right\} \text {. }
$$

A distribuição de probabilidade a priori $P^{*}[\cdot]$ e as probabilidades condicionais $V\left[D_{\mathbf{u}} \mid \cdot\right]$ 
podem ser obtidas a seguir.

$$
\begin{aligned}
& \text { cruzamento }(\cdot) \quad P^{*}[\cdot] \quad V\left[D_{\mathbf{u}} \mid \cdot\right] \\
& \left(\left(a_{1}, a_{2}\right),\left(a_{1}, a_{2}\right)\right) \quad 2^{2} \prod_{k=1}^{2} f_{a_{k}}^{2} \quad(1 / 2)^{n}(1 / 4)^{n_{i}} \\
& \left(\left(a_{1}, a_{2}\right),\left(a_{2}, a_{2}\right)\right) \quad 2^{2} f_{a_{1}} f_{a_{2}}^{3} \quad(1 / 2)^{n}(1 / 2)^{m} \\
& \left(\left(a_{1}, a_{2}\right),\left(a_{2}, F_{i}\right)\right) \quad 2^{3} f_{a_{1}} f_{a_{2}}^{2} f_{F_{i}}, i=1,2 \quad(1 / 4)^{n}(1 / 4)^{m} \\
& \left(\left(a_{1}, a_{2}\right),\left(a_{2},(x x x x)^{c}\right)\right) \quad 2^{3} f_{a_{1}} f_{a_{2}}^{2}\left(1-\sum_{j=1}^{2}\left(f_{a_{j}}+f_{F_{j}}\right)\right) \quad(1 / 4)^{n}(1 / 4)^{m}
\end{aligned}
$$

Considerando $w=w\left[n, m, f_{a_{1}}, f_{a_{2}}\right]$ como a função definida na expressão abaixo

$$
w=H\left[n, f_{a_{1}}\right]+\left(2^{n+m-1}-1\right) f_{a_{2}},
$$

estabelecemos:

Proposição 3.3.5 A distribuição de probabilidade a posteriori para o genótipo do demandado $P\left[\cdot \mid D_{\mathbf{u}}\right]$, uma vez que observamos os genótipos $\left(a_{1}, a_{2}\right)$ e $\left(a_{2}, a_{2}\right)$ em $n \in m d \epsilon$ seus irmãos, respectivamente, é

$$
\begin{aligned}
\text { genótipo }(\cdot) & P\left[\cdot \mid D_{\mathbf{u}}\right] \\
\left(a_{1}, a_{1}\right) & 2^{n-1} f_{a_{1}} / 4 w \\
\left(a_{1}, a_{2}\right) & \left(H\left[n+1, f_{a_{1}}\right]+\left(2^{n+m}-1\right) f_{a_{2}}\right) / 4 w \\
\left(a_{i}, F_{j}\right) & f_{F_{j}} / 4 w, i, j=1,2 \\
\left(a_{i},(x x x x)^{c}\right) & \left(1-\sum_{j=1}^{2}\left(f_{a_{j}}+f_{F_{j}}\right)\right) / 4 w, i=1,2 \\
\left(a_{2}, a_{2}\right) & \left(H\left[n, f_{a_{1}}\right]+\left(2^{n+m}-1\right) f_{a_{2}}\right) / 4 w
\end{aligned}
$$

onde w é como o definido na expressão 3.13 .

Desse resultado, obtemos:

Corolário 3.3.3 Sob as condiçôes da proposiçâo 3.3.5, temos que a razão de l'trossimilhanças $R V[D]$ e a probabilidade condicional $V_{0}[D]$, do demandante ter recebido do 
demandado o(s) alelo(s) de interesse após termos obscrvado D, estão dadas nos seguintes resultados

$$
\begin{aligned}
& \text { I } \\
& V_{0}[D] \\
& R V[D] \\
& a_{1} \quad \frac{v_{1}\left[n, m, f_{a_{1}}, f_{a_{2}}\right]}{4 w\left[n, m, f_{a_{1}}, f_{a_{2}}\right]} \\
& \frac{4 f_{a_{1}} w\left[n, m, f_{a_{1}}, f_{a_{2}}\right]}{v_{1}\left[n, m, f_{a_{1}}, f_{a_{2}}\right]} \\
& a_{2} \quad \frac{v_{2}\left[n, m, f_{a_{1}}, f_{a_{2}}\right]}{2 w\left[n, m, f_{a_{1}}, f_{a_{2}}\right]} \\
& \frac{2 f_{a_{2}} w\left[n, m, f_{a_{1}}, f_{a_{2}}\right]}{v_{2}\left[n, m, f_{a_{1}}, f_{a_{2}}\right]} \\
& F_{i} \quad \frac{f_{F_{t}}}{4 w\left[n, m, f_{a_{1}}, f_{a_{2}}\right]} \\
& 4 w\left[n, m, f_{a_{1}}, f_{a_{2}}\right], \quad i=1,2 \\
& a_{1} e a_{2} \quad \frac{v_{3}\left[n, m, f_{a_{1}}, f_{a_{2}}\right]}{4 w\left[n, m, f_{a_{1}}, f_{a_{2}}\right]} \\
& \frac{4 \sum_{i=1}^{2} f_{a_{i}} w\left[n, m, f_{a_{1}}, f_{a_{2}}\right]}{v_{3}\left[n, m, f_{a_{1}}, f_{a_{2}}\right]} \\
& a_{1} \text { e } F_{j} \quad \frac{v_{4 j}\left[n, m, f_{a_{1}}, f_{a_{2}}, f_{F_{j}}\right]}{4 w\left[n, m, f_{a_{1}}, f_{a_{2}}\right]} \\
& \frac{4\left(f_{a_{1}}+f_{F_{j}}\right) w\left[n, m, f_{a_{1}}, f_{a_{2}}\right]}{v_{4 j}\left[n, m, f_{a_{1}}, f_{a_{2}}, f_{F_{j}}\right]}, j=1,2 \\
& a_{2} \text { e } F_{j} \quad \frac{v_{5 j}\left[n, m, f_{a_{1}}, f_{a_{2}}, f_{F_{j}}\right]}{4 w\left[n, m, f_{a_{1}}, f_{a_{2}}\right]} \\
& \frac{4\left(f_{a_{2}}+f_{F_{j}}\right) w\left[n, m, f_{a_{1}}, f_{a_{2}}\right]}{v_{5 j}\left[n, m, f_{a_{1}}, f_{a_{2}}, f_{F_{j}}\right]}, j=1,2 \\
& F_{1} \text { e } F_{2} \\
& \frac{\sum_{i=1}^{2} f_{F_{i}}}{4 w\left[n, m, f_{a_{1}}, f_{a_{2}}\right]} \\
& 4 w\left[n, f_{a_{1}}, f_{a_{2}}\right],
\end{aligned}
$$

onde $v_{i}=v_{i}\left[n, m, f_{a_{1}}, f_{a_{2}}\right], \quad i=1,2,3, e v_{k j}=v_{k j}\left[n, m, f_{a_{1}}, f_{a_{2}}, f_{F_{j}}\right], \quad k=4,5$ e j=1,2, sâo dadas por

$$
\begin{aligned}
v_{1} & =H\left[n+1, f_{a_{1}}\right]+\left(2^{n+m-1}-1\right) f_{a_{2}} \\
v_{2} & =H\left[n, f_{a_{1}}\right]+\left(3 \times 2^{n+m-2}-1\right) f_{a_{2}} \\
v_{3} & =H\left[n+1, f_{a_{1}}\right]+2 H\left[n, f_{a_{1}}\right]+\left(2^{n+m+1}-3\right) f_{a_{2}} \\
v_{4 j} & =H\left[n+1, f_{a_{1}}\right]+\left(2^{n+m-1}-1\right) f_{a_{2}}+f_{F_{j}}, j=1,2 \\
v_{5 j} & =2 H\left[n, f_{a_{1}}\right]+2\left(3 \times 2^{n+m-2}-1\right) f_{a_{2}}+f_{F_{j}}, j=1,2 .
\end{aligned}
$$

\section{Caso 3.3.1}

Sejam $F_{1}$ e $a_{i}, i=1,2,3$ quatro alelos diferentes. Suponhamos que, ao observarmos $s$ 
irmãos do demandado, independentemente, ocorra uma das seguintes situações:

$$
\begin{aligned}
& D_{\mathbf{u}}=\left\{\left(a_{1}, a_{1}\right)_{n},\left(a_{2}, a_{3}\right)_{m}\right\}, \text { onde } s=n+m, \text { ou } \\
& D_{\mathbf{u}}=\left\{\left(a_{1}, a_{1}\right)_{n},\left(a_{1}, a_{2}\right)_{m},\left(a_{2}, a_{3}\right)_{r}\right\}, \text { com } s=n+m+r \text {, ou } \\
& D_{\mathbf{u}}=\left\{\left(a_{1}, a_{1}\right)_{n},\left(a_{1}, a_{2}\right)_{m},\left(a_{1}, a_{3}\right)_{r}\right\}, \text { onde } s=n+m+r \text {, ou } \\
& D_{\mathbf{u}}=\left\{\left(a_{1}, a_{1}\right)_{n},\left(a_{1}, a_{2}\right)_{m},\left(a_{2}, a_{3}\right)_{r},\left(a_{1}, a_{3}\right)_{t}\right\}, \text { se } s=n+m+r+t .
\end{aligned}
$$

Em qualquer uma das situaçôes acima, a distribuição de probabilidade a posteriori $P^{*}\left[\cdot \mid D_{\mathbf{u}}\right]$ para os cruzamentos entre os genótipos dos pais do demandado é

$$
P^{*}\left[\left(g_{i}, g_{j}\right) \mid D_{\mathbf{u}}\right]= \begin{cases}1 & \text { se } g_{i}=\left(a_{1}, a_{2}\right) \text { e } g_{j}=\left(a_{1}, a_{3}\right) \\ 0 & \text { caso contrário }\end{cases}
$$

Dessa distribuição de probabilidade obtemos $P\left[\cdot \mid D_{\mathbf{u}}\right]$ a qual explicitamos a seguir.

Proposição 3.3.6 Sob as condições dadas acima, a distribuição de probabilidade a posteriori para o genótipo do demandado $P\left[\cdot \mid D_{\mathbf{u}}\right]$ é dada por

$$
\begin{aligned}
\text { genótipo }(\cdot) & P\left[\cdot \mid D_{\mathbf{u}}\right] \\
\left(a_{1}, a_{i}\right) & 1 / 4, \quad i=1,2,3 \\
\left(a_{2}, a_{3}\right) & 1 / 4,
\end{aligned}
$$

onde os diferentes conjuntos $D_{\mathbf{u}}$ são dados nas expressões 3.15 a 3.18 .

De maneira análoga aos casos anteriores, obtemos de $P\left[\cdot \mid D_{\mathrm{u}}\right]$ a probabilidade condicional $V_{0}[D]$ e a razão $R V[D]$ que estão dadas na tabela a seguir.

Tabela 3.5 Probabilidade condicional $V_{0}[D]$ e razão de verossimilhanças $R V[D]$ - Caso 2.3.1

$$
\begin{array}{lll}
I & V_{0}[D] & R V[D] \\
a_{1} & 1 / 2 & 2 f_{a_{1}}
\end{array}
$$




$\begin{array}{ccl}a_{j} & 1 / 4 & 4 f_{a_{j}}, j=2,3 \\ a_{1} \text { е } a_{j} & 3 / 4 & 4\left(f_{a_{1}}+f_{a_{j}}\right) / 3, j=2,3 \\ a_{2} \text { е } a_{3} & 1 / 2 & 2\left(f_{a_{2}}+f_{a_{3}}\right) \\ a_{1} \text { е } F_{1} & 1 / 2 & 2\left(f_{a_{1}}+f_{F_{1}}\right) \\ a_{j} \text { е } F_{1} & 1 / 4 & 4\left(f_{a_{3}}+f_{F_{1}}\right) j=2,3\end{array}$

\section{Caso 3.3.2}

Sejam $a_{i}$ e $F_{j}$, para $i=1,2,3$ e $j=1,2$, cinco alelos diferentes. Suponhamos que, ao observarmos $n+m$ irmãos do demandado, independentemente, encontramos em $n$ deles o genótipo $\left(a_{1}, a_{2}\right)$ e nos outros $m$ irmãos o genótipo $\left(a_{1}, a_{3}\right)$ - isto é,

$$
D_{\mathbf{u}}=\left\{\left(a_{1}, a_{2}\right)_{n},\left(a_{1}, a_{3}\right)_{m}\right\} \text {. }
$$

Para essa situação a distribuição de probabilidade a priori para os cruzamentos entre os pais do demandado $P^{*}[\cdot]$ e as probabilidades condicionais $V\left[D_{\mathrm{u}} \mid \cdot\right]$ tornam-se:

$$
\begin{aligned}
& \text { cruzamento }(\cdot) \quad P^{*}[\cdot] \\
& V\left[D_{\mathbf{u}} \mid \cdot\right] \\
& \left(\left(a_{1}, a_{1}\right),\left(a_{2}, a_{3}\right)\right) \quad 2^{2} f_{a_{1}} \prod_{j=1}^{3} f_{a_{3}} \\
& (1 / 2)^{n}(1 / 2)^{m} \\
& \left(\left(a_{1}, a_{2}\right),\left(a_{1}, a_{3}\right)\right) \quad 2^{3} f_{a_{1}} \prod_{j=1}^{3} f_{a_{1}} \\
& (1 / 4)^{n}(1 / 4)^{m} \\
& \left(\left(a_{1}, a_{2}\right),\left(a_{2}, a_{3}\right)\right) \quad 2^{3} f_{a_{2}} \prod_{j=1}^{3} f_{a_{j}} \\
& (1 / 4)^{n}(1 / 4)^{m} \\
& \left(\left(a_{1}, a_{3}\right),\left(a_{2}, a_{3}\right)\right) \quad 2^{3} f_{a_{3}} \prod_{j=1}^{3} f_{a_{3}} \\
& (1 / 4)^{n}(1 / 4)^{m} \\
& \left(\left(a_{1}, F_{i}\right),\left(a_{2}, a_{3}\right)\right) \quad 2^{3} f_{F_{i}} \prod_{j=1}^{3} f_{a_{j}}, i=1,2 \\
& (1 / 4)^{n}(1 / 4)^{m} \\
& \left(\left(a_{1},(x x x x x)^{c}\right),\left(a_{2}, a_{3}\right)\right) \quad 2^{3} \prod_{j=1}^{3} f_{a_{j}}\left(1-\sum_{j=1}^{3} f_{a_{j}}-\sum_{k=1}^{2} f_{F_{k}}\right) \\
& (1 / 4)^{n}(1 / 4)^{m}
\end{aligned}
$$

Com isso, a distribuição de probabilidade a posteriori para o genótipo do demandado $P\left[\cdot \mid D_{\mathbf{u}}\right]$ assume a forma fornecida na proposição abaixo.

Proposição 3.3.7 A distribuição de probabilidade a posteriori para o genótipo do demandado $P\left[\cdot \mid D_{\mathbf{u}}\right]$, uma vez que observamos os genótipos $\left(a_{1}, a_{2}\right)$ e $\left(a_{1}, a_{3}\right)$ em n e $m$ de 
seus irmãos, respectivamente, é dada pela expressão

$$
\begin{aligned}
& \text { genótipo }(\cdot) \quad P\left[\cdot \mid D_{\mathbf{u}}\right] \\
& \left(a_{i}, a_{i}\right) \quad \frac{f_{a_{i}}}{4 w\left[n, m, f_{a_{1}}\right]}, \quad i=1,2,3 \\
& \left(a_{1}, a_{j}\right) \quad \frac{1+2^{n+m} f_{a_{1}}}{4 w\left[n, m, f_{a_{1}}\right]}, j=2,3 \\
& \left(a_{2}, a_{3}\right) \quad \frac{\sum_{k=1}^{3} f_{a_{k}}}{4 w\left[n, m, f_{a_{1}}\right]} \\
& \left(a_{j}, F_{i}\right) \quad \frac{f_{F_{i}}}{4 w\left[n, m, f_{a_{1}}\right]}, j=2,3 ; \quad i=1,2 \\
& \left(a_{j},(x x x x x)^{c}\right) \quad \frac{1-\sum_{i=1}^{3} f_{a_{i}}-\sum_{k=1}^{2} f_{F_{k}}}{4 w\left[n, m, f_{a_{1}}\right]}, j=2,3,
\end{aligned}
$$

onde $w\left[n, m, f_{a_{1}}\right]$ é a função definida por

$$
w\left[n, m, f_{a_{1}}\right]=1+2^{n+m-1} f_{a_{1}} .
$$

Como conseqüência da proposição anterior obtemos:

Corolário 3.3.4 Sob as condiçôes da proposição 3.3.7, temos que a razâo de verossimilhanças $R V[D]$ e a probabilidade condicional $V_{0}[D]$, do demandante ter recebido do demandado o(s) alelo(s) de interesse após termos observado $D$, são dadas a seguir.

$$
\begin{aligned}
& V_{0}[D] \\
& R V[D] \\
& a_{1} \quad \frac{1+\left(2^{n+m}+1\right) f_{a_{1}}}{4 w\left[n, m, f_{a_{1}}\right]} \\
& \frac{4 f_{a_{1}} w\left[n, m, f_{a_{1}}\right]}{1+\left(2^{n+m}+1\right) f_{a_{1}}} \\
& a_{j} \quad \frac{1+f_{a_{j}}+2^{n+m-1} f_{a_{1}}}{4 w\left[n, m, f_{a_{1}}\right]} \\
& \frac{4 f_{a_{j}} w\left[n, m, f_{a_{1}}\right]}{1+f_{a_{j}}+2^{n+m-1} f_{a_{1}}}, j=2,3 \\
& F_{i} \quad \frac{f_{F_{i}}}{4 w\left[n, m, f_{a_{1}}\right]} \\
& a_{1} \text { e } a_{j} \quad \frac{2+f_{a_{\jmath}}+\left(3 \times 2^{n+m-1}+1\right) f_{a_{1}}}{4 w\left[n, m, f_{a_{1}}\right]} \quad \frac{4\left(f_{a_{1}}+f_{a_{\jmath}}\right) w\left[n, m, f_{a_{1}}\right]}{2+f_{a_{\jmath}}+\left(3 \times 2^{n+m-1}+1\right) f_{a_{1}}}, j=2,3
\end{aligned}
$$




$$
\begin{array}{lll}
a_{2} \text { e } a_{3} & \frac{2+f_{a_{2}}+f_{a_{3}}+2^{n+m} f_{a_{1}}}{4 w\left[n, m, f_{a_{1}}\right]} & \frac{4\left(f_{a_{2}}+f_{a_{3}}\right) w\left[n, m, f_{a_{1}}\right]}{2+f_{a_{2}}+f_{a_{3}}+2^{n+m} f_{a_{1}}} \\
a_{1} \text { e } F_{i} & \frac{1+\left(2^{n+m}+1\right) f_{a_{1}}+f_{F_{i}}}{4 w\left[n, m, f_{a_{1}}\right]} & \frac{4\left(f_{a_{1}}+f_{F_{i}}\right) w\left[n, m, f_{a_{1}}\right]}{1+\left(2^{n+m}+1\right) f_{a_{1}}+f_{F_{i}}}, i=1,2 \\
a_{j} e F_{1} & \frac{1+f_{a_{j}}+2^{n+m-1} f_{a_{1}}+f_{F_{1}}}{4 w\left[n, m, f_{a_{1}}\right]} & \frac{4\left(f_{a_{j}}+f_{F_{1}}\right) w\left[n, m, f_{a_{1}}\right]}{1+f_{a_{3}}+2^{n+m-1} f_{a_{1}}+f_{F_{1}}}, j=2,3 \\
F_{1} e F_{2} & \frac{\sum_{i=1}^{2} f_{F_{i}}}{4 w\left[n, m, f_{a_{1}}\right]} & 4 w\left[n, m, f_{a_{1}}\right] .
\end{array}
$$

\section{Caso 3.3.3}

Consideremos os seguintes quatro alelos $F_{1}$ e $a_{i}, i=1,2,3$, diferentes. Suponhamos que o conjunto de genótipos encontrado, ao observarmos $n+m+r$ irmãos do demandado, independentemente, seja representado por

$$
D_{\mathbf{u}}=\left\{\left(a_{1}, a_{2}\right)_{n},\left(a_{2}, a_{3}\right)_{m},\left(a_{1}, a_{3}\right)_{r}\right\} .
$$

Baseados nesses pressupostos, derivamos as probabilidades condicionais $V\left[D_{\mathbf{u}} \mid \cdot\right]$, as quais apresentaremos a seguir juntamente com os valores declarados para a distribuição de probabilidade a priori $P^{*}[\cdot]$.

$$
\begin{array}{ccc}
\text { cruzamento }(\cdot) & P^{*}[\cdot] & V\left[D_{\mathbf{u}} \mid \cdot\right] \\
\left(\left(a_{1}, a_{2}\right),\left(a_{2}, a_{3}\right)\right) & 2^{3} f_{a_{2}} \prod_{i=1}^{3} f_{a_{i}} & (1 / 4)^{n}(1 / 4)^{m}(1 / 4)^{r} \\
\left(\left(a_{1}, a_{3}\right),\left(a_{2}, a_{3}\right)\right) & 2^{3} f_{a_{3}} \prod_{i=1}^{3} f_{a_{i}} & (1 / 4)^{n}(1 / 4)^{m}(1 / 4)^{r} \\
\left(\left(a_{1}, a_{2}\right),\left(a_{1}, a_{3}\right)\right) & 2^{3} f_{a_{1}} \prod_{i=1}^{3} f_{a_{i}} & (1 / 4)^{n}(1 / 4)^{m}(1 / 4)^{r}
\end{array}
$$

Dos resultados acima derivamos a distribuição a posteriori $P\left[\cdot \mid D_{\mathbf{u}}\right]$, estabelecida na seguinte proposição.

Proposição 3.3.8 Sob as condições anteriores, a distribuição de probabilidade a posteriori para o genótipo do demandado $P\left[\cdot \mid D_{\mathbf{u}}\right]$ é a seguinte

$$
\text { genótipo }(\cdot) \quad P\left[\cdot \mid D_{\mathbf{u}}\right]
$$




$$
\begin{array}{ll}
\left(a_{i}, a_{i}\right) & \frac{f_{a_{i}}}{4 \sum_{j=1}^{3} f_{a_{3}}}, i=1,2,3 \\
\left(a_{i}, a_{j}\right) & \frac{1}{4}, i<j ; i=1,2, \quad j=2,3 .
\end{array}
$$

Essa distribuição de probabilidade a posteriori nos fornece o seguinte corolário.

Corolário 3.3.5 Sob as condições da proposição 3.3.8, a razão de verossimilhanças $R V[D]$ e a probabilidade condicional $V_{0}[D]$, do demandante ter recebido do demandado $o(s)$ alelo(s) de interesse após termos observado $D$, sâo dadas pelos seguintes resultados.

$$
\begin{array}{cll}
\multicolumn{1}{c}{I} & \multicolumn{1}{c}{R V[D]} \\
a_{i} & \frac{f_{a_{i}}+\sum_{k=1}^{3} f_{a_{k}}}{4 \sum_{k=1}^{3} f_{a_{k}}} & \frac{4 f_{a_{i}} \sum_{k=1}^{3} f_{a_{k}}}{f_{a_{i}}+\sum_{k=1}^{3} f_{a_{k}}}, i=1,2,3 \\
a_{i} \text { e } a_{j} & \frac{2 \sum_{k=1}^{3} f_{a_{k}}+f_{a_{i}}+f_{a_{j}}}{4 \sum_{k=1}^{3} f_{a_{k}}} & \frac{4\left(f_{a_{i}}+f_{a_{j}}\right) \sum_{k=1}^{3} f_{a_{k}}}{2 \sum_{k=1}^{3} f_{a_{k}}+f_{a_{i}}+f_{a_{j}}}, i \neq j, \quad i, j=1,2,3 \\
a_{i} \text { e } F_{1} & \frac{f_{a_{i}}+\sum_{k=1}^{3} f_{a_{k}}}{4 \sum_{k=1}^{3} f_{a_{k}}} & \frac{4\left(f_{a_{i}}+f_{F_{1}}\right) \sum_{j=1}^{3} f_{a_{j}}}{f_{a_{i}}+\sum_{k=1}^{3} f_{a_{k}}}, i=1,2,3 .
\end{array}
$$

\section{Caso 3.4.1}

Sejam $F_{1}$ e $a_{i}, i=1, \cdots, 4$, cinco alelos diferentes. Suponhamos que, ao observarmos $n+m$ irmãos do demandado, independentemente, encontramos em $n$ deles o genótipo $\left(a_{1}, a_{2}\right)$ e nos outros $m$ irmãos encontramos o genótipo $\left(a_{3}, a_{4}\right)$ - ou seja,

$$
D_{\mathbf{u}}=\left\{\left(a_{1}, a_{2}\right)_{n},\left(a_{3}, a_{4}\right)_{m}\right\} .
$$

As distribuições de probabilidades a priori $P^{*}[\cdot]$ e a posteriori $P^{*}\left[\cdot \mid D_{\mathbf{u}}\right]$ para os cruzamentos entre os pais do demandado, além das probabilidades condicionais $V\left[\cdot \mid D_{\mathbf{u}}\right]$ são apresentadas a seguir.

$$
\begin{array}{cccc}
\text { cruzamento }(\cdot) & P^{*}[\cdot] & V\left[D_{\mathbf{u}} \mid \cdot\right] & P^{*}\left[\cdot \mid D_{\mathbf{u}}\right] \\
\left(\left(a_{1}, a_{3}\right),\left(a_{2}, a_{4}\right)\right) & 2^{3} \prod_{i=1}^{4} f_{a_{i}} & (1 / 4)^{n}(1 / 4)^{m} & 1 / 2 \\
\left(\left(a_{1}, a_{4}\right),\left(a_{2}, a_{3}\right)\right) & 2^{3} \prod_{i=1}^{4} f_{a_{\mathbf{i}}} & (1 / 4)^{n}(1 / 4)^{m} & 1 / 2 .
\end{array}
$$


Dos resultados anteriores derivamos imediatamente a distribuição $P\left[\cdot \mid D_{\mathbf{u}}\right]$, como pode ser visto na seguinte proposição.

Proposição 3.3.9 Sob as considerações anteriores temos que a distribuição de probabilidade a posteriori para o genótipo do demandado $P\left[\cdot \mid D_{\mathbf{u}}\right]$ é

$$
\begin{aligned}
\text { genótipo }(\cdot) & P\left[\cdot \mid D_{\mathbf{u}}\right] \\
\left(a_{i}, a_{i+1}\right) & 1 / 4, \quad i=1,3 \\
\left(a_{i}, a_{j}\right) & 1 / 8, \quad i=1,2, j=3,4 .
\end{aligned}
$$

Como nos casos anteriores, da distribuição de probabilidade $P\left[\cdot \mid D_{\mathrm{u}}\right]$ derivamos a probabilidade condicional $V_{0}[D]$ e, conseqüentemente, a razão de verossimilhança $R V[D]$, as quais são dadas na seguinte tabela:

Tabela 3.6 Probabilidade condicional $V_{0}[D]$ e razão de verossimilhanças $R V[D]$ - Caso 2.4.1

$$
\begin{array}{ccl}
I & V_{0}[D] & R V[D] \\
a_{i} & 1 / 4 & 4 f_{a_{i}}, \quad i=1, \cdots, 4 \\
a_{i} \text { e } a_{j} & 1 / 2 & 2\left(f_{a_{i}}+f_{a_{j}}\right), \quad i \neq j, i, j=1, \cdots, 4 . \\
a_{i} \text { e } F_{1} & 1 / 4 & 4\left(f_{a_{i}}+f_{F_{1}}\right), \quad i=1, \cdots, 4 .
\end{array}
$$

\section{Caso 3.4.2}

Consideremos, como no caso 3.4.1, os cinco diferentes alelos $F_{1}$ e $a_{i}, i=1, \cdots, 4$. Suponhamos que, ao observarmos $s$ irmãos do demandado, independentemente, ocorra uma das seguintes situações:

$$
\begin{aligned}
& D_{\mathbf{u}}=\left\{\left(a_{1}, a_{2}\right)_{n},\left(a_{2}, a_{4}\right)_{m},\left(a_{3}, a_{4}\right)_{r}\right\}, \quad \text { se } s=n+m+r, \text { ou } \\
& D_{\mathbf{u}}=\left\{\left(a_{1}, a_{2}\right)_{n},\left(a_{1}, a_{3}\right)_{m},\left(a_{3}, a_{4}\right)_{r}\right\}, \quad \text { com } s=n+m+r, \text { ou } \\
& D_{\mathbf{u}}=\left\{\left(a_{1}, a_{2}\right)_{n},\left(a_{2}, a_{4}\right)_{m},\left(a_{1}, a_{3}\right)_{r},\left(a_{3}, a_{4}\right)_{t}\right\}, \quad \text { onde } s=n+m+r=t .(3 .
\end{aligned}
$$


Em qualquer uma das situações apresentadas acima, temos que a distribuição de probabilidade a posteriori $P^{*}\left[\cdot \mid D_{\mathbf{u}}\right]$ para os cruzamentos entre os genótipos dos pais do demandado é

$$
P^{*}\left[\left(g_{i}, g_{j}\right) \mid D_{\mathbf{u}}\right]= \begin{cases}1 & \text { se } g_{i}=\left(a_{1}, a_{4}\right) \text { e } g_{j}=\left(a_{2}, a_{3}\right) \\ 0 & \text { caso contrário. }\end{cases}
$$

Neste caso particular, a distribuição de probabilidade a posteriori para o genótipo do demandado $P\left[\cdot \mid D_{\mathbf{u}}\right]$ é

$$
P\left[\left(a_{i}, a_{j}\right) \mid D_{\mathbf{u}}\right]=1 / 4 \text { para } i=1,4 \text {, e } j=2,3,
$$

enquanto que a probabilidade condicional $V_{0}[D]$ e a razão $R V[D]$ coincidem exatamente com os resultados apresentados anteriormente na tabela 3.6.

No capítulo 4 apresentaremos, em detalhes, a análise necessária para determinarmos a probabilidade a posteriori de paternidade quando os parentes observados do demandado são alguns de seus filhos e a mãe destes indivíduos. 


\section{Capítulo 4}

\section{Análise para esposa e filhos}

\subsection{Introdução}

Iniciamos este capítulo apresentando, detalhadamente, a metodologia que propomos para determinar a distribuição de probabilidade a posteriori para o genótipo do demandado, uma vez que foi observada uma determinada estrutura genotípica em alguns de seus filhos e na mãe destes indivíduos, que será chamada de esposa do demandado. Esta distribuição de probabilidade a posteriori é a base para determinar a probabilidade de paternidade após terem sido observados os genótipos dos filhos e da esposa do demandado, da mãe do demandante e do próprio demandante - isto é, a probabilidade a posteriori de paternidade - cujo método de cálculo foi exibido na seção 1.5.

Na seção 4.3, utilizamos a metodologia desenvolvida na seção 4.2 para calcular tanto a distribuição de probabilidade a posteriori para o genótipo do demandado quanto a razão entre as verossimilhanças do demandado não ser o pai do demandante e do demandado ser o pai do demandante, para cada um dos possiveis casos determinados pelos dados referentes aos genótipos dos filhos e da esposa do demandado. Estes dois elementos são fundamentais no cálculo da probabilidade a posteriori de paternidade, a qual é obtida substituindo os valores encontrados pelos correspondentes elementos nas expressões 1.8 ou 1.9 do capítulo 1 . 


\subsection{Descrição geral da metodologia}

Sejam $\mathcal{B}_{L},\left(G_{L}, \mathcal{A}_{G_{L}}\right), Z$ e $P[\cdot]$ como definidos na seção 2.2. Suponhamos que estejam disponíveis dados do demandante e de sua mãe, além de dados referentes à esposa e a alguns filhos do demandado. Isto é, a árvore genealógica que consideraremos possui a seguinte estrutura:

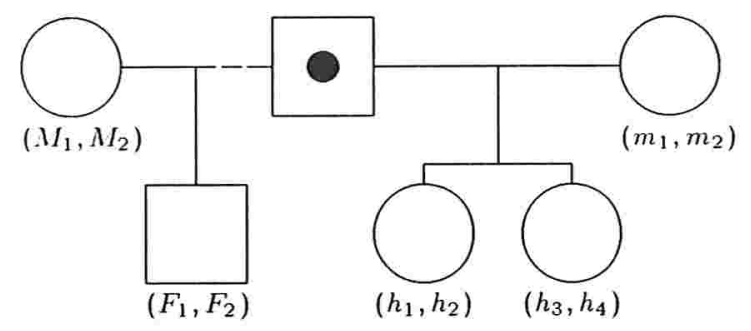

Árvore genealógica correspondente ao caso esposa e filhos do demandado

Sejam $M, F, X$ e $M_{X}$ variáveis aleatórias $\mathcal{A}_{G_{L}}$ mensuráveis que denotam, respectivamente, os genótipos da mãe do demandante, do demandante, do demandado e da esposa do demandado, e consideremos $U$ como sendo o vetor aleatório formado pelos genótipos dos filhos do demandado (com sua esposa) constituído por componentes $\mathcal{A}_{G_{L}}$ mensuráveis.

Se os valores observados de $M, F, M_{X}$ e $U$ são respectivamente $\left(M_{1}, M_{2}\right),\left(F_{1}, F_{2}\right)$, $\left(m_{1}, m_{2}\right)$ e $\mathbf{u}$, o conjunto dos dados $D$ correspondente a este experimento é formado por

$$
D=\left\{\left(M_{1}, M_{2}\right),\left(F_{1}, F_{2}\right),\left(m_{1}, m_{2}\right), \mathbf{u}\right\} .
$$

Inicialmente, o interesse é determinar a distribuição de probabilidade para o genótipo do demandado, após serem observados os genótipos de sua esposa, dos filhos do demandado com sua esposa, e o(s) alelo(s) de interesse - isto é, queremos obter a distribuição de probabilidade a posteriori $P[\cdot \mid D]$ da variável aleatória $X$. Para determinarmos esta distribuição de probabilidade propomos o seguinte procedimento.

Primeiramente, consideremos a distribuição de probabilidade $P$, definida em 3.1, que 
descreve a incerteza sobre o genótipo do demandado, antes de serem observados genótipos de alguns filhos e da esposa do demandado, e o(s) alelo(s) de interesse - isto é, $P$ é a distribuição de probabilidade a priori para o genótipo do demandado.

Agora, suponhamos que foram observados independentemente o genótipo da mãe do demandante, do demandante, da esposa do demandado e os genótipos de $s$ filhos do demandado, e sejam $\left(M_{1}, M_{2}\right),\left(F_{1}, F_{2}\right),\left(m_{1}, m_{2}\right)$ e $\mathbf{u}$ os genótipos observados respectivamente. Consideremos $D_{\mathbf{u}}$ como o conjunto formado por todos os elementos $(x, y)_{q}$ onde $(x, y)$ é o genótipo observado em um dos filhos do demandado e $q$ representa o número de vezes que este genótipo foi observado nos $s$ filhos - isto é, $q$ representa o número de vezes que o genótipo $(x, y)$ ocorre no vetor $\mathbf{u}$. Na verdade $D_{\mathbf{u}}$ é uma outra representação do vetor $u$. Por exemplo, se

$$
D_{\mathbf{u}}=\left\{\left(h_{1}, h_{2}\right)_{n},\left(h_{2}, h_{2}\right)_{m}\right\},
$$

entende-se que os genótipos $\left(h_{1}, h_{2}\right)$ e $\left(h_{2}, h_{2}\right)$ foram observados em $n$ e $m$ filhos do demandado, respectivamente, onde $n+m=s$ e $h_{1}, h_{2}$ pertencem a $\mathcal{B}_{L}$.

Seja $V\left[g_{k} \mid\left(g_{i}, m_{X}\right)\right]$ a probabilidade condicional de que o genótipo $g_{k}$ provenha do cruzamento entre os genótipos $g_{i}$ e $m_{X}=\left(m_{1}, m_{2}\right)$, dada na tabela 3.1. Para cada $i=1, \cdots, N$, calculamos a probabilidade condicional $V\left[D_{\mathbf{u}} \mid\left(g_{i}, m_{X}\right)\right]$ a qual fornece a probabilidade de ocorrência do conjunto $D_{\mathbf{u}}$ supondo que o cruzamento entre os genótipos do demandado e sua esposa tenha sido $\left(g_{i}, m_{X}\right)$. Esta probabilidade será utilizada posteriormente no cálculo da probabilidade a posteriori para o genótipo do demandado como podemos ver na expressão 4.3 .

A forma como calculamos $V\left[D_{\mathbf{u}} \mid\left(g_{i}, m_{X}\right)\right]$ será ilustrada considerando $m_{X}=\left(h_{1}, h_{2}\right)$ e o conjunto $D_{\mathbf{u}}$ dado na expressão 4.1. Para isto, suporemos, sem perda de generalidade, que $h_{k}=b_{k}$ para $k=1,2$. Neste caso, obtemos

$$
\begin{aligned}
V\left[D_{\mathbf{u}} \mid\left(g_{i}, m_{X}\right)\right]= & \left(V\left[\left(h_{1}, h_{2}\right) \mid\left(g_{i}, m_{X}\right)\right]\right)^{n}\left(V\left[\left(h_{2}, h_{2}\right) \mid\left(g_{i}, m_{X}\right)\right]\right)^{m} \\
= & \left\{\begin{array}{cl}
\frac{1}{2^{n}} \frac{1}{2^{m}} & \text { se } g_{i}=\left(h_{2}, h_{2}\right) \\
\frac{1}{2^{n}} \frac{1}{2^{2 m}} & \text { se } g_{i}=\left(h_{1}, h_{2}\right) \\
\frac{1}{2^{2 n}} \frac{1}{2^{2 m}} & \text { se } g_{i}=\left(h_{2}, h\right) \text { e } h \neq h_{j}, j=1,2 \\
0 & \text { caso contrário. }
\end{array}\right.
\end{aligned}
$$

O próximo passo é a atualização da distribuição de probabilidade a priori $P$. Para isto, usaremos a informação obtida ao observarmos os filhos e a esposa do demandado, a qual 
é traduzida no conjunto $D_{\mathbf{u}, m_{X}}=D_{\mathbf{u}} \cup\left\{\left\{\left(m_{1}, m_{2}\right)\right\}\right\}$ e utilizaremos o Teorema de Bayes como mecanismo de atualização de probabilidade.

Seja

$$
\delta=\sum_{i=1}^{N} V\left[D_{\mathbf{u}} \mid\left(g_{i}, m_{X}\right)\right] P\left[g_{i}\right]
$$

Das expressões 3.1 e 4.2 obtemos que a distribuição de probabilidade a posteriori $P\left[\cdot \mid D_{\mathbf{u}, m_{X}}\right]$ para o genótipo do demandado - uma vez que foram observados $s$ filhos e a esposa do demandado e cujos genótipos estão descritos no conjunto $D_{\mathbf{u}, m_{X}}$ - é dada pela expressão

$$
\begin{aligned}
P\left[g_{i} \mid D_{\mathbf{u}, m_{X}}\right] & =\frac{V\left[D_{\mathbf{u}} \mid\left(g_{i}, m_{X}\right)\right] P\left[g_{i}\right]}{\delta} \\
& =\frac{V\left[D_{\mathbf{u}} \mid\left(g_{i}, m_{X}\right)\right] \times P\left[g_{i}\right]}{\sum_{j=1}^{N} V\left[D_{\mathbf{u}} \mid\left(g_{j}, m_{X}\right)\right] P\left[g_{j}\right]}, \quad i=1, \cdots, N .
\end{aligned}
$$

Em resumo, considerando que a variável aleatória $X$, que denota o genótipo do demandado, é $\mathcal{A}_{G_{L}}$ mensurável, $P$ a medida de probabilidade definida sobre o espaço $\left(G_{L}, \mathcal{A}_{G_{L}}\right)$ definida na expressão 3.1 , a qual descreve a incerteza a priori sobre $X, m_{X}$ o genótipo observado na esposa do demandado e $\mathrm{u}$ o vetor dos genótipos observados nos filhos do demandado com sua esposa, representado no conjunto $D_{\mathbf{u}}$, provamos o seguinte resultado.

Teorema 4.2.1 Se $m_{X}$ e u são obtidos ao observarmos independentemente a esposa $e$ $s$ filhos do demandado, então a distribuição de probabilidade a posteriori $P\left[\cdot \mid D_{\mathbf{u}, m_{X}}\right]$ para $X$ é dada pela expressão

$$
P\left[g_{i} \mid D_{\mathbf{u}, m_{X}}\right]=\frac{V\left[D_{\mathbf{u}} \mid\left(g_{i}, m_{X}\right)\right] P\left[g_{i}\right]}{\sum_{j=1}^{N} V\left[D_{\mathbf{u}} \mid\left(g_{j}, m_{X}\right)\right] P\left[g_{j}\right]}, \quad i=1, \cdots, N,
$$

onde $V\left[\cdot \mid\left(g_{j}, m_{X}\right)\right]$ e $P[\cdot]$ são dadas respectivamente pelas expressões da tabela 2.1 e 3.1.

A probabilidade condicional $V_{0}[D]$, cujo cálculo envolve a distribuição de probabilidade a posteriori para o genótipo do demandado estabelecida no teorema 4.2 .1 e as probabilidades condicionais $V\left[\cdot \mid\left(g_{t}, g_{k}\right)\right]$, é apresentada no seguinte resultado. 
Corolário 4.2.1 A probabilidade condicional de que o demandante possua o genótipo $\left(F_{1}, F_{2},\right)$ dado que sua mãe tem o genótipo $\left(M_{1}, M_{2}\right)$, os filhos do demandado apresentam o(s) genótipo(s) $\mathrm{u}$, a esposa do demandado possui o genótipo $m_{X}$ e supondo que o demandado é o verdadeiro pai do demandante, é dada por

$$
V_{0}[D]=\gamma_{\left(M_{1}, M_{2}\right)} \sum_{b_{i} \in I} \sum_{k=1}^{N} \delta_{b_{i} g_{k}} \frac{V\left[D_{\mathbf{u}} \mid\left(g_{k}, m_{X}\right)\right] P\left[g_{k}\right]}{\sum_{j=1}^{N} V\left[D_{\mathbf{u}} \mid\left(g_{j}, m_{X}\right)\right] P\left[g_{j}\right]},
$$

onde $\gamma_{\left(M_{1}, M_{2}\right)}, \delta_{b_{i} g_{k}}$ e $P[\cdot]$ são definidas, respectivamente, pelas expressões 1.12, $1.15 \mathrm{e}$ 3.1. A probabilidade condicional $V\left[D_{\mathbf{u}} \mid \cdot\right]$ está dada na tabela 3.1.

Prova: Para cada $r=1, \cdots, N$, basta substituirmos na expressão 1.14 da proposição 1.5.2 o valor da probabilidade a posteriori para o genótipo do demandado, $P\left[g_{r} \mid D_{\mathbf{u}, m_{X}}\right]$, dada pela expressão 4.3 .

Na próxima seção, aplicaremos a metodologia introduzida aqui considerando todos os diferentes conjuntos $D_{\mathbf{u}, m X}$ que trazem informação sobre os genótipos observados na esposa e nos filhos do demandado. Para facilitar a apresentação dos resultados correspondentes aos conjuntos $D_{\mathbf{u}, m X}$ que determinam diferentes distribuições de probabilidade a posteriori para o genótipo do demandado, estes serão referenciados ao longo deste capítulo pelo código caso c.i.j a ser dado na primeira coluna da tabela 4.1, onde c indica o número do capítulo, $\mathrm{i}$ indica o número de alelos diferentes que aparecem em $D_{\mathbf{u}}$ e $\mathbf{j}$ enumera as diferentes associações com igual número de alelos.

Tabela 4.1 Dados relevantes ao observarmos filhos e esposa do demandado.

caso

\section{genótipos observados}

4.1.1
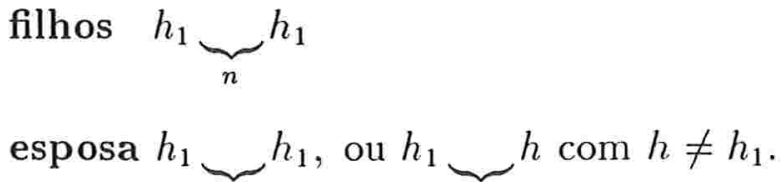

4.2 .1

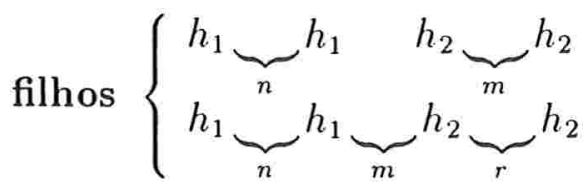


esposa $h_{1} \underbrace{h} h_{2}$

4.2.2 filhos $h_{1} \underbrace{}_{n} h_{2}$

esposa $\left\{\begin{array}{l}i) \quad h_{1} \underbrace{h_{2}} \\ \text { ii) } h_{j} \underbrace{}_{j}, \text { ou } h_{j} \underbrace{h} \operatorname{com} h \neq h_{j}, h_{\sigma(j)}, j=1,2, j \text { fixo. }\end{array}\right.$

4.2.3

filhos $h_{1} \underbrace{}_{n} h_{2} \underbrace{}_{m} h_{2}$

esposa $\begin{cases}\text { i) } & h_{2} \underbrace{h_{2}}, \text { ou } h_{2} \underbrace{2} h \operatorname{com} h \neq h_{1}, h_{2} . \\ \text { ii) } & h_{1} \underbrace{2}\end{cases}$

4.3.1

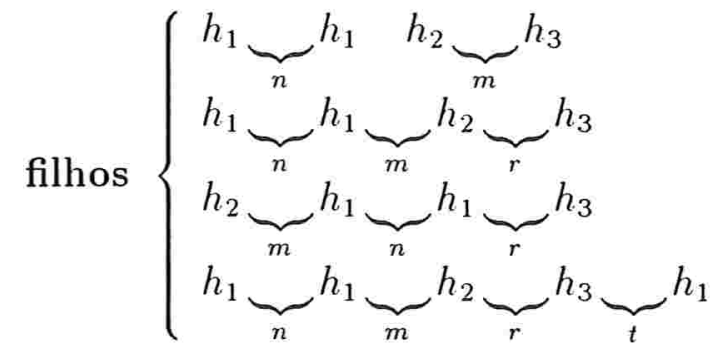

esposa $h_{1} \underbrace{}_{2}$, ou $h_{1} \underbrace{}_{3}$.

4.3.2 filhos $h_{2} \underbrace{}_{n} h_{1} \underbrace{h_{3}}_{m}$

esposa $\begin{cases}\text { i) } & h_{1} \underbrace{h} \operatorname{com} h \neq h_{j}, \quad j=2,3 . \\ \text { ii) } & h_{1} \underbrace{h_{2}}, \text { ou } h_{1} \underbrace{h_{3}} \\ \text { iii) } & h_{2} \underbrace{h_{3}}\end{cases}$

4.3.3 filhos $h_{1} \underbrace{}_{n} h_{2} \underbrace{h_{3}}_{m} \underbrace{}_{r} h_{1}$

esposa $h_{1} \underbrace{h_{2}}$, ou $h_{1} \underbrace{h_{3}}$, ou $h_{2} \underbrace{h_{3}}$.

4.4.1 filhos $h_{1} \underbrace{}_{n} h_{2} \quad h_{3} \underbrace{}_{m} h_{4}$

esposa $h_{1} \underbrace{h_{3}}$, ou $h_{1} \underbrace{h_{4}}$, ou $h_{2} \underbrace{h_{3}}$, ou $h_{2} \underbrace{h_{4}}$. 
4.4 .2

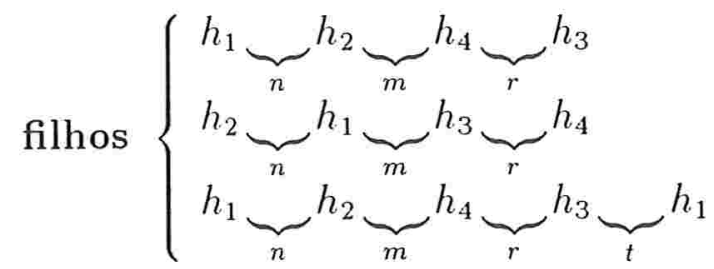

esposa $h_{1} \underbrace{h_{4}}$, ou $h_{2} \underbrace{h_{3}}$.

\subsection{Análise dos casos}

Nesta seção, aplicamos a metodologia desenvolvida na seção 4.2 para determinar a distribuição de probabilidade a posteriori para o genótipo do demandado, considerando cada um dos casos relacionados na tabela 4.1, exibida no final da seção anterior.

Além disso, pelos argumentos fornecidos no capítulo 1, exibiremos apenas a probabilidade condicional $V_{0}[D]$ - ou $R V[D]$ quando possível - necessária ao cálculo da probabilidade a posteriori de paternidade. Quanto à outra probabilidade condicional $V_{1}[D]$, também necessária ao cálculo desta probabilidade a posteriori, será omitida por ser diretamente obtida da proposição 1.5 .1 .

Ao longo desta seção, não tornaremos explícitos aqueles genótipos cujas probabilidades a posteriori sejam nulas.

\section{Caso 4.1.1}

Sejam $h_{1}, F_{1}$ e $F_{2}$ três alelos diferentes. Suponhamos que, ao considerarmos $n$ filhos do demandado, independentemente, observamos em cada um deles o genótipo $\left(h_{1}, h_{1}\right)$ - isto é, $D_{\mathbf{u}}=\left\{\left(h_{1}, h_{1}\right)_{n}\right\}$. Além disso, na esposa do demandado - a mãe destes $n$ indivíduos - observamos o genótipo $\left(h_{1}, h_{1}\right)$ ou $\left(h_{1}, h\right)$ sendo $h$ um alelo qualquer distinto de $h_{1}$.

Sob as considerações dadas acima, as probabilidades $P[\cdot]$ e $V\left[D_{\mathbf{u}} \mid\left(\cdot, m_{X}\right)\right]$ podem ser 
obtidas a seguir

$$
\begin{array}{clcc}
\text { genótipo } & \multicolumn{1}{c}{P[\cdot]} & V\left[D_{\mathbf{u}} \mid\left(\cdot,\left(h_{1}, h_{1}\right)\right)\right] & V\left[D_{\mathbf{u}} \mid\left(\cdot,\left(h_{1}, h\right)\right)\right] \\
\left(h_{1}, h_{1}\right) & f_{h_{1}}^{2} & 1 & (1 / 2)^{n} \\
\left(h_{1}, F_{i}\right) & 2 f_{h_{1}} f_{F_{i}}, i=1,2 & (1 / 2)^{n} & (1 / 4)^{n} \\
\left(h_{1},(x x x)^{c}\right) & 2 f_{h_{1}}\left(1-f_{h_{1}}-\sum_{k=1}^{2} f_{F_{k}}\right) & (1 / 2)^{n} & (1 / 4)^{n}
\end{array}
$$

Conseqüentemente, para obtermos a distribuição de probabilidade $P\left[\cdot \mid D_{\mathbf{u}, m_{X}}\right]$. é necessário apenas calcular o valor de $\delta$ definido na expressão 4.2. Para os casos que consideramos aqui, $\delta$ torna-se

$$
\delta= \begin{cases}\frac{f_{h_{1}} H\left[n, f_{h_{1}}\right]}{2^{n-1}} & \text { se } m_{X}=\left(h_{1}, h_{1}\right) \\ \frac{f_{h_{1}} H\left[n, f_{h_{1}}\right]}{2^{2 n-1}} & \text { se } m_{X}=\left(h_{1}, h\right), \quad h \neq h_{1}\end{cases}
$$

e a distribuição de probabilidade a posteriori para o genótipo do demandado $P\left[\cdot \mid D_{\mathbf{u}, m_{X}}\right]$, é apresentada no seguinte resultado.

Proposição 4.3.1 A distribuição de probabilidade a posteriori para o genótipo do demandado $P\left[\cdot \mid D_{\mathbf{u}, m_{X}}\right]$, uma vez que em sua esposa foi observado o genótipo $m_{X}$ e em $n$ de seus filhos com sua esposa foi observado o genótipo $\left(h_{1}, h_{1}\right)$ é a seguinte.

$$
\begin{aligned}
\text { genótipo }(\cdot) & P\left[(\cdot) \mid \mathbf{u}, m_{X}\right] \\
\left(h_{1}, h_{1}\right) & \frac{2^{n-1} f_{h_{1}}}{H\left[n, f_{h_{1}}\right]} \\
\left(h_{1}, F_{i}\right) & \frac{f_{F_{i}}}{H\left[n, f_{h_{1}}\right]}, \quad i=1,2 \\
\left(h_{1},(x x x)^{c}\right) & \frac{1-f_{h_{1}}-\sum_{i=1}^{2} f_{F_{i}}}{H\left[n, f_{h_{1}}\right]}
\end{aligned}
$$

Consideremos, como antes, o conjunto $I$ como sendo o conjunto formado pelo(s) alelo(s) de interesse.

Como visto na proposição 4.2.1, da distribuição de probabilidade a posteriori para o genótipo do demandado - dada neste caso pela expressão 4.5 - obtemos a probabilidade 
condicional do demandante ter recebido do demandado o(s) alelo(s) de interesse após termos observado $D$ e usando a proposição 1.5 .1 , obtemos a razão $R V[D]$ para cada conjunto $I$ como podemos ver no seguinte corolário.

Corolário 4.3.1 Sob as condiçōes da proposição 4.3.1, temos que a razão de verossimilhanças $R V[D]$ e a probabilidade condicional $V_{0}[D]$, do demandante ter recebido do demandado o(s) alelo(s) de interesse após termos observado D, estão dadas a seguir

$$
\begin{aligned}
& \text { I } \\
& V_{0}[D] \\
& R V[D] \\
& h_{1} \quad \frac{H\left[n+1, f_{h_{1}}\right]}{2 H\left[n, f_{h_{1}}\right]} \\
& \frac{2 f_{h_{1}} H\left[n, f_{h_{1}}\right]}{H\left[n+1, f_{h_{1}}\right]} \\
& F_{i} \quad \frac{f_{F_{i}}}{2 H\left[n, f_{h_{1}}\right]} \\
& h_{1} \text { e } F_{i} \quad \frac{H\left[n+1, f_{h_{1}}\right]+f_{F_{1}}}{2 H\left[n, f_{h_{1}}\right]} \\
& 2 H\left[n, f_{h_{1}}\right], \quad i=1,2 \\
& F_{1} \text { e } F_{2} \quad \frac{\sum_{i=1}^{2} f_{F_{i}}}{2 H\left[n, f_{h_{1}}\right]} \\
& \frac{2\left(f_{h_{1}}+f_{F_{i}}\right) H\left[n, f_{h_{1}}\right]}{H\left[n+1, f_{h_{1}}\right]+f_{F_{i}}}, ; i=1,2 \\
& 2 H\left[n, f_{h_{1}}\right]
\end{aligned}
$$

\section{Caso 4.2.1}

Sejam $h_{1}, h_{2}$ e $F_{1}$ três alelos diferentes.

Suponhamos que, ao observarmos independentemente $s$ filhos do demandado, ocorra uma das seguintes situações:

$$
\begin{aligned}
& D_{\mathbf{u}}=\left\{\left(h_{1}, h_{1}\right)_{n},\left(h_{2}, h_{2}\right)_{m}\right\}, \text { onde } s=n+m \text {, ou } \\
& D_{\mathbf{u}}=\left\{\left(h_{1}, h_{1}\right)_{n},\left(h_{1}, h_{2}\right)_{m},\left(h_{2}, h_{2}\right)_{r}\right\}, \quad \text { com } s=n+m+r .
\end{aligned}
$$

Em qualquer uma dessas situações o genótipo observado na esposa do demandado é $m_{X}=\left(h_{1}, h_{2}\right)$ e conseqüentemente temos que a distribuiçào de probabilidade a posteriori $P\left[\cdot \mid D_{\mathbf{u}, m_{X}}\right]$, para o genótipo do demandado, é a distribuição

$$
P\left[g_{i} \mid D_{\mathbf{u}, m_{X}}\right]= \begin{cases}1 & \text { se } g_{i}=\left(h_{1}, h_{2}\right) \\ 0 & \text { caso contrário, }\end{cases}
$$


A razão de verossimilhança $R V[D]$ e a probabilidade condicional $V_{0}[D]$, que é obtida da expressão 4.8. estão dadas na seguinte tabela.

Tabela 4.2 Probabilidade condicional $V_{0}[D]$ e razão

de verossimilhanças $R V[D]$ - Caso 4.2.1

$$
\begin{array}{ccl}
I & V_{0}[D] & \multicolumn{1}{c}{R V[D]} \\
h_{i} & 1 / 2 & 2 f_{h_{i}}, i=1,2 \\
h_{1} \text { e } h_{2} & 1 & f_{h_{1}}+f_{h_{2}} \\
h_{i} \text { e } F_{1} & 1 / 2 & 2\left(f_{h_{i}}+f_{F_{1}}\right) i=1,2
\end{array}
$$

\section{Caso 4.2.2}

Sejam $h_{i}$ e $F_{i}$ para $i=1,2$ quatro alelos diferentes. Suponhamos que, ao considerarmos $n$ filhos do demandado, independentemente, observamos em cada um deles o genótipo $\left(h_{1}, h_{2}\right)$ - isto é, $D_{\mathbf{u}}=\left\{\left(h_{1}, h_{2}\right)_{n}\right\}$.

Ao observarmos o genótipo da esposa do demandado pode ocorrer uma das seguintes situações:

$$
\begin{aligned}
& \text { i) } m_{X}=\left(h_{1}, h_{2}\right) \\
& \text { ii) } m_{X}=\left(h_{j}, h_{j}\right) \text {, ou } m_{X}=\left(h_{j}, h\right) \operatorname{com} h \neq h_{j}, h_{\sigma(j)}, j=1,2, j \text { fixo. }
\end{aligned}
$$

i) Suponhamos que $m_{X}=\left(h_{1}, h_{2}\right)$. Neste caso as probabilidades $P[\cdot]$ e $V\left[D_{\mathbf{u}} \mid\left(\cdot, m_{X}\right)\right]$ podem ser obtidas a seguir

$$
\begin{array}{llc}
\text { genótipo }(\cdot) & \multicolumn{1}{c}{P[\cdot]} & V\left[D_{\mathbf{u}} \mid\left(\cdot, m_{X}\right)\right] \\
\left(h_{i}, h_{i}\right) & f_{h_{i}}^{2}, i=1,2 & (1 / 2)^{n} \\
\left(h_{1}, h_{2}\right) & 2 f_{h_{1}} f_{h_{2}} & (1 / 2)^{n} \\
\left(h_{i}, F_{j}\right) & 2 f_{h_{i}} f_{F_{j}}, i, j=1,2 & (1 / 4)^{n} \\
\left(h_{i},(x x x x)^{c}\right) & 2 f_{h_{i}}\left(1-\sum_{k=1}^{2}\left(f_{h_{k}}+f_{F_{k}}\right)\right), i=1,2 & (1 / 4)^{n}
\end{array}
$$


Considerando a função

$$
w=w\left[n, f_{h_{1}}, f_{h_{2}}\right]=\left(\sum_{k=1}^{2} H\left[n, f_{h_{k}}\right]-1\right) \sum_{k=1}^{2} f_{h_{k}},
$$

fornecemos a distribuição de probabilidade a posteriori para o genótipo do demandado $P\left[\cdot \mid D_{\mathbf{u}, m_{X}}\right]$ no seguinte resultado.

Proposição 4.3.2 A distribuição de probabilidade a posteriori para o genótipo do demandado $P\left[\cdot \mid D_{\mathbf{u}, m_{X}}\right]$, uma vez que em sua esposa e em $n$ de seus filhos foi observado o genótipo $\left(h_{1}, h_{2}\right)$ é a seguinte.

$$
\begin{aligned}
& \text { genótipo }(\cdot) \quad P\left[\cdot \mid D_{\mathrm{u}, m_{X}}\right] \\
& \left(h_{i}, h_{i}\right) \quad 2^{n-1} f_{h_{i}}^{2} / w, \quad i=1,2 \\
& \left(h_{1}, h_{2}\right) \quad 2^{n} f_{h_{1}} f_{h_{2}} / w \\
& \left(h_{i}, F_{j}\right) \quad f_{h_{i}} f_{F_{j}} / w, \quad i, j=1,2 \\
& \left(h_{i},(x x x x)^{c}\right) \quad f_{h_{i}}\left(1-\sum_{j=1}^{2}\left(f_{h_{\jmath}}+f_{F_{\jmath}}\right)\right) / w, \quad i=1,2 \text {, }
\end{aligned}
$$

onde w é a função definida na expressão 4.9.

Como conseqüência do resultado anterior surge, naturalmente, o seguinte corolário.

Corolário 4.3.2 Sob as condições da proposição 4.3.2, temos que a razão de verossimilhanças $R V[D]$ e a probabilidade condicional $V_{0}[D]$, do demandante ter recebido do demandado o(s) alelo(s) de interesse após termos observado D, estão dadas a seguir

$$
\begin{array}{ccc}
I & V_{0}[D] & R V[D] \\
h_{i} & \frac{v_{i}\left[n, f_{h_{1}}, f_{h_{2}}\right]}{2 w\left[n, f_{h_{1}}, f_{h_{2}}\right]} & \frac{2 w\left[n, f_{h_{1}}, f_{h_{2}}\right]}{v_{i}\left[n, f_{h_{1}}, f_{h_{2}}\right]}, i=1,2 \\
F_{j} & \frac{f_{F_{j}} \sum_{i=1}^{2} f_{h_{i}}}{2 w\left[n, f_{h_{1}}, f_{h_{2}}\right]} & 2\left(\sum_{k=1}^{2} H\left[n, f_{h_{k}}\right]-1\right), j=1,2
\end{array}
$$




$$
\begin{array}{lll}
h_{1} e h_{2} & \frac{v_{3}\left[n, f_{h_{1}}, f_{h_{2}}\right]}{2 w\left[n, f_{h_{1}}, f_{h_{2}}\right]} & \frac{2\left(f_{h_{1}}+f_{h_{2}}\right) w\left[n, f_{h_{1}}, f_{h_{2}}\right]}{v_{3}\left[n, f_{h_{1}}, f_{h_{2}}\right]} \\
h_{i} e F_{j} & \frac{v_{i j}\left[n, f_{h_{i}}, f_{h_{\sigma(i)}}, f_{F_{j}}\right]}{2 w\left[n, f_{h_{1}}, f_{h_{2}}\right]} & \frac{2\left(f_{h_{i}}+f_{F_{3}}\right) w\left[n, f_{h_{1}}, f_{h_{2}}\right]}{v_{i j}\left[n, f_{h_{i}}, f_{h_{\sigma(i)}}, f_{F_{3}}\right]}, i, j=1,2 \\
F_{1} e F_{2} & \frac{\sum_{i=1}^{2} f_{F_{i}} \sum_{i=1}^{2} f_{h_{i}}}{2 w\left[n, f_{h_{1}}, f_{h_{2}}\right]} & 2\left(\sum_{k=1}^{2} H\left[n, f_{h_{k}}\right]-1\right),
\end{array}
$$

onde $v_{i}=v_{i}\left[n, f_{h_{1}}, f_{h_{2}}\right], \quad i=1,2,3, \epsilon v_{i j}=v_{i j}\left[n, f_{h_{1}}, f_{h_{2}}, f_{F_{j}}\right], i, j=1,2$, são dadas por

$$
\begin{aligned}
v_{i} & =f_{h_{i}}\left(H\left[n+1, f_{h_{i}}\right]+\left(2^{n}-1\right) f_{h_{\sigma(i)}}\right), \quad i=1,2 \\
v_{3} & =\left(f_{h_{1}}+f_{h_{2}}\right)\left(H\left[n+1, f_{h_{1}}\right]+\left(2^{n}-1\right) f_{h_{2}}\right) \\
v_{i j} & =f_{h_{i}}+\left(f_{h_{1}}+f_{h_{2}}\right)\left(f_{F_{3}}+\left(2^{n}-1\right) f_{h_{i}}\right), \quad i, j=1,2 .
\end{aligned}
$$

ii) Seja $h$ um alelo qualquer tal que $h \neq h_{j}, j=1,2$. Para cada $j=1,2, j$ fixado, suponhamos que o genótipo observado na esposa do demandado é $m_{X}=\left(h_{j}, h_{j}\right)$, ou $m_{X}=\left(h_{j}, h\right)$. Neste caso, as probabilidades $P[\cdot]$ e $V\left[D_{\mathbf{u}} \mid\left(\cdot, m_{X}\right)\right]$ podem ser obtidas a seguir

\begin{tabular}{llcc} 
genótipo $(\cdot)$ & \multicolumn{1}{c}{$P[\cdot]$} & $V\left[D_{\mathbf{u}} \mid\left(\cdot,\left(h_{j}, h_{j}\right)\right)\right]$ & $V\left[D_{\mathbf{u}} \mid\left(\cdot,\left(h_{j}, h\right)\right)\right]$ \\
$\left(h_{\sigma(j)}, h_{\sigma(j)}\right)$ & $f_{h_{\sigma(\jmath)}}^{2}$ & 1 & $(1 / 2)^{n}$ \\
$\left(h_{1}, h_{2}\right)$ & $2 f_{h_{1}} f_{h_{2}}$ & $(1 / 2)^{n}$ & $(1 / 4)^{n}$ \\
$\left(h_{\sigma(j)}, F_{i}\right)$ & $2 f_{h_{\sigma(\jmath)}} f_{F_{i}}, i=1,2$ & $(1 / 2)^{n}$ & $(1 / 4)^{n}$ \\
$\left(h_{\sigma(j)},(x x x x)^{c}\right)$ & $2 f_{h_{\sigma(\jmath)}}\left(1-\sum_{k=1}^{2}\left(f_{h_{k}}+f_{F_{k}}\right)\right)$ & $(1 / 2)^{n}$ & $(1 / 4)^{n}$.
\end{tabular}

Das probabilidades acima deduzimos imediatamente a distribuição de probabilidade $a$ posteriori para o genótipo do demandado $P\left[\cdot \mid D_{\mathbf{u}, m_{X}}\right]$, a qual fornecemos no seguinte resultado.

Proposição 4.3.3 Sob as condições estabelecidas acima, a distribuição de probabilidade a posteriori para o genótipo do demandado $P\left[\cdot \mid D_{\mathbf{u}, m_{X}}\right]$ é dada pela seguinte expressão.

$$
\text { genótipo }(\cdot) \quad P\left[\cdot \mid D_{\mathbf{u}, m_{X}}\right]
$$




$$
\begin{aligned}
\left(h_{\sigma(j)}, h_{\sigma(j)}\right) & \frac{2^{n-1} f_{h_{\sigma(\jmath)}}}{H\left[n, f_{h_{\sigma(j)}}\right]} \\
\left(h_{1}, h_{2}\right) & \frac{f_{h_{j}}}{H\left[n, f_{h_{\sigma(\jmath)}}\right]} \\
\left(h_{\sigma(j)}, F_{i}\right) & \frac{f_{F_{i}}}{H\left[n, f_{\left.h_{\sigma(\jmath)}\right]}\right.}, i=1,2 \\
\left(h_{\sigma(j)},(x x x x)^{c}\right) & \frac{1-\sum_{k=1}^{2}\left(f_{h_{k}}+f_{F_{k}}\right.}{H\left[n, f_{h_{\sigma(\jmath)}}\right]} .
\end{aligned}
$$

Conseqüentemente, do resultado anterior decorre o seguinte corolário.

Corolário 4.3.3 Sob as condições da proposição 4.3.3, temos que a razão de verossimilhanças $R V[D]$ e a probabilidade condicional $V_{0}[D]$, do demandante ter recebido do demandado o(s) alelo(s) de interesse após termos observado $D$, estão dadas a seguir

$$
\begin{aligned}
& V_{0}[D] \quad R V[D] \\
& h_{j} \quad \frac{f_{h_{j}}}{2 H\left[n, f_{h_{\sigma(j)}}\right]} \quad 2 H\left[n, f_{h_{\sigma(j)}}\right] \\
& h_{\sigma(j)} \quad \frac{H\left[n+1, f_{h_{\sigma(j)}}\right]}{2 H\left[n, f_{h_{\sigma(j)}}\right]} \quad \frac{2 f_{h_{\sigma(\jmath)}} H\left[n, f_{h_{\sigma(\jmath)}}\right]}{H\left[n+1, f_{h_{\sigma(\jmath)}}\right]} \\
& F_{i} \quad \frac{f_{F_{i}}}{2 H\left[n, f_{h_{\sigma(\jmath)}}\right]} \quad 2 H\left[n, f_{h_{\sigma(\jmath)}}\right], i=1,2 \\
& \begin{array}{lll}
h_{j} e h_{\sigma(j)} & \frac{f_{h_{\jmath}}+H\left[n+1, f_{h_{\sigma(j)}}\right]}{2 H\left[n, f_{h_{\sigma(j)}}\right]} \quad \frac{2\left(f_{h_{\jmath}}+f_{h_{\sigma(\jmath)}}\right) H\left[n, f_{h_{\sigma(j)}}\right]}{f_{h_{\jmath}}+H\left[n+1, f_{h_{\sigma(j)}}\right]}
\end{array} \\
& h_{j} \text { e } F_{i} \quad \frac{f_{h_{\jmath}}+f_{F_{i}}}{2 H\left[n, f_{h_{\sigma(\jmath)}}\right]} \quad 2 H\left[n, f_{h_{\sigma(\jmath)}}\right], i=1,2 \\
& h_{\sigma(j)} \text { e } F_{i} \quad \frac{f_{F_{i}}+H\left[n+1, f_{h_{\sigma(j)}}\right]}{2 H\left[n, f_{h_{\sigma(j)}}\right]} \quad \frac{2\left(f_{F_{i}}+f_{h_{\sigma(j)}}\right) H\left[n, f_{h_{\sigma(j)}}\right]}{f_{F_{i}}+H\left[n+1, f_{h_{\sigma(\jmath)}}\right]}, i=1,2 \\
& \begin{array}{cll}
F_{1} \text { e } F_{2} & \frac{\sum_{i=1}^{2} f_{F_{i}}}{2 H\left[n, f_{h_{\sigma(\jmath)}}\right]} \quad 2 H\left[n, f_{h_{\sigma(j)}}\right]
\end{array}
\end{aligned}
$$




\section{Caso 4.2.3}

Consideremos quatro alelos diferentes $h_{i}$ e $F_{i}, i=1,2$. Suponhamos que foram observados $n+m$ filhos do demandado, independentemente, encontrando em $n$ deles o genótipo $\left(h_{1}, h_{2}\right)$ e nos outros $m$ filhos o genótipo $\left(h_{2}, h_{2}\right)$ - isto é,

$$
D_{\mathbf{u}}=\left\{\left(h_{1}, h_{2}\right)_{n},\left(h_{2}, h_{2}\right)_{m}\right\} .
$$

Além disso, ao observarmos o genótipo da esposa do demandado pode ocorrer uma das seguintes situações:

$$
\begin{aligned}
& \text { i) } \quad m_{X}=\left(h_{2}, h_{2}\right) \text {, ou } m_{X}=\left(h_{2}, h\right) \text { com } h \neq h_{j}, j=1,2 \\
& \text { ii) } \quad m_{X}=\left(h_{1}, h_{2}\right)
\end{aligned}
$$

i) Seja $h$ um alelo qualquer tal que $h \neq h_{j}, j=1,2$. Suponhamos que o genótipo observado na esposa do demandado é $m_{X}=\left(h_{2}, h_{2}\right)$, ou $m_{X}=\left(h_{2}, h\right)$.

Neste caso a distribuição de probabilidade a posteriori $P\left[\cdot \mid D_{\mathbf{u}, m_{X}}\right]$ para o genótipo do demandado é dada pela expressão 4.8 e em conseqüência, a razão de verossimilhança $R V[D]$ e a probabilidade condicional $V_{0}[D]$ estão dadas na tabela 4.2 .

ii) Suponhamos que na esposa do demandado observamos o genótipo $m_{X}=\left(h_{1}, h_{2}\right)$. As probabilidades $P[\cdot]$ e $V\left[D_{\mathbf{u}} \mid\left(\cdot, m_{X}\right)\right]$ podem ser obtidas a seguir

$$
\begin{array}{clc}
\text { genótipo }(\cdot) & \multicolumn{1}{c}{P[\cdot]} & V\left[D_{\mathbf{u}} \mid\left(\cdot,\left(h_{1}, h_{2}\right)\right)\right] \\
\left(h_{2}, h_{2}\right) & f_{h_{2}}^{2} & (1 / 2)^{n}(1 / 2)^{m} \\
\left(h_{1}, h_{2}\right) & 2 f_{h_{1}} f_{h_{2}} & (1 / 2)^{n}(1 / 4)^{m} \\
\left(h_{2}, F_{i}\right) & 2 f_{h_{2}} f_{F_{i}}, i=1,2 & (1 / 4)^{n}(1 / 4)^{m} \\
\left(h_{2},(x x x x)^{c}\right) & 2 f_{h_{2}}\left(1-\sum_{k=1}^{2}\left(f_{h_{k}}+f_{F_{k}}\right)\right) & (1 / 4)^{n}(1 / 4)^{m}
\end{array}
$$

Consideremos a função $w=w\left[n, m, f_{h_{1}}, f_{h_{2}}\right]$ definida por

$$
w\left[n, m, f_{h_{1}}, f_{h_{2}}\right]=H\left[n+1, f_{h_{1}}\right]+\left(2^{n+m-1}-1\right) f_{h_{2}} .
$$

A distribuição de probabilidade a posteriori para o genótipo do demandado $P\left[\cdot \mid D_{\mathbf{u}, m_{X}}\right]$, é apresentada no seguinte resultado. 
Proposição 4.3.4 A distribuiçâo de probabilidade a posteriori para o genótipo do demandado $P\left[\cdot \mid D_{\mathbf{u}, m_{X}}\right]$, uma vez que em sua esposa foi observado o genótipo $m_{X}$, em $n$ de seus filhos o genótipo $\left(h_{1}, h_{2}\right)$ e nos outros $m$ filhos o genótipo $\left(h_{2}, h_{2}\right)$ é a seguinte.

$$
\begin{aligned}
\text { genótipo }(\cdot) & \multicolumn{1}{c}{P\left[(\cdot) \mid D_{\mathbf{u}, m_{X}}\right]} \\
\left(h_{2}, h_{2}\right) & 2^{n+m-1} f_{h_{2}} / w \\
\left(h_{1}, h_{2}\right) & 2^{n} f_{h_{1}} / w \\
\left(h_{2}, F_{i}\right) & f_{F_{i}} / w, \quad i=1,2 \\
\left(h_{2},(x x x x)^{c}\right) & \left(1-\sum_{k=1}^{2}\left(f_{h_{k}}+f_{F_{k}}\right)\right) / w,
\end{aligned}
$$

onde $w$ é a função definida pela expressão 4.12.

Da expressão 4.13 calculamos a probabilidade condicional do demandante ter recebido do demandado o(s) alelo(s) de interesse após termos observado $D$ e imediatamente, usando a proposição 1.5 .1 , obtemos a razão $R V[D]$ para cada conjunto $I$ como podemos ver no seguinte corolário.

Corolário 4.3.4 Sob as condições da proposição 4.3.4, temos que a razão de verossimilhanças $R V[D]$ e a probabilidade condicional $V_{0}[D]$, do demandante ter recebido do demandado o(s) alelo(s) de interesse após termos observado $D$, estão dadas a seguir

$$
\begin{array}{ccl}
\multicolumn{1}{c}{I} & \multicolumn{1}{c}{V_{0}[D]} & \multicolumn{1}{c}{R V[D]} \\
h_{1} & \frac{2^{n-1} f_{h_{1}}}{w\left[n, m, f_{h_{1}}, f_{h_{2}}\right]} & \frac{H\left(n+1, f_{h_{1}}\right)+\left(2^{n+m-1}-1\right) f_{h_{2}}}{2^{n-1}} \\
h_{2} & \frac{v_{1}\left[n, m, f_{h_{1}}, f_{h_{2}}\right]}{2 w\left[n, m, f_{h_{1}}, f_{h_{2}}\right]} & \frac{2 f_{h_{2}} w\left[n, m, f_{h_{1}}, f_{h_{2}}\right]}{H\left(n+1, f_{h_{1}}\right)+\left(2^{n+m}-1\right) f_{h_{2}}} \\
F_{i} & \frac{f_{F_{i}}}{2 w\left[n, m, f_{h_{1}}, f_{h_{2}}\right]} & 2\left(H\left(n+1, f_{h_{1}}\right)+\left(2^{n+m-1}-1\right) f_{h_{2}}\right), i=1,2 \\
h_{1} e h_{2} & \frac{v_{2}\left[n, m, f_{h_{1}}, f_{h_{2}}\right]}{2 w\left[n, m, f_{h_{1}}, f_{h_{2}}\right]} & \frac{2\left(f_{h_{1}}+f_{h_{2}}\right) w\left[n, m, f_{h_{1}}, f_{h_{2}}\right]}{H\left(n+2, f_{h_{1}}\right)+\left(2^{n+m}-1\right) f_{h_{2}}} \\
h_{1} e F_{i} & \frac{2^{n} f_{h_{1}}+f_{F_{i}}}{2 w\left[n, m, f_{h_{1}}, f_{h_{2}}\right]} & \frac{2\left(f_{h_{1}}+f_{F_{1}}\right) w\left[n, m, f_{h_{1}}, f_{h_{2}}\right]}{2^{n} f_{h_{1}}+f_{F_{1}}}, i=1,2
\end{array}
$$




$$
\begin{array}{lll}
h_{2} \text { e } F_{i} & \frac{v_{1 i}\left[n, m, f_{h_{1}}, f_{h_{2}}, f_{F_{i}}\right]}{2 w\left[n, m, f_{h_{1}}, f_{h_{2}}\right]} & \frac{2\left(f_{h_{2}}+f_{F_{i}}\right) w\left[n, m, f_{h_{1}}, f_{h_{2}}\right]}{H\left(n+1, f_{h_{1}}\right)+\left(2^{n+m}-1\right) f_{h_{2}}+f_{F_{i}}}, i=1,2 \\
F_{1} e F_{2} & \frac{\sum_{i=1}^{2}, f_{F_{i}}}{2 w\left[n, m, f_{h_{1}}, f_{h_{2}}\right]} & 2\left(H\left(n+1, f_{h_{1}}\right)+\left(2^{n+m-1}-1\right) f_{h_{2}}\right),
\end{array}
$$

onde

$$
\begin{aligned}
v_{1}\left[n, m, f_{h_{1}}, f_{h_{2}}\right] & =H\left(n+1, f_{h_{1}}\right)+\left(2^{n+m}-1\right) f_{h_{2}} \\
v_{2}\left[n, m, f_{h_{1}}, f_{h_{2}}\right] & =H\left(n+2, f_{h_{1}}\right)+\left(2^{n+m}-1\right) f_{h_{2}} \\
v_{1 i}\left[n, m, f_{h_{1}}, f_{h_{2}}, f_{F_{i}}\right] & =v_{1}\left[n, m, f_{h_{1}}, f_{h_{2}}\right]+f_{F_{i}}, \quad i=1,2 .
\end{aligned}
$$

\section{Caso 4.3.1}

Sejam $F_{1}$ e $h_{i}, i=1,2,3$ quatro alelos diferentes. Suponhamos que, ao observarmos $s$ filhos do demandado, independentemente, ocorra uma das seguintes situações:

$$
\begin{aligned}
& D_{\mathbf{u}}=\left\{\left(h_{1}, h_{1}\right)_{n},\left(h_{2}, h_{3}\right)_{m}\right\}, \text { onde } s=n+m \text {, ou } \\
& D_{\mathbf{u}}=\left\{\left(h_{1}, h_{1}\right)_{n},\left(h_{1}, h_{2}\right)_{m},\left(h_{2}, h_{3}\right)_{r}\right\}, \text { com } s=n+m+r, \text { ou } \\
& D_{\mathbf{u}}=\left\{\left(h_{1}, h_{1}\right)_{n},\left(h_{1}, h_{2}\right)_{m},\left(h_{1}, h_{3}\right)_{r}\right\}, \text { onde } s=n+m+r \text { ou } \\
& D_{\mathbf{u}}=\left\{\left(h_{1}, h_{1}\right)_{n},\left(h_{1}, h_{2}\right)_{m},\left(h_{2}, h_{3}\right)_{r},\left(h_{1}, h_{3}\right)_{t}\right\}, \text { se } s=n+m+r+t .
\end{aligned}
$$

Para cada $j=2,3, j$ fixo, suponhamos que o genótipo observado na esposa do demandado é $m_{X}=\left(h_{1}, h_{j}\right)$. Então, o demandado necessariamente devia possuir o genótipo $\left(h_{1}, h_{\tau(j)}\right)$ e portanto, em qualquer uma das situaçôes acima, a distribuição de probabilidade a posteriori $P\left[\cdot \mid D_{\mathbf{u}, m_{X}}\right]$ para o genótipo do demandado é

$$
P\left[g_{i} \mid D_{\mathbf{u}, m_{X}}\right]= \begin{cases}1 & \text { se } g_{i}=\left(h_{1}, h_{\tau(j)}\right) \\ 0 & \text { caso contrário, }\end{cases}
$$

A razão de verossimilhança $R V[D]$ e a probabilidade condicional $V_{0}[D]$, que é obtida da expressão 4.18 , estão dadas na seguinte tabela.

Tabela 4.3 Probabilidade condịcional $V_{0}[D]$ e razão de verossimilhanças $R V[D]$ - Caso 4.3.1

$$
\begin{array}{lll}
I & V_{0}[D] & R V[D]
\end{array}
$$




$$
\begin{array}{ccl}
h_{1} & 1 / 2 & 2 f_{h_{1}} \\
h_{\tau(j)} & 1 / 2 & 2 f_{h_{\tau(j)}} \\
h_{1} \text { e } h_{\tau(j)} & 1 & f_{h_{1}}+f_{h_{\tau(\jmath)}} \\
h_{1} \text { е } F_{1} & 1 / 2 & 2\left(f_{h_{1}}+f_{F_{1}}\right) \\
h_{\tau(j)} \text { е } F_{1} & 1 / 2 & 2\left(f_{h_{\tau(\jmath)}}+f_{F_{1}}\right)
\end{array}
$$

\section{Caso 4.3.2}

Sejam $h_{i}$ e $F_{j}$. para $i=1,2,3$ e $j=1,2$, cinco alelos diferentes. Suponhamos que, ao observarmos $n+m$ filhos do demandado, independentemente, encontramos em $n$ deles o genótipo $\left(h_{1}, h_{2}\right)$ e nos outros $m$ filhos o genótipo $\left(h_{1}, h_{3}\right)$ - isto é,

$$
D_{\mathbf{u}}=\left\{\left(h_{1}, h_{2}\right)_{n},\left(h_{1}, h_{3}\right)_{m}\right\} .
$$

Ao observarmos o genótipo da esposa do demandado, pode ocorrer uma das seguintes situações:

$$
\begin{aligned}
& \text { i) } \quad m_{X}=\left(h_{1}, h\right) \text { com } h \neq h_{j}, \quad j=2,3 \text {. } \\
& \text { ii) } \quad m_{X}=\left(h_{1}, h_{2}\right) \text {, ou } m_{X}=\left(h_{1}, h_{3}\right) \\
& \text { iii) } \quad m_{X}=\left(h_{2}, h_{3}\right)
\end{aligned}
$$

i) Seja $h$ um alelo qualquer tal que $h \neq h_{j}, j=2,3$ e suponhamos que o genótipo observado na esposa do demandado é $m_{X}=\left(h_{1}, h\right)$.

Neste caso particular o único genótipo possível para o demandado é $\left(h_{2}, h_{3}\right)$ e, portanto, a distribuição de probabilidade a posteriori $P\left[\cdot \mid D_{\mathbf{u}, m_{X}}\right]$ para o genótipo do demandado é

$$
P\left[g_{i} \mid D_{\mathbf{u}, m_{X}}\right]= \begin{cases}1 & \text { se } g_{i} \neq\left(h_{2}, h_{3}\right) \\ 0 & \text { caso contrário }\end{cases}
$$

A razão de verossimilhança $R V[D]$ e a probabilidade condicional $V_{0}[D]$, que é obtida da expressão 4.18, estão dadas na seguinte tabela. 
Tabela 4.4 Probabilidade condicional $V_{0}[D]$ e razão de verossimilhanças $R V[D]$ - Caso 4.3 .2 i)

$$
\begin{array}{rcl}
I & V_{0}[D] & \multicolumn{1}{c}{R V[D]} \\
h_{j} & 1 / 2 & 2 f_{h_{\jmath}}, j=2,3 \\
h_{2} \text { e } h_{3} & 1 & f_{h_{2}}+f_{h_{3}} \\
h_{1} \text { е } h_{j} & 1 / 2 & 2\left(f_{h_{1}}+f_{h_{\jmath}}\right), \quad j=2,3 \\
h_{j} \text { е } F_{i} & 1 / 2 & 2\left(f_{h_{\jmath}}+f_{F_{i}}\right), \quad i=1,2 ; j=2,3
\end{array}
$$

ii) Para cada $j=2,3, j$ fixo, suponhamos que o genótipo observado na esposa do demandado é $m_{X}=\left(h_{1}, h_{j}\right)$.

Para essa situação, a distribuição de probabilidade a priori para o genótipo do demandado $P[\cdot]$ e a probabilidade condicional $V\left[D_{\mathbf{u}} \mid\left(\cdot, m_{X}\right)\right]$ tornam-se:

$$
\begin{array}{rlr}
\text { genótipo }(\cdot) & P[\cdot] & V\left[D_{\mathbf{u}} \mid\left(\cdot, m_{X}\right)\right] \\
\left(h_{1}, h_{\tau(j)}\right) & 2 f_{h_{1}} f_{h_{\tau(j)}} & (1 / 4)^{n}(1 / 4)^{m} \\
\left(h_{j}, h_{\tau(j)}\right) & 2 f_{h_{j}} f_{h_{\tau(j)}} & (1 / 4)^{n}(1 / 4)^{m}
\end{array}
$$

Da expressão acima estabelecemos:

Proposição 4.3.5 A distribuição de probabilidade a posteriori para o genótipo do demandado $P\left[\cdot \mid D_{\mathbf{u}, m_{X}}\right]$, uma vez que observamos o genótipo $m_{X}=\left(h_{1}, h_{j}\right)$ na sua esposa e os genótipos $\left(h_{1}, h_{2}\right)$ e $\left(h_{1}, h_{3}\right)$ em $n$ e $m$ de seus filhos, respectivamente, é dada pela expressão

$$
\begin{aligned}
\text { genótipo (·) } & P\left[\cdot \mid D_{\mathbf{u}, m_{X}}\right] \\
\left(h_{1}, h_{\tau(j)}\right) & \frac{f_{h_{1}}}{f_{h_{1}}+f_{h_{j}}} \\
\left(h_{j}, h_{\tau(j)}\right) & \frac{f_{h_{\jmath}}}{f_{h_{1}}+f_{h_{j}}}
\end{aligned}
$$


Como conseqüência da proposição anterior obtemos:

Corolário 4.3.5 Sob as condições da proposição 4.3.5, temos que a razão de verossimilhanças $R V[D]$ e a probabilidade condicional $V_{0}[D]$, do demandante ter recebido do demandado o(s) alelo(s) de interesse após termos observado $D$, são dadas a seguir.

$$
\begin{array}{cll}
\multicolumn{1}{c}{I} & \multicolumn{1}{c}{V_{0}[D]} & \multicolumn{1}{c}{R V[D]} \\
h_{k} & \frac{f_{h_{k}}}{2\left(f_{h_{1}}+f_{h_{\jmath}}\right)} & 2\left(f_{h_{1}}+f_{h_{\jmath}}\right), k \neq \tau(j) \\
h_{\tau(j)} & 1 / 2 & 2 f_{h_{\tau(\jmath)}} \\
h_{1} e h_{j} & 1 / 2 & 2\left(f_{h_{1}}+f_{h_{\jmath}}\right) \\
h_{i} e h_{\tau(j)} & \frac{2 f_{h_{i}}+f_{h_{j}}}{2\left(f_{h_{1}}+f_{h_{j}}\right)} & \frac{2\left(f_{h_{i}}+f_{h_{\tau(\jmath)}}\right)\left(f_{h_{1}}+f_{h_{\jmath}}\right)}{2 f_{h_{i}}+f_{h_{\jmath}}}, i=1, j \\
h_{i} e F_{k} & \frac{f_{h_{i}}}{2\left(f_{h_{1}}+f_{h_{j}}\right)} & \frac{2\left(f_{h_{i}}+f_{F_{k}}\right)\left(f_{h_{1}}+f_{h_{\jmath}}\right)}{f_{h_{i}}}, i \neq \tau(j), k=1,2 \\
h_{\tau(j)} e F_{k} & 1 / 2 & 2\left(f_{h_{\tau(\jmath)}}+f_{F_{k}}\right), k=1,2
\end{array}
$$

iii) Consideremos a situação quando o genótipo observado na esposa do demandado é $m_{X}=\left(h_{2}, h_{3}\right)$.

Para essa situação, a distribuição de probabilidade a priori para o genótipo do demandado $P[\cdot]$ e a probabilidade condicional $V\left[D_{\mathbf{u}} \mid\left(\cdot, m_{X}\right)\right]$ podem ser obtidas a seguir.

$$
\begin{array}{rll}
\text { genótipo }(\cdot) & \multicolumn{1}{c}{P[\cdot]} & V\left[D_{\mathbf{u}} \mid\left(\cdot, m_{X}\right)\right] \\
\left(h_{1}, h_{1}\right) & f_{h_{1}}^{2} & (1 / 2)^{n}(1 / 2)^{m} \\
\left(h_{1}, h_{j}\right) & 2 f_{h_{1}} f_{h_{\jmath}}, j=2,3 & (1 / 4)^{n}(1 / 4)^{m} \\
\left(h_{1}, F_{i}\right) & 2 f_{h_{1}} f_{F_{i}}, i=1,2 & (1 / 4)^{n}(1 / 4)^{m} \\
\left(h_{1},(x x x x x)^{c}\right) & 2 f_{h_{1}}\left(1-\sum_{k=1}^{3} f_{h_{k}}-\sum_{j=1}^{2} f_{F_{J}}\right) & (1 / 4)^{n}(1 / 4)^{m}
\end{array}
$$

Considerando $w=w\left[n, m, f_{h_{1}}\right]$ como a função definida na expressão abaixo

$$
w=1+\left(2^{n+m-1}-1\right) f_{h_{1}},
$$

estabelecemos: 
Proposição 4.3.6 A distribuição de probabilidade a posteriori para o genótipo do demandado $P\left[\cdot \mid D_{\mathbf{u}, m_{X}}\right]$, uma vez que observamos o genótipo $\left(h_{2}, h_{3}\right)$ na sua esposa e os genótipos $\left(h_{1}, h_{2}\right)$ e $\left(h_{2}, h_{2}\right)$ em $n$ e $m$ de seus filhos, respectivamente, é

$$
\begin{aligned}
\text { genótipo }(\cdot) & \multicolumn{1}{c}{P\left[\cdot \mid D_{\mathbf{u}, m_{X}}\right]} \\
\left(h_{1}, h_{1}\right) & 2^{n+m-1} f_{h_{1}} / w \\
\left(h_{1}, h_{j}\right) & f_{h_{j}} / w, j=2,3 \\
\left(h_{1}, F_{i}\right) & f_{F_{i}} / w, i=1,2 \\
\left(h_{1},(x x x x x)^{c}\right) & \left(1-\sum_{k=1}^{3} f_{h_{k}}-\sum_{j=1}^{2} f_{F_{j}}\right) / w
\end{aligned}
$$

onde w é a função definida pela expressão 4.20.

Desse resultado, obtemos:

Corolário 4.3.6 Sob as condições da proposiçâo 4.3.6, temos que a razão de verossimilhanças $R V[D]$ e a probabilidade condicional $V_{0}[D]$, do demandante ter recebido do demandado o (s) alelo(s) de interesse após termos observado D, estão dadas nos seguintes resultados

$$
\begin{array}{cll} 
& \multicolumn{1}{c}{V_{0}[D]} & \multicolumn{1}{c}{R V[D]} \\
h_{1} & \frac{1+\left(2^{n+m}-1\right) f_{h_{1}}}{2 w\left[n, m, f_{h_{1}}\right]} & \frac{2 f_{h_{1}}\left\{1+\left(2^{n+m-1}-1\right) f_{h_{1}}\right\}}{1+\left(2^{n+m}-1\right) f_{h_{1}}} \\
h_{j} & \frac{f_{h_{j}}}{2 w\left[n, m, f_{h_{1}}\right]} & 2\left(1+\left(2^{n+m}-1\right) f_{h_{1}}\right), j=2,3 \\
F_{i} & \frac{f_{F_{i}}}{2 w\left[n, m, f_{h_{1}}\right]} & 2\left(1+\left(2^{n+m}-1\right) f_{h_{1}}\right), i=1,2 \\
h_{1} \text { e } h_{j} & \frac{1+\left(2^{n+m}-1\right) f_{h_{1}}+f_{h_{3}}}{2 w\left[n, m, f_{h_{1}}\right]} & \frac{2\left(f_{h_{1}}+f_{h_{\jmath}}\right)\left\{1+\left(2^{n+m-1}-1\right) f_{h_{1}}\right\}}{1+\left(2^{n+m}-1\right) f_{h_{1}}+f_{h_{j}}}, j=2,3 \\
h_{1} \text { e } F_{i} & \frac{1+\left(2^{n+m}-1\right) f_{h_{1}}+f_{F_{1}}}{2 w\left[n, m, f_{h_{1}}\right]} & \frac{2\left(f_{h_{1}}+f_{F_{i}}\right)\left\{1+\left(2^{n+m-1}-1\right) f_{h_{1}}\right\}}{1+\left(2^{n+m}-1\right) f_{h_{1}}+f_{F_{i}}}, i=1,2 \\
h_{2} \text { e } h_{3} & \frac{f_{h_{2}}+f_{h_{3}}}{2 w\left[n, m, f_{h_{1}}\right]} & 2\left\{1+\left(2^{n+m-1}-1\right) f_{h_{1}}\right\}
\end{array}
$$




$$
\begin{array}{lll}
h_{j} \in F_{i} & \frac{f_{h_{j}}+f_{F_{i}}}{2 w\left[n, m, f_{h_{1}}\right]} & 2\left\{1+\left(2^{n+m-1}-1\right) f_{h_{1}}\right\}, j=2,3, i=1,2 \\
F_{1} \in F_{2} & \frac{\sum_{i=1}^{2} f_{F_{i}}}{2 w\left[n, m, f_{h_{1}}\right]} & 2\left\{1+\left(2^{n+m-1}-1\right) f_{h_{1}}\right\} .
\end{array}
$$

\section{Caso 4.3.3}

Consideremos os seguintes quatro alelos $F_{1}$ e $h_{i}, i=1,2,3$, diferentes. Suponhamos que o conjunto de genótipos encontrado, ao observarmos $n+m+r$ filhos do demandado, independentemente, esteja representado por

$$
D_{\mathbf{u}}=\left\{\left(h_{1}, h_{2}\right)_{n},\left(h_{2}, h_{3}\right)_{m},\left(h_{1}, h_{3}\right)_{r}\right\} .
$$

Consideremos $i, j \in\{1,2,3\}$ com $i<j, i, j$ fixados. Suponhamos que o genótipo observado na esposa do demandado é $m_{X}=\left(h_{i}, h_{j}\right)$ e definamos

$$
\{k(i, j)\}=\{1,2,3\}-\{i, j\} .
$$

Com esses pressupostos, derivamos a probabilidade condicional $V\left[D_{\mathbf{u}} \mid\left(\cdot, m_{X}\right)\right]$, a qual apresentaremos a seguir juntamente com os valores declarados para a distribuição de probabilidade a priori $P[\cdot]$.

$$
\begin{array}{ccc}
\text { genótipo }(\cdot) & P[\cdot] & V\left[D_{\mathbf{u}} \mid\left(\cdot, m_{X}\right)\right] \\
\left(h_{i}, h_{k(i, j)}\right) & 2 f_{h_{i}} f_{h_{k(i, j)}} & (1 / 4)^{n}(1 / 4)^{m}(1 / 4)^{r} \\
\left(h_{j}, h_{k(i, j)}\right) & 2 f_{h}, f_{h_{k(i, j)}} & (1 / 4)^{n}(1 / 4)^{m}(1 / 4)^{r}
\end{array}
$$

Dos resultados acima, derivamos a distribuição a posteriori $P\left[\cdot \mid D_{\mathbf{u}, m_{X}}\right]$, estabelecida na seguinte proposição.

Proposição 4.3.7 Sob as condições anteriores, a distribuição de probabilidade a posteriori para o genótipo do demandado $P\left[\cdot \mid D_{\mathbf{u}, m_{X}}\right]$ é a seguinte

$$
\text { genótipo }(\cdot) \quad P\left[\cdot \mid D_{\mathbf{u}, m_{X}}\right]
$$




$$
\begin{array}{ll}
\left(h_{i}, h_{k(i, j)}\right) & \frac{f_{h_{i}}}{f_{h_{i}}+f_{h_{j}}} \\
\left(h_{j}, h_{k(i, j)}\right) & \frac{f_{h_{j}}}{f_{h_{i}}+f_{h_{j}}}
\end{array}
$$

Essa distribuição de probabilidade a posteriori nos fornece o seguinte corolário.

Corolário 4.3.7 Sob as condiçôes da proposição 4.3.7, a razão de verossimilhanças $R V[D]$ e a probabilidade condicional $V_{0}[D]$, do demandante ter recebido do demandado $o(s)$ alelo(s) de interesse após termos observado D, são dadas pelos seguintes resultados.

$$
\begin{array}{rll}
\multicolumn{1}{c}{I} & \multicolumn{1}{c}{V_{0}[D]} & \multicolumn{1}{c}{R V[D]} \\
h_{r} & \frac{f_{h_{r}}}{2\left(f_{h_{i}}+f_{h_{j}}\right)} & 2\left(f_{h_{i}}+f_{h_{j}}\right), r=i, j \\
h_{k(i, j)} & 1 / 2 & 2 f_{h_{k(i, j)}} \\
h_{k(i, j)} e h_{r} & \frac{f_{h_{r}}+f_{h_{i}}+f_{h_{j}}}{2\left\{f_{h_{i}}+f_{h_{j}}\right\}} & \frac{2\left(f_{h_{i}}+f_{h_{j}}\right)\left(f_{h_{r}}+f_{h_{k(i, j)}}\right)}{f_{h_{r}}+f_{h_{i}}+f_{h_{j}}}, r=i, j . \\
h_{i} e h_{j} & 1 / 2 & 2\left(f_{h_{i}}+f_{h_{j}}\right) \\
h_{k(i, j)} \text { e } F_{1} & 1 / 2 & 2\left(f_{h_{k(i, j)}}+f_{F_{1}}\right) \\
h_{r} \text { e } F_{1} & \frac{f_{h_{r}}}{2\left\{f_{h_{i}}+f_{h_{j}}\right\}} & \frac{2\left(f_{h_{i}}+f_{h_{j}}\right)\left(f_{h_{r}}+f_{F_{1}}\right)}{f_{h_{r}}}, r=i, j .
\end{array}
$$

\section{Caso 4.4.1}

Sejam $F_{1}$ e $h_{i}, i=1, \cdots, 4$, cinco alelos diferentes. Suponhamos que, ao observarmos $n+m$ filhos do demandado, independentemente, encontramos em $n$ deles o genótipo $\left(h_{1}, h_{2}\right)$ e nos outros $m$ filhos o genótipo $\left(h_{3}, h_{4}\right)$ - ou seja,

$$
D_{\mathbf{u}}=\left\{\left(h_{1}, h_{2}\right)_{n},\left(h_{3}, h_{4}\right)_{m}\right\} \text {. }
$$


Consideremos a função $\gamma(\cdot)$ definida da seguinte forma

$$
\begin{aligned}
\gamma:\{3,4\} & \longrightarrow\{3,4\} \\
i & \longmapsto \gamma(i)=\left\{\begin{array}{l}
4 \text { se } i=3 \\
3 \text { se } i=4
\end{array}\right.
\end{aligned}
$$

Suponhamos que o genótipo observado na esposa do demandado é $m_{X}=\left(h_{i}, h_{j}\right)$, onde $i \in\{1,2\}$ e $j \in\{3,4\}$. Neste caso, o genótipo do demandado é $\left(h_{\sigma(i)}, h_{\gamma(j)}\right)$ e portanto, a distribuição de probabilidade a posteriori $P\left[\cdot \mid D_{\mathbf{u}, m_{X}}\right]$ para o genótipo do demandado é

$$
P\left[g_{k} \mid D_{\mathbf{u}, m_{X}}\right]= \begin{cases}1 & \text { se } g_{k}=\left(h_{\sigma(i)}, h_{\gamma(j)}\right) \\ 0 & \text { caso contrário }\end{cases}
$$

A razão de verossimilhança $R V[D]$ e a probabilidade condicional $V_{0}[D]$, que é obtida da expressão 4.23 , estão dadas na seguinte tabela.

Tabela 4.5 Probabilidade condicional $V_{0}[D]$ e razão de verossimilhanças $R V[D]$ - Caso 3.4.1

$$
\begin{array}{rll}
I & V_{0}[D] & \multicolumn{1}{l}{R V[D]} \\
h_{k} & 1 / 2 & 2 f_{h_{k}}, k=\sigma(i), \gamma(j) . \\
h_{l} \text { e } h_{k} & 1 / 2 & 2\left(f_{h_{l}}+f_{h_{k}}\right), l=i, j, k=\sigma(i), \gamma(j) . \\
h_{\sigma(i)} \text { e } h_{\gamma(j)} & 1 / 2 & 2\left(f_{h_{\sigma(i)}}+f_{h_{\gamma(j)}}\right) \\
h_{k} \text { e } F_{1} & 1 / 2 & 2\left(f_{h_{k}}+f_{F_{1}}\right), k=\sigma(i), \gamma(j) .
\end{array}
$$

\section{Caso 4.4.2}

Consideremos, como no caso 4.4.1, os cinco diferentes alelos $F_{1}$ e $h_{i}, i=1, \cdots, 4$. Suponhamos que, ao observarmos $s$ filhos do demandado, independentemente, ocorra uma das seguintes situações:

$$
\begin{aligned}
& D_{\mathbf{u}}=\left\{\left(h_{1}, h_{2}\right)_{n},\left(h_{2}, h_{4}\right)_{m},\left(h_{3}, h_{4}\right)_{r}\right\}, \text { se } s=n+m+r, \text { ou } \\
& D_{\mathbf{u}}=\left\{\left(h_{1}, h_{2}\right)_{n},\left(h_{1}, h_{3}\right)_{m},\left(h_{3}, h_{4}\right)_{r}\right\}, \quad \text { com } s=n+m+r, \text { ou } \\
& D_{\mathbf{u}}=\left\{\left(h_{1}, h_{2}\right)_{n},\left(h_{2}, h_{4}\right)_{m},\left(h_{1}, h_{3}\right)_{r},\left(h_{3}, h_{4}\right)_{t}\right\}, \text { onde } s=n+m+r=t(4.2
\end{aligned}
$$


Suponhamos que o genótipo observado na esposa do demandado é $m_{X}=\left(h_{i}, h_{j}\right)$, onde $i$ pertence a $\{1,2\}, j$ pertence a $\{3,4\}$ e $i+j$ é um número impar.

Neste caso particular, em qualquer uma das situações apresentadas acima, temos que o genótipo do demandado é $\left(h_{\sigma(i)}, h_{\gamma(j)}\right)$ e, portanto, a distribuição de probabilidade $a$ posteriori $P\left[\cdot \mid D_{\mathbf{u}, m_{X}}\right]$ para o genótipo do demandado é

$$
P\left[g_{k} \mid D_{\mathbf{u}, m_{X}}\right]= \begin{cases}1 & \text { se } g_{k}=\left(h_{\sigma(i)}, h_{\gamma(j)}\right) \\ 0 & \text { caso contrário, }\end{cases}
$$

enquanto que a probabilidade condicional $V_{0}[D]$ e a razão $R V[D]$ coincidem exatamente com os resultados apresentados anteriormente na tabela 4.5 sob a condição $i+j$ (ou, equivalentemente $\sigma(i)+\gamma(j))$ é um número impar.

No capítulo 5, apresentaremos, a análise necessária para determinarmos a probabilidade a posteriori de paternidade quando os parentes observados do demandado são alguns de seus filhos, mas no caso que consideraremos no próximo capítulo, não estará disponível a informação genotípica da mãe destes filhos do demandado. 


\section{Capítulo 5}

\section{Análise para filhos}

\subsection{Introdução}

Neste capitulo, primeiramente apresentamos, em detalhes, a metodologia proposta para determinar a distribuição de probabilidade a posteriori para o genótipo do demandado, uma vez que foi observada uma determinada estrutura genotípica em alguns de seus filhos. Esta distribuição de probabilidade a posteriori é a base para determinar a probabilidade de paternidade após terem sido observados os genótipos dos filhos do demandado, da mãe do demandante e do próprio demandante - isto é, a probabilidade a posteriori de paternidade - cujo método de cálculo foi exibido na seção 1.5.

Na seção 5.3 utilizamos a metodologia desenvolvida na seção anterior para calcular tanto a distribuição de probabilidade a posteriori para o genótipo do demandado quanto a razão entre as verossimilhanças do demandado não ser o pai do demandante e do demandado ser o pai do demandante, para cada um dos possíveis casos determinados pelos dados referentes aos genótipos dos filhos e da esposa do demandado. Estes dois elementos são fundamentais no cálculo da probabilidade a posteriori de paternidade, a qual é obtida substituindo os valores encontrados aqui para estes elementos na expressão 1.18 . 


\subsection{Descrição geral da metodologia}

Sejam $\mathcal{B}_{L},\left(G_{L}, \mathcal{A}_{G_{L}}\right), Z$ e $P[\cdot]$ como definidos na seção 3.2. Suponhamos que estejam disponíveis dados do demandante e de sua mãe, além de dados referentes a alguns filhos do demandado. Isto é, a árvore genealógica que estudaremos apresenta a seguinte estrutura:

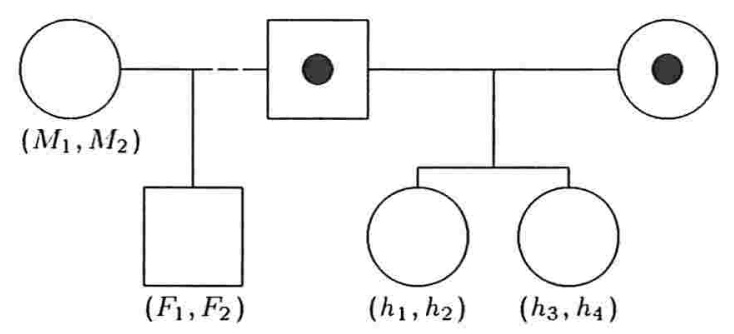

Árvore genealógica correspondente ao caso filhos do demandado

Sejam $M, F$ e $X$ variáveis aleatórias $\mathcal{A}_{G_{L}}$ mensuráveis que denotam respectivamente os genótipos da mãe do demandante, do demandante e do demandado, e consideremos $U$ como sendo o vetor aleatório formado pelos genótipos dos filhos do demandado - filhos da mesma mulher - constituído por componentes $\mathcal{A}_{G_{L}}$ mensuráveis.

Se os valores observados de $M, F$ e $U$ são respectivamente $\left(M_{1}, M_{2}\right),\left(F_{1}, F_{2}\right)$ e u, o conjunto dos dados $D$ correspondente a este experimento é formado por

$$
D=\left\{\left(M_{1}, M_{2}\right),\left(F_{1}, F_{2}\right), \mathbf{u}\right\} .
$$

Inicialmente, o interesse é determinar a distribuição de probabilidade para o genótipo do demandado, após observar os genótipos dos filhos do demandado e o(s) alelo(s) de interesse - isto é, queremos obter a distribuição de probabilidade a posteriori $P[\cdot \mid D]$ da variável aleatória $X$. Para determinarmos esta distribuição de probabilidade propomos o seguinte procedimento.

Primeiramente, consideremos a distribuição de probabilidade $P$, definida em 3.1 , que descreve a incerteza sobre o genótipo do demandado, antes de serem observados genótipos 
de alguns filhos do demandado e o(s) alelo(s) de interesse - isto é, $P$ é a distribuição de probabilidade a priori para o genótipo do demandado.

Suponhamos agora, que foram observados, independentemente, o genótipo da mãe do demandante, do demandante e os genótipos de $s$ filhos do demandado, e sejam $\left(M_{1}, M_{2}\right)$, $\left(F_{1}, F_{2}\right)$ e u os genótipos observados, respectivamente. Consideremos $D_{\mathbf{u}}$ como o conjunto formado por todos os elementos $(x, y)_{q}$ onde $(x, y)$ é o genótipo observado em um dos filhos do demandado e $q$ representa o número de vezes que este genótipo foi observado nos $s$ filhos - isto é, $q$ representa o número de vezes que o genótipo $(x, y)$ ocorre no vetor u. Na verdade $D_{\mathbf{u}}$ é uma outra representação do vetor u. Por exemplo, se

$$
D_{\mathbf{u}}=\left\{\left(h_{1}, h_{2}\right)_{n},\left(h_{2}, h_{2}\right)_{m}\right\},
$$

entende-se que os genótipos $\left(h_{1}, h_{2}\right)$ e $\left(h_{2}, h_{2}\right)$ foram observados em $n$ e $m$ filhos do demandado, respectivamente, onde $n+m=s$ e $h_{1}, h_{2}$ pertencem a $\mathcal{B}_{L}$.

Para cada $i=1, \cdots, N$, calculamos a probabilidade condicional $v\left[D_{\mathbf{u}} \mid g_{i}\right]$ de que os genótipos de $s$ irmãos, filhos dos mesmos pais, estejam representados no conjunto $D_{\mathbf{u}}$ dado que o genótipo de um de seus pais é $g_{i}$. Esta probabilidade condicional será utilizada no cálculo da probabilidade a posteriori para o genótipo do demandado como podemos ver na expressão 5.4 e é definida pela seguinte expressão.

$$
v\left[D_{\mathbf{u}} \mid g_{i}\right]=\sum_{j=1}^{N} V\left[D_{\mathbf{u}} \mid\left(g_{i}, g_{j}\right)\right] P\left[g_{j}\right],
$$

onde $V\left[D_{\mathbf{u}} \mid\left(g_{i}, g_{j}\right)\right]$ é a probabilidade condicional de ocorrência do conjunto $D_{\mathbf{u}}$, supondo que os genótipos ali representados provêm do cruzamento entre os genótipos $g_{i}$ e $g_{j}$. (Veja tabela 3.1)

A forma como calculamos $v\left[D_{\mathbf{u}} \mid g_{i}\right]$ será ilustrada considerando $g_{i}=\left(h_{1}, h_{2}\right)$ e o conjunto $D_{\mathbf{u}}$ dado na expressão 5.1 , onde, sem perda de generalidade podemos supor que $h_{k}=b_{k}$ para $k=1,2$. Para este caso, as probabilidades condicionais $V\left[D_{\mathbf{u}} \mid\left(g_{i}, g_{j}\right)\right]$ são não nulas quando $g_{j}$ é $\left(h_{2}, h_{2}\right)$, ou $\left(h_{1}, h_{2}\right)$, ou $\left(h_{2}, h\right)$ com $h \neq h_{k}, k=1,2$. Logo,

$$
\begin{aligned}
v\left[D_{\mathbf{u}} \mid g_{i}\right]= & V\left[D_{\mathbf{u}} \mid\left(g_{i},\left(h_{2}, h_{2}\right)\right)\right] P\left[\left(h_{2}, h_{2}\right)\right]+V\left[D_{\mathbf{u}} \mid\left(g_{i},\left(h_{1}, h_{2}\right)\right)\right] P\left[\left(h_{1}, h_{2}\right)\right] \\
& +\sum_{k \neq 1,2} V\left[D_{\mathbf{u}} \mid\left(g_{i},\left(h_{2}, h_{k}\right)\right)\right] P\left[\left(h_{2}, h_{k}\right)\right] \\
= & \frac{1}{2^{n}} \frac{1}{2^{m}} f_{h_{2}}^{2}+\frac{1}{2^{n}} \frac{1}{2^{2 m}} 2 f_{h_{1}} f_{h_{2}}+\frac{1}{2^{2 n}} \frac{1}{2^{2 m}} 2 f_{h_{2}}\left(1-\sum_{k=1}^{2} f_{h_{k}}\right)
\end{aligned}
$$




$$
=\frac{f_{h_{2}}}{2^{2 n+2 m-1}}\left\{H\left[n+1, f_{h_{1}}\right]+\left(2^{2 n+2 m-1}-1\right) f_{h_{2}}\right\}
$$

O próximo passo é a atualização da distribuição de probabilidade a priori $P$. Para isto, usamos a informação obtida da observação dos filhos do demandado, a qual é traduzida no conjunto $D_{\mathbf{u}}$ e utilizamos o Teorema de Bayes como mecanismo de atualização de probabilidade.

Seja

$$
\delta=\sum_{i=1}^{N} v\left[D_{\mathbf{u}} \mid g_{i}\right] P\left[g_{i}\right]
$$

Das expressões 3.1 e 5.3 obtemos que a distribuição de probabilidade a posteriori $P\left[\cdot \mid D_{\mathbf{u}}\right]$ para o genótipo do demandado - uma vez que foram observados $s$ filhos do demandado cujos genótipos estejam descritos no conjunto $D_{\mathbf{u}}$ - é dada pela expressão

$$
\begin{aligned}
P\left[g_{k} \mid D_{\mathbf{u}}\right] & =\frac{v\left[D_{\mathbf{u}} \mid g_{k}\right] \times P\left[g_{k}\right]}{\delta} \\
& =\frac{v\left[D_{\mathbf{u}} \mid g_{k}\right] \times P\left[g_{k}\right]}{\sum_{j=1}^{N} v\left[D_{\mathbf{u}} \mid g_{j}\right] \times P\left[g_{j}\right]}, \quad k=1, \cdots, N .
\end{aligned}
$$

Em resumo, considerando a variável aleatória $X, \mathcal{A}_{G_{L}}$ mensurável, que denota o genótipo do demandado, $P$ a medida de probabilidade definida sobre o espaço $\left(G_{L}, \mathcal{A}_{G_{L}}\right)$ definida na expressão 3.1 , a qual descreve a incerteza a priori sobre $X$ e u o vetor dos genótipos observados nos filhos do demandado, representado no conjunto $D_{\mathbf{u}}$, provamos o seguinte resultado.

Teorema 5.2.1 Se u é obtido ao observarmos independentemente s filhos do demandado, então a distribuição de probabilidade a posteriori $P\left[\cdot \mid D_{\mathbf{u}}\right]$ para $X$ é dada pela expressão

$$
P\left[g_{k} \mid D_{\mathbf{u}}\right]=\frac{v\left[D_{\mathbf{u}} \mid g_{k}\right] P\left[g_{k}\right]}{\sum_{j=1}^{N} v\left[D_{\mathbf{u}} \mid g_{j}\right] P\left[g_{j}\right]}, \quad k=1, \cdots, N,
$$

onde $v\left[D_{\mathbf{u}} \mid \cdot\right]$ e $P[\cdot]$ são dadas respectivamente pelas expressões 5.2 e 3.1 . 
Para o caso que estamos aqui considerando, a probabilidade condicional $V_{0}[D]$ é apresentada no seguinte resultado.

Corolário 5.2.1 A probabilidade condicional de que o demandante possua o genótipo $\left(F_{1}, F_{2}\right)$ dado que sua mãe tem o genótipo $\left(M_{1}, M_{2}\right)$, os filhos do demandado apresentam o(s) genótipo(s) u e supondo que o demandado é o pai do demandante é dada por

$$
V_{0}[D]=\gamma_{\left(M_{1}, M_{2}\right)} \sum_{b_{i} \in I} \sum_{k=1}^{N} \delta_{b_{i} g_{k}} \frac{v\left[D_{\mathbf{u}} \mid g_{k}\right] \times P\left[g_{k}\right]}{\sum_{j=1}^{N} v\left[D_{\mathbf{u}} \mid g_{j}\right] \times P\left[g_{j}\right]},
$$

onde $\gamma_{\left(M_{1}, M_{2}\right)}, \delta_{b_{1} g_{k}}, v\left[D_{\mathbf{u}} \mid \cdot\right]$ e $P[\cdot]$ são dadas, respectivamente, pelas expressões 1.12, 1.15, 5.2 e 3.1.

Prova: $\mathrm{O}$ resultado se segue ao substituirmos na expressão $1.14 \mathrm{o}$ valor da probabilidade a posteriori $P\left[\cdot \mid D_{\mathbf{u}}\right]$ - dado pela expressão 5.4 .

Finalmente, utilizando as expressões 1.8 ou 1.9 determinarmos a probabilidade a posteriori de paternidade $\pi[\theta=0 \mid D]$ estabelecida após ser observada a informação fornecida pelos dados $D$.

$\mathrm{Na}$ próxima seção, aplicaremos a metodologia aqui introduzida considerando todos os diferentes conjuntos $D_{\mathrm{u}}$ que trazem informação sobre os genótipos observados na esposa e nos filhos do demandado. Para facilitar a apresentação dos resultados correspondentes aos conjuntos $D_{\mathbf{u}}$ que determinam diferentes distribuições de probabilidade a posteriori para o genótipo do demandado, estes serão referenciados ao longo deste capítulo pelo código caso c.i.j a ser dado na primeira coluna da tabela 5.1, onde $\mathrm{c}$ indica o número do capítulo, $\mathbf{i}$ o número de alelos diferentes que aparecem em $D_{\mathbf{u}}$ e $\mathbf{j}$ enumera as diferentes associações com igual número de alelos. 
Tabela 5.1 Dados relevantes ao observarmos filhos do demandado.

caso

genótipos observados

5.1 .1

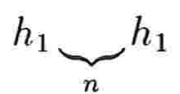

5.2 .1
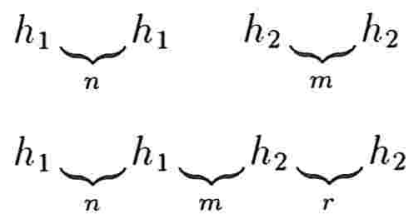

5.2 .2

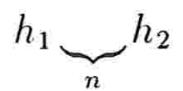

5.2 .3

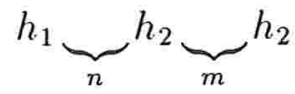

5.3 .1
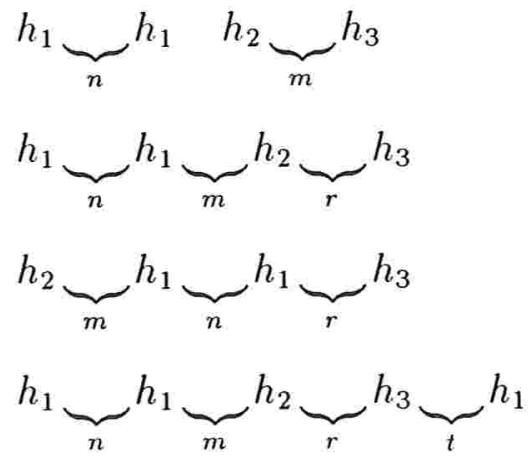

5.3 .2

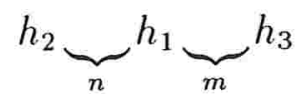

5.3 .3

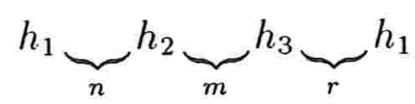

5.4 .1

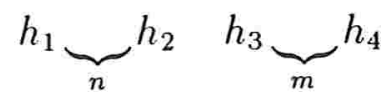

5.4 .2

$$
\begin{aligned}
& h_{1} \underbrace{}_{n} h_{2} \underbrace{h_{4}}_{m} \underbrace{h_{3}}_{r} \\
& h_{2} \underbrace{}_{n} h_{1} \underbrace{}_{m} h_{3} \underbrace{}_{r} h_{4} \\
& h_{1} \underbrace{}_{n} h_{2} \underbrace{}_{m} h_{4} \underbrace{}_{r} h_{3} \underbrace{h_{1}}_{t}
\end{aligned}
$$




\subsection{Análise dos casos}

Nesta seção, aplicamos a metodologia desenvolvida na seção 5.2 para determinar a distribuição de probabilidade a posteriori para o genótipo do demandado, considerando cada um dos casos relacionados na tabela 5.1, exibida no final da seção anterior.

Além disso, pelos argumentos fornecidos no capítulo 1, exibiremos apenas a probabilidade condicional $V_{0}[D]$ - ou $R V[D]$ quando possível - necessária ao cálculo da probabilidade a posteriori de paternidade. Quanto à outra probabilidade condicional $V_{1}[D]$, também necessária ao cálculo desta probabilidade a posteriori, será omitida por ser diretamente obtida da proposição 1.5.1.

Ao longo desta seção não tornaremos explícitos aqueles genótipos cujas probabilidades a posteriori sejam nulas.

\section{Caso 5.1.1}

Sejam $h_{1}, F_{1}$ e $F_{2}$ três alelos diferentes. Suponhamos que, ao considerarmos $n$ filhos do demandado, independentemente, observamos em cada um deles o genótipo $\left(h_{1}, h_{1}\right)$ - isto é, $D_{\mathbf{u}}=\left\{\left(h_{1}, h_{1}\right)_{n}\right\}$.

Consideremos todos os genótipos da forma $\left(h_{1}, \alpha\right)$, ou equivalentemente $\left(F_{i}, \alpha\right)$ para $i=1,2$, onde $\alpha$ é um alelo qualquer no loco $L$.

Sob essas considerações, as probabilidades $P[\cdot]$ e $v\left[D_{\mathbf{u}} \mid \cdot\right]$ podem ser obtidas a seguir

$$
\begin{array}{ccl}
\text { genótipo }(\cdot) & P[\cdot] & v\left[D_{\mathbf{u}} \mid \cdot\right] \\
\left(h_{1}, h_{1}\right) & f_{h_{1}}^{2} & \frac{f_{h_{1}} H\left[n, f_{h_{1}}\right]}{2^{n-1}} \\
\left.\left(h_{1}, F_{i}\right)\right) & 2 ; f_{h_{1}} f_{F_{i}} & \frac{f_{h_{1}} H\left[n, f_{h_{1}}\right]}{2^{2 n-1}}, i=1,2 \\
\left.\left(h_{1},(x x x)^{c}\right)\right) & 2 f_{h_{1}}\left(1-f_{h_{1}}-\sum_{j=1}^{2} f_{F_{3}}\right) & \frac{f_{h_{1}} H\left[n, f_{h_{1}}\right]}{2^{2 n-1}}
\end{array}
$$

Conseqüentemente, para obtermos a distribuição $P\left[\cdot \mid D_{\mathbf{u}}\right]$ é necessário apenas calcular o 
valor de $\delta$ definido na expressão 5.3. Para o caso que consideramos aqui, $\delta$ torna-se

$$
\delta=\frac{H^{2}\left[n, f_{h_{1}}\right]}{2^{2(n-1)}}
$$

e do teorema 5.2.1 obtemos o seguinte resultado.

Proposição 5.3.1 A distribuição de probabilidade a posteriori para o genótipo do demandado $P\left[\cdot \mid D_{\mathbf{u}}\right]$, uma vez que em $n$ de seus filhos foi observado o genótipo $\left(h_{1}, h_{1}\right)$ é a seguinte.

$$
\begin{aligned}
\text { genótipo }(\cdot) & P\left[\cdot \mid D_{\mathbf{u}}\right] \\
\left(h_{1}, h_{1}\right) & \frac{2^{n-1} f_{h_{1}}}{H\left[n, f_{h_{1}}\right]} \\
\left(h_{1}, F_{i}\right) & \frac{f_{F_{i}}}{H\left[n, f_{h_{1}}\right]}, \quad i=1,2 \\
\left(h_{1},(x x x)^{c}\right) & \frac{1-f_{h_{1}}-\sum_{i=1}^{2} f_{F_{i}}}{H\left[n, f_{h_{1}}\right]}
\end{aligned}
$$

Da distribuição de probabilidade a posteriori para o genótipo do demandado - dada neste caso pela expressão 5.7 - obtemos a probabilidade condicional do demandante ter recebido do demandado o(s) alelo(s) de interesse após termos observado $D$, e imediatamente, usando a proposição 1.5.1, logramos a razào $R V[D]$ para ca.da conjunto de alelos de interesse $I$ como podemos ver no seguinte corolário.

Corolário 5.3.1 Sob as condiçôes da proposiçâo 5.3.1, temos que a razão de verossimilhanças $R V[D]$ e a probabilidade condicional $V_{0}[D]$, do demandante ter recebido do demandado o(s) alelo(s) de interesse após termos observado $D$, estão dadas a seguir

$$
\begin{array}{ccc}
I & V_{0}[D] & R V[D] \\
h_{1} & \frac{H\left[n+1, f_{h_{1}}\right]}{2 H\left[n, f_{h_{1}}\right]} & \frac{2 f_{h_{1}} H\left[n, f_{h_{1}}\right]}{H\left[n+1, f_{h_{1}}\right]} \\
F_{i} & \frac{f_{F_{i}}}{2 H\left[n, f_{h_{1}}\right]} & 2 H\left[n, f_{h_{1}}\right], \quad i=1,2
\end{array}
$$




$$
\begin{array}{lll}
h_{1} \text { e } F_{i} & \frac{H\left[n+1, f_{h_{1}}\right]+f_{F_{i}}}{2 H\left[n, f_{h_{1}}\right]} & \frac{2\left(f_{h_{1}}+f_{F_{i}}\right) H\left[n, f_{h_{1}}\right]}{H\left[n+1, f_{h_{1}}\right]+f_{F_{i}}}, ; i=1,2 \\
F_{1} \text { e } F_{2} & \frac{\sum_{i=1}^{2} f_{F_{i}}}{2 H\left[n, f_{h_{1}}\right]} & 2 H\left[n, f_{h_{1}}\right]
\end{array}
$$

\section{Caso 5.2.1}

Sejam $h_{1}, h_{2}$ e $F_{1}$ três alelos diferentes. Suponhamos que, ao observarmos independentemente $s$ filhos do demandado, ocorra uma das seguintes situações:

$$
\begin{aligned}
& D_{\mathbf{u}}=\left\{\left(h_{1}, h_{1}\right)_{n},\left(h_{2}, h_{2}\right)_{m}\right\}, \text { onde } s=n+m \text {, ou } \\
& D_{\mathbf{u}}=\left\{\left(h_{1}, h_{1}\right)_{n},\left(h_{1}, h_{2}\right)_{m},\left(h_{2}, h_{2}\right)_{r}\right\}, \quad \operatorname{com} s=n+m+r .
\end{aligned}
$$

Neste caso particular, em qualquer uma das situações acima consideradas, temos que o genótipo do demandado deve ser $\left(h_{1}, h_{2}\right)$ e, portanto, a distribuição de probabilidade $a$ posteriori $P\left[\cdot \mid D_{\mathbf{u}}\right]$ para o genótipo do demandado, é a distribuição

$$
P\left[g_{i} \mid D_{\mathbf{u}}\right]= \begin{cases}1 & \text { se } g_{i}=\left(h_{1}, h_{2}\right) \\ 0 & \text { caso contrário, }\end{cases}
$$

A razão de verossimilhança $R V[D]$ e a probabilidade condicional $V_{0}[D]$, que é obtida da expressão 5.10, estão dadas na seguinte tabela.

Tabela 5.2 Probabilidade condicional $V_{0}[D]$ e razão de verossimilhanças $R V[D]$ - Caso 5.2.1

$$
\begin{array}{ccl}
I & V_{0}[D] & \multicolumn{1}{c}{R V[D]} \\
h_{i} & 1 / 2 & 2 f_{h_{i}}, \quad i=1,2 \\
h_{1} \text { e } h_{2} & 1 & f_{h_{1}}+f_{h_{2}} \\
h_{i} \text { e } F_{1} & 1 / 2 & 2\left(f_{h_{i}}+f_{F_{1}}\right) i=1,2
\end{array}
$$

\section{Caso 5.2.2}


Sejam $h_{i}$ e $F_{i}$ para $i=1,2$ quatro alelos diferentes. Suponhamos que, ao considerarmos $n$ filhos do demandado, independentemente, observamos em cada um deles o genótipo $\left(h_{1}, h_{2}\right)$ - isto é, $D_{\mathbf{u}}=\left\{\left(h_{1}, h_{2}\right)_{n}\right\}$.

Para este caso, as probabilidades $P[\cdot]$ e $v\left[D_{\mathbf{u}} \mid \cdot\right]$ podem ser obtidas a seguir

$$
\begin{array}{ccl}
\text { genótipo }(\cdot) & P[\cdot] & v\left[D_{\mathbf{u}} \mid \cdot\right] \\
\left(h_{i}, h_{i}\right) & f_{h_{i}}^{2} & \frac{f_{h_{\sigma(i)}} H\left[n, f_{h_{\sigma(i)}}\right]}{2^{n-1}}, i=1,2 \\
\left(h_{1}, h_{2}\right) & 2 f_{h_{1}} f_{h_{2}} & \frac{u\left[n, f_{h_{1}}, f_{h_{2}}\right]}{2^{2 n-1}} \\
\left(h_{i}, F_{j}\right) & 2 f_{h_{i}} f_{F_{j}} & \frac{f_{h_{\sigma(i)}} H\left[n, f_{h_{\sigma(i)}}\right]}{2^{2 n-1}}, i, j=1,2 \\
\left(h_{i},(x x x x)^{c}\right) & 2 f_{h_{i}}\left(1-\sum_{k=1}^{2}\left(f_{h_{k}}+f_{F_{k}}\right)\right) & \frac{f_{h_{\sigma(i)}} H\left[n, f_{h_{\sigma(i)}}\right]}{2^{2 n-1}}, i=1,2,
\end{array}
$$

onde $u\left[n, f_{h_{1}}, f_{h_{2}}\right]=\left(f_{h_{1}}+f_{h_{2}}\right)\left\{H\left[n, f_{h_{1}}\right]+\left(2^{n-1}-1\right) f_{h_{2}}\right\}$.

Considerando a função

$$
w=w\left[n, f_{h_{1}}, f_{h_{2}}\right]=1+\left(2^{n-1}-1\right)\left(f_{h_{1}}+f_{h_{2}}+2^{n-1} f_{h_{1}} f_{h_{2}}\right),
$$

damos a distribuição de probabilidade a posteriori para o genótipo do demandado $P\left[\cdot \mid D_{\mathbf{u}}\right]$ no seguinte resultado.

Proposição 5.3.2 A distribuição de probabilidade a posteriori para o genótipo do demandado $P\left[\cdot \mid D_{\mathbf{u}}\right]$, uma vez que em $n$ de seus filhos foi observado o genótipo $\left(h_{1}, h_{2}\right)$ é a seguinte.

$$
\begin{aligned}
& \text { genótipo }(\cdot) \quad P\left[\cdot \mid D_{\mathbf{u}}\right] \\
& \left(h_{i}, h_{i}\right) \quad 2^{n-1} f_{h_{i}} H\left[n, f_{h_{\sigma(i)}}\right] / 2 w, \quad i=1,2 \\
& \left(h_{1}, h_{2}\right) \quad\left(f_{h_{1}}+f_{h_{2}}\right)\left\{H\left[n, f_{h_{1}}\right]+\left(2^{n-1}-1\right) f_{h_{2}}\right\} / 2 w \\
& \left(h_{i}, F_{j}\right) \quad f_{F_{j}} H\left[n, f_{h_{\sigma(i)}}\right] / 2 w, i, j=1,2 \\
& \left(h_{i},(x x x x)^{c}\right) \quad H\left[n, f_{h_{\sigma(i)}}\right]\left(1-\sum_{j=1}^{2}\left(f_{h_{j}}+f_{F_{j}}\right)\right) / 2 w, \quad i=1,2 \text {, }
\end{aligned}
$$


onde w é a função definida na expressão 5.11 .

Do resultado anterior, obtemos o seguinte corolário.

Corolário 5.3.2 Sob as condiçôes da proposiçâo 5.3.2, temos que a razão de verossimilhanças $R V[D]$ e a probabilidade condicional $V_{0}[D]$, do demandante ter recebido do demandado o(s) alelo(s) de interesse após termos observado D, estão dadas a seguir

$$
\begin{aligned}
& \begin{array}{lll}
I & V_{0}[D] & R V[D]
\end{array} \\
& h_{i} \quad \frac{v_{i}\left[n, f_{h_{1}}, f_{h_{2}}\right]}{4 w\left[n, f_{h_{1}}, f_{h_{2}}\right]} \quad \frac{4 f_{h_{1}} w\left[n, f_{h_{1}}, f_{h_{2}}\right]}{v_{i}\left[n, f_{h_{1}}, f_{h_{2}}\right]}, i=1,2 \\
& F_{j} \quad \frac{f_{F_{j}} \sum_{i=1}^{2} H\left[n, f_{h_{i}}\right]}{4 w\left[n, f_{h_{1}}, f_{h_{2}}\right]} \quad \frac{4 w\left[n, f_{h_{1}}, f_{h_{2}}\right]}{\sum_{i=1}^{2} H\left[n, f_{h_{i}}\right]}, j=1,2 \\
& h_{1} e h_{2} \quad \frac{v_{3}\left[n, f_{h_{1}}, f_{h_{2}}\right]}{4 w\left[n, f_{h_{1}}, f_{h_{2}}\right]} \quad \frac{4\left(f_{h_{1}}+f_{h_{2}}\right) w\left[n, f_{h_{1}}, f_{h_{2}}\right]}{v_{3}\left[n, f_{h_{1}}, f_{h_{2}}\right]} \\
& h_{i} \text { e } F_{j} \quad \frac{v_{i j}\left[n, f_{h_{i}}, f_{h_{\sigma(i)}}, f_{F_{j}}\right]}{4 w\left[n, f_{h_{1}}, f_{h_{2}}\right]} \quad \frac{4\left(f_{h_{i}}+f_{F_{j}}\right) w\left[n, f_{h_{1}}, f_{h_{2}}\right]}{v_{i j}\left[n, f_{h_{i}}, f_{h_{\sigma(i)}}, f_{F_{j}}\right]}, i, j=1,2 \\
& F_{1} \text { e } F_{2} \quad \frac{\sum_{i=1}^{2} f_{F_{i}} \sum_{i=1}^{2} H\left[n, f_{h_{i}}\right]}{4 w\left[n, f_{h_{1}}, f_{h_{2}}\right]} \quad \frac{4 w\left[n, f_{h_{1}}, f_{h_{2}}\right]}{\sum_{i=1}^{2} H\left[n, f_{h_{i}}\right]}
\end{aligned}
$$

onde $v_{i}=v_{i}\left[n, f_{h_{1}}, f_{h_{2}}\right], i=1,2,3$, e $v_{i j}=v_{i j}\left[n, f_{h_{1}}, f_{h_{2}}, f_{F_{j}}\right], i, j=1,2$, são dadas por

$$
\begin{aligned}
v_{i}= & \left(1+f_{h_{i}}\right) H\left[n, f_{h_{i}}\right]+2^{n-1} f_{h_{i}} H\left[n+1, f_{h_{\sigma(i)}}\right]+\left(2^{n-1}-1-f_{h_{i}}\right) f_{h_{\sigma(i)}}, i=1,2 \\
v_{3}= & 2+\left(3 \times 2^{n-1}-1\right)\left(f_{h_{1}}+f_{h_{2}}\right)+\left(2^{n-1}-1\right)\left(f_{h_{1}}^{2}+f_{h_{2}}^{2}\right)+\left(2^{2 n}-2^{n}-2\right) f_{h_{1}} f_{h_{2}} \\
v_{i j}= & \left(2^{n-1}-1-f_{h_{i}}\right) f_{h_{\sigma(i)}}+f_{F_{j}} H\left[n, f_{h_{\sigma(i)}}\right]+2^{n-1} f_{h_{i}} H\left[n+1, f_{h_{\sigma(i)}}\right] \\
& +\left(1+f_{h_{i}}+f_{F_{j}}\right) H\left[n, f_{h_{i}}\right], \quad i, j=1,2 .
\end{aligned}
$$

\section{Caso 5.2.3}


Consideremos quatro alelos diferentes $h_{i}$ e $F_{i}, i=1,2$. Suponhamos que foram observados $n+m$ filhos do demandado, independentemente, encontrando em $n$ deles o genótipo $\left(h_{1}, h_{2}\right)$ e nos outros $m$ filhos o genótipo $\left(h_{2}, h_{2}\right)$ - isto é,

$$
D_{\mathbf{u}}=\left\{\left(h_{1}, h_{2}\right)_{n},\left(h_{2}, h_{2}\right)_{m}\right\} .
$$

As probabilidades $P[\cdot]$ e $v\left[D_{\mathbf{u}} \mid \cdot\right]$ podem ser obtidas a seguir

$$
\begin{array}{ccc}
\text { genótipo }(\cdot) & P[\cdot] & v\left[D_{\mathbf{u}} \mid \cdot\right] \\
\left(h_{2}, h_{2}\right) & f_{h_{2}}^{2} & \frac{f_{h_{1}} f_{h_{2}}}{2^{n+m-1}} \\
\left(h_{1}, h_{2}\right) & 2 f_{h_{1}} f_{h_{2}} & \frac{f_{h_{2}} u\left[n, m, f_{h_{1}}, f_{h_{2}}\right]}{2^{2 n+2 m-1}} \\
\left(h_{2}, F_{j}\right) & 2 f_{h_{2}} f_{F_{j}} & \frac{f_{h_{1}} f_{h_{2}}}{2^{2 n+2 m-1}}, j=1,2 \\
\left(h_{2},(x x x x)^{c}\right) & 2 f_{h_{2}}\left(1-\sum_{k=1}^{2}\left(f_{h_{k}}+f_{F_{k}}\right)\right) & \frac{f_{h_{1}} f_{h_{2}}}{2^{2 n+2 m-1}},
\end{array}
$$

onde a função $u=u\left[n, m, f_{h_{1}}, f_{h_{2}}\right]$ é definida pela expressão

$$
u\left[n, m, f_{h_{1}}, f_{h_{2}}\right]=H\left[n+1, f_{h_{1}}\right]+\left(2^{n+m-1}-1\right) f_{h_{2}} .
$$

Considerando a funçâo

$$
w=w\left[n, m, f_{h_{1}}, f_{h_{2}}\right]=H\left[n, f_{h_{1}}\right]+\left(2^{n+m-1}-1\right) f_{h_{2}},
$$

fornecemos a distribuição de probabilidade a posteriori para o genótipo do demandado $P\left[\cdot \mid D_{\mathbf{u}}\right]$ no seguinte resultado.

Proposição 5.3.3 A distribuição de probabilidade a posteriori para o genótipo do demandado $P\left[\cdot \mid D_{\mathbf{u}}\right]$, uma vez que foi observado em $n$ de seus filhos o genótipo $\left(h_{1}, h_{2}\right)$ e nos outros $m$ filhos o genótipo $\left(h_{2}, h_{2}\right)$ é a seguinte.

$$
\begin{array}{rc}
\text { genótipo }(\cdot) & P\left[\cdot \mid D_{\mathbf{u}}\right] \\
\left(h_{2}, h_{2}\right) & 2^{n+m-1} f_{h_{2}} / 2 w
\end{array}
$$




$$
\begin{aligned}
\left(h_{1}, h_{2}\right) & u\left[n, m, f_{h_{1}}, f_{h_{2}}\right] / 2 w \\
\left(h_{2}, F_{j}\right) & f_{F_{j}} / 2 w, j=1,2 \\
\left(h_{2},(x x x x)^{c}\right) & \left(1-\sum_{j=1}^{2}\left(f_{h_{j}}+f_{F_{j}}\right)\right) / 2 w
\end{aligned}
$$

onde $u$ e $w$ são as funçôes definidas pelas expressôes 5.13 e 5.14, respectivamente.

Da expressão 5.15 calculamos a probabilidade condicional do demandante ter recebido do demandado o(s) alelo(s) de interesse, após termos observado $D$ e, imediatamente, usando a proposição 1.5 .1 , obtemos a razão $R V[D]$ para cada conjunto $I$, como podemos ver no seguinte corolário.

Corolário 5.3.3 Sob as condições da proposição 5.3.3, temos que a razâo de verossimilhanças $R V[D]$ e a probabilidade condicional $V_{0}[D]$, do demandante ter recebido do demandado o(s) alelo(s) de interesse após termos observado D, estão dadas a seguir

$$
\begin{array}{ccc}
\multicolumn{1}{c}{I} & \multicolumn{1}{c}{V_{0}[D]} & R V[D] \\
h_{1} & \frac{v_{1}\left[n, m, f_{h_{1}}, f_{h_{2}}\right]}{4 w\left[n, m, f_{h_{1}}, f_{h_{2}}\right]} & \frac{4 f_{h_{1}} w\left[n, m, f_{h_{1}}, f_{h_{2}}\right]}{v_{1}\left[n, m, f_{h_{1}}, f_{h_{2}}\right]} \\
h_{2} & \frac{v_{2}\left[n, m, f_{h_{1}}, f_{h_{2}}\right]}{2 w\left[n, m, f_{h_{1}}, f_{h_{2}}\right]} & \frac{2 f_{h_{2}} w\left[n, m, f_{h_{1}}, f_{h_{2}}\right]}{v_{2}\left[n, m, f_{h_{1}}, f_{h_{2}}\right]} \\
F_{i} & \frac{f_{F_{i}}}{4 w\left[n, m, f_{h_{1}}, f_{h_{2}}\right]} & 4 w\left[n, m, f_{h_{1}}, f_{h_{2}}\right], i=1,2 \\
h_{1} \text { e } h_{2} & \frac{v_{3}\left[n, m, f_{h_{1}}, f_{h_{2}}\right]}{4 w\left[n, m, f_{h_{1}}, f_{h_{2}}\right]} & \frac{4 \sum_{i=1}^{2} f_{h_{i}} w\left[n, m, f_{h_{1}}, f_{h_{2}}\right]}{v_{3}\left[n, m, f_{h_{1}}, f_{h_{2}}\right]} \\
h_{1} \text { e } F_{j} & \frac{v_{4 j}\left[n, m, f_{h_{1}}, f_{h_{2}}, f_{F_{j}}\right]}{4 w\left[n, m, f_{h_{1}}, f_{h_{2}}\right]} & \frac{4\left(f_{h_{1}}+f_{F_{j}}\right) w\left[n, m, f_{h_{1}}, f_{h_{2}}\right]}{v_{4 j}\left[n, m, f_{h_{1}}, f_{h_{2}}, f_{F_{j}}\right]}, j=1,2 \\
h_{2} \text { e } F_{j} & \frac{v_{5 j}\left[n, m, f_{h_{1}}, f_{h_{2}}, f_{F_{j}}\right]}{4 w\left[n, m, f_{h_{1}}, f_{h_{2}}\right]} & \frac{4\left(f_{h_{2}}+f_{F_{j}}\right) w\left[n, m, f_{h_{1}}, f_{h_{2}}\right]}{v_{5 j}\left[n, m, f_{h_{1}}, f_{h_{2}}, f_{F_{j}}\right]}, j=1,2 \\
F_{1} \text { e } F_{2} & \frac{\sum_{i=1}^{2} f_{F_{i}}}{4 w\left[n, m, f_{h_{1}}, f_{h_{2}}\right]} & 4 w\left[n, f_{h_{1}}, f_{h_{2}}\right],
\end{array}
$$


onde $v_{i}=v_{i}\left[n, m, f_{h_{1}}, f_{h_{2}}\right], \quad i=1,2,3, e v_{k j}=v_{k j}\left[n, m, f_{h_{1}}, f_{h_{2}}, f_{F_{j}}\right], \quad k=4,5$ e $j=1,2$, são dadas por

$$
\begin{aligned}
v_{1} & =H\left[n+1, f_{h_{1}}\right]+\left(2^{n+m-1}-1\right) f_{h_{2}} \\
v_{2} & =H\left[n, f_{h_{1}}\right]+\left(3 \times 2^{n+m-2}-1\right) f_{h_{2}} \\
v_{3} & =H\left[n+1, f_{h_{1}}\right]+2 H\left[n, f_{h_{1}}\right]+\left(2^{n+m+1}-3\right) f_{h_{2}} \\
v_{4 j} & =H\left[n+1, f_{h_{1}}\right]+\left(2^{n+m-1}-1\right) f_{h_{2}}+f_{F_{j}}, j=1,2 \\
v_{5 j} & =2 H\left[n, f_{h_{1}}\right]+2\left(3 \times 2^{n+m-2}-1\right) f_{h_{2}}+f_{F_{j}}, \quad j=1,2 .
\end{aligned}
$$

\section{Caso 5.3.1}

Sejam $F_{1}$ e $h_{i}, i=1,2,3$ quatro alelos diferentes. Suponhamos que, ao observarmos $s$ filhos do demandado, independentemente, ocorra uma das seguintes situações:

$$
\begin{aligned}
& D_{\mathbf{u}}=\left\{\left(h_{1}, h_{1}\right)_{n},\left(h_{2}, h_{3}\right)_{m}\right\}, \text { onde } s=n+m, \text { ou } \\
& D_{\mathbf{u}}=\left\{\left(h_{1}, h_{1}\right)_{n},\left(h_{1}, h_{2}\right)_{m},\left(h_{2}, h_{3}\right)_{r}\right\}, \text { com } s=n+m+r \text {, ou } \\
& D_{\mathbf{u}}=\left\{\left(h_{1}, h_{1}\right)_{n},\left(h_{1}, h_{2}\right)_{m},\left(h_{1}, h_{3}\right)_{r}\right\}, \text { onde } s=n+m+r, \text { ou } \\
& D_{\mathbf{u}}=\left\{\left(h_{1}, h_{1}\right)_{n},\left(h_{1}, h_{2}\right)_{m},\left(h_{2}, h_{3}\right)_{r},\left(h_{1}, h_{3}\right)_{t}\right\}, \text { se } s=n+m+r+t .
\end{aligned}
$$

Para cada uma das situações 5.16 - 5.19, a distribuição de probabilidade a posteriori para o genótipo do demandado $P\left[\cdot \mid D_{\mathbf{u}}\right]$ é dada no seguinte resultado.

Proposição 5.3.4 Sob as condições dadas acima, a distribuição de probabilidade a posteriori para o genótipo do demandado $P\left[\cdot \mid D_{\mathbf{u}}\right]$ é a seguinte.

$$
\begin{aligned}
\text { genótipo }(\cdot) & P\left[\cdot \mid D_{\mathbf{u}}\right] \\
\left(h_{1}, h_{2}\right) & 1 / 2 \\
\left(h_{1}, h_{3}\right) & 1 / 2
\end{aligned}
$$

A razão de verossimilhança $R V[D]$ e a probabilidade condicional $V_{0}[D]$, que é obtida da expressão 5.20, estão dadas na seguinte tabela. 
Tabela 5.3 Probabilidade condicional $V_{0}[D]$ e razão de verossimilhanças $R V[D]$ - Caso 5.3.1

\begin{tabular}{ccl}
$I$ & $V_{0}[D]$ & \multicolumn{1}{c}{$R V[D]$} \\
$h_{1}$ & $1 / 2$ & $2 f_{h_{1}}$ \\
$h_{j}$ & $1 / 4$ & $4 f_{h_{j}}, j=2,3$ \\
$h_{1}$ е $h_{j}$ & $3 / 4$ & $4\left(f_{h_{1}}+f_{h_{j}}\right) / 3, \quad j=2,3$ \\
$h_{2}$ е $h_{3}$ & $1 / 2$ & $2\left(f_{h_{2}}+f_{h_{3}}\right)$ \\
$h_{1}$ е $F_{1}$ & $1 / 2$ & $2\left(f_{h_{1}}+f_{F_{1}}\right)$ \\
$h_{j}$ е $F_{1}$ & $1 / 4$ & $4\left(f_{h_{j}}+f_{F_{1}}\right) j=2,3$
\end{tabular}

Caso 5.3.2

Sejam $h_{i}$ e $F_{j}$, para $i=1,2,3$ e $j=1,2$, cinco alelos diferentes. Suponhamos que, ao observarmos $n+m$ filhos do demandado, independentemente, encontramos em $n$ deles o genótipo $\left(h_{1}, h_{2}\right)$ e nos outros $m$ filhos o genótipo $\left(h_{1}, h_{3}\right)$ - isto é,

$$
D_{\mathbf{u}}=\left\{\left(h_{1}, h_{2}\right)_{n},\left(h_{1}, h_{3}\right)_{m}\right\} \text {. }
$$

Para essa situação, a distribuição de probabilidade a priori para o genótipo do demandado $P[\cdot]$ e a probabilidade condicional $v\left[D_{\mathbf{u}} \mid \cdot\right]$ podem ser obtidas a seguir.

$$
\begin{array}{ccc}
\text { genótipo }(\cdot) & P[\cdot] & V\left[D_{\mathbf{u}} \mid \cdot\right] \\
\left(h_{1}, h_{1}\right) & f_{h_{1}}^{2} & \frac{f_{h_{2}} f_{h_{3}}}{2^{n+m-1}} \\
\left(h_{1}, h_{j}\right) & 2 f_{h_{1}} f_{h_{3}} & \frac{\left(f_{h_{1}}+f_{h_{3}}\right) f_{h_{r}}}{2^{2 n+2 m-1}}, j=2,3 \text { e } r \neq 1, j \\
\left(h_{1}, F_{i}\right) & 2 f_{h_{1}} f_{F_{i}} & \frac{f_{h_{2}} f_{h_{3}}}{2^{2 n+2 m-1}}, i=1,2 \\
\left(h_{1},(x x x x x)^{c}\right) & 2 f_{h_{1}}\left(1-\sum_{k=1}^{3} f_{h_{k}}-\sum_{l=1}^{2} f_{F_{l}}\right) & \frac{f_{h_{2}} f_{h_{3}}}{2^{2 n+2 m-1}} \\
\left(h_{2}, h_{3}\right) & 2 f_{h_{2}} f_{h_{3}} & \frac{f_{h_{1}}\left\{1+\left(2^{n+m-1}-1\right) f_{h_{1}}\right\}}{2^{2 n+2 m-1}}
\end{array}
$$


Considerando $w=w\left[n, m, f_{h_{1}}\right]$ como a função definida na expressão abaixo

$$
w=1+2^{n+m-1} f_{h_{1}},
$$

estabelecemos:

Proposição 5.3.5 A distribuiçâo de probabilidade a posteriori para o genótipo do demandado $P\left[\cdot \mid D_{\mathbf{u}}\right]$, uma vez que observamos os genótipos $\left(h_{1}, h_{2}\right)$ e $\left(h_{1}, h_{3}\right)$ em n e $m$ de seus filhos, respectivamente, é

$$
\begin{aligned}
\text { genótipo }(\cdot) & P\left[\cdot \mid D_{\mathbf{u}}\right] \\
\left(h_{1}, h_{1}\right) & 2^{n+m-1} f_{h_{1}} / 2 w \\
\left(h_{1}, h_{j}\right) & \left(f_{h_{1}}+f_{h_{\jmath}}\right) / 2 w, j=2,3 \\
\left(h_{1}, F_{i}\right) & f_{F_{i}} / 2 w, i=1,2 \\
\left(h_{1},(x x x x x)^{c}\right) & \left(1-\sum_{k=1}^{3} f_{h_{k}}-\sum_{j=1}^{2} f_{F_{j}}\right) / 2 w, \\
\left(h_{2}, h_{3}\right) & \left\{1+\left(2^{n+m-1}-1\right) f_{h_{1}}\right\} / 2 w,
\end{aligned}
$$

onde $w$ é a funçâo definida pela expressâo 5.21.

Desse resultado, obtemos:

Corolário 5.3.4 Sob as condiçôes da proposição 5.3.5, temos que a razão de verossimilhanças $R V[D]$ e a probabilidade condicional $V_{0}[D]$, do demandante ter recebido do demandado o(s) alelo(s) de interesse, após termos observado D, estão dadas nos seguintes resultados

$$
\begin{array}{lll}
I & \multicolumn{1}{c}{V_{0}[D]} & R V[D] \\
h_{1} & \frac{1+\left(2^{n+m}+1\right) f_{h_{1}}}{4 w\left[n, m, f_{h_{1}}\right]} & \frac{4 f_{h_{1}} w\left[n, m, f_{h_{1}}\right]}{1+\left(2^{n+m}+1\right) f_{h_{1}}} \\
h_{j} & \frac{1+f_{h_{j}}+2^{n+m-1} f_{h_{1}}}{4 w\left[n, m, f_{h_{1}}\right]} & \frac{4 f_{h_{j}} w\left[n, m, f_{h_{1}}\right]}{1+f_{h_{j}}+2^{n+m-1} f_{h_{1}}}, j=2,3 \\
F_{i} & \frac{f_{F_{i}}}{4 w\left[n, m, f_{h_{1}}\right]} & 4 w\left[n, m, f_{h_{1}}\right], i=1,2
\end{array}
$$




$$
\begin{array}{lll}
h_{1} e h_{j} & \frac{2+f_{h_{j}}+\left(3 \times 2^{n+m-1}+1\right) f_{h_{1}}}{4 w\left[n, m, f_{h_{1}}\right]} & \frac{4\left(f_{h_{1}}+f_{h_{h}}\right) w\left[n, m, f_{h_{1}}\right]}{2+f_{h_{\jmath}}+\left(3 \times 2^{n+m-1}+1\right) f_{h_{1}}}, j=2,3 \\
h_{2} e h_{3} & \frac{2+f_{h_{2}}+f_{h_{3}}+2^{n+m} f_{h_{1}}}{4 w\left[n, m, f_{h_{1}}\right]} & \frac{4\left(f_{h_{2}}+f_{h_{2}}\right) w\left[n, m, f_{h_{1}}\right]}{2+f_{h_{2}}+f_{h_{3}}+2^{n+m} f_{h_{1}}} \\
h_{1} e F_{i} & \frac{1+\left(2^{n+m}+1\right) f_{h_{1}}+f_{F_{i}}}{4 w\left[n, m, f_{h_{1}}\right]} & \frac{4\left(f_{h_{1}}+f_{F_{i}}\right) w\left[n, m, f_{h_{1}}\right]}{1+\left(2^{n+m}+1\right) f_{h_{1}}+f_{F_{i}}}, i=1,2 \\
h_{j} e F_{1} & \frac{1+f_{h_{j}}+2^{n+m-1} f_{h_{1}}+f_{F_{1}}}{4 w\left[n, m, f_{h_{1}}\right]} & \frac{4\left(f_{h_{j}}+f_{F_{1}}\right) w\left[n, m, f_{h_{1}}\right]}{1+f_{h_{j}}+2^{n+m-1} f_{h_{1}}+f_{F_{1}}}, j=2,3 \\
F_{1} e F_{2} & \frac{\sum_{i=1}^{2} f_{F_{i}}}{4 w\left[n, m, f_{h_{1}}\right]} & 4 w\left[n, m, f_{h_{1}}\right] .
\end{array}
$$

\section{Caso 5.3.3}

Consideremos os seguintes quatro alelos $F_{1}$ e $h_{i}, i=1,2,3$, diferentes. Suponhamos que o conjunto de genótipos encontrado, ao observarmos $n+m+r$ filhos do demandado, independentemente, esteja representado por

$$
D_{\mathbf{u}}=\left\{\left(h_{1}, h_{2}\right)_{n},\left(h_{2}, h_{3}\right)_{m},\left(h_{1}, h_{3}\right)_{r}\right\} .
$$

Para este caso, derivamos a probabilidade condicional $v\left[D_{\mathbf{u}} \mid \cdot\right]$, a qual apresentaremos a seguir juntamente com os valores declarados para a distribuição de probabilidade $a$ priori $P[\cdot]$.

$$
\begin{array}{ccc}
\text { genótipo }(\cdot) & P[\cdot] & v\left[D_{\mathbf{u}} \cdot \cdot\right] \\
\left(h_{i}, h_{j}\right) & 2 f_{h_{i}} f_{h_{3}} & \frac{f_{h_{r}}\left(f_{h_{i}}+f_{h_{j}}\right)}{2^{2 n+2 m+2 r-1}}, r \neq i, j ; i<j, i=1,2 ; j=2,3
\end{array}
$$

Do resultado acima, derivamos a distribuição a posteriori $P\left[\cdot \mid D_{\mathbf{u}}\right]$, estabelecida na seguinte proposição.

Proposição 5.3.6 Sob as condições anteriores, a distribuição de probabilidade a posteriori para o genótipo do demandado $P\left[\cdot \mid D_{\mathbf{u}}\right]$ é a seguinte

$$
\text { genótipo }(\cdot) \quad P\left[\cdot \mid D_{\mathbf{u}}\right]
$$




$$
\left(h_{i}, h_{j}\right) \quad \frac{f_{h_{i}}+f_{h_{j}}}{2 \sum_{k=1}^{3} f_{h_{k}}}, i<j, i=1,2 ; j=2,3
$$

Essa distribuição de probabilidade a posteriori nos fornece o seguinte corolário.

Corolário 5.3.5 Sob as condições da proposição 5.3.6, a razão de verossimilhanças $R V[D]$ e a probabilidade condicional $V_{0}[D]$, do demandante ter recebido do demandado $o(s)$ alelo(s) de interesse, após termos observado $D$, sâo dadas pelos seguintes resultados.

$$
\begin{array}{cll}
\multicolumn{1}{c}{I} & \multicolumn{1}{c}{V_{0}[D]} & R V[D] \\
h_{i} & \frac{f_{h_{i}}+\sum_{k=1}^{3} f_{h_{k}}}{4 \sum_{k=1}^{3} f_{h_{k}}} & \frac{4 f_{h_{i}} \sum_{k=1}^{3} f_{h_{k}}}{f_{h_{i}}+\sum_{k=1}^{3} f_{h_{k}}}, i=1,2,3 \\
h_{i} \text { e } h_{j} & \frac{2 \sum_{k=1}^{3} f_{h_{k}}+f_{h_{i}}+f_{h_{j}}}{4 \sum_{k=1}^{3} f_{h_{k}}} & \frac{4\left(f_{h_{i}}+f_{h_{\jmath}}\right) \sum_{k=1}^{3} f_{h_{k}}}{2 \sum_{k=1}^{3} f_{h_{k}}+f_{h_{i}}+f_{h_{j}}}, i \neq j, i, j=1,2,3 \\
h_{i} \text { e } F_{1} & \frac{f_{h_{i}}+\sum_{k=1}^{3} f_{h_{k}}}{4 \sum_{k=1}^{3} f_{h_{k}}} & \frac{4\left(f_{h_{i}}+f_{F_{1}}\right) \sum_{j=1}^{3} f_{h_{j}}}{f_{h_{i}}+\sum_{k=1}^{3} f_{h_{k}}}, i=1,2,3 .
\end{array}
$$

\section{Caso 5.4.1}

Sejam $F_{1}$ e $h_{i}, i=1, \cdots, 4$, cinco alelos diferentes. Suponhamos que, ao observarmos $n+m$ filhos do demandado, independentemente, encontramos em $n$ deles o genótipo $\left(h_{1}, h_{2}\right)$ e nos outros $m$ irmãos o genótipo $\left(h_{3}, h_{4}\right)$ - ou seja,

$$
D_{\mathbf{u}}=\left\{\left(h_{1}, h_{2}\right)_{n},\left(h_{3}, h_{4}\right)_{m}\right\} \text {. }
$$

Para este caso, as probabilidades $P[\cdot]$ e $v\left[D_{\mathbf{u}} \mid \cdot\right]$ podem ser obtidas a seguir.

$$
\begin{array}{rrl}
\text { genótipo }(\cdot) & P[\cdot] & v\left[D_{\mathbf{u}} \mid \cdot\right] \\
\left(h_{i}, h_{j}\right) & 2 f_{h_{i}} f_{h_{j}} & \frac{f_{h_{\sigma(i)}} f_{h_{\gamma(j)}}}{2^{2 n+2 m-2}}, i=1,2 ; j=3,4 .
\end{array}
$$

Dos resultados acima, derivamos a distribuição a posteriori $P\left[\cdot \mid D_{\mathbf{u}}\right]$, estabelecida na seguinte proposição. 
Proposição 5.3.7 Sob as condiçôts anteriores. a distribuiçâo de probabilidade a posteriori para o genótipo do demandado $P\left[\cdot \mid D_{\mathbf{u}}\right]$ é a seguinte

$$
\begin{aligned}
\text { genótipo }(\cdot) & P\left[\cdot \mid D_{\mathbf{u}}\right] \\
\left(h_{i}, h_{j}\right) & 1 / 4, i=1,2 ; j=3,4
\end{aligned}
$$

A razão de verossimilhança $R V[D]$ e a probabilidade condicional $V_{0}[D]$, que é obtida da expressão 5.24 , estão dadas na seguinte tabela.

Tabela 5.4 Probabilidade condicional $V_{0}[D]$ e razão de verossimilhanças $R V[D]$ - Caso 5.4.1

$$
\begin{array}{ccl}
I & V_{0}[D] & R V[D] \\
h_{i} & 1 / 4 & 4 f_{h_{i}}, i=1, \cdots, 4 \\
h_{i} \text { e } h_{j} & 1 / 2 & 2\left(f_{h}+f_{h_{\jmath}}\right), i<j, i, j=1, \cdots, 4 \\
h_{i} \text { e } F_{1} & 1 / 4 & 4\left(f_{h_{i}}+f_{F_{1}}\right), i=1, \cdots, 4 .
\end{array}
$$

\section{Caso 5.4.2}

Consideremos, como no caso 5.4.1, os cinco diferentes alelos $F_{1}$ e $h_{i}, i=1, \cdots, 4$. Suponhamos que, ao observarmos $s$ filhos do demandado, independentemente, ocorra uma das seguintes situações:

$$
\begin{aligned}
& D_{\mathbf{u}}=\left\{\left(h_{1}, h_{2}\right)_{n},\left(h_{2}, h_{4}\right)_{m},\left(h_{3}, h_{4}\right)_{r}\right\}, \quad \text { se } s=n+m+r, \text { ou } \\
& D_{\mathbf{u}}=\left\{\left(h_{1}, h_{2}\right)_{n},\left(h_{1}, h_{3}\right)_{m},\left(h_{3}, h_{4}\right)_{r}\right\}, \quad \text { com } s=n+m+r, \text { ou } \\
& D_{\mathbf{u}}=\left\{\left(h_{1}, h_{2}\right)_{n},\left(h_{2}, h_{4}\right)_{m},\left(h_{1}, h_{3}\right)_{r},\left(h_{3}, h_{4}\right)_{t}\right\}, \quad \text { onde } s=n+m+r=t(5.27)
\end{aligned}
$$

Em cada uma das situações 5.25 - 5.2 $\bar{\imath}$, derivamos a distribuição de probabilidade $a$ posteriori para o genótipo do demandado $P\left[\cdot \mid D_{\mathbf{u}}\right]$ a qual fornecemos no seguinte resultado. 
Proposição 5.3.8 Sob as condições dadas acima, a distribuição de probabilidade a posteriori para o genótipo do demandado $P\left[\cdot \mid D_{\mathbf{u}}\right]$ é a seguinte.

$\begin{aligned} \text { genótipo }(\cdot) & P\left[\cdot \mid D_{\mathbf{u}}\right] \\ \left(h_{1}, h_{4}\right) & 1 / 2 \\ \left(h_{2}, h_{3}\right) & 1 / 2\end{aligned}$

A razão de verossimilhança $R V[D]$ e a probabilidade condicional $V_{0}[D]$, que é obtida da expressão 5.28 , estão dadas na tabela 5.4 .

Comparando os resultados obtidos nos casos 3.1.1 - 3.4.2 com os resultados dos casos 5.1.1 - 5.4.2, obtemos que se analisamos $s$ irmãos ou $s$ filhos do demandado e, se o conjunto determinado pelos genótipos observados nos irmãos é igual ao conjunto determinado pelos genótipos observados nos filhos, então a inferência que podemos fazer - a respeito da probabilidade de paternidade do demandado, é igual em qualquer uma das situações. Este resultado é formalizado a seguir.

Proposição 5.3.9 Suponhamos que foram observados, independentemente, s irmãos e $s$ filhos do demandado. Sejam $D_{\mathbf{u}_{1}}$ e $D_{\mathbf{u}_{2}}$ os conjuntos que representam, respectivamente, os genótipos dos irmãos e dos filhos. Se

$$
D_{\mathbf{u}_{1}}=D_{\mathbf{u}_{2}}
$$

então as correspondentes verossimilhanças de pai, são iguais. Além disso, se a probabilidade a priori de paternidade é igual, em cada uma das situaçôes aqui consideradas, entâo as correspondentes probabilidades a posteriori de paternidade também sâo iguais.

No capítulo 6 apresentaremos, detalhadamente, a análise necessária para determinarmos a probabilidade a posteriori de paternidade, quando está disponível a informação genotípica de um ou ambos os pais do demandado. 


\section{Capítulo 6}

\section{Análise para pais do demandado}

\subsection{Introdução}

Neste capítulo, primeiramente apresentamos, em detalhes, a metodologia proposta para determinar a distribuição de probabilidade a posteriori para o genótipo do demandado, uma vez que foi observada uma determinada estrutura genotípica em um de seus pais, que, sem perda de generalidade, vamos supor é a mãe do demandado. Esta distribuição de probabilidade a posteriori é a base para determinar a probabilidade de paternidade após ter sido observado o genótipo da mãe do demandado, da mãe do demandante e do próprio demandante - isto é, a probabilidade a posteriori de paternidade - cujo método de cálculo foi exibido na seção 1.5 .

Na seção 6.3, utilizamos a metodologia desenvolvida na seção 6.2 para calcular tanto a distribuição de probabilidade a posteriori para o genótipo do demandado quanto a razão entre as verossimilhanças do demandado não ser o pai do demandante e do demandado ser o pai do demandante, para cada um dos possíveis casos determinados pelos dados referentes ao genótipo da mãe do demandado. Estes dois elementos são fundamentais no cálculo da probabilidade a posteriori de paternidade, a qual é obtida substituindo os valores encontrados aqui para estes elementos na expressão 1.18.

$\mathrm{Na}$ seção 6.4, apresentamos a metodologia proposta para determinar a distribuição de probabilidade a posteriori para o genótipo do demandado, uma vez que foi observada 
uma determinada estrutura genotípica em seus dois pais e na seção 6.5 , utilizamos a metodologia desenvolvida na seção 6.4 para calcular, tanto a distribuição de probabilidade a posteriori para o genótipo do demandado quanto a razão entre as verossimilhanças do demandado não ser o pai do demandante e do demandado ser o pai do demandante, para cada um dos possíveis casos determinados pelos dados referentes aos genótipos dos pais do demandado.

\subsection{Descrição geral da metodologia I}

Sejam $\mathcal{B}_{L},\left(G_{L}, \mathcal{A}_{G_{L}}\right), Z$ e $P[\cdot]$ como definidos na seção 3.2. Suponhamos que estejam disponíveis dados do demandante e de sua mãe, além de dados referentes à mãe do demandado. Isto é, a árvore genealógica que estudaremos apresenta a seguinte estrutura:

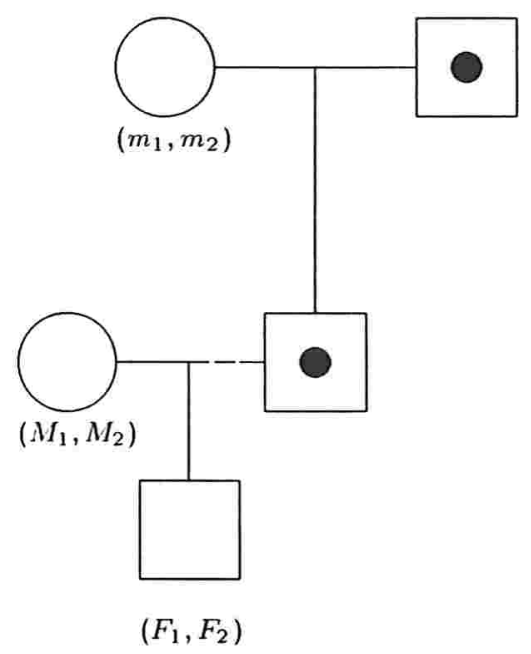

Árvore genealógica correspondente ao caso mãe do demandado

Sejam $M, U, F$ e $X$ variáveis aleatórias $\mathcal{A}_{G_{L}}$ mensuráveis que denotam, respectivamente, os genótipos da mãe do demandante, da mãe do demandado, do demandante e do demandado. 
Se os valores observados de $M, F$ e $U$ são, respectivamente, $\left(M_{1}, M_{2}\right),\left(F_{1}, F_{2}\right)$ e $\mathbf{u}$, o conjunto dos dados $D$ correspondente a este experimento é formado por

$$
D=\left\{\left(M_{1}, M_{2}\right),\left(F_{1}, F_{2}\right), \mathbf{u}\right\} .
$$

Inicialmente, o interesse é determinar a distribuição de probabilidade para o genótipo do demandado, após observar o genótipo da mãe do demandado e o(s) alelo(s) de interesse - isto é, queremos obter a distribuição de probabilidade a posteriori $P[\cdot \mid D]$ da variável aleatória $X$. Para determinarmos esta distribuição de probabilidade propomos o seguinte procedimento.

Primeiramente, consideremos a distribuição de probabilidade $P$, definida em 3.1 , que descreve a incerteza sobre o genótipo do demandado, antes de ser observado o genótipo da mãe do demandado e o(s) alelo(s) de interesse - isto é, $P$ é a distribuição de probabilidade a priori para o genótipo do demandado.

Agora, suponhamos que foram observados, independentemente, o genótipo da mãe do demandante, do demandante e o genótipo da mãe do demandado, e sejam $\left(M_{1}, M_{2}\right)$, $\left(F_{1}, F_{2}\right)$ e u os genótipos observados respectivamente.

Para cada $i, k=1, \cdots, N$, calculamos a probabilidade condicional $V\left[g_{k} \mid\left(\mathrm{u}, g_{i}\right)\right]$ de que $g_{k}$ seja o genótipo do demandado, dado que o genótipo de sua mãe é u e o genotipo de seu pai é $g_{i}$ (Ver capítulo 3). Esta probabilidade condicional será utilizada no cálculo da probabilidade a posteriori para o genótipo do demandado, como podemos ver na expressão 6.1. A distribuição de probabilidade a posteriori $P[\cdot \mid \mathrm{u}]$ é apresentada no seguinte resultado.

Proposição 6.2.1 Seja $X$ a variável aleatória que denota o genótipo do demandado, $e$ é $\mathcal{A}_{G_{L}}$ mensurável, $P$ como a medida de probabilidade definida sobre o espaço $\left(G_{L}, \mathcal{A}_{G_{L}}\right)$ definida na expressão 3.1, a qual descreve a incerteza a priori sobre $X$ e $\mathbf{u} o$ vetor do genótipo observado na mãe do demandado. A distribuiçâo de probabilidade a posteriori $P[\cdot \mid \mathbf{u}]$ para $X$ é dada pela expressão

$$
P\left[g_{k} \mid \mathbf{u}\right]=\sum_{j=1}^{N} V\left[g_{k} \mid\left(\mathbf{u}, g_{j}\right)\right] \times P\left[g_{j}\right], k=1, \cdots, N .
$$

Demonstração: A distribuição de probabilidade dada pela expressão 3.1 descreve, também, a incerteza sobre o genótipo do pai do demandado. Uma vez observado o 
genótipo da mãe do demandante $\mathbf{u}$, da expressão 3.1 e da tabela 3.1 obtemos imediatamente que a distribuição de probabilidade a posteriori $P[\cdot \mid \mathbf{u}]$ para o genótipo do demandado, é dada pela expressão

$$
P\left[g_{k} \mid \mathbf{u}\right]=\sum_{j=1}^{N} V\left[g_{k} \mid\left(\mathbf{u}, g_{j}\right)\right] \times P\left[g_{j}\right], \quad k=1, \cdots, N,
$$

Na próxima seção, aplicaremos a metodologia introduzida aqui considerando todos os diferentes vetores $u$ que trazem informação sobre o genótipo observado na mãe do demandado. Neste caso, devemos considerar somente duas situações. A primeira quando o genótipo da mãe do demandado seja homozigoto e a segunda quando seja heterozigoto.

\subsection{Análise dos casos}

Nesta seção, aplicamos a metodologia desenvolvida na seção 6.2 para determinar a distribuição de probabilidade a posteriori para o genótipo do demandado, considerando os dois casos determinados pelo genótipo da mãe do demandado. Além disso, pelos argumentos fornecidos no capítulo 1 , exibiremos apenas a probabilidade condicional $V_{0}[D]$ - ou $R V[D]$ quando possível - necessária ao cálculo da probabilidade a posteriori de paternidade. Quanto à outra probabilidade condicional $V_{1}[D]$, também necessária ao cálculo desta probabilidade a posteriori, será omitida por ser diretamente obtida da proposição 1.5.1.

Ao longo desta seção não tornaremos explícitos aqueles genótipos cujas probabilidades a posteriori sejam nulas.

\section{Caso 6.1}

Sejam $a_{1}, F_{1}$ e $F_{2}$ três alelos diferentes. Suponhamos que, ao considerarmos a mãe do demandado observemos o genótipo $\mathbf{u}=\left(a_{1}, a_{1}\right)$.

Para obtermos a distribuição de probabilidade $P[\cdot \mid \mathbf{u}]$ é necessário apenas considerar os genótipos da forma $\left(a_{1}, h\right)$, onde $h$ é um alelo qualquer. Esta distribuição de probabilidade é dada no seguinte resultado. 
Proposição 6.3.1 A distribuição de probabilidade a posteriori para o genótipo do demandado $P[\cdot \mid \mathbf{u}]$, uma vez que em sua mãe foi observado o genótipo $\left(a_{1}, a_{1}\right)$, é a seguinte.

$$
\begin{aligned}
\text { genótipo }(\cdot) & P[\cdot \mid \mathbf{u}] \\
\left(a_{1}, a_{1}\right) & f_{a_{1}} \\
\left(a_{1}, F_{i}\right) & f_{F_{i}}, \quad i=1,2 \\
\left(a_{1},(x x x)^{c}\right) & 1-f_{a_{1}}-\sum_{i=1}^{2} f_{F_{i}}
\end{aligned}
$$

\section{Demonstração}

Da expressão 6.1 temos que a probabilidade a posteriori $P\left[\left(a_{1}, a_{1}\right) \mid \mathbf{u}\right]$, de que o genótipo do demandado seja $\left(a_{1}, a_{1}\right)$ uma vez que foi observado na sua mãe o genótipo $\left(a_{1}, a_{1}\right)$, é dada por

$$
\begin{aligned}
P\left[\left(a_{1}, a_{1}\right) \mid \mathbf{u}\right]= & V\left[\left(a_{1}, a_{1}\right) \mid \mathbf{u},\left(a_{1}, a_{1}\right)\right] P\left[\left(a_{1}, a_{1}\right)\right] \\
& +\sum_{h \neq a_{1}} V\left[\left(a_{1}, a_{1}\right) \mid \mathbf{u},\left(a_{1}, h\right)\right] P\left[\left(a_{1}, h\right)\right] \\
= & f_{a_{1}}^{2}+2 f_{a_{1}}\left(1-f_{a_{1}}\right) / 2=f_{a_{1}}
\end{aligned}
$$

e se $h$ é um alelo qualquer, diferente do alelo $a_{1}$, a probabilidade $a$ posteriori $P\left[\left(a_{1}, h\right) \mid \mathbf{u}\right]$ é dada por

$$
\begin{aligned}
P\left[\left(a_{1}, h\right) \mid \mathbf{u}\right]= & V\left[\left(a_{1}, h\right) \mid \mathbf{u},(h, h)\right] P[(h, h)]+V\left[\left(a_{1}, h\right) \mid \mathbf{u},\left(a_{1}, h\right)\right] P\left[\left(a_{1}, h\right)\right] \\
& +\sum_{b \neq a_{1}, h} V\left[\left(a_{1}, a_{1}\right) \mid \mathbf{u},(h, b)\right] \times P[(h, b)] \\
= & f_{h}^{2}+2 f_{a_{1}} f_{h} / 2+2 f_{h}\left(1-f_{a_{1}}-f_{h}\right) / 2=f_{h} .
\end{aligned}
$$

Das expressões 6.3 e 6.4, segue-se o resultado.

Da distribuição de probabilidade a posteriori para o genótipo do demandado - dada neste caso pela expressão 6.2 - obtemos a probabilidade condicional do demandante ter 
recebido do demandado o(s) alelo(s) de interesse, após termos observado $D$ e a razão $R V[D]$ para cada conjunto de alelos de interesse $I$, como podemos ver no seguinte corolário.

Corolário 6.3.1 Sob as condições da proposição 6.3.1, temos que a razão de verossimilhanças $R V[D]$ e a probabilidade condicional $V_{0}[D]$, do demandante ter recebido do demandado o(s) alelo(s) de interesse, após termos observado D. estão dadas a seguir

$$
\begin{array}{ccl}
I & V_{0}[D] & R V[D] \\
a_{1} & \left(1+f_{a_{1}}\right) / 2 & \frac{2 f_{a_{1}}}{1+f_{a_{1}}} \\
F_{i} & f_{F_{i}} / 2 & 2, i=1,2 \\
a_{1} \text { e } F_{i} & \left(1+f_{a_{1}}+f_{F_{i}}\right) / 2 & \frac{2\left(f_{a_{1}}+f_{F_{i}}\right)}{1+f_{a_{1}}+f_{F_{i}}}, i=1,2 \\
F_{1} \text { e } F_{2} & \sum_{i=1}^{2} f_{F_{i}} / 2 & 2
\end{array}
$$

\section{Caso 6.2}

Sejam $a_{1}, a_{2}, F_{1}$ e $F_{2}$ quatro alelos diferentes. Suponhamos que, ao considerarmos a mãe do demandado, observamos o genótipo $\mathbf{u}=\left(a_{1}, a_{2}\right)$.

Neste caso, a distribuição de probabilidade $P[\cdot \mid \mathbf{u}]$ é dada no seguinte resultado.

Proposição 6.3.2 A distribuição de probabilidade a posteriori para o genótipo do demandado $P[\cdot \mid \mathbf{u}]$, uma vez que em sua mãe foi observado o genótipo $\left(a_{1}, a_{2}\right)$, é a seguinte.

$$
\begin{aligned}
\text { genótipo }(\cdot) & P[\cdot \mid \mathbf{u}] \\
\left(a_{i}, a_{i}\right) & f_{a_{i}} / 2, \quad i=1,2 \\
\left(a_{1}, a_{2}\right) & \sum_{i=1}^{2} f_{a_{i}} / 2 \\
\left(a_{i}, F_{j}\right) & f_{F_{j}} / 2, \quad i, j=1,2 \\
\left(a_{i},(x x x x)^{c}\right) & 1-\sum_{k=1}^{2}\left(f_{a_{k}}+f_{F_{k}}\right), \quad i=1,2
\end{aligned}
$$




\section{Demonstração}

Da expressão 6.1 temos que para $i=1,2$, a probabilidade a posteriori $P\left[\left(a_{i}, a_{i}\right) \mid \mathbf{u}\right]$, de que o genótipo do demandado seja $\left(a_{i}, a_{i}\right)$ - uma vez que foi observado, na sua mãe o genótipo $u=\left(a_{i}, a_{\sigma(i)}\right)$, é dada por

$$
\begin{aligned}
P\left[\left(a_{i}, a_{i}\right) \mid \mathbf{u}\right]= & V\left[\left(a_{i}, a_{i}\right) \mid \mathbf{u},\left(a_{i}, a_{i}\right)\right] P\left[\left(a_{i}, a_{i}\right)\right] \\
& +\sum_{h \neq a_{i}} V\left[\left(a_{i}, a_{i}\right) \mid \mathbf{u},\left(a_{i}, h\right)\right] P\left[\left(a_{i}, h\right)\right] \\
= & f_{a_{i}}^{2} / 2+2 f_{a_{i}}\left(1-f_{a_{i}}\right) / 4=f_{a_{i}} / 2 .
\end{aligned}
$$

Em forma semelhante, a probabilidade a posteriori $P\left[\left(a_{1}, a_{2}\right) \mid \mathbf{u}\right]$ é dada por

$$
\begin{aligned}
P\left[\left(a_{1}, a_{2}\right) \mid \mathbf{u}\right]= & V\left[\left(a_{1}, a_{2}\right) \mid \mathbf{u},\left(a_{1}, a_{2}\right)\right] P\left[\left(a_{1}, a_{2}\right)\right] \\
& +\sum_{j=1}^{2} V\left[\left(a_{1}, a_{2}\right) \mid \mathbf{u},\left(a_{j}, a_{j}\right)\right] P\left[\left(a_{j}, a_{j}\right)\right] \\
& +\sum_{i=1}^{2} \sum_{h \neq a_{1}, a_{2}} V\left[\left(a_{1}, a_{2}\right) \mid \mathbf{u},\left(a_{i}, h\right)\right] P[(b, h)] \\
= & \sum_{j=1}^{2} f_{a_{j}} / 2
\end{aligned}
$$

e se $b$ é um alelo qualquer, diferente dos alelos $a_{1}$ e $a_{2}$, temos que, para $i=1,2$ a probabilidade a posteriori $P\left[\left(a_{i}, b\right) \mid \mathbf{u}\right]$ é dada por

$$
\begin{aligned}
P\left[\left(a_{i}, b\right) \mid \mathbf{u}\right] & =V\left[\left(a_{i}, b\right) \mid \mathbf{u},(b, b)\right] P[(b, b)]+\sum_{h \neq b} V\left[\left(a_{i}, b\right) \mid \mathbf{u},(b, h)\right] P[(b, h)] \\
& =f_{b}^{2} / 2+2 f_{b}\left(1-f_{b}\right) / 4=f_{b} / 2
\end{aligned}
$$

Das expressões 6.6 - 6.8 segue-se o resultado.

Da distribuição de probabilidade a posteriori para o genótipo do demandado - dada neste caso pela expressão 6.5 - obtemos a probabilidade condicional do demandante ter 
recebido do demandado o(s) alelo(s) de interesse após termos observado $D$ e a razão $R V[D]$ para cada conjunto de alelos de interesse $I$, como podemos ver no seguinte corolário.

Corolário 6.3.2 Sob as condiçôes da proposição 6.3.2, temos que a razão de verossimilhanças $R V[D]$ e a probabilidade condicional $V_{0}[D]$, do demandante ter recebido do demandado o(s) alelo(s) de interesse após termos observado D, estão dadas a seguir

$$
\begin{array}{ccl}
I & V_{0}[D] & R V[D] \\
a_{i} & \left(1+2 f_{a_{i}}\right) / 4 & \frac{4 f_{a_{i}}}{1+2 f_{a_{i}}}, i=1,2 \\
F_{i} & f_{F_{i}} / 2 & 2 i=1,2 \\
a_{1} \text { e } a_{2} & \left(1+f_{a_{1}}+f_{a_{2}}\right) / 2 & \frac{2\left(f_{a_{1}}+f_{a_{2}}\right)}{1+f_{a_{1}}+f_{a_{2}}} \\
& & \frac{4\left(f_{a_{i}}+f_{F_{j}}\right)}{1+2\left(f_{a_{i}}+f_{F_{j}}\right)}, i, j=1,2 \\
a_{i} \text { e } F_{j} & \left(1+2\left(f_{a_{i}}+f_{F_{j}}\right)\right) / 4 & \\
F_{1} \text { e } F_{2} & \sum_{j=1}^{2} f_{F_{j}} / 2 & 2
\end{array}
$$

Comparando os resultados obtidos nos casos 6.1 e 6.2 deste capítulo, com o resultado 5.3 .9 - na situação particular $s=1$ - obtemos que, se analisamos um irmão, ou um filho, ou um dos pais do demandado e, se os genótipos observados nesses indivíduos é o mesmo, então a inferência que podemos fazer - a respeito da probabilidade de paternidade do demandado, é igual em qualquer uma das situações. Este resultado é formalizado a seguir.

Proposição 6.3.3 Suponhamos que ao considerarmos, independentemente, um irmão, um filho e um dos pais do demandado, observamos, respectivamente, os genótipos $u_{1}, u_{2}$ $e u_{3}$. Se esses três genótipos são iguais, então as correspondentes verossimilhanças de pai, também são. Além disso, se a probabilidade a priori de paternidade é igual, em cada uma das situações aqui consideradas, então as correspondentes probabilidades a posteriori de paternidade também são iguais. 


\subsection{Descrição geral da metodologia II}

Sob as considerações feitas na seção 6.2 , suponhamos que estejam disponíveis dados do demandante e de sua mãe, além de dados referentes aos pais do demandado. Isto é, a árvore genealógica que estudaremos apresenta a seguinte estrutura:

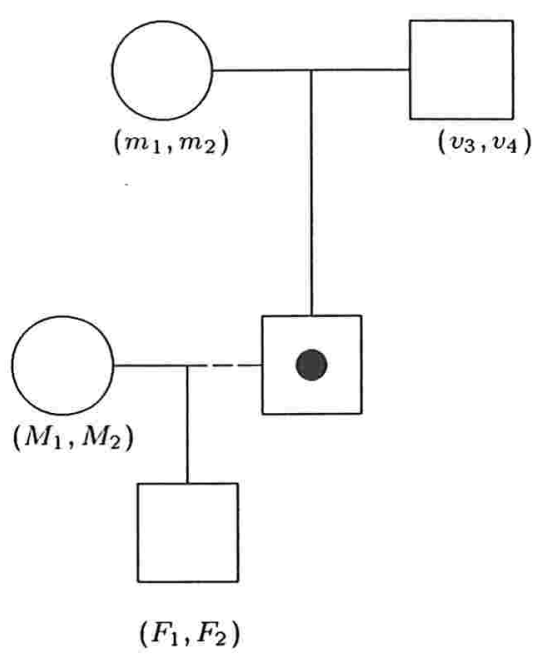

Árvore genealógica correspondente ao caso pais do demandado

Sejam $M, F$ e $X$ variáveis aleatórias $\mathcal{A}_{G_{L}}$ mensuráveis que denotam, respectivamente, os genótipos da mãe do demandante, do demandante e do demandado, e consideremos $U$ como sendo o vetor aleatório formado pelos genótipos dos pais do demandado constituído por componentes $\mathcal{A}_{G_{L}}$ mensuráveis.

Se os valores observados de $M, F$ e $U$ são respectivamente $\left(M_{1}, M_{2}\right),\left(F_{1}, F_{2}\right)$ e $\mathbf{u}$, o conjunto dos dados $D$ correspondente a este experimento é formado por

$$
D=\left\{\left(M_{1}, M_{2}\right),\left(F_{1}, F_{2}\right), \mathbf{u}\right\} .
$$

Nosso interesse é determinar a distribuição de probabilidade para o genótipo do demandado, após observar o genótipo de seus pais e o(s) alelo(s) de interesse - isto é, queremos 
obter a distribuição de probabilidade a posteriori $P[\cdot \mid D]$ da variável aleatória $X$. Para determinarmos esta distribuição de probabilidade propomos o seguinte procedimento.

Consideremos a distribuição de probabilidade $P$, definida em 3.1, que descreve a incerteza sobre o genótipo do demandado, antes de ser observado o genótipo de seus pais e o(s) alelo(s) de interesse - isto é, $P$ é a distribuição de probabilidade a priori para o genótipo do demandado.

Suponhamos que foram observados, independentemente, o genótipo da mãe do demandante, do demandante e os genótipos dos pais do demandado, e sejam $\left(M_{1}, M_{2}\right),\left(F_{1}, F_{2}\right)$ e $\mathbf{u}$ os genótipos observados, respectivamente. Consideremos $D_{\mathbf{u}}$ como o conjunto formado por todos os elementos $(x, y)_{q}$ onde $(x, y)$ é o genótipo observado em um dos pais do demandado e $q$ representa o número de vezes que este genótipo foi observado nos pais - isto é, $q$ representa o número de vezes que o genótipo $(x, y)$ ocorre no vetor $\mathrm{u}$. Na verdade $D_{\mathbf{u}}$ é uma outra representação do vetor $\mathbf{u}$. Por exemplo, se

$$
D_{\mathbf{u}}=\left\{\left(a_{1}, a_{2}\right)_{2}\right\},
$$

entende-se que o genótipo $\left(a_{1}, a_{2}\right)$ foi observado nos dois pais do demandado, onde $a_{1}, a_{2}$ pertencem a $\mathcal{B}_{L}$.

A distribuição de probabilidade a posteriori $P\left[\cdot \mid D_{\mathbf{u}}\right]$ para o genótipo do demandado - uma vez que foram observados seus pais, cujos genótipos estejam representados no conjunto $D_{\mathbf{u}}$ - é imediata.

Assim, considerando a variável aleatória $X^{\prime}$ que denota o genótipo do demandado, e é $\mathcal{A}_{G_{L}}$ mensurável, $P$ como a medida de probabilidade definida sobre o espaço $\left(G_{L}, \mathcal{A}_{G_{L}}\right)$ definida na expressão 3.1 , a qual descreve a incerteza a priori sobre $X$ e $D_{\mathbf{u}}$ o conjunto que representa os genótipos observados nos pais do demandado, temos que a distribuição de probabilidade a posteriori $P\left[\cdot \mid D_{\mathbf{u}}\right]$ para $X$ é dada pela expressão

$$
P\left[g_{k} \mid D_{\mathbf{u}}\right]=V\left[g_{k} \mid D_{\mathbf{u}}\right], \quad k=1, \cdots, N,
$$

onde $V\left[g_{k} \mid D_{\mathbf{u}}\right]$ é a probabilidade condicional de que o genótipo $g_{k}$ provenha do cruzamento entre os genótipos representados no conjunto $D_{\mathbf{u}}$.

$\mathrm{Na}$ próxima seção, aplicaremos a metodologia aqui introduzida considerando todos os diferentes conjuntos $D_{\mathbf{u}}$ que trazem informação sobre os genótipos observados nos pais 
do demandado. Para facilitar a apresentação dos resultados correspondentes a.os conjuntos $D_{\mathbf{u}}$ que determinam diferentes distribuições de probabilidade a posteriori para o genótipo do demandado, estes serão referenciados no que resta deste capítulo pelo código caso c.i.j a ser dado na primeira coluna da tabela 6.1 , onde c indica o capítulo, $\mathrm{i}$ indica o número de alelos diferentes que aparecem em $D_{\mathbf{u}}$ e $\mathbf{j}$ enumera as diferentes associações com igual número de alelos.

Tabela 6.1 Dados relevantes ao observarmos os pais do demandado.

caso genótipos observados

6.1 .1

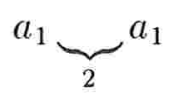

6.2 .1
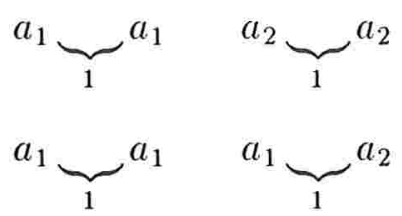

6.2 .3

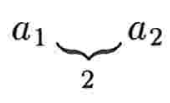

6.3 .1
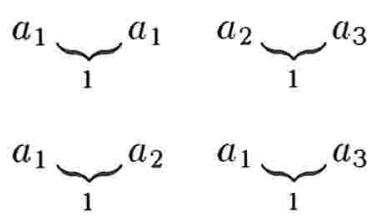

6.4 .1
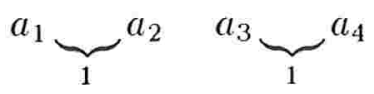

\subsection{Análise dos casos}

Nesta seção, aplicamos a metodologia desenvolvida na seção 6.4 para determinar a distribuição de probabilidade a posteriori para o genótipo do demandado, considerando cada um dos casos relacionados na tabela 6.1 , exibida no final da seção anterior.

Segundo os argumentos fornecidos no capítulo 1, exibiremos apenas a probabilidade condicional $V_{0}[D]$ - ou $R V[D]$ quando possível - necessária ao cálculo da probabilidade a posteriori de paternidade. Quanto à outra probabilidade condicional $V_{1}[D]$, também 
necessária ao cálculo desta probabilidade a posteriori, será omitida por ser diretamente obtida da proposição 1.5.1.

Ao longo desta seção, não tornaremos explícitos aqueles genótipos cujas probabilidades a posteriori sejam nulas.

\section{Caso 6.1.1}

Sejam $a_{1}, F_{1}$ e $F_{2}$ três alelos diferentes. Suponhamos que, ao considerarmos os pais do demandado, independentemente, observamos em cada um deles o genótipo $\left(a_{1}, a_{1}\right)$ - isto é, $D_{\mathbf{u}}=\left\{\left(a_{1}, a_{1}\right)_{2}\right\}$.

Sob as condições estabelecidas acima, obtemos imediatamente a distribuição de probabilidade a posteriori $P\left[\cdot \mid D_{\mathbf{u}}\right]$ para o genótipo do demandado, uma vez que em seus pais foi observado o genótipo $\left(a_{1}, a_{1}\right)$, sendo a distribuição

$$
P\left[g_{i} \mid D_{\mathbf{u}}\right]= \begin{cases}1 & \text { se } g_{i}=\left(a_{1}, a_{1}\right) \\ 0 & \text { caso contrário, }\end{cases}
$$

Da distribuição de probabilidade a posteriori, dada pela expressão 6.11 , obtemos a probabilidade condicional do demandante ter recebido do demandado o(s) alelo(s) de interesse após termos observado $D$ e a razão $R V[D]$ para cada conjunto de alelos de interesse $I$ como podemos ver no seguinte resultado.

Proposição 6.5.1 Suponhamos que distribuição de probabilidade a posteriori $P\left[\cdot \mid D_{\mathbf{u}}\right]$ para o genótipo do demandado é dada pela expressão 6.11. Então, a razão de verossimilhanças $R V[D]$ e a probabilidade condicional $V_{0}[D]$, do demandante ter recebido do demandado o(s) alelo(s) de interesse, após termos observado D, estão dadas a seguir

$$
\begin{aligned}
& I \quad V_{0}[D] \quad R V[D] \\
& a_{1} \quad 1 \quad f_{a_{1}} \\
& a_{1} \in F_{i} \quad 1 \quad f_{a_{1}}+f_{F_{i}}, i=1,2
\end{aligned}
$$

Caso 6.2.1 
Sejam $a_{i}$ e $F_{i}$ para $i=1,2$ quatro alelos diferentes. Suponhamos que, ao considerarmos os pais do demandado. independentemente, observamos em um deles o genótipo $\left(a_{1}, a_{1}\right)$ e no outro pai o genótipo $\left(a_{2}, a_{2}\right)$ - isto é, $D_{\mathbf{u}}=\left\{\left(a_{1}, a_{1}\right)_{1},\left(a_{2}, a_{2}\right)_{1}\right\}$.

Das condições estabelecidas acima obtemos que a distribuição de probabilidade a posteriori $P\left[\cdot \mid D_{\mathrm{u}}\right]$ para o genótipo do demandado, uma vez que em seus pais foram observados os genótipos $\left(a_{1}, a_{1}\right)$ e $\left(a_{2}, a_{2}\right)$, é a distribuição

$$
P\left[g_{i} \mid D_{\mathbf{u}}\right]= \begin{cases}1 & \text { se } g_{i}=\left(a_{1}, a_{2}\right) \\ 0 & \text { caso contrário }\end{cases}
$$

Como conseqüência da expressão anterior, surge naturalmente o seguinte resultado.

Proposição 6.5.2 Se a distribuição de probabilidade a posteriori $P\left[\cdot \mid D_{\mathbf{u}}\right]$ para o genótipo do demandado é dada pela expressão 6.13, temos que a razão de verossimilhanças $R V[D]$ $\epsilon$ a probabilidade condicional $V_{0}[D]$, do demandante ter recebido do demandado o(s) alelo(s) de interesse após termos observado D, estão dadas a seguir

$$
\begin{aligned}
& I \quad V_{0}[D] \quad R V[D] \\
& a_{i} \quad 1 / 2 \quad 2 f_{a_{i}}, \quad i=1,2 \\
& \begin{array}{lllll}
a_{1} & e & a_{2} & 1 & f_{a_{1}}+f_{a_{2}}
\end{array} \\
& a_{i} \text { e } F_{j} \quad 1 / 2 \quad 2\left(f_{a_{i}}+f_{F_{j}}\right), i, j=1,2
\end{aligned}
$$

\section{Caso 6.2.2}

Consideremos quatro alelos diferentes $a_{i}$ e $F_{i}, i=1,2$. Suponhamos que, ao considerarmos os pais do demandado, independentemente, observamos em um deles o genótipo $\left(a_{1}, a_{1}\right)$ e no outro pai o genótipo $\left(a_{1}, a_{2}\right)$ - isto é, $D_{\mathbf{u}}=\left\{\left(a_{1}, a_{1}\right)_{1},\left(a_{1}, a_{2}\right)_{1}\right\}$.

Da expressão 6.10 obtemos imediatamente a a distribuição de probabilidade a posteriori $P\left[\cdot \mid D_{\mathbf{u}}\right]$ para o genótipo do demandado, uma vez que em seus pais foram observados os genótipos $\left(a_{1}, a_{1}\right)$ e $\left(a_{1}, a_{2}\right)$, sendo a distribuição

$$
P\left[g_{i} \mid D_{\mathbf{u}}\right]=\left\{\begin{array}{l}
1 / 2 \text { se } g_{i}=\left(a_{1}, a_{1}\right) \text { ou } g_{i}=\left(a_{1}, a_{2}\right) \\
0 \quad \text { caso contrário, }
\end{array}\right.
$$


Utilizando a distribuição de probabilidade a posteriori, dada pela expressão 6.15 , obtemos a probabilidade condicional do demandante ter recebido do demandado o(s) alelo(s) de interesse após termos observado $D$ e a razão $R V[D]$ para cada conjunto de alelos de interesse $I$, como podemos ver no seguinte resultado.

Proposição 6.5.3 Suponhamos que a distribuição de probabilidade a posteriori $P\left[\cdot \mid D_{\mathbf{u}}\right]$ para o genótipo do demandado é dada pela expressâo 6.15 ; então, a razão de verossimilhanças $R V[D]$ e a probabilidade condicional $V_{0}[D]$, do demandante ter recebido do demandado o(s) alelo(s) de interesse após termos observado D, estão dadas a seguir

\begin{tabular}{|c|c|c|}
\hline$I$ & $V_{0}[D]$ & $R V[D]$ \\
\hline$a_{1}$ & $3 / 4$ & $4 f_{a_{1}} / 3$ \\
\hline$a_{2}$ & $1 / 4$ & $4 f_{a_{2}}$ \\
\hline$a_{1} \quad e \quad a_{2}$ & 1 & $f_{a_{1}}+f_{a_{2}}$ \\
\hline$a_{1} e F_{j}$ & $3 / 4$ & $4\left(f_{a_{1}}+f_{F_{j}}\right) / 3, \quad j=1,2$ \\
\hline$a_{2} e F_{j}$ & $1 / 4$ & $4\left(f_{a_{1}}+f_{F_{j}}\right), \quad j=1,2$ \\
\hline
\end{tabular}

Caso 6.2.3

Sejam $a_{1}, a_{2}, F_{1}$ e $F_{2}$ quatro alelos diferentes. Suponhamos que, ao considerarmos os pais do demandado, independentemente, observamos em cada um deles o genótipo $\left(a_{1}, a_{2}\right)$ isto é, $D_{\mathbf{u}}=\left\{\left(a_{1}, a_{2}\right)_{2}\right\}$.

Ao considerarmos a expressão 6.10 estabelecemos a distribuição de probabilidade a posteriori $P\left[\cdot \mid D_{\mathbf{u}}\right]$ para o genótipo do demandado, uma vez que em seus pais foram observados os genótipos $\left(a_{1}, a_{1}\right)$ e $\left(a_{1}, a_{2}\right)$, dada pela seguinte expressão

$$
P\left[g_{i} \mid D_{\mathbf{u}}\right]=\left\{\begin{array}{l}
1 / 4 \quad \text { se } g_{i}=\left(a_{1}, a_{1}\right) \text { ou } g_{i}=\left(a_{2}, a_{2}\right) \\
1 / 2 \quad \text { se } g_{i}=\left(a_{1}, a_{2}\right) \\
0 \quad \text { caso contrário, }
\end{array}\right.
$$

Desse resultado, obtemos: 
Proposição 6.5.4 Se a distribuição de probabilidade a posteriori $P\left[\cdot \mid D_{\mathbf{u}}\right]$ para o genótipo do demandado é dada pela expressão 6.17, entâo a razão de verossimilhanças $R V[D]$ e a probabilidade condicional $V_{0}[D]$, do demandante ter recebido do demandado o(s) alelo $(s)$ de interesse após termos observado $D$, estão dadas a seguir

$$
\begin{aligned}
& I \quad V_{0}[D] \quad R V[D] \\
& a_{i} \quad 1 / 2 \quad 2 f_{a_{i}}, \quad i=1,2
\end{aligned}
$$

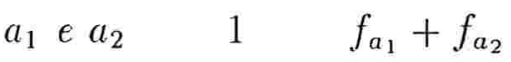

$$
\begin{aligned}
& a_{i} \text { e } F_{j} \quad 1 / 2 \quad 2\left(f_{a_{i}}+f_{F_{j}}\right), i, j=1,2
\end{aligned}
$$

\section{Caso 6.3.1}

Consideremos cinco alelos diferentes $a_{i}, i=1,2,3$ e $F_{j}, j=1,2$. Suponhamos que, ao considerarmos os pais do demandado, independentemente, observamos em um deles o genótipo $\left(a_{1}, a_{1}\right)$ e no outro pai o genótipo $\left(a_{2}, a_{3}\right)$ - isto é, $D_{\mathbf{u}}=\left\{\left(a_{1}, a_{1}\right)_{1},\left(a_{2}, a_{3}\right)_{1}\right\}$.

Para este caso particular, a distribuição de probabilidade a posteriori $P\left[\cdot \mid D_{\mathbf{u}}\right]$ para o genótipo do demandado, uma vez que em seus pais foram observados os genótipos $\left(a_{1}, a_{1}\right)$ e $\left(a_{2}, a_{3}\right)$, é a distribuição

$$
P\left[g_{i} \mid D_{\mathbf{u}}\right]= \begin{cases}1 / 2 & \text { se } g_{i}=\left(a_{1}, a_{2}\right) \text { ou } \quad g_{i}=\left(a_{1}, a_{3}\right) \\ 0 & \text { caso contrário, }\end{cases}
$$

Imediatamente - da expressão 6.19 - obtemos a probabilidade condicional do demandante ter recebido do demandado o(s) alelo(s) de interesse após termos observado $D$ e a razão $R V[D]$ para cada conjunto de alelos de interesse $I$, como podemos ver no seguinte resultado.

Proposição 6.5.5 Suponhamos que a distribuição de probabilidade a posteriori $P\left[\cdot \mid D_{\mathbf{u}}\right]$ para o genótipo do demandado é dada pela expressão 6.19 ; então, a razão de verossimilhanças $R V[D]$ e a probabilidade condicional $V_{0}[D]$, do demandante ter recebido do demandado o(s) alelo(s) de interesse após termos observado $D$, estão dadas a seguir

$$
I \quad V_{0}[D] \quad R V[D]
$$




\begin{tabular}{|c|c|c|}
\hline$a_{1}$ & $1 / 2$ & $2 f_{a_{1}}$ \\
\hline$a_{i}$ & $1 / 4$ & $4 f_{a_{i}}, \quad i=2,3$ \\
\hline$a_{1}$ e $a_{i}$ & $3 / 4$ & $4\left(f_{a_{1}}+f_{a_{i}}\right) / 3, \quad i=2,3$ \\
\hline$a_{2}$ e $a_{3}$ & $1 / 2$ & $2\left(f_{a_{2}}+f_{a_{3}}\right)$ \\
\hline$a_{1} e F_{j}$ & $1 / 2$ & $2\left(f_{a_{1}}+f_{F_{j}}\right), \quad j=1,2$ \\
\hline$a_{i}$ e $F_{j}$ & $1 / 4$ & $4\left(f_{a_{i}}+f_{F_{j}}\right), \quad i=2,3, j=1,2$ \\
\hline
\end{tabular}

\section{Caso 6.3.2}

Consideremos cinco alelos diferentes $a_{i}, i=1,2,3$ e $F_{j}, j=1,2$. Suponhamos que, ao considerarmos os pais do demandado, independentemente, observamos em um deles o genótipo $\left(a_{1}, a_{2}\right)$ e no outro pai o genótipo $\left(a_{1}, a_{3}\right)$ - isto é, $D_{\mathbf{u}}=\left\{\left(a_{1}, a_{2}\right)_{1},\left(a_{1}, a_{3}\right)_{1}\right\}$.

Neste caso, a distribuição de probabilidade a posteriori $P\left[\cdot \mid D_{\mathbf{u}}\right]$ para o genótipo do demandado, uma vez que em seus pais foram observados os genótipos $\left(a_{1}, a_{2}\right)$ e $\left(a_{1}, a_{3}\right)$, é a distribuição

$$
P\left[g_{i} \mid D_{\mathbf{u}}\right]=\left\{\begin{array}{c}
1 / 4 \quad \text { se } g_{i}=\left(a_{2}, a_{3}\right) \text { ou } g_{i}=\left(a_{1}, a_{j}\right), j=1,2,3 \\
0 \quad \text { caso contrário, }
\end{array}\right.
$$

Da distribuição de probabilidade a posteriori $P\left[\cdot \mid D_{\mathbf{u}}\right]$ para o genótipo do demandado dada pela expressão 6.21 - obtemos que a razão de verossimilhanças $R V[D]$. e a probabilidade condicional $V_{0}[D]$, do demandante ter recebido do demandado o(s) alelo(s) de interesse após termos observado $D$, estão dadas como na expressão 6.20 .

\section{Caso 6.4.1}

Sejam $F_{1}$ e $a_{i}, i=1, \cdots, 4$ cinco alelos diferentes. Suponhamos que, ao considerarmos os pais do demandado, independentemente, observamos em um deles o genótipo $\left(a_{1}, a_{2}\right)$ e no outro pai o genótipo $\left(a_{3}, a_{4}\right)$ - isto é, $D_{\mathbf{u}}=\left\{\left(a_{1}, a_{2}\right)_{1},\left(a_{3}, a_{4}\right)_{1}\right\}$.

A distribuição de probabilidade a posteriori $P\left[\cdot \mid D_{\mathbf{u}}\right]$ para o genótipo do demandado, uma vez que em seus pais foram observados os genótipos $\left(a_{1}, a_{2}\right)$ e $\left(a_{3}, a_{4}\right)$, é estabelecida 
imediatamente da expressão 6.10 e é dada pela seguinte expressão

$$
P\left[g_{i} \mid D_{\mathbf{u}}\right]=\left\{\begin{array}{cl}
1 / 4 & \text { se } g_{i}=\left(a_{j}, a_{k}\right), j=1,2 ; k=3,4 \\
0 & \text { caso contrário, }
\end{array}\right.
$$

Desse resultado, obtemos:

Proposição 6.5.6 Se a distribuiçâo de probabilidade a posteriori $P\left[\cdot \mid D_{\mathbf{u}}\right]$ para o genótipo do demandado é dada pela expressão 6.22; então, a raz̃a de verossimilhanças $R V[D]$ e a probabilidade condicional $V_{0}[D]$, do demandante ter recebido do demandado o(s) alelo $(s)$ de interesse após termos observado $D$, estão dadas a seguir

$$
\begin{array}{ccl}
I & V_{0}[D] & R V[D] \\
a_{j} & 1 / 4 & 4 f_{a_{\jmath}}, j=1, \cdots, 4 \\
a_{j} \text { e } a_{k} & 1 / 2 & 2\left(f_{a_{j}}+f_{a_{k}}\right), \quad 1 \leq j<k \leq 4 \\
a_{j} \text { e } F_{1} & 1 / 4 & 4\left(f_{a_{j}}+f_{F_{1}}\right), \quad j=1, \cdots, 4 .
\end{array}
$$

Dos resultados estabelecidos nas expressões 6.12 - 6.23 obtemos o seguinte corolário.

Corolário 6.5.1 Sob as condições das proposições 6.5.1 - 6.5.6, temos que a razão de verossimilhanças $R V[D]$ e a probabilidade condicional $V_{0}[D]$, do demandante ter recebido do demandado o(s) alelo(s) de interesse após termos observado D. estão dadas a seguir

$$
\begin{aligned}
V_{0}[D] & =\frac{m}{4} \\
R V[D] & =\frac{4}{m} \sum_{b_{i} \in I} f_{b_{i}} \text { se } m \geq 1,
\end{aligned}
$$

onde $m$ é o número de vezes que o(s) alelo(s) de interesse é(são) observado(s) nos genótipos dos pais do demandado.

A análise necessária para determinarmos a probabilidade a posteriori de paternidade quando está disponível a informação genotípica de um dos pais do demandado e alguns de seus irmãos - todos eles com os mesmos pais - é apresentada no próximo capítulo. 


\section{Capítulo 7}

\section{Análise para um pai e irmãos do demandado}

\subsection{Introdução}

Neste capítulo, apresentamos, detalhadamente, a metodologia proposta para determinar a distribuição de probabilidade a posteriori para o genótipo do demandado, uma vez que foi observada uma determinada estrutura genotípica em alguns de seus irmãos e em um de seus pais - que vamos supor, sem perda de generalidade, é a mãe do demandado. Esta distribuição de probabilidade a posteriori é a base para determinar a probabilidade de paternidade após terem sido observados os genótipos da mãe e dos irmãos do demandado, da mãe do demandante e do próprio demandante - isto é, a probabilidade a posteriori de paternidade - cujo método de cálculo foi exibido na seção 1.5.

Na seção 7.3, utilizamos a metodologia desenvolvida na seção anterior para calcular tanto a distribuição de probabilidade a posteriori para o genótipo do demandado quanto a razão entre as verossimilhanças do demandado não ser o pai do demandante e do demandado ser o pai do demandante, para cada um dos possíveis casos determinados pelos dados referentes aos genótipos da mãe e dos irmãos do demandado. Estes dois elementos são fundamentais no cálculo da probabilidade a posteriori de paternidade, a qual é obtida substituindo os valores encontrados aqui para estes elementos na expressão 1.5.1. 


\subsection{Descrição geral da metodologia}

Sejam $\mathcal{B}_{L},\left(G_{L}, \mathcal{A}_{G_{L}}\right), Z$ e $P[\cdot]$ como definidos na seção 3.2. Suponhamos que estejam disponíveis dados do demandante e de sua mãe, além de dados referentes à mãe e a alguns irmàos do demandado. Isto é, a árvore genealógica que estudaremos apresenta a seguinte estrutura:

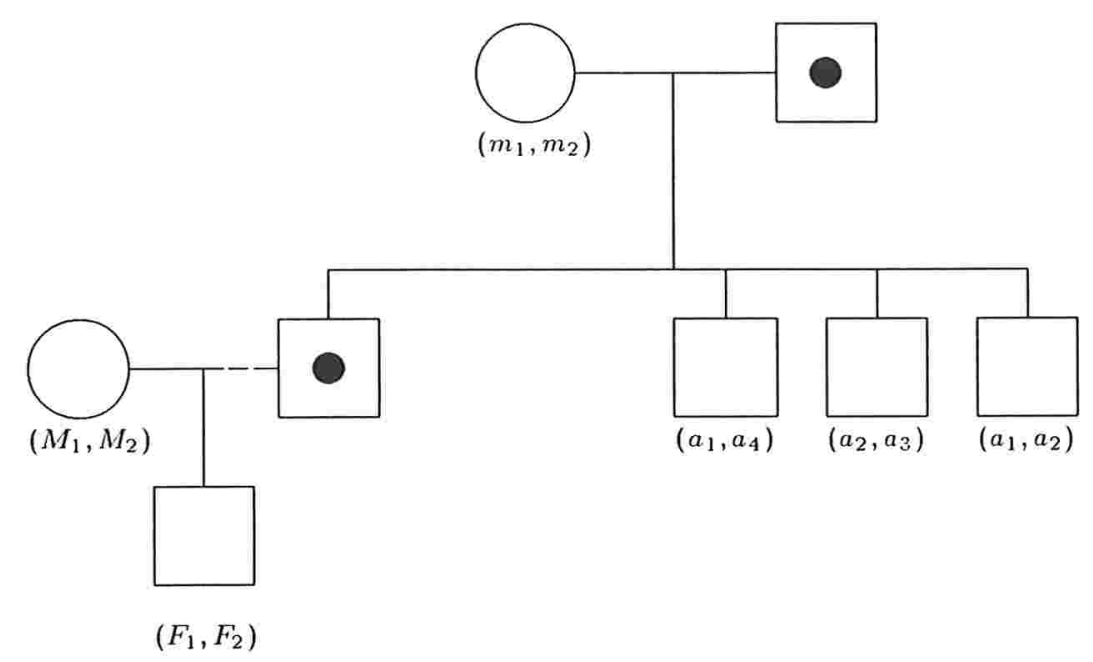

Árvore genealógica correspondente ao caso mãe e irmãos do demandado

Sejam $M, F, X$ e $M_{X}$ variáveis aleatórias $\mathcal{A}_{G_{L}}$ mensuráveis que denotam, respectivamente, os genótipos da mãe do demandante, do demandante, do demandado e da mãe do demandado, e consideremos $U$ como sendo o vetor aleatório formado pelos genótipos dos irmãos do demandado - o demandado e seus irmãos têm os mesmos pais - constituído por componentes $\mathcal{A}_{G_{L}}$ mensuráveis.

Se os valores observados de $M, F, M_{X}$ e $U$ são respectivamente $\left(M_{1}, M_{2}\right),\left(F_{1}, F_{2}\right),\left(m_{1}, m_{2}\right)$ e u, o conjunto dos dados $D$ correspondente a este experimento é formado por

$$
D=\left\{\left(M_{1}, M_{2}\right),\left(F_{1}, F_{2}\right),\left(m_{1}, m_{2}\right), \mathbf{u}\right\} .
$$

O interesse inicial é determinar a distribuição de probabilidade para o genótipo do demandado, após observar os genótipos de sua mãe e de seus irmãos e o(s) alelo(s) de 
interesse - isto é, queremos obter a distribuição de probabilidade a posteriori $P[\cdot \mid D]$ da variável aleatória $X$. Para determinarmos esta distribuição de probabilidade, propomos o seguinte procedimento.

Primeiramente, consideremos a distribuição de probabilidade $P$, definida em 3.1, que descreve a incerteza sobre o genótipo do pai do demandado (ou do demandado), antes de serem observados genótipos de alguns filhos e da esposa do pai do demandado, e o(s) alelo(s) de interesse - isto é, $P$ é a distribuição de probabilidade a priori para o genótipo do pai do demandado.

Suponhamos que foram observados, independentemente o genótipo da mãe do demandante, do demandante, da mãe do demandado e os genótipos de $s$ irmãos do demandado, e sejam $\left(M_{1}, M_{2}\right),\left(F_{1}, F_{2}\right),\left(m_{1}, m_{2}\right)$ e u os genótipos observados, respectivamente. Consideremos $D_{\mathbf{u}}$ como o conjunto formado por todos os elementos $(x, y)_{q}$ onde $(x, y)$ é o genótipo observado em um dos irmãos do demandado e $q$ representa o número de vezes que este genótipo foi observado nos $s$ irmãos - isto é, $q$ representa o número de vezes que o genótipo $(x, y)$ ocorre no vetor $\mathbf{u}$. Como antes, $D_{\mathbf{u}}$ é uma outra representação do vetor $\mathrm{u}$.

Seguindo a metodología proposta no capítulo 4, determinamos a distribuição de probabilidade a posteriori $\bar{P}\left[\cdot \mid D_{\mathbf{u}, m_{X}}\right]$ para o genótipo do pai do demandado - uma vez que foram observados $s$ irmãos e a mãe do demandado cujos genótipos estejam descritos no conjunto $D_{\mathbf{u}, m_{X}}$. Esta distribuição de probabilidade é dada pela expressão

$$
\bar{P}\left[g_{i} \mid D_{\mathbf{u}, m_{X}}\right]=\frac{V\left[D_{\mathbf{u}} \mid\left(g_{i}, m_{X}\right)\right] P\left[g_{i}\right]}{\sum_{j=1}^{N} V\left[D_{\mathbf{u}} \mid\left(g_{j}, m_{X}\right)\right] P\left[g_{j}\right]}, \quad i=1, \cdots, N,
$$

onde $V\left[D_{\mathbf{u}} \mid\left(g_{j}, m_{X}\right)\right]$ é a probabilidade condicional de que os genótipos representados no conjunto $D_{\mathbf{u}}$ provenham do cruzamento entre os genótipos $g_{j}$ e $m_{X}=\left(m_{1}, m_{2}\right)$ (Veja o capítulo 4 para maiores detalhes).

Assim, temos observado o genótipo da mãe do demandado $m_{X}=\left(m_{1}, m_{2}\right)$ e dispomos da distribuição de probabilidade a posteriori $\bar{P}\left[\cdot \mid D_{\mathbf{u}, m_{X}}\right]$ para o genótipo do pai do demandado - dada pela expressão 7.1. Portanto, utilizando estes resultados, obtemos que a distribuição de probabilidade a posteriori $P\left[\cdot \mid D_{\mathbf{u}, m_{X}}\right]$ para o genótipo do demandado - uma vez que foram observados $s$ irmõs e a mãe do demandado, cujos genótipos estejam descritos no conjunto $D_{\mathbf{u}, m_{X}}$ - é dada pela expressão

$$
P\left[g_{k} \mid D_{\mathbf{u}, m_{X}}\right]=\sum_{i=1}^{N} V\left[g_{k} \mid\left(g_{i}, m_{X}\right)\right] \bar{P}\left[g_{i} \mid D_{\mathbf{u}, m_{X}}\right], k=1, \cdots, N .
$$


Em resumo, considerando a variável aleatória $X$ que denota o genótipo do demandado, e é $\mathcal{A}_{G_{L}}$ mensurável, $P$ como a medida de probabilidade definida sobre o espaço $\left(G_{L}, \mathcal{A}_{G_{L}}\right)$ definida na expressão 3.1 , a qual descreve a incerteza a priori sobre $X, m_{X}$ o genótipo observado na mãe do demandado e u o vetor dos genótipos observados nos irmãos do demandado - representado no conjunto $D_{\mathbf{u}}$, provamos o seguinte resultado.

Teorema 7.2.1 Se $m_{X}$ e u são obtidos ao observarmos independentemente a mãe $e$ $s$ irmãos do demandado, então a distribuição de probabilidade a posteriori $P\left[\cdot \mid D_{\mathbf{u}, m_{X}}\right]$ para $X$ é dada pela expressão

$$
P\left[g_{k} \mid D_{\mathbf{u}, m_{X}}\right]=\frac{\sum_{i=1}^{N}\left(V\left[g_{k} \mid\left(g_{i}, m_{X}\right)\right] V\left[D_{\mathbf{u}} \mid\left(g_{i}, m_{X}\right)\right] P\left[g_{i}\right]\right)}{\sum_{j=1}^{N} V\left[D_{\mathbf{u}} \mid\left(g_{j}, m_{X}\right)\right] P\left[g_{j}\right]}, k=1, \cdots, N,
$$

onde $V\left[\cdot \mid\left(g_{j}, m_{X}\right)\right]$ e $P[\cdot]$ sâo dadas respectivamente pelas expressões da tabela 3.1 e 3.1 .

Na próxima, seção aplicaremos a metodologia aqui introduzida considerando todos os diferentes conjuntos $D_{\mathbf{u}, m X}$ que trazem informação sobre os genótipos observados na mãe e nos irmãos do demandado. Para facilitar a apresentação dos resultados correspondentes aos conjuntos $D_{\mathbf{u}, m X}$, que determinam diferentes distribuições de probabilidade a posteriori para o genótipo do demandado, estes serão referenciados ao longo deste capítulo pelo código caso c.i.j a ser dado na primeira coluna da tabela 7.1, onde $\mathbf{c}$ indica o capítulo, $\mathbf{i}$ indica o número de alelos diferentes que aparecem em $D_{\mathbf{u}}$ e $\mathbf{j}$ enumera as diferentes associações com igual número de alelos.

Tabela 7.1 Dados relevantes ao observarmos irmãos e mãe do demandado.

caso genótipos observados

7.1 .1
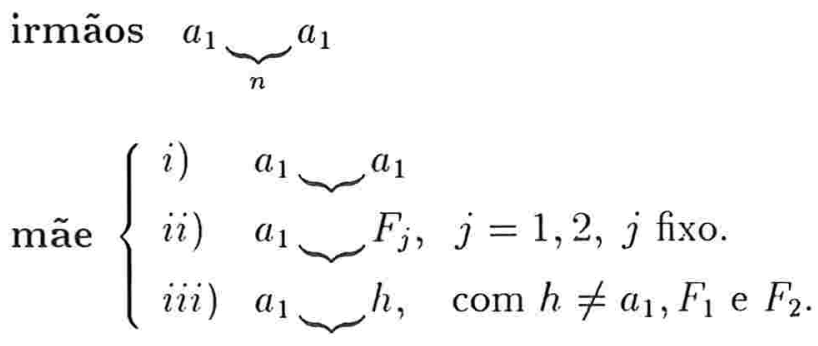

7.2 .1

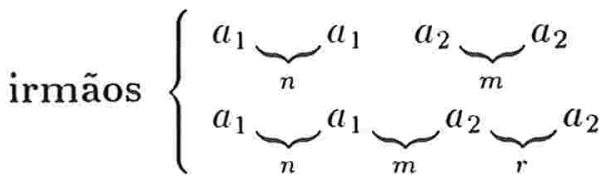


mãe $a_{1} \underbrace{a_{2}}$

7.2.2

irmãos $a_{1} \underbrace{a_{2}}_{n}$

mãe $\begin{cases}i) \quad a_{k} a_{k}, \quad k=1,2, k \text { fixo. } \\ i i) \quad a_{k} F_{i}, \quad i, k=1,2, i, k \text { fixos. } \\ \text { iii) } a_{k} h, \quad \operatorname{com} h \neq a_{k}, F_{1} \text { e } F_{2}, \quad k=1,2, k \text { fixo. } \\ i v) \quad a_{1} a_{2}\end{cases}$

7.2.3 irmãos $a_{1} \underbrace{a_{1}}_{n} \underbrace{a_{2}}_{m}$

mãe $\begin{cases}\text { i) } & a_{1} \underbrace{a_{1}} \\ i i) & a_{1} \underbrace{F_{1}} \\ \text { iii) } & a_{1} \underbrace{h} \operatorname{com} h \neq a_{1}, a_{2} \text { e } F_{1} \\ \text { iv) } & a_{1}{ }^{a_{2}}\end{cases}$

7.3.1

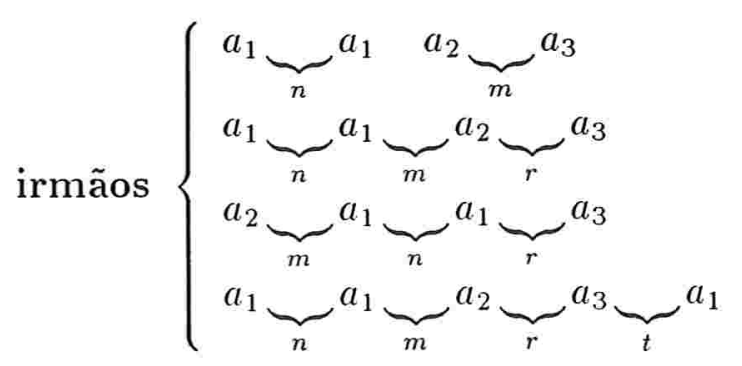

mãe $a_{1} \underbrace{a_{2}}$, ou $a_{1} \underbrace{a_{3}}$.

7.3.2 irmãos $a_{2} \underbrace{}_{n} a_{1} \underbrace{}_{m} a_{3}$

mãe $\begin{cases}i) & a_{1} \underbrace{a_{1}} \\ i i) & a_{1} \underbrace{h} \text { com } h \neq a_{j}, j=1,2,3 . \\ i i i) & a_{1}{ }^{a_{2}}, \text { ou } a_{1} \underbrace{a_{3}} \\ \text { iv) } & a_{2} \underbrace{a_{3}}\end{cases}$

7.3.3 irmãos $a_{1} \underbrace{a_{2}}_{n} \underbrace{a_{3}}_{m} \underbrace{a_{1}}_{r}$ 
mãe $a_{1} \underbrace{a_{2}}$, ou $a_{1} \underbrace{a_{3}}$, ou $a_{2} \underbrace{a_{3}}$.

7.4.1 irmãos $a_{1} \underbrace{a_{2}}_{n} \quad a_{3} \underbrace{a_{4}}_{m}$

mãe $a_{1} \underbrace{a_{3}}$, ou $a_{1} \underbrace{a_{4}}$, ou $a_{2} \underbrace{a_{3}}$, ou $a_{2} \underbrace{a_{4}}$.

7.4.2 irmãos $\left\{\begin{array}{l}a_{2} \underbrace{{ }_{n}}_{n} a_{1} \underbrace{m}_{m} a_{3} \underbrace{r}_{r} a_{4} \\ a_{1} \underbrace{a_{2}}_{m} \underbrace{a_{4}}_{m} a_{3} \underbrace{a_{1}}_{t}\end{array}\right.$

mãe $a_{1} \underbrace{a_{4}}$, ou $a_{2} \underbrace{a_{3}}$.

\subsection{Análise dos casos}

Nesta seção, aplicamos a metodologia desenvolvida na seção 7.2 para determinar a distribuição de probabilidade a posteriori para o genótipo do demandado, considerando cada um dos casos relacionados na tabela 7.1, exibida no final da seção anterior.

Segundo os argumentos fornecidos no capítulo 1, exibiremos apenas a probabilidade condicional $V_{0}[D]$ - ou $R V[D]$ quando possível - necessária ao cálculo da probabilidade a posteriori de paternidade. Quanto à outra probabilidade condicional $V_{1}[D]$, também necessária ao cálculo desta probabilidade a posteriori, será omitida por ser diretamente obtida da proposição 1.5.1.

Ao longo desta seção não tornaremos explícitos aqueles genótipos cujas probabilidades a posteriori sejam nulas.

\section{Caso 7.1.1}

Sejam $a_{1}, F_{1}$ e $F_{2}$ três alelos diferentes. Suponhamos que, ao considerarmos $n$ irmãos do demandado, independentemente, observamos em cada um deles o genótipo $\left(a_{1}, a_{1}\right)$ - isto é, $D_{\mathbf{u}}=\left\{\left(a_{1}, a_{1}\right)_{n}\right\}$. Além disso, na mãe do demandado observamos o genótipo $\left(a_{1}, a_{1}\right)$ ou $\left(a_{1}, h\right)$ sendo $h$ um alelo qualquer distinto de $a_{1}$. 
A distribuição de probabilidade a posteriori para o genótipo do pai do demandado $\bar{P}\left[\cdot \mid D_{\mathbf{u}, m_{X}}\right]$, estabelecida na proposição 4.3 .1 , é a seguinte.

$$
\begin{aligned}
\text { genótipo }(\cdot) & \bar{P}\left[(\cdot) \mid \mathbf{u}, m_{X}\right] \\
\left(a_{1}, a_{1}\right) & \frac{2^{n-1} f_{a_{1}}}{H\left[n, f_{a_{1}}\right]} \\
\left(a_{1}, F_{i}\right) & \frac{f_{F_{i}}}{H\left[n, f_{a_{1}}\right]}, \quad i=1,2 \\
\left(a_{1},(x x x)^{c}\right) & \frac{1-f_{a_{1}}-\sum_{i=1}^{2} f_{F_{i}}}{H\left[n, f_{a_{1}}\right]}
\end{aligned}
$$

Para determinarmos a distribuição de probabilidade a posteriori para o genótipo do demandado $P\left[\cdot \mid D_{\mathbf{u}, m_{X}}\right]$, consideramos as seguintes situaçòes:

i) Seja $m_{X}=\left(a_{1}, a_{1}\right)$ o genótipo observado na mãe do demandado. Das expressões 7.2 (ou 7.3) e 7.4 obtemos a distribuição de probabilidade a posteriori para o genótipo do demandado $P\left[\cdot \mid D_{\mathbf{u}, m_{X}}\right]$, dada no seguinte resultado.

Proposição 7.3.1 A distribuição de probabilidade a posteriori para o genótipo do demandado $P\left[\cdot \mid D_{\mathbf{u}, m_{X}}\right]$, uma vez que em sua mãe foi observado o genótipo $m_{X}=\left(a_{1}, a_{1}\right)$ e em $n$ de seus irmàos foi observado o genótipo $\left(a_{1}, a_{1}\right)$, $\dot{\epsilon}$ a seguinte.

$$
\begin{array}{rc}
\text { genótipo }(\cdot) & P\left[(\cdot) \mid \mathbf{u}, m_{X}\right] \\
\left(a_{1}, a_{1}\right) & \frac{H\left[n+1, f_{a_{1}}\right]}{2 H\left[n, f_{a_{1}}\right]} \\
\left(a_{1}, F_{i}\right) & \frac{f_{F_{i}}}{2 H\left[n, f_{a_{1}}\right]}, \quad i=1,2 \\
\left(a_{1},(x x x)^{c}\right) & \frac{1-f_{a_{1}}-\sum_{i=1}^{2} f_{F_{i}}}{2 H\left[n, f_{a_{1}}\right]}
\end{array}
$$

Dessa distribuição de probabilidade a posteriori para o genótipo do demandado - dada neste caso pela expressão 7.5 - obtemos a probabilidade condicional do demandante ter 
recebido do demandado o(s) alelo(s) de interesse após termos observado $D$ e imediatamente, usando a proposição 1.5 .1 , logramos a razão $R V[D]$ para cada conjunto $I$, como podemos ver no seguinte corolário.

Corolário 7.3.1 Sob as condições da proposição 7.3.1, temos que a razão de verossimilhanças $R V[D]$ e a probabilidade condicional $V_{0}[D]$, do demandante ter recebido do demandado o(s) alelo(s) de interesse após termos observado D. estão dadas a seguir

$$
\begin{array}{ccc}
\multicolumn{1}{c}{I} & V_{0}[D] & R V[D] \\
a_{1} & \frac{3+\left(2^{n+1}-3\right) f_{a_{1}}}{4 H\left[n, f_{a_{1}}\right]} & \frac{4 f_{a_{1}} H\left[n, f_{a_{1}}\right]}{3+\left(2^{n+1}-3\right) f_{a_{1}}} \\
F_{i} & \frac{f_{F_{i}}}{4 H\left[n, f_{a_{1}}\right]} & 4 H\left[n, f_{a_{1}}\right], i=1.2 \\
a_{1} \text { e } F_{i} & \frac{3+\left(2^{n+1}-3\right) f_{a_{1}}+f_{F_{i}}}{4 H\left[n, f_{a_{1}}\right]} & \frac{4\left(f_{a_{1}}+f_{F_{i}}\right) H\left[n, f_{a_{1}}\right]}{3+\left(2^{n+1}-3\right) f_{a_{1}}+f_{F_{i}}}, ; i=1,2 \\
F_{1} \text { e } F_{2} & \frac{\sum_{i=1}^{2} f_{F_{i}}}{4 H\left[n, f_{a_{1}}\right]} & 4 H\left[n, f_{a_{1}}\right]
\end{array}
$$

ii) Suponhamos que o genótipo observado na mãe do demandado é $m_{X}=\left(a_{1}, F_{i}\right)$ para $i=1,2, i$ fixado.

A distribuição de probabilidade a posteriori, para o genótipo do demandado $P\left[\cdot \mid D_{\mathbf{u}, m_{X}}\right]$, é dada a seguir.

Proposição 7.3.2 A distribuição de probabilidade a posteriori para o genótipo do demandado $P\left[\cdot \mid D_{\mathbf{u}, m_{X}}\right]$, uma vez que em sua mãe foi observado o genótipo $m_{X}=\left(a_{1}, F_{i}\right)$ e em $n$ de seus irmãos foi observado o genótipo $\left(a_{1}, a_{1}\right)$, é a seguinte.

$$
\begin{array}{rc}
\text { genótipo }(\cdot) & P\left[(\cdot) \mid \mathbf{u}, m_{X}\right] \\
\left(a_{1}, a_{1}\right) & \frac{H\left[n+1, f_{a_{1}}\right]}{4 H\left[n, f_{a_{1}}\right]} \\
\left(a_{1}, F_{i}\right) & \frac{H\left[n+1, f_{a_{1}}\right]+f_{F_{i}}}{4 H\left[n, f_{a_{1}}\right]}
\end{array}
$$




$$
\begin{aligned}
\left(a_{1}, F_{\sigma(i)}\right) & \frac{f_{F_{\sigma(i)}}}{4 H\left[n, f_{a_{1}}\right]} \\
\left(a_{1},(x x x)^{c}\right) & \frac{1-f_{a_{1}}-\sum_{k=1}^{2} f_{F_{k}}}{4 H\left[n, f_{a_{1}}\right]} \\
\left(F_{i}, F_{i}\right) & \frac{f_{F_{i}}}{4 H\left[n, f_{a_{1}}\right]} \\
\left(F_{i}, F_{\sigma(i)}\right) & \frac{f_{F_{\sigma(i)}}}{4 H\left[n, f_{a_{1}}\right]} \\
\left(F_{i},(x x x)^{c}\right) & \frac{1-f_{a_{1}}-\sum_{k=1}^{2} f_{F_{k}}}{4 H\left[n, f_{a_{1}}\right]}
\end{aligned}
$$

Da distribuição de probabilidade a posteriori para o genótipo do demandado - dada pela expressão 7.6 - obtemos a probabilidade condicional do demandante ter recebido do demandado o(s) alelo(s) de interesse - após termos observado $D$ - e a razão $R V[D]$ para cada conjunto $I$, como podemos ver no seguinte corolário.

Corolário 7.3.2 Sob as condiçôes da proposição 7.3.2, temos que a razão de verossimilhanças $R V[D]$ e a probabilidade condicional $V_{0}[D]$, do demandante ter recebido do demandado o(s) alelo(s) de interesse após termos observado $D$, estão dadas a seguir

$$
\begin{array}{cll}
\multicolumn{1}{c}{I} & \multicolumn{1}{c}{V_{0}[D]} & R V[D] \\
a_{1} & \frac{2+\left(3 \times 2^{n-1}-2\right) f_{a_{1}}}{4 H\left[n, f_{a_{1}}\right]} & \frac{4 f_{a_{1}} H\left[n, f_{a_{1}}\right]}{2+\left(3 \times 2^{n-1}-2\right) f_{a_{1}}} \\
F_{i} & \frac{H\left[n+1, f_{a_{1}}\right]+f_{F_{i}}}{4 H\left[n, f_{a_{1}}\right]} & \frac{4 f_{F_{i}} H\left[n, f_{a_{1}}\right]}{H\left[n+1, f_{a_{1}}\right]+f_{F_{i}}} \\
F_{\sigma(i)} & \frac{f_{F_{\sigma(i)}}}{4 H\left[n, f_{a_{1}}\right]} & 4 H\left[n, f_{a_{1}}\right] \\
a_{1} \text { e } F_{i} & \frac{3+\left(2^{n+1}-3\right) f_{a_{1}}+f_{F_{i}}}{4 H\left[n, f_{a_{1}}\right]} & \frac{4\left(f_{a_{1}}+f_{F_{i}}\right) H\left[n, f_{a_{1}}\right]}{3+\left(2^{n+1}-3\right) f_{a_{1}}+f_{F_{i}}} \\
a_{1} \text { e } F_{\sigma(i)} & \frac{2+\left(3 \times 2^{n-1}-2\right) f_{a_{1}}+f_{F_{\sigma(i)}}}{4 H\left[n, f_{a_{1}}\right]} & \frac{4\left(f_{a_{1}}+f_{F_{\sigma_{(i)}}}\right) H\left[n, f_{a_{1}}\right]}{2+\left(3 \times 2^{n-1}-2\right) f_{a_{1}}+f_{F_{\sigma(i)}}}
\end{array}
$$




$$
F_{1} \text { e } F_{2} \quad \frac{H\left[n, f_{a_{1}}\right]+\sum_{i=1}^{2} f_{F_{t}}}{4 H\left[n, f_{a_{1}}\right]} \quad \frac{4 H\left[n, f_{a_{1}}\right] \sum_{k=1}^{2} f_{F_{k}}}{H\left[n, f_{a_{1}}\right]+\sum_{k=1}^{2} f_{F_{k}}}
$$

iii) Seja $h$ um alelo qualquer tal que $h \neq a_{1}, F_{1}, F_{2}$ e suponhamos que o genótipo observado na mãe do demandado é $m_{X}=\left(a_{1}, h\right)$.

Das expressões 7.3 e 7.4 obtemos:

Proposição 7.3.3 A distribuição de probabilidade a posteriori para o genótipo do demandado $P\left[\cdot \mid D_{\mathbf{u}, m_{X}}\right]$, uma vez que em sua mâe foi observado o genótipo $m_{X}=\left(a_{1}, h\right)$ $\left(h \neq a_{1}, F_{1}, F_{2}\right)$ e em $n$ de seus irmãos foi observado o genótipo $\left(a_{1}, a_{1}\right)$, é a seguinte.

$$
\begin{aligned}
\text { genótipo }(\cdot) & P\left[(\cdot) \mid \mathbf{u}, m_{X}\right] \\
\left(a_{1}, a_{1}\right) & \frac{H\left[n+1, f_{a_{1}}\right]}{4 H\left[n, f_{a_{1}}\right]} \\
\left(a_{1}, F_{i}\right) & \frac{f_{F_{i}}}{4 H\left[n, f_{a_{1}}\right]}, \quad i=1,2 \\
\left(a_{1},(x x x)^{c}\right) & \frac{H\left[n+1, f_{a_{1}}\right]-\sum_{k=1}^{2} f_{F_{k}}}{4 H\left[n, f_{a_{1}}\right]} \\
\left(F_{i},(x x x)^{c}\right) & \frac{f_{F_{i}}}{4 H\left[n, f_{a_{1}}\right]}, i=1,2 \\
\left((x x x)^{c},(x x x)^{c}\right) & \frac{1-f_{a_{1}}-\sum_{k=1}^{2} f_{F_{k}}}{4 H\left[n, f_{a_{1}}\right]}
\end{aligned}
$$

Do resultado anterior, obtemos a probabilidade condicional do demandante ter recebido do demandado o(s) alelo(s) de interesse - após termos observado $D$ - e a razão $R V[D]$ para cada conjunto $I$, como podemos ver a seguir.

Corolário 7.3.3 Sob as condiçôes da proposição 7.3.3, temos que a razão de verossimilhanças $R V[D]$ e a probabilidade condicional $V_{0}[D]$, do demandante ter recebido do demandado o(s) alelo(s) de interesse após termos observado $D$, estâa dadas a seguir

$$
V_{0}[D] \quad R V[D]
$$




$$
\begin{array}{lll}
a_{1} & \frac{2+\left(3 \times 2^{n-1}-2\right) f_{a_{1}}}{4 H\left[n, f_{a_{1}}\right]} & \frac{4 f_{a_{1}} H\left[n, f_{a_{1}}\right]}{2+\left(3 \times 2^{n-1}-2\right) f_{a_{1}}} \\
F_{i} & \frac{f_{F_{i}}}{4 H\left[n, f_{a_{1}}\right]} & 4 H\left[n, f_{a_{1}}\right], i=1,2 \\
a_{1} \text { e } F_{i} & \frac{2+\left(3 \times 2^{n-1}-2\right) f_{a_{1}}+f_{F_{i}}}{4 H\left[n, f_{a_{1}}\right]} & \frac{4\left(f_{a_{1}}+f_{F_{i}}\right) H\left[n, f_{a_{1}}\right]}{2+\left(3 \times 2^{n-1}-2\right) f_{a_{1}}+f_{F_{i}}}, i=1,2 \\
F_{1} \text { e } F_{2} & \frac{\sum_{k=1}^{2} f_{F_{k}}}{4 H\left[n, f_{a_{1}}\right]} & 4 H\left[n, f_{a_{1}}\right]
\end{array}
$$

\section{Caso 7.2.1}

Sejam $a_{1}, a_{2}$ e $F_{1}$ três alelos diferentes. Suponhamos que, ao observarmos independentemente $s$ irmãos do demandado, ocorra uma das seguintes situações:

$$
\begin{aligned}
& D_{\mathbf{u}}=\left\{\left(a_{1}, a_{1}\right)_{n},\left(a_{2}, a_{2}\right)_{m}\right\}, \text { onde } s=n+m \text {, ou } \\
& D_{\mathbf{u}}=\left\{\left(a_{1}, a_{1}\right)_{n},\left(a_{1}, a_{2}\right)_{m},\left(a_{2}, a_{2}\right)_{r}\right\}, \quad \text { com } s=n+m+r .
\end{aligned}
$$

Em qualquer uma dessas situações, o genótipo observado na mãe do demandado é $m_{X}=$ $\left(a_{1}, a_{2}\right)$ e, conseqüentemente, temos que a distribuição de probabilidade a posteriori $\bar{P}\left[\cdot \mid D_{\mathbf{u}, m_{X}}\right]$ para o genótipo do pai do demandado é a distribuição

$$
\bar{P}\left[g_{i} \mid D_{\mathbf{u}, m_{X}}\right]= \begin{cases}1 & \text { se } g_{i}=\left(a_{1}, a_{2}\right) \\ 0 & \text { caso contrário, }\end{cases}
$$

A distribuição de probabilidade $P\left[\cdot \mid D_{\mathbf{u}, m_{X}}\right]$ - obtida das expressòes $7.2,7.4$ e 7.10 - é dada no seguinte resultado.

Proposição 7.3.4 Sob as condições estabelecidas acima temos que a distribuiçâo de probabilidade a posteriori para o genótipo do demandado $P\left[\cdot \mid D_{\mathbf{u}, m_{X}}\right]$ é a seguinte.

$$
\begin{aligned}
\text { genótipo }(\cdot) & P\left[\cdot \mid \mathbf{u}, m_{X}\right] \\
\left(a_{i}, a_{i}\right) & \frac{1}{4}, i=1,2 \\
\left(a_{1}, a_{2}\right) & \frac{1}{2}
\end{aligned}
$$


A razão de verossimilhança $R V[D]$ e a probabilidade condicional $V_{0}[D]$, que é obtida da expressão 7.11, estão dadas na seguinte tabela.

Tabela 7.2 Probabilidade condicional $V_{0}[D]$ e razào de verossimilhanças $R V[D]$ - Caso 2.1

$$
\begin{array}{ccl}
I & V_{0}[D] & R V[D] \\
a_{i} & 1 / 2 & 2 f_{a_{i}}, \quad i=1,2 \\
a_{1} \text { e } a_{2} & 1 & f_{a_{1}}+f_{a_{2}} \\
a_{i} \text { e } F_{1} & 1 / 2 & 2\left(f_{a_{i}}+f_{F_{1}}\right) \quad i=1,2
\end{array}
$$

\section{Caso 7.2.2}

Sejam $a_{i}$ e $F_{i}$ para $i=1,2$ quatro alelos diferentes. Suponhamos que, ao considerarmos $n$ irmãos do demandado, independentemente, observamos em cada um deles o genótipo $\left(a_{1}, a_{2}\right)$ - isto é, $D_{\mathbf{u}}=\left\{\left(a_{1}, a_{2}\right)_{n}\right\}$.

Ao observarmos o genótipo da mãe do demandado, pode ocorrer uma das seguintes situações:

i) Se $m_{X}=\left(a_{k}, a_{k}\right)$ para $k=1,2$ ( $k$ fixo) temos que a distribuição de probabilidade $a$ posteriori $\bar{P}\left[\cdot \mid D_{\mathbf{u}, m_{X}}\right]$ para o genótipo do pai do demandado é a distribuição

$$
\begin{aligned}
\text { genótipo (·) } & \bar{P}\left[\cdot \mid D_{\mathbf{u}, m_{X}}\right] \\
\left(a_{\sigma(k)}, a_{\sigma(k)}\right) & \frac{2^{n-1} f_{a_{\sigma(k)}}}{H\left[n, f_{a_{\sigma(k)}}\right]} \\
\left(a_{\sigma(k)}, a_{k}\right) & \frac{f_{a_{k}}}{H\left[n, f_{a_{\sigma(k)}}\right]} \\
\left(a_{\sigma(k)}, F_{i}\right) & \frac{f_{F_{1}}}{H\left[n, f_{a_{\sigma(k)}}\right]}, \quad i=1,2 \\
\left(a_{\sigma(k)},(x x x x)^{c}\right) & \frac{1-\sum_{k=1}^{2}\left(f_{a_{k}}+f_{F_{k}}\right)}{H\left[n, f_{a_{\sigma(k)}}\right]} .
\end{aligned}
$$


Das expressões 7.2 e 7.12 obtemos:

Proposição 7.3.5 A distribuição de probabilidade a posteriori para o genótipo do demandado $P\left[\cdot \mid D_{\mathbf{u}, m_{X}}\right]$, uma vez que em sua mãe foi observado o genótipo $m_{X}=\left(a_{k}, a_{k}\right)$ e em $n$ de seus irmãos foi observado o genótipo $\left(a_{1}, a_{2}\right)$, é a seguinte.

$$
\begin{aligned}
\text { genótipo }(\cdot) & P\left[(\cdot) \mid \mathbf{u}, m_{X}\right] \\
\left(a_{k}, a_{k}\right) & \frac{f_{a_{k}}}{2 H\left[n, f_{a_{\sigma(k)}}\right]} \\
\left(a_{k}, a_{\sigma(k)}\right) & \frac{H\left[n+1, f_{a_{\sigma(k)}}\right]}{2 H\left[n, f_{a_{\sigma(k)}}\right]} \\
\left(a_{k}, F_{j}\right) & \frac{f_{F_{j}}}{2 H\left[n, f_{a_{\sigma(k)}}\right]}, j=1,2 \\
\left(a_{k},(x x x x)^{c}\right) & \frac{1-\sum_{i=1}^{2}\left(f_{a_{i}}+f_{F_{i}}\right)}{2 H\left[n, f_{a_{\sigma(k)}}\right]}
\end{aligned}
$$

Conseqüentemente, do resultado anterior decorre o seguinte corolário.

Corolário 7.3.4 Sob as condições da proposição 7.3.5, temos que a razão de verossimilhanças $R V[D]$ e a probabilidade condicional $V_{0}[D]$, do demandante ter recebido do demandado o(s) alelo(s) de interesse após termos observado $D$, estão dadas a seguir

$$
\begin{aligned}
& V_{0}[D] \quad R V[D] \\
& a_{k} \quad \frac{f_{a_{k}}+2 H\left[n, f_{a_{\sigma(k)}}\right]}{4 H\left[n, f_{a_{\sigma(k)}}\right]} \quad \frac{4 f_{a_{k}} H\left[n, f_{a_{\sigma(k)}}\right]}{f_{a_{k}}+2 H\left[n, f_{a_{\sigma(k)}}\right]} \\
& a_{\sigma(k)} \quad \frac{H\left[n+1, f_{a_{\sigma(k)}}\right]}{4 H\left[n, f_{a_{\sigma(k)}}\right]} \quad \frac{4 f_{a_{\sigma(k)}} H\left[n, f_{a_{\sigma(k)}}\right]}{H\left[n+1, f_{a_{\sigma(k)}}\right]} \\
& F_{i} \quad \frac{f_{F_{i}}}{4 H\left[n, f_{a_{\sigma(k)}}\right]} \quad 4 H\left[n, f_{a_{\sigma(k)}}\right], i=1,2 \\
& a_{k} e a_{\sigma(k)} \quad \frac{3+\left(2^{n+1}-3\right) f_{a_{\sigma(k)}}+f_{a_{k}}}{4 H\left[n, f_{a_{\sigma(k)}}\right]} \quad \frac{4\left(f_{a_{k}}+f_{a_{\sigma(k)}}\right) H\left[n, f_{a_{\sigma(k)}}\right]}{3+\left(2^{n+1}-3\right) f_{a_{\sigma(k)}}+f_{a_{k}}}
\end{aligned}
$$




$$
\begin{array}{rll}
a_{k} \text { e } F_{i} & \frac{f_{F_{i}}+f_{a_{k}}+2 H\left[n, f_{a_{\sigma(k)}}\right]}{4 H\left[n, f_{a_{\sigma(k)}}\right]} & \frac{4\left(f_{a_{k}}+f_{F_{i}}\right) H\left[n, f_{a_{\sigma(k)}}\right]}{f_{a_{k}}+f_{F_{i}}+2 H\left[n, f_{a_{\sigma(k)}}\right]}, i=1,2 \\
a_{\sigma(k)} \text { e } F_{i} & \frac{f_{F_{i}}+H\left[n+1, f_{a_{\sigma(k)}}\right]}{4 H\left[n, f_{a_{\sigma(k)}}\right]} & \frac{4\left(f_{F_{i}}+f_{a_{\sigma(k)}}\right) H\left[n, f_{a_{\sigma(k)}}\right]}{f_{F_{i}}+H\left[n+1, f_{a_{\sigma(k)}}\right]}, i=1,2 \\
F_{1} \text { e } F_{2} & \frac{\sum_{i=1}^{2} f_{F_{i}}}{4 H\left[n, f_{a_{\sigma(k)}}\right]} & 4 H\left[n, f_{a_{\sigma(k)}}\right] .
\end{array}
$$

ii) Seja $m_{X}=\left(a_{k}, F_{i}\right)$ para $i, k=1,2$ com $i$ e $k$ fixos. Neste caso particular, obtemos que a distribuição de probabilidade a posteriori $\bar{P}\left[\cdot \mid D_{\mathbf{u}, m_{X}}\right]$ para o genótipo do pai do demandado é dada pela expressão 7.12 .

Desse fato e da expressão 7.2 deduzimos a distribuição de probabilidade a posteriori para o genótipo do demandado $P\left[\cdot \mid D_{\mathbf{u}, m_{X}}\right]$, a qual fornecemos no seguinte resultado.

Proposição 7.3.6 A distribuição de probabilidade a posteriori para o genótipo do demandado $P\left[\cdot \mid D_{\mathbf{u}, m_{X}}\right]$, uma vez que em $n$ de seus irmãos foi observado o genótipo $\left(a_{1}, a_{2}\right)$ e em sua mãe foi observado o genótipo $m_{X}=\left(a_{k}, F_{i}\right)$ é a seguinte.

$$
\begin{array}{rc}
\text { genótipo (·) } & P\left[(\cdot) \mid \mathbf{u}, m_{X}\right] \\
\left(a_{k}, a_{k}\right) & \frac{f_{a_{k}}}{4 H\left[n, f_{a_{\sigma(k)}}\right]} \\
\left(a_{k}, a_{\sigma(k)}\right) & \frac{H\left[n+1, f_{a_{\sigma(k)}}\right]}{4 H\left[n, f_{a_{\sigma(k)}}\right]} \\
\left(a_{k}, F_{i}\right) & \frac{f_{a_{k}}+f_{F_{i}}}{4 H\left[n, f_{a_{\sigma(k)}}\right]} \\
\left(a_{\sigma(k)}, F_{i}\right) & \frac{H\left[n+1, f_{a_{\sigma(k)}}\right]}{4 H\left[n, f_{a_{\sigma(k)}}\right]} \\
\left(a_{k},(x x x x)^{c}\right) & \frac{1-\sum_{j=1}^{2}\left(f_{a_{j}}+f_{F_{j}}\right)}{4 H\left[n, f_{a_{\sigma(k)}}\right]} \\
\left(F_{i}, F_{i}\right) & \frac{f_{F_{i}}}{4 H\left[n, f_{a_{\sigma(k)}}\right]}
\end{array}
$$




$$
\begin{aligned}
\left(F_{i}, F_{\sigma(i)}\right) & \frac{f_{F_{\sigma(i)}}}{4 H\left[n, f_{a_{\sigma(k)}}\right]} \\
\left(F_{i},(x x x x)^{c}\right) & \frac{1-\sum_{j=1}^{2}\left(f_{a_{j}}+f_{F_{3}}\right)}{4 H\left[n, f_{a_{\sigma(k)}}\right]}
\end{aligned}
$$

Conseqüentemente, do resultado anterior decorre o seguinte corolário.

Corolário 7.3.5 Sob as condições da proposição 7.3.6. temos que a razão de verossimilhanças $R V[D]$ e a probabilidade condicional $V_{0}[D]$, do demandante ter recebido do demandado o(s) alelo(s) de interesse após termos observado D. estão dadas a seguir

$$
\begin{aligned}
& I \quad V_{0}[D] \\
& R V[D] \\
& a_{k} \quad \frac{f_{a_{k}}+H\left[n, f_{a_{\sigma(k)}}\right]}{4 H\left[n, f_{a_{\sigma(k)}}\right]} \\
& \frac{4 f_{a_{k}} H\left[n, f_{a_{\sigma(k)}}\right]}{f_{a_{k}}+H\left[n, f_{a_{\sigma(k)}}\right]} \\
& a_{\sigma(k)} \quad \frac{H\left[n+1, f_{a_{\sigma(k)}}\right]}{4 H\left[n, f_{a_{\sigma(k)}}\right]} \\
& F_{i} \quad \frac{f_{F_{i}}+H\left[n, f_{a_{\sigma(k)}}\right]}{4 H\left[n, f_{a_{\sigma(k)}}\right]} \\
& \frac{4 f_{a_{\sigma(k)}} H\left[n, f_{a_{\sigma(k)}}\right]}{H\left[n+1, f_{a_{\sigma(k)}}\right]} \\
& \frac{4 f_{F_{i}} H\left[n, f_{a_{\sigma(k)}}\right]}{f_{F_{i}}+H\left[n, f_{a_{\sigma(k)}}\right]} \\
& F_{\sigma(i)} \quad \frac{f_{F_{\sigma(i)}}}{4 H\left[n, f_{a_{\sigma(k)}}\right]} \\
& a_{k} e a_{\sigma(k)} \frac{2+\left(3 \times 2^{n+1}-2\right) f_{a_{\sigma(k)}}+f_{a_{k}}}{4 H\left[n, f_{a_{\sigma(k)}}\right]} \\
& a_{k} \text { e } F_{i} \quad \frac{f_{F_{i}}+f_{a_{k}}+2 H\left[n, f_{a_{\sigma(k)}}\right]}{4 H\left[n, f_{a_{\sigma(k)}}\right]} \\
& a_{\sigma(k)} \text { e } F_{i} \quad \frac{f_{F_{i}}+2+\left(3 \times 2^{n+1}-2\right) f_{a_{\sigma(k)}}}{4 H\left[n, f_{a_{\sigma(k)}}\right]} \\
& 4 H\left[n, f_{a_{\sigma(k)}}\right] \\
& a_{k} e F_{\sigma(i)} \quad \frac{f_{F_{\sigma(i)}}+f_{a_{k}}+H\left[n, f_{a_{\sigma(k)}}\right]}{4 H\left[n, f_{a_{\sigma(k)}}\right]} \\
& a_{\sigma(k)} e F_{\sigma(i)} \quad \frac{f_{F_{\sigma(1)}}+H\left[n+1, f_{a_{\sigma(k)}}\right]}{4 H\left[n, f_{a_{\sigma(k)}}\right]} \\
& \frac{4\left(f_{a_{k}}+f_{a_{\sigma(k)}}\right) H\left[n, f_{a_{\sigma(k)}}\right]}{2+\left(3 \times 2^{n+1}-2\right) f_{a_{\sigma(k)}}+f_{a_{k}}} \\
& \frac{4\left(f_{a_{k}}+f_{F_{i}}\right) H\left[n, f_{a_{\sigma(k)}}\right]}{f_{a_{k}}+f_{F_{i}}+2 H\left[n, f_{a_{\sigma(k)}}\right]} \\
& \frac{4\left(f_{F_{i}}+f_{a_{\sigma(k)}}\right) H\left[n, f_{a_{\sigma(k)}}\right]}{f_{F_{i}}+2+\left(3 \times 2^{n+1}-2\right) f_{a_{\sigma(k)}}} \\
& \frac{4\left(f_{a_{k}}+f_{F_{\sigma(i)}}\right) H\left[n, f_{a_{\sigma(k)}}\right]}{f_{a_{k}}+f_{F_{\sigma(1)}}+H\left[n, f_{a_{\sigma(k)}}\right]} \\
& \frac{4\left(f_{F_{\sigma(t)}}+f_{a_{\sigma(k)}}\right) H\left[n, f_{a_{\sigma(k)}}\right]}{f_{F_{\sigma(t)}}+H\left[n+1, f_{a_{\sigma(k)}}\right]}
\end{aligned}
$$




$$
F_{1} e F_{2} \quad \frac{H\left[n, f_{a_{\sigma(k)}}\right]+\sum_{i=1}^{2} f_{F_{i}}}{4 H\left[n, f_{a_{\sigma(k)}}\right]} \quad \frac{4 H\left[n, f_{a_{\sigma(k)}}\right] \sum_{j=1}^{2} f_{F_{j}}}{H\left[n, f_{a_{\sigma(k)}}\right]+\sum_{j=1}^{2} f_{F_{3}}}
$$

iii) Seja $h$ um alelo qualquer tal que $h$ é diferente dos alelos $a_{1}, a_{2}, F_{1}$ e $F_{2}$. Suponhamos que $m_{X}=\left(a_{k}, h\right)$ para $k=1,2$ ( $k$ fixo). Como na situação anterior, obtemos que a distribuição de probabilidade a posteriori $\bar{P}\left[\cdot \mid D_{\mathbf{u}, m_{X}}\right]$ para o genótipo do pai do demandado é dada pela expressão 7.12 .

Neste caso, a distribuição de probabilidade a posteriori para o genótipo do demandado $P\left[\cdot \mid D_{\mathbf{u}, m_{X}}\right]$ é dada no seguinte resultado.

Proposição 7.3.7 Sob as condiçòes estabelecidas acima, temos que a distribuição de probabilidade a posteriori para o genótipo do demandado $P\left[\cdot \mid D_{\mathbf{u}, m_{X}}\right]$, uma vez que em $n$ de seus irmãos foi observado o genótipo $\left(a_{1}, a_{2}\right)$ e em sua mãe foi observado o genótipo $m_{X}=\left(a_{k}, h\right)$, é a seguinte.

$$
\begin{aligned}
\text { genótipo }(\cdot) & P\left[(\cdot) \mid \mathbf{u}, m_{X}\right] \\
\left(a_{k}, a_{k}\right) & \frac{f_{a_{k}}}{4 H\left[n, f_{\left.a_{\sigma(k)}\right]}\right.} \\
\left(a_{k}, a_{\sigma(k)}\right) & \frac{H\left[n+1, f_{a_{\sigma(k)}}\right]}{4 H\left[n, f_{a_{\sigma(k)}}\right]} \\
\left(a_{k}, F_{j}\right) & \frac{f_{F_{j}}}{4 H\left[n, f_{\left.a_{\sigma(k)}\right]}\right]}, j=1,2 \\
\left(a_{k},(x x x x)^{c}\right) & \frac{1-f_{a_{\sigma(k)}}-\sum_{j=1}^{2} f_{F_{j}}}{4 H\left[n, f_{a_{\sigma(k)}}\right]} \\
\left(a_{\sigma(k)},(x x x x)^{c}\right) & \frac{H\left[n+1, f_{a_{\sigma(k)}}\right]}{4 H\left[n, f_{a_{\sigma(k)}}\right]} \\
\left(F_{j},(x x x x)^{c}\right) & \frac{f_{F_{j}}}{4 H\left[n, f_{\left.a_{\sigma(k)}\right]}\right.}, j=1,2 \\
\left((x x x x)^{c},(x x x x)^{c}\right) & \frac{1-\sum_{i=1}^{2}\left(f_{a_{t}}+f_{F_{i}}\right)}{4 H\left[n, f_{a_{\sigma(k)}}\right]}
\end{aligned}
$$


Do resultado anterior obtemos:

Corolário 7.3.6 Sob as condiçôes da proposição 7.3.7, temos que a razão de verossimilhanças $R V[D]$ e a probabilidade condicional $V_{0}[D]$, do demandante ter recebido do demandado o(s) alelo(s) de interesse após termos observado D, estão dadas a seguir

$$
\begin{aligned}
& I \quad V_{0}[D] \\
& R V[D] \\
& a_{k} \quad \frac{f_{a_{k}}+H\left[n, f_{a_{\sigma(k)}}\right]}{4 H\left[n, f_{a_{\sigma(k)}}\right]} \\
& \frac{4 f_{a_{k}} H\left[n, f_{a_{\sigma(k)}}\right]}{f_{a_{k}}+H\left[n, f_{a_{\sigma(k)}}\right]} \\
& a_{\sigma(k)} \quad \frac{H\left[n+1, f_{a_{\sigma(k)}}\right]}{4 H\left[n, f_{a_{\sigma(k)}}\right]} \\
& \frac{4 f_{a_{\sigma(k)}} H\left[n, f_{a_{\sigma(k)}}\right]}{H\left[n+1, f_{a_{\sigma(k)}}\right]} \\
& F_{i} \quad \frac{f_{F_{i}}}{4 H\left[n, f_{a_{\sigma(k)}}\right]} \\
& a_{k} \text { e } a_{\sigma(k)} \quad \frac{2+\left(3 \times 2^{n+1}-2\right) f_{a_{\sigma(k)}}+f_{a_{k}}}{4 H\left[n, f_{a_{\sigma(k)}}\right]} \quad \frac{4\left(f_{a_{k}}+f_{a_{\sigma(k)}}\right) H\left[n, f_{a_{\sigma(k)}}\right]}{2+\left(3 \times 2^{n+1}-2\right) f_{a_{\sigma(k)}}+f_{a_{k}}} \\
& a_{k} \quad \text { e } F_{i} \quad \frac{f_{F_{i}}+f_{a_{k}}+H\left[n, f_{a_{\sigma(k)}}\right]}{4 H\left[n, f_{a_{\sigma(k)}}\right]} \\
& \frac{4\left(f_{a_{k}}+f_{F_{i}}\right) H\left[n, f_{a_{\sigma(k)}}\right]}{f_{a_{k}}+f_{F_{i}}+H\left[n, f_{a_{\sigma(k)}}\right]}, i=1,2 \\
& a_{\sigma(k)} \text { e } F_{i} \quad \frac{f_{F_{i}}+H\left[n+1, f_{a_{\sigma(k)}}\right]}{4 H\left[n, f_{a_{\sigma(k)}}\right]} \\
& \frac{4\left(f_{F_{i}}+f_{a_{\sigma(k)}}\right) H\left[n, f_{a_{\sigma(k)}}\right]}{f_{F_{i}}+H\left[n+1, f_{a_{\sigma(k)}}\right]}, i=1,2 \\
& F_{1} \text { e } F_{2} \quad \frac{\sum_{i=1}^{2} f_{F_{i}}}{4 H\left[n, f_{a_{\sigma(k)}}\right]} \\
& 4 H\left[n, f_{a_{\sigma(k)}}\right] .
\end{aligned}
$$

iv) Suponhamos que o genótipo observado na mãe do demandado é $m_{X}=\left(a_{1}, a_{2}\right)$.

A distribuição de probabilidade a posteriori para o genótipo do pai do demandado $\bar{P}\left[\cdot \mid D_{\mathbf{u}, m_{X}}\right]$ - obtida na proposição 4.3 .2 - é a seguinte.

$$
\begin{aligned}
\text { genótipo }(\cdot) & \bar{P}\left[\cdot \mid D_{\mathbf{u}, m_{X}}\right] \\
\left(a_{i}, a_{i}\right) & 2^{n-1} f_{a_{i}}^{2} / w, \quad i=1,2 \\
\left(a_{1}, a_{2}\right) & 2^{n} f_{a_{1}} f_{a_{2}} / w
\end{aligned}
$$




$$
\begin{array}{cl}
\left(a_{i}, F_{j}\right) & f_{a_{i}} f_{F_{j}} / w, i, j=1,2 \\
\left(a_{i},(x x x x)^{c}\right) & f_{a_{i}}\left(1-\sum_{j=1}^{2}\left(f_{a_{j}}+f_{F_{j}}\right)\right) / w, \quad i=1,2,
\end{array}
$$

onde $w=w\left[n, f_{a_{1}}, f_{a_{2}}\right]$ é a função definida pela expressão

$$
w=\left(\sum_{k=1}^{2} H\left[n, f_{a_{k}}\right]-1\right) \sum_{k=1}^{2} f_{a_{k}},
$$

Considerando as expressões 7.16, 7.17 e 7.2 fornecemos a distribuição de probabilidade a posteriori para o genótipo do demandado $P\left[\cdot \mid D_{\mathbf{u}, m_{X}}\right]$, no seguinte resultado.

Proposição 7.3.8 Sob as condiçôes estabelecidas acima temos que a distribuição de probabilidade a posteriori para o genótipo do demandado $P\left[\cdot \mid D_{\mathbf{u}, m_{X}}\right]$, uma vez que em sua mãe e em $n$ de seus irmãos foi observado o genótipo $\left(a_{1}, a_{2}\right)$, é a seguinte.

$$
\begin{aligned}
\text { genótipo }(\cdot) & P\left[(\cdot) \mid \mathbf{u}, m_{X}\right] \\
\left(a_{i}, a_{i}\right) & \frac{f_{a_{i}}\left(\sum_{k=1}^{2} H\left[n+1, f_{a_{k}}\right]-1\right)}{4 w\left[n, f_{a_{1}}, f_{a_{2}}\right]}, i=1,2 \\
\left(a_{1}, a_{2}\right) & \frac{\left(\sum_{k=1}^{2} H\left[n+1, f_{a_{k}}\right]-1\right) \sum_{k=1}^{2} f_{a_{k}}}{4 w\left[n, f_{a_{1}}, f_{a_{2}}\right]} \\
\left(a_{i}, F_{j}\right) & \frac{f_{F_{j}} \sum_{k=1}^{2} f_{a_{k}}}{4 w\left[n, f_{a_{1}}, f_{a_{2}}\right]}, i, j=1,2 \\
\left(a_{i},(x x x x)^{c}\right) & \frac{\left(1-\sum_{k=1}^{2}\left(f_{a_{k}}+f_{F_{k}}\right)\right) \sum_{k=1}^{2} f_{a_{k}}}{4 w\left[n, f_{a_{1}}, f_{a_{2}}\right]}
\end{aligned}
$$

Como conseqüência do resultado anterior surge, naturalmente, o seguinte corolário.

Corolário 7.3.7 Sob as condiçòes da proposição 7.3.8, temos que a razão de verossimilhanças $R V[D]$ e a probabilidade condicional $V_{0}[D]$, do demandante ter recebido do 
demandado o(s) alelo(s) de interesse após termos observado D, estâo dadas a seguir

$$
\begin{aligned}
& \text { I } \\
& V_{0}[D] \\
& R V[D] \\
& a_{i} \quad \frac{u_{i}\left[n, f_{a_{1}}, f_{a_{2}}\right]}{4 w\left[n, f_{a_{1}}, f_{a_{2}}\right]} \\
& \frac{4 f_{a_{i}} w\left[n, f_{a_{1}}, f_{a_{2}}\right]}{u_{i}\left[n, f_{a_{1}}, f_{a_{2}}\right]}, i=1,2 \\
& F_{i} \quad \frac{f_{F_{i}} \sum_{k=1}^{2} f_{a_{k}}}{4 w\left[n, f_{a_{1}}, f_{a_{2}}\right]} \\
& 4\left(\sum_{k=1}^{2} H\left[n, f_{a_{k}}\right]-1\right), \quad i=1,2 \\
& a_{1} \quad e \quad a_{2} \quad \frac{u_{3}\left[n, f_{a_{1}}, f_{a_{2}}\right]}{4 w\left[n, f_{a_{1}}, f_{a_{2}}\right]} \\
& \frac{4\left(f_{a_{1}}+f_{a_{2}}\right) w\left[n, f_{a_{1}}, f_{a_{2}}\right]}{u_{3}\left[n, f_{a_{1}}, f_{a_{2}}\right]} \\
& a_{i} e F_{j} \quad \frac{u_{i j}\left[n, f_{a_{1}}, f_{a_{2}}, f_{F_{j}}\right]}{4 w\left[n, f_{a_{1}}, f_{a_{2}}\right]} \\
& \frac{4\left(f_{a_{i}}+f_{F_{j}}\right) w\left[n, f_{a_{1}}, f_{a_{2}}\right]}{u_{i j}\left[n, f_{a_{1}}, f_{a_{2}}, f_{F_{j}}\right]}, \quad i, j=1,2 \\
& F_{1} e F_{2} \quad \frac{\sum_{k=1}^{2} f_{F_{k}} \sum_{k=1}^{2} f_{a_{k}}}{4 w\left[n, f_{a_{1}}, f_{a_{2}}\right]} \\
& 4\left(\sum_{k=1}^{2} H\left[n, f_{a_{k}}\right]-1\right) \text {, }
\end{aligned}
$$

onde para $i=1,2,3$ e $j=1,2$ as funções $u_{i}=u_{i}\left[n, f_{a_{1}}, f_{a_{2}}\right]$ e $u_{i j}=u_{i j}\left[n, f_{a_{1}}, f_{a_{2}}, f_{F_{j}}\right]$ são dadas por

$$
\begin{aligned}
& u_{i}=f_{a_{i}}\left(\sum_{k=1}^{2} H\left[n+1, f_{a_{k}}\right]-1\right)+\left(\sum_{k=1}^{2} H\left[n, f_{a_{k}}\right]-1\right) \sum_{k=1}^{2} f_{a_{k}}, i=1,2 \\
& u_{3}=\left(\sum_{k=1}^{2} H\left[n+1, f_{a_{k}}\right]-1\right) \sum_{k=1}^{2} f_{a_{k}}+2\left(\sum_{k=1}^{2} H\left[n, f_{a_{k}}\right]-1\right) \\
& u_{i j}=f_{a_{i}}\left(\sum_{k=1}^{2} H\left[n+1, f_{a_{k}}\right]-1\right)+\left(f_{F_{j}}-1+\sum_{k=1}^{2} H\left[n, f_{a_{k}}\right]\right) \sum_{k=1}^{2} f_{a_{k}}, i, j=1,2 .
\end{aligned}
$$

\section{Caso 7.2.3}

Consideremos três alelos diferentes $a_{1}, a_{2}$ e $F_{1}$. Suponhamos que foram observados $n+m$ irmãos do demandado, independentemente, encontrando em $n$ deles o genótipo $\left(a_{1}, a_{1}\right)$ e nos outros $m$ irmãos o genótipo $\left(a_{1}, a_{2}\right)$ - isto é,

$$
D_{\mathbf{u}}=\left\{\left(a_{1}, a_{1}\right)_{n},\left(a_{1}, a_{2}\right)_{m}\right\}
$$


Além disso, ao observarmos o genótipo da mãe do demandado pode ocorrer uma das seguintes situações:

$$
\begin{aligned}
& \text { i) } m_{X}=\left(a_{1}, a_{1}\right) \\
& \text { ii) } m_{X}=\left(a_{1}, F_{1}\right) \\
& \text { iii) } m_{X}=\left(a_{1}, h\right) \text { com } h \neq F_{1} \text { e } h \neq a_{j}, j=1,2 \\
& \text { iv) } m_{X}=\left(a_{1}, a_{2}\right)
\end{aligned}
$$

i) Se $m_{X}=\left(a_{1}, a_{1}\right)$ temos que a distribuição de probabilidade a posteriori $\bar{P}\left[\cdot \mid D_{\mathbf{u}, m_{X}}\right]$ para o genótipo do pai do demandado é a distribuição

$$
\bar{P}\left[g_{i} \mid D_{\mathbf{u}, m_{X}}\right]= \begin{cases}1 & \text { se } g_{i}=\left(a_{1}, a_{2}\right) \\ 0 & \text { caso contrário, }\end{cases}
$$

Das expressões 7.2 e 7.19 obtemos que a distribuição de probabilidade a posteriori para o genótipo do demandado $P\left[\cdot \mid D_{\mathbf{u}, m_{X}}\right]$ é dada pela seguinte express ao.

$$
P\left[g_{i} \mid D_{\mathbf{u}, m_{X}}\right]=\left\{\begin{array}{cl}
1 / 2 & \text { se } g_{i}=\left(a_{1}, a_{1}\right) \text { ou } g_{i}=\left(a_{1}, a_{2}\right) \\
0 & \text { caso contrário, }
\end{array}\right.
$$

A razão de verossimilhança $R V[D]$ e a probabilidade condicional $V_{0}[D]$, que é obtida da expressão 7.20 , estão dadas na seguinte tabela.

Tabela 7.2 Probabilidade condicional $V_{0}[D]$ e razão de verossimilhanças $R V[D]$ - Caso $7.2 .3 \mathrm{i}$

$$
\begin{array}{ccl}
I & V_{0}[D] & \multicolumn{1}{c}{R V[D]} \\
a_{1} & 3 / 4 & 4 f_{a_{1}} / 3 \\
a_{2} & 1 / 4 & 4 f_{a_{2}} \\
a_{1} \text { е } a_{2} & 1 & f_{a_{1}}+f_{a_{2}} \\
a_{1} \text { е } F_{1} & 3 / 4 & 4\left(f_{a_{1}}+f_{F_{1}}\right) / 3 \\
a_{2} \text { е } F_{1} & 1 / 4 & 4\left(f_{a_{2}}+f_{F_{1}}\right)
\end{array}
$$


ii) Suponhamos que o genótipo observado na mãe do demandado é $m_{X}=\left(a_{1}, F_{1}\right)$. Neste caso, a distribuição de probabilidade a posteriori $\bar{P}\left[\cdot \mid D_{\mathbf{u}, m_{X}}\right]$ para o genótipo do pai do demandado, é dada pela expressão 7.19 e, conseqüentemente, a distribuição de probabilidade a posteriori para o genótipo do demandado $P\left[\cdot \mid D_{\mathbf{u}, m_{X}}\right]$ é a seguinte.

$$
\begin{array}{rr}
\text { genótipo }(\cdot) & P\left[\cdot \mid \mathbf{u}, m_{X}\right] \\
\left(a_{1}, a_{i}\right) & 1 / 4, \quad i=1,2 \\
\left(a_{i}, F_{1}\right) & 1 / 4, \quad i=1,2
\end{array}
$$

Como consequiência do resultado anterior, temos que a probabilidade condicional $V_{0}[D]$ e a razão de verossimilhança $R V[D]$ estão dadas por:

Tabela 7.3 Probabilidade condicional $V_{0}[D]$ e razão de verossimilhanças $R V[D]$ - Caso 7.2 .3 ii

$$
\begin{array}{ccl}
I & V_{0}[D] & \multicolumn{1}{c}{R V[D]} \\
a_{1} & 1 / 2 & 2 f_{a_{1}} \\
a_{2} & 1 / 4 & 4 f_{a_{2}} \\
F_{1} & 1 / 4 & 4 f_{F_{1}} \\
a_{1} \text { e } a_{2} & 3 / 4 & 4\left(f_{a_{1}}+f_{a_{2}}\right) / 3 \\
a_{1} \text { e } F_{1} & 3 / 4 & 4\left(f_{a_{1}}+f_{F_{1}}\right) / 3 \\
a_{2} \text { e } F_{1} & 1 / 4 & 4\left(f_{a_{2}}+f_{F_{1}}\right)
\end{array}
$$

iii) Seja $h$ um alelo qualquer tal que $h \neq F_{1}$ e $h \neq a_{j}, j=1,2$. Se o genótipo observado na mãe do demandado é $m_{X}=\left(a_{1}, h\right)$ temos que a distribuição de probabilidade $a$ posteriori $\bar{P}\left[\cdot \mid D_{\mathbf{u}, m_{X}}\right]$ para o genótipo do pai do demandado é dada pela expressão 7.19 e conseqüentemente, a distribuição de probabilidade a posteriori para o genótipo do demandado $P\left[\cdot \mid D_{\mathbf{u}, m_{X}}\right]$ é a seguinte.

$$
\begin{array}{rr}
\text { genótipo }(\cdot) & P\left[\cdot \mid \text { u. } m_{X}\right] \\
\left(a_{1}, a_{i}\right) & 1 / 4, \quad i=1,2 \\
\left(a_{i},(x x x)^{c}\right) & 1 / 4, \quad i=1,2
\end{array}
$$


A razão de verossimilhança $R V[D]$ e a probabilidade condicional $V_{0}[D]$, obtida do resultado anterior, estão dadas na tabela seguinte.

Tabela 7.4 Probabilidade condicional $V_{0}[D]$ e razão

de verossimilhanças $R V[D]$ - Caso 7.2 .3 iii

$$
\begin{array}{ccl}
I & V_{0}[D] & \multicolumn{1}{c}{R V[D]} \\
a_{1} & 1 / 2 & 2 f_{a_{1}} \\
a_{2} & 1 / 4 & 4 f_{a_{2}} \\
a_{1} \text { е } a_{2} & 3 / 4 & 4\left(f_{a_{1}}+f_{a_{2}}\right) / 3 \\
a_{1} \text { е } F_{1} & 1 / 2 & 2\left(f_{a_{1}}+f_{F_{1}}\right) \\
a_{2} \text { е } F_{1} & 1 / 4 & 4\left(f_{a_{2}}+f_{F_{1}}\right)
\end{array}
$$

iv) Suponhamos que o genótipo observado na mãe do demandado é $m_{X}=\left(a_{1}, a_{2}\right)$.

A distribuição de probabilidade a posteriori para o genótipo do pai do demandado $\bar{P}\left[\cdot \mid D_{\mathbf{u}, m_{X}}\right]$ - obtida na proposição 4.3 .4 - é a seguinte.

$$
\begin{array}{rc}
\text { genótipo }(\cdot) & \bar{P}\left[\cdot \mid D_{\mathbf{u}, m_{X}}\right] \\
\left(a_{1}, a_{1}\right) & \frac{2^{n+m-1} f_{a_{1}}}{w\left[n, m, f_{a_{1}}, f_{a_{2}}\right]} \\
\left(a_{1}, a_{2}\right) & \frac{2^{m} f_{a_{2}}}{w\left[n, m, f_{a_{1}}, f_{a_{2}}\right]} \\
\left(a_{1}, F_{1}\right) & \frac{f_{F_{1}}}{w\left[n, m, f_{a_{1}}, f_{a_{2}}\right]} \\
\left(a_{1},(x x x)^{c}\right) & \frac{1-f_{F_{1}}-\sum_{j=1}^{2} f_{a_{j}}}{w\left[n, m, f_{a_{1}}, f_{a_{2}}\right]}
\end{array}
$$

onde $w=w\left[n, m, f_{a_{1}}, f_{a_{2}}\right]$ é a funçào definida pela expressão

$$
w=H\left[m+1, f_{a_{2}}\right]+\left(2^{n+m-1}-1\right) f_{a_{1}},
$$

Considerando as expressões 7.23, 7.24 e 7.2, fornecemos a distribuição de probabilidade a posteriori para o genótipo do demandado $P\left[\cdot \mid D_{\mathbf{u}, m_{X}}\right]$ no seguinte resultado. 
Proposição 7.3.9 Sob as condiçôts estabelecidas acima, temos que a distribuiçấo de probabilidade a posteriori para o genótipo do demandado $P\left[\cdot \mid D_{\mathbf{u}, m_{X}}\right]$, uma vez que em sua mãe e em $m$ de seus irmãos foi observado o genótipo $\left(a_{1}, a_{2}\right)$ e nos outros $n$ irmáos do demandado foi observado o genótipo $\left(a_{1}, a_{1}\right)$, é a seguinte.

$$
\begin{aligned}
& \text { genótipo }(\cdot) \quad P\left[\cdot \mid \mathrm{u}, m_{X}\right] \\
& \left(a_{1}, a_{1}\right) \quad \frac{H\left[m+1, f_{a_{2}}\right]+\left(2^{n+m}-1\right) f_{a_{1}}}{4 w\left[n, m, f_{a_{1}}, f_{a_{2}}\right]} \\
& \left(a_{1}, a_{2}\right) \quad \frac{H\left[m+2, f_{a_{2}}\right]+\left(2^{n+m}-1\right) f_{a_{1}}}{4 w\left[n, m, f_{a_{1}}, f_{a_{2}}\right]} \\
& \left(a_{i}, F_{1}\right) \quad \frac{f_{F_{1}}}{4 w\left[n, m, f_{a_{1}}, f_{a_{2}}\right]}, \quad i=1,2 \\
& \left(a_{2}, a_{2}\right) \quad \frac{2^{m} f_{a_{2}}}{4 w\left[n, m, f_{a_{1}}, f_{a_{2}}\right]} \\
& \left(a_{i},(x x x)^{c}\right) \quad \frac{1-f_{F_{1}}-\sum_{r=1}^{2} f_{a_{r}}}{4 w\left[n, m, f_{a_{1}}, f_{a_{2}}\right]}, \quad i=1,2 .
\end{aligned}
$$

Como conseqüência do resultado anterior, surge naturalmente o seguinte corolário.

Corolário 7.3.8 Sob as condições da proposição 7.3.9, temos que a razão de verossimilhanças $R V[D]$ e a probabilidade condicional $V_{0}[D]$, do demandante ter recebido do demandado o(s) alelo(s) de interesse após termos observado D, estäo dadas a seguir

$$
\begin{aligned}
& I \\
& V_{0}[D] \\
& R V[D] \\
& a_{i} \quad \frac{u_{i}\left[n, m, f_{a_{1}}, f_{a_{2}}\right]}{4 w\left[n, m, f_{a_{1}}, f_{a_{2}}\right]} \\
& \frac{4 f_{a_{i}} w\left[n, m, f_{a_{1}}, f_{a_{2}}\right]}{u_{i}\left[n, m, f_{a_{1}}, f_{a_{2}}\right]}, \quad i=1,2 \\
& F_{1} \quad \frac{f_{F_{1}}}{4 w\left[n, m, f_{a_{1}}, f_{a_{2}}\right]} \\
& 4 w\left[n, m, f_{a_{1}}, f_{a_{2}}\right] \\
& a_{1} \text { e } a_{2} \quad \frac{u_{3}\left[n, m, f_{a_{1}}, f_{a_{2}}\right]}{4 w\left[n, m, f_{a_{1}}, f_{a_{2}}\right]} \\
& \frac{4\left(f_{a_{1}}+f_{a_{2}}\right) w\left[n, m, f_{a_{1}}, f_{a_{2}}\right]}{u_{3}\left[n, m, f_{a_{1}}, f_{a_{2}}\right]} \\
& a_{i} \text { e } F_{1} \quad \frac{u_{i}\left[n, m, f_{a_{1}}, f_{a_{2}}\right]+f_{F_{1}}}{4 w\left[n, m, f_{a_{1}}, f_{a_{2}}\right]} \\
& \frac{4\left(f_{a_{1}}+f_{F_{1}}\right) w\left[n, m, f_{a_{1}}, f_{a_{2}}\right]}{u_{i}\left[n, m, f_{a_{1}}, f_{a_{2}}\right]+f_{F_{1}}}, \quad i=1,2,
\end{aligned}
$$


onde para $i=1, \cdots, 3$ as funçôes $u_{i}=u_{i}\left[n, m, f_{a_{1}}, f_{a_{2}}\right]$ sâo dadas por

$$
\begin{aligned}
& u_{1}=2 H\left[m+1, f_{a_{2}}\right]+\left(3 \times 2^{n+m-1}-2\right) f_{a_{1}} \\
& u_{2}=H\left[m+2, f_{a_{2}}\right]+\left(2^{n+m-1}-1\right) f_{a_{1}} \\
& u_{3}=3+\left(2^{m+2}-3\right) f_{a_{2}}+\left(2^{n+m+1}-3\right) f_{a_{1}} .
\end{aligned}
$$

\section{Caso 7.3.1}

Sejam $F_{1}$ e $a_{i}, i=1,2,3$ quatro alelos diferentes. Suponhamos que, ao observarmos $s$ irmãos do demandado, independentemente, ocorra uma das seguintes situações:

$$
\begin{aligned}
& D_{\mathbf{u}}=\left\{\left(a_{1}, a_{1}\right)_{n},\left(a_{2}, a_{3}\right)_{m}\right\}, \text { onde } s=n+m \text {, ou } \\
& D_{\mathbf{u}}=\left\{\left(a_{1}, a_{1}\right)_{n},\left(a_{1}, a_{2}\right)_{m},\left(a_{2}, a_{3}\right)_{r}\right\}, \text { com } s=n+m+r \text {, ou } \\
& D_{\mathbf{u}}=\left\{\left(a_{1}, a_{1}\right)_{n},\left(a_{1}, a_{2}\right)_{m},\left(a_{1}, a_{3}\right)_{r}\right\}, \text { onde } s=n+m+r \text {, ou } \\
& D_{\mathbf{u}}=\left\{\left(a_{1}, a_{1}\right)_{n},\left(a_{1}, a_{2}\right)_{m},\left(a_{2}, a_{3}\right)_{r},\left(a_{1}, a_{3}\right)_{t}\right\}, \text { se } s=n+m+r+t .
\end{aligned}
$$

Consideremos a função $\tau(\cdot)$ definida da seguinte forma

$$
\begin{aligned}
\tau:\{2,3\} & \longrightarrow\{2,3\} \\
i & \longmapsto \tau(i)=\left\{\begin{array}{l}
3 \text { se } i=2 \\
2 \text { se } i=3
\end{array}\right.
\end{aligned}
$$

Para cada $j=2,3, j$ fixo, suponhamos que o genótipo observado na mãe do demandado é $m_{X}=\left(a_{1}, a_{j}\right)$. Então, o pai do demandado necessariamente deve possuir o genótipo $\left(a_{1}, a_{\tau(j)}\right)$ e, portanto, em qualquer uma das situações acima, a distribuição de probabilidade a posteriori $\bar{P}\left[\cdot \mid D_{\mathbf{u}, m_{X}}\right]$ para o genótipo do pai do demandado é

$$
\bar{P}\left[g_{i} \mid D_{\mathbf{u}, m_{X}}\right]= \begin{cases}1 & \text { se } g_{i}=\left(a_{1}, a_{\tau(j)}\right) \\ 0 & \text { caso contrário }\end{cases}
$$

Conseqüentemente, a distribuiçào de probabilidade a posteriori para o genótipo do demandado $P\left[\cdot \mid D_{\mathbf{u}, m_{X}}\right]$, é apresentada no resultado seguinte. 
Proposição 7.3.10 Sob as condições estabelecidas acima, e em qualquer uma das situações 7.26 - 7.29, temos que a distribuição de probabilidade a posteriori para o genótipo do demandado $P\left[\cdot \mid D_{\mathbf{u}, m_{X}}\right]$, é a seguinte.

$$
\begin{aligned}
\text { genótipo }(\cdot) & P\left[\cdot \mid \mathrm{u}, m_{X}\right] \\
\left(a_{1}, a_{i}\right) & 1 / 4, \quad i=1,2,3 \\
\left(a_{2}, a_{3}\right) & 1 / 4
\end{aligned}
$$

A razão de verossimilhança $R V[D]$ e a probabilidade condicional $V_{0}[D]$, obtida do resultado anterior, estão dadas no seguinte corolário.

Corolário 7.3.9 Sob as condiçôes da proposiçâo 7.3.10, temos que a razão de verossimilhanças $R V[D]$ e a probabilidade condicional $V_{0}[D]$, do demandante ter recebido do demandado o(s) alelo(s) de interesse após termos observado D, estão dadas a seguir

$$
\begin{aligned}
& I \quad V_{0}[D] \quad R V[D] \\
& a_{1} \quad 1 / 2 \quad 2 f_{a_{1}} \\
& a_{j} \quad 1 / 4 \quad 4 f_{a_{j}}, j=2,3 \\
& a_{1} \quad e \quad a_{j} \quad 3 / 4 \quad \frac{4\left(f_{a_{1}}+f_{a_{\jmath}}\right)}{3}, j=2,3 \\
& \begin{array}{llll}
a_{2} & e & a_{3} & 1 / 2
\end{array} 2\left(f_{a_{2}}+f_{a_{3}}\right) \\
& \begin{array}{lll}
a_{1} \text { e } F_{1} & 1 / 2 & 2\left(f_{a_{1}}+f_{F_{1}}\right)
\end{array} \\
& a_{j} \text { e } F_{1} \quad 1 / 4 \quad 4\left(f_{a_{j}}+f_{F_{1}}\right), j=2,3
\end{aligned}
$$

\section{Caso 7.3.2}

Sejam $a_{i}$ e $F_{j}$, para $i=1,2,3$ e $j=1,2$, cinco alelos diferentes. Suponhamos que, ao observarmos $n+m$ irmàos do demandado, independentemente, encontramos em $n$ deles o genótipo $\left(a_{1}, a_{2}\right)$ e nos outros $m$ irmàos o genótipo $\left(a_{1}, a_{3}\right)$ - isto é,

$$
D_{\mathbf{u}}=\left\{\left(a_{1}, a_{2}\right)_{n},\left(a_{1}, a_{3}\right)_{m}\right\} \text {. }
$$


Ao observarmos o genótipo da mãe do demandado, pode ocorrer uma das seguintes situações:

$$
\begin{aligned}
& \text { i) } m_{X}=\left(a_{1}, a_{1}\right) \\
& \text { ii) } m_{X}=\left(a_{1}, h\right) \text { com } h \neq a_{j}, j=1,2,3 \\
& \text { iii) } m_{X}=\left(a_{1}, a_{2}\right), \text { ou } m_{X}=\left(a_{1}, a_{3}\right) \\
& \text { iv) } m_{X}=\left(a_{2}, a_{3}\right)
\end{aligned}
$$

i) Suponhamos que o genótipo da mãe do demandado é $m_{X}=\left(a_{1}, a_{1}\right)$. Neste caso particular, o único genótipo possível para o pai do demandado é $\left(a_{2}, a_{3}\right)$ e, portanto, a distribuição de probabilidade a posteriori $\bar{P}\left[\cdot \mid D_{\mathbf{u}, m_{X}}\right]$ para o genótipo do pai do demandado é

$$
\bar{P}\left[g_{i} \mid D_{\mathbf{u}, m_{X}}\right]= \begin{cases}1 & \text { se } g_{i}=\left(a_{2}, a_{3}\right) \\ 0 & \text { caso contrário, }\end{cases}
$$

Das expressões 7.31 e 7.2 obtemos imediatamente a distribuição de probabilidade $a$ posteriori para o genótipo do demandado $P\left[\cdot \mid D_{\mathbf{u}, m_{X}}\right]$, dada a seguir.

$$
\begin{array}{rr}
\text { genótipo }(\cdot) & P\left[\cdot \mid \mathbf{u}, m_{X}\right] \\
\left(a_{1}, a_{i}\right) & 1 / 2, \quad i=2,3
\end{array}
$$

A razão de verossimilhança $R V[D]$ e a probabilidade condicional $V_{0}[D]$, que é obtida da expressão 7.32 , estão dadas na seguinte tabela.

Tabela 7.5 Probabilidade condicional $V_{0}[D]$ e razâo de verossimilhanças $R V[D]$ - Caso $7.3 .2 \mathrm{i}$

$$
\begin{array}{ccl}
I & V_{0}[D] & R V[D] \\
a_{1} & 1 / 2 & 2 f_{a_{1}} \\
a_{j} & 1 / 4 & 4 f_{a_{j}}, j=2,3 \\
a_{1} \text { е } a_{j} & 3 / 4 & 4\left(f_{a_{1}}+f_{a_{j}}\right) / 3, \quad j=2,3
\end{array}
$$




$$
\begin{array}{lll}
a_{2} \text { е } a_{3} & 1 / 2 & 2\left(f_{a_{2}}+f_{a_{3}}\right) \\
a_{1} \text { е } F_{i} & 1 / 2 & 2\left(f_{a_{1}}+f_{F_{i}}\right), i=1,2 \\
a_{j} \text { е } F_{i} & 1 / 4 & 4\left(f_{a_{3}}+f_{F_{i}}\right), i=1,2 ; j=2,3 .
\end{array}
$$

ii) Seja $h$ um alelo qualquer tal que $h \neq a_{j}$ para $j=1, \cdots 3$.

Se o genótipo da mãe do demandado é $m_{X}=\left(a_{1}, h\right)$ temos que o único genótipo possível para o pai do demandado é $\left(a_{2}, a_{3}\right)$ e, portanto, a distribuição de probabilidade a posteriori $\bar{P}\left[\cdot \mid D_{\mathbf{u}, m_{X}}\right]$ para o genótipo do pai do demandado é dada pela expressão 7.31. Logo, a distribuição de probabilidade a posteriori para o genótipo do demandado $P\left[\cdot \mid D_{\mathbf{u}, m_{X}}\right]$ é

$$
\begin{array}{rc}
\text { genótipo }(\cdot) & P\left[\cdot \mid \mathrm{u}, m_{X}\right] \\
\left(a_{1}, a_{i}\right) & 1 / 4, \quad i=2,3 \\
\left(a_{i}, h\right) & 1 / 4, \quad i=2,3
\end{array}
$$

A razão de verossimilhança $R V[D]$ e a probabilidade condicional $V_{0}[D]$, obtida do resultado anterior, estão dadas na seguinte tabela.

Tabela 7.6 Probabilidade condicional $V_{0}[D]$ e razão de verossimilhanças $R V[D]$ - Caso 7.3 .2 ii

$$
\begin{array}{ccl}
I & V_{0}[D] & \multicolumn{1}{c}{R V[D]} \\
a_{j} & 1 / 4 & 4 f_{a_{\jmath}}, j=1,2,3 \\
h & 1 / 4 & 4 f_{h} \\
a_{i} \text { e } a_{j} & 1 / 2 & 2\left(f_{a_{\imath}}+f_{a_{\jmath}}\right), \quad i<j, i, j=1,2,3 \\
a_{j} \text { e } h & 1 / 2 & 2\left(f_{a_{\jmath}}+f_{h}\right), j=1,2,3 \\
h \text { е } F_{i} & 1 / 4 & 4\left(f_{h}+f_{F_{i}}\right) \quad \text { se } v \neq F_{i}, i=1,2 \\
a_{j} \text { е } F_{i} & 1 / 4 & 4\left(f_{a_{3}}+f_{F_{i}}\right), i=1,2 ; j=1,2,3 .
\end{array}
$$


iii) Para cada $k=2,3, k$ fixo, suponhamos que o genótipo observado na màe do demandado é $m_{X}=\left(a_{1}, a_{k}\right)$.

A distribuição de probabilidade a posteriori para o genótipo do pai do demandado $\bar{P}\left[\cdot \mid D_{\mathbf{u}, m_{X}}\right]$ - obtida na proposição 4.3 .5 - é dada pela expressão

$$
\begin{array}{rr}
\text { genótipo (.) } & \bar{P}\left[\cdot \mid D_{\mathbf{u}}\right] \\
\left(a_{1}, a_{\tau(k)}\right) & \frac{f_{a_{1}}}{f_{a_{1}}+f_{a_{k}}} \\
\left(a_{k}, a_{\tau(k)}\right) & \frac{f_{a_{k}}}{f_{a_{1}}+f_{a_{k}}}
\end{array}
$$

Do resultado anterior, obtemos que distribuição de probabilidade a posteriori para o genótipo do demandado $P\left[\cdot \mid D_{\mathbf{u}, m_{X}}\right]$, é a distribuição

$$
\begin{aligned}
& \text { genótipo }(\cdot) \quad P\left[\cdot \mid \mathbf{u}, m_{X}\right] \\
& \qquad \begin{aligned}
\left(a_{i}, a_{i}\right) & \frac{f_{a_{i}}}{4\left(f_{a_{1}}+f_{a_{k}}\right)}, i=1, k \\
\left(a_{j}, a_{r}\right) & \frac{f_{a_{1}}+f_{a_{k}}}{4\left(f_{a_{1}}+f_{a_{k}}\right)}, j<r, j=1,2 ; r=2,3
\end{aligned}
\end{aligned}
$$

A razão de verossimilhança $R V[D]$ e a probabilidade condicional $V_{0}[D]$, obtida da expressão 7.35 , estão dadas na seguinte tabela.

Tabela 7.7 Probabilidade condicional $V_{0}[D]$ e razão de verossimilhanças $R V[D]$ - Caso 7.3.2 iii

$$
\begin{array}{ccc}
\multicolumn{1}{c}{I} & V_{0}[D] & R V[D] \\
a_{i} & \frac{f_{a_{i}}+f_{a_{1}}+f_{a_{k}}}{4\left(f_{a_{1}}+f_{a_{k}}\right)} & \frac{4 f_{a_{i}}\left(f_{a_{1}}+f_{a_{k}}\right)}{f_{a_{i}}+f_{a_{1}}+f_{a_{k}}}, i=1, k \\
a_{\tau(k)} & 1 / 4 & 4 f_{a_{\tau(k)}} \\
a_{1} \text { e } a_{k} & 3 / 4 & \frac{4\left(f_{a_{1}}+f_{a_{k}}\right)}{3}
\end{array}
$$




$$
\begin{array}{rcl}
a_{i} \text { е } a_{\tau(k)} & \frac{f_{a_{i}}+2\left(f_{a_{1}}+f_{a_{k}}\right)}{4\left(f_{a_{1}}+f_{a_{k}}\right)} & \frac{4 f_{a_{i}}\left(f_{a_{i}}+f_{a_{\tau(k)}}\right)}{f_{a_{i}}+2\left(f_{a_{1}}+f_{a_{k}}\right)}, i=1, k \\
a_{i} \text { е } F_{j} & \frac{f_{a_{i}}+f_{a_{1}}+f_{a_{k}}}{4\left(f_{a_{1}}+f_{a_{k}}\right)} & \frac{4\left(f_{a_{i}}+f_{F_{j}}\right)\left(f_{a_{1}}+f_{a_{k}}\right)}{f_{a_{i}}+f_{a_{1}}+f_{a_{k}}}, i=1, k, j=1,2 \\
a_{\tau(k)} \text { е } F_{j} & 1 / 4 & 4\left(f_{a_{\tau(k)}}+f_{F_{j}}\right), j=1,2 .
\end{array}
$$

iv) Seja $m_{X}=\left(a_{2}, a_{3}\right)$ o genótipo observado na mãe do demandado.

Da proposição 3.3.6, obtemos que a distribuição de probabilidade a posteriori para o genótipo do pai do demandado $\bar{P}\left[\cdot \mid D_{\mathbf{u}, m_{X}}\right]$ é

$$
\begin{aligned}
\text { genótipo }(\cdot) & \bar{P}\left[\cdot \mid D_{\mathbf{u}, m_{X}}\right] \\
\left(a_{1}, a_{1}\right) & 2^{n+m-1} f_{a_{1}} / w \\
\left(a_{1}, a_{j}\right) & f_{a_{j}} / w, j=2,3 \\
\left(a_{1}, F_{i}\right) & f_{F_{i}} / w, i=1,2 \\
\left(a_{1},(x x x x x)^{c}\right) & \left(1-\sum_{k=1}^{3} f_{a_{k}}-\sum_{j=1}^{2} f_{F_{j}}\right) / w
\end{aligned}
$$

onde $w=w\left[n, m, f_{a_{1}}\right]$ é a função definida na expressào abaixo

$$
w=1+\left(2^{n+m-1}-1\right) f_{a_{1}} .
$$

Da expressão 7.36, deduzimos a distribuição de probabilidade a posteriori para o genótipo do demandado $P\left[\cdot \mid D_{\mathbf{u}, m_{X}}\right]$, apresentada no seguinte resultado.

Proposição 7.3.11 A distribuição de probabilidade a posteriori para o genótipo do demandado $P\left[\cdot \mid D_{\mathbf{u}, m_{X}}\right]$, uma vez que observamos o genótipo $\left(a_{2}, a_{3}\right)$ na sua mâe e os genótipos $\left(a_{1}, a_{2}\right)$ e $\left(a_{1}, a_{3}\right)$ em $n$ e $m$ de seus irmãos, respectivamente, é

$$
\begin{array}{lc}
\text { genótipo }(\cdot) & P\left[\cdot \mid D_{\mathbf{u}, m_{X}}\right] \\
\left(a_{1}, a_{j}\right) & \left(1+\left(2^{n+m}-1\right) f_{a_{1}}\right) / 4 w, j=2,3
\end{array}
$$




$$
\begin{aligned}
\left(a_{j}, a_{j}\right) & f_{a_{j}} / 4 w, j=2,3 \\
\left(a_{2}, a_{3}\right) & \left(f_{a_{2}}+f_{a_{3}}\right) / 4 w \\
\left(a_{j}, F_{i}\right) & f_{F_{i}} / 4 w, i=1,2 ; j=2,3 \\
\left(a_{j},(x x x x x)^{c}\right) & \left(1-\sum_{k=1}^{3} f_{a_{k}}-\sum_{j=1}^{2} f_{F_{j}}\right) / 4 w, j=2,3,
\end{aligned}
$$

onde w é a função definida pela expressão $7.3 \%$

Desse resultado, obtemos:

Corolário 7.3.10 Sob as condições da proposição 7.3.11, temos que a razão de verossimilhanças $R V[D]$ e a probabilidade condicional $V_{0}[D]$, do demandante ter recebido do demandado o(s) alelo(s) de interesse após termos observado $D$, estão dadas nos seguintes resultados

$$
\begin{array}{cll} 
& \multicolumn{1}{c}{V_{0}[D]} & R V[D] \\
a_{1} & \frac{1+\left(2^{n+m}-1\right) f_{a_{1}}}{4 w\left[n, m, f_{a_{1}}\right]} & \frac{4 f_{a_{1}}\left\{1+\left(2^{n+m-1}-1\right) f_{a_{1}}\right\}}{1+\left(2^{n+m}-1\right) f_{a_{1}}} \\
a_{j} & \frac{1+\left(2^{n+m-1}-1\right) f_{a_{1}}+f_{a_{j}}}{4 w\left[n, m, f_{a_{1}}\right]} & \frac{4 f_{a_{j}}\left\{1+\left(2^{n+m-1}-1\right) f_{a_{1}}\right\}}{1+\left(2^{n+m-1}-1\right) f_{a_{1}}+f_{a_{j}}}, j=2,3 \\
a_{1} \text { e } a_{j} & \frac{2+\left(3 \times 2^{n+m-1}-2\right) f_{a_{1}}+f_{a_{j}}}{4 w\left[n, m, f_{a_{1}}\right]} & \frac{4\left(f_{a_{1}}+f_{a_{j}}\right)\left\{1+\left(2^{n+m-1}-1\right) f_{a_{1}}\right\}}{2+\left(3 \times 2^{n+m-1}-2\right) f_{a_{1}}+f_{a_{j}}}, j=2,3 \\
a_{1} \text { e } F_{i} & \frac{1+\left(2^{n+m}-1\right) f_{a_{1}}+f_{F_{i}}}{4 w\left[n, m, f_{a_{1}}\right]} & \frac{4\left(f_{a_{1}}+f_{F_{i}}\right)\left\{1+\left(2^{n+m-1}-1\right) f_{a_{1}}\right\}}{1+\left(2^{n+m}-1\right) f_{a_{1}}+f_{F_{i}}}, i=1,2 \\
a_{2} \text { e } a_{3} & \frac{2+\left(2^{n+m}-2\right) f_{a_{1}}+f_{a_{2}}+f_{a_{3}}}{4 w\left[n, m, f_{a_{1}}\right]} & \frac{4\left(f_{a_{2}}+f_{a_{3}}\right) w\left[n, m, f_{a_{1}}\right]}{2+\left(2^{n+m}-2\right) f f_{a_{1}}+f_{a_{2}}+f_{a_{3}}} \\
a_{j} \text { e } F_{i} & \frac{f_{a_{j}}+f_{F_{i}}+w\left[n, m, f_{a_{1}}\right]}{4 w\left[n, m, f_{a_{1}}\right]} & \frac{4\left(f_{a_{j}}+f_{F_{i}}\right) w\left[n, m, f_{a_{1}}\right]}{f_{a_{j}}+f_{F_{i}}+w\left[n, m, f_{a_{1}}\right]}, j=2,3, i=1,2 \\
F_{1} \text { e } F_{2} & \frac{\sum_{i=1}^{2} f_{F_{i}}}{4 w\left[n, m, f_{a_{1}}\right]} & 4\left(1+\left(2^{n+m-1}-1\right) f_{a_{1}}\right) .
\end{array}
$$

\section{Caso 7.3.3}


Consideremos os seguintes quatro alelos $F_{1}$ e $a_{i}, i=1,2,3$, diferentes. Suponhamos que o conjunto de genótipos encontrado, ao observarmos $n+m+r$ irmãos do demandado, independentemente, esteja representado por

$$
D_{\mathbf{u}}=\left\{\left(a_{1}, a_{2}\right)_{n},\left(a_{2}, a_{3}\right)_{m},\left(a_{1}, a_{3}\right)_{r}\right\} .
$$

Consideremos $i, j \in\{1,2,3\}$ com $i<j, i, j$ fixados. Suponhamos que o genótipo observado na mãe do demandado é $m_{X}=\left(a_{i}, a_{j}\right)$ e definamos

$$
\{k(i, j)\}=\{1,2,3\}-\{i, j\} .
$$

A distribuição de probabilidade a posteriori para o genótipo do pai do demandado $\bar{P}\left[\cdot \mid D_{\mathbf{u}, m_{X}}\right]$ - obtida na proposição 4.3 .7 - é a seguinte

$$
\begin{aligned}
\text { genótipo }(\cdot) & \bar{P}\left[\cdot \mid D_{\mathbf{u}, m_{X}}\right] \\
\left(a_{i}, a_{k(i, j)}\right) & \frac{f_{a_{i}}}{f_{a_{i}}+f_{a_{j}}} \\
\left(a_{j}, a_{k(i, j)}\right) & \frac{f_{a_{j}}}{f_{a_{i}}+f_{a_{j}}}
\end{aligned}
$$

Dessa distribuição de probabilidade obtemos:

Proposição 7.3.12 Sob as condiçôes acima, a distribuição de probabilidade a posteriori para o genótipo do demandado $P\left[\cdot \mid D_{\mathbf{u}, m_{X}}\right]$, é a seguinte.

$$
\begin{array}{rr}
\text { genótipo }(\cdot) & P\left[\cdot \mid D_{\mathbf{u}, m_{X}}\right] \\
\left(a_{i}, a_{i}\right) & \frac{f_{a_{i}}}{4\left(f_{a_{i}}+f_{a_{j}}\right)} \\
\left(a_{j}, a_{j}\right) & \frac{f_{a_{j}}}{4\left(f_{a_{i}}+f_{a_{j}}\right)} \\
\left(a_{i}, a_{j}\right) & 1 / 4 \\
\left(a_{i}, a_{k}\right) & 1 / 4 \\
\left(a_{j}, a_{k}\right) & 1 / 4 .
\end{array}
$$


Essa distribuição de probabilidade a posteriori nos fornece o seguinte corolário.

Corolário 7.3.11 Sob as condições da proposição 7.3.12, temos que a razão de verossimilhanças $R V[D]$ e a probabilidade condicional $V_{0}[D]$, do demandante ter recebido do demandado o (s) alelo $(s)$ de interesse após termos observado D, estâo dadas nos seguintes resultados

$$
\begin{array}{ccc} 
& \multicolumn{1}{c}{\begin{array}{c}
\text { V } \\
\text { a }
\end{array}} & \multicolumn{1}{c}{R V[D]} \\
a_{t} & \frac{f_{a_{t}}+f_{a_{i}}+f_{a_{j}}}{4\left(f_{a_{i}}+f_{a_{\jmath}}\right)} & \frac{4 f_{a_{t}}\left(f_{a_{i}}+f_{a_{\jmath}}\right)}{f_{a_{t}}+f_{a_{i}}+f_{a_{\jmath}}}, t=i, j \\
a_{k} & 1 / 4 & 4 f_{a_{k}} \\
a_{i} \text { e } a_{j} & 3 / 4 & \frac{4\left(f_{a_{i}}+f_{a_{j}}\right)}{3} \\
a_{t} \text { e } a_{k} & \frac{f_{a_{t}}+2\left(f_{a_{i}}+f_{a_{j}}\right)}{4\left(f_{a_{i}}+f_{a_{\jmath}}\right)} & \frac{4\left(f_{a_{t}}+f_{a_{k}}\right)\left(f_{a_{t}}+f_{a_{\jmath}}\right)}{f_{a_{t}}+2\left(f_{a_{i}}+f_{a_{j}}\right)}, t=i, j \\
a_{t} \text { e } F_{1} & \frac{f_{a_{t}}+f_{a_{i}}+f_{a_{j}}}{4\left(f_{a_{i}}+f_{a_{j}}\right)} & \frac{4\left(f_{a_{t}}+f_{F_{1}}\right)\left(f_{a_{i}}+f_{a_{\jmath}}\right)}{f_{a_{t}}+f_{a_{i}}+f_{a_{\jmath}}}, t \\
a_{k} \text { e } F_{1} & 1 / 4 & 4\left(f_{a_{k}}+f_{F_{1}}\right) .
\end{array}
$$

\section{Caso 7.4.1}

Sejam $F_{1}$ e $a_{i}, i=1, \cdots, 4$, cinco alelos diferentes. Suponhamos que, ao observarmos $n+m$ irmãos do demandado, independentemente, encontramos em $n$ deles o genótipo $\left(a_{1}, a_{2}\right)$ e nos outros $m$ irmãos o genótipo $\left(a_{3}, a_{4}\right)$ - ou seja,

$$
D_{\mathbf{u}}=\left\{\left(a_{1}, a_{2}\right)_{n},\left(a_{3}, a_{4}\right)_{m}\right\} .
$$

Suponhamos que o genótipo observado na mãe do demandado é $m_{X}=\left(a_{i}, a_{j}\right)$, onde $i \in\{1,2\}$ e $j \in\{3,4\}$. Neste caso o genótipo do pai do demandado é $\left(a_{\sigma(i)}, a_{\gamma(j)}\right)$ e, portanto, a distribuição de probabilidade a posteriori $\bar{P}\left[\cdot \mid D_{\mathbf{u}, m_{X}}\right]$ para o genótipo do pai demandado é

$$
\bar{P}\left[g_{k} \mid D_{\mathbf{u}, m_{X}}\right]= \begin{cases}1 & \text { se } g_{k}=\left(a_{\sigma(i)}, a_{\gamma(j)}\right) \\ 0 & \text { caso contrário, }\end{cases}
$$


A distribuição de probabilidade a posteriori para o genótipo do demandado $P\left[\cdot \mid D_{\mathbf{u}, m_{X}}\right]$ - obtida das expressões 7.41 e 7.2 - é dada a seguir.

$$
\begin{array}{rc}
\text { genótipo }(\cdot) & P\left[\cdot \mid \mathbf{u}, m_{X}\right] \\
\left(a_{k}, a_{u}\right) & \frac{1}{4}, \text { se } k=i, j \text { e } u=\sigma(i), \gamma(j)
\end{array}
$$

A razão de verossimilhança $R V[D]$ e a probabilidade condicional $V_{0}[D]$, que é obtida da expressão 7.42 , estão dadas na seguinte tabela.

Tabela 7.8 Probabilidade condicional $V_{0}[D]$ e razão de verossimilhanças $R V[D]$ - Caso 7.4.1

$\begin{array}{ccl}I & V_{0}[D] & R V[D] \\ a_{t} & 1 / 4 & 4 f_{a_{t}}, t=1, \cdots, 4 \\ a_{t_{1}} \text { e } a_{t_{2}} & 1 / 2 & 2\left(f_{a_{t_{1}}}+f_{a_{t_{2}}}\right), \quad \text { se } 1 \leq t_{1}<t_{2} \leq 4 . \\ a_{t} \text { e } F_{1} & 1 / 4 & 4\left(f_{a_{t}}+f_{F_{1}}\right), t=1, \cdots, 4 .\end{array}$

\section{Caso 7.4.2}

Consideremos, como no caso 7.4.1, os cinco diferentes alelos $F_{1}$ e $a_{i}, i=1, \cdots, 4$. Suponhamos que, ao observarmos $s$ irmãos do demandado, independentemente, ocorra. uma das seguintes situações:

$$
\begin{aligned}
& D_{\mathbf{u}}=\left\{\left(a_{1}, a_{2}\right)_{n},\left(a_{2}, a_{4}\right)_{m},\left(a_{3}, a_{4}\right)_{r}\right\}, \quad \text { se } s=n+m+r, \text { ou } \\
& D_{\mathbf{u}}=\left\{\left(a_{1}, a_{2}\right)_{n},\left(a_{1}, a_{3}\right)_{m},\left(a_{3}, a_{4}\right)_{r}\right\}, \quad \text { com } s=n+m+r, \text { ou } \\
& D_{\mathbf{u}}=\left\{\left(a_{1}, a_{2}\right)_{n},\left(a_{2}, a_{4}\right)_{m},\left(a_{1}, a_{3}\right)_{r},\left(a_{3}, a_{4}\right)_{t}\right\}, \quad \text { onde } s=n+m+r=t .(7 .
\end{aligned}
$$

Seja $m_{X}=\left(a_{i}, a_{j}\right)$ o genótipo observado na mãe do demandado, onde $i$ pertence ao conjunto $\{1,2\}, j$ pertence ao conjunto $\{3,4\}$ e $i+j$ é um número impar.

Neste caso particular, em qualquer uma das situações apresentadas acima, temos que o genótipo do pai do demandado é $\left(a_{\sigma(i)}, a_{\gamma(j)}\right)$ e, portanto, a distribuição de probabilidade a posteriori $\bar{P}\left[\cdot \mid D_{\mathbf{u}, m_{X}}\right]$ para o genótipo do pai do demandado, a distribuição de 
probabilidade a posteriori $P\left[\cdot \mid D_{\mathbf{u}, m_{X}}\right]$ para o genótipo do demandado, a probabilidade condicional $V_{0}[D]$ e a razão $R V[D]$ coincidem exatamente com os correspondentes resultados obtidos no caso 7.4.1.

No capítulo 8, apresentaremos, detalhadamente, a análise necessária para determinarmos a probabilidade a posteriori de paternidade quando observarmos o genótipo da mãe e de alguns filhos do demandado. 


\section{Capítulo 8}

\section{Análise para um pai e filhos do demandado}

\subsection{Introdução}

Neste capítulo, primeiramente apresentamos, em detalhes, a metodologia proposta para determinar a distribuição de probabilidade a posteriori para o genótipo do demandado, uma vez que foi observada uma determinada estrutura genotípica em alguns de seus filhos - engendrados na mesma mulher - e um dos pais do demandado - que consideraremos, sem perda de generalidade sua mãe. Esta distribuição de probabilidade a posteriori é a base para determinar a probabilidade de paternidade após terem sido observados os genótipos da mãe e dos filhos do demandado, da mãe do demandante e do próprio demandante - isto é, a probabilidade a posteriori de paternidade - cujo método de cálculo foi exibido na seção 1.5.

Na seção 8.3 , utilizamos a metodologia desenvolvida na seção $\$ .2$ para calcular tanto a distribuição de probabilidade a posteriori para o genótipo do demandado quanto a razão entre as verossimilhanças do demandado não ser o pai do demandante e do demandado ser o pai do demandante, para cada um dos possíveis casos determinados pelos dados referentes aos genótipos da màe e dos filhos do demandado. Por motivos de espaço, apresentaremos somente os resultados correspondentes aos casos em que os genótipos observados nos filhos do demandado sào todos iguais. 


\subsection{Descrição geral da metodologia}

Sejam $\mathcal{B}_{L},\left(G_{L}, \mathcal{A}_{G_{L}}\right), Z$ e $P[\cdot]$ como definidos na seção 3.2. Suponhamos que estejam disponíveis dados do demandante e de sua mãe, além de dados referentes à mãe e a alguns filhos do demandado. Isto é, a árvore genealógica que estudaremos apresenta a seguinte estrutura:

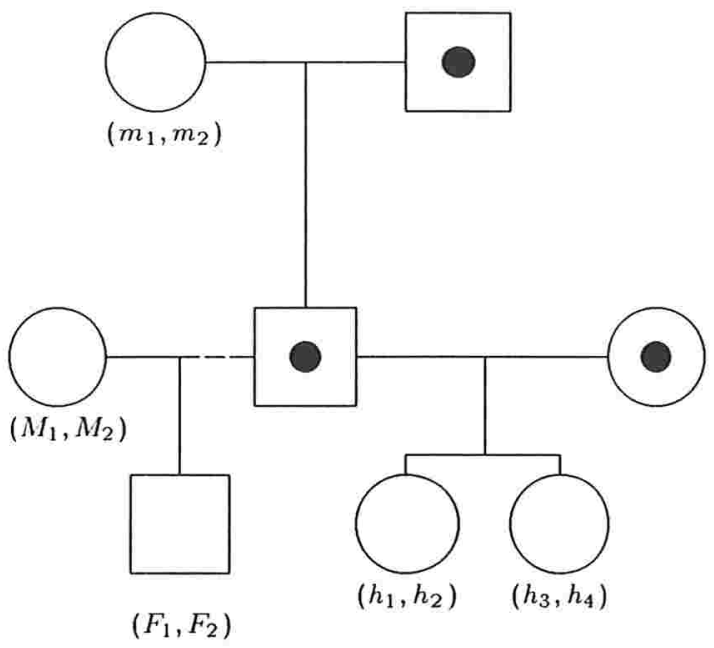

Árvore genealógica correspondente ao caso

mãe e filhos do demandado

Sejam $M, F, X$ e $M_{X}$ variáveis aleatórias $\mathcal{A}_{G_{L}}$ mensuráveis que denotam respectivamente os genótipos da mãe do demandante, do demandante. do demandado e da mãe do demandado, e consideremos $U$ como sendo o vetor aleatório formado pelos genótipos dos filhos do demandado - todos eles concebidos pela mesma mulher - constituído por componentes $\mathcal{A}_{G_{L}}$ mensuráveis.

Se os valores observados de $M, F, U$ e $M_{X}$ são respectivamente $\left(M_{1}, M_{2}\right),\left(F_{1}, F_{2}\right)$, u e $\left(m_{1}, m_{2}\right)$, o conjunto dos dados $D$ correspondente a este experimento é formado por

$$
D=\left\{\left(M_{1}, M_{2}\right),\left(F_{1}, F_{2}\right),\left(m_{1}, m_{2}\right), \mathbf{u}\right\} \text {. }
$$


Inicialmente, o interesse é determinar a distribuição de probabilidade para o genótipo do demandado, após observar os genótipos de sua mãe e de seus filhos e o(s) alelo(s) de interesse - isto é, queremos obter a distribuição de probabilidade a posteriori $P[\cdot \mid D]$ da variável aleatória $X$. Para determinarmos esta distribuição de probabilidade propomos o seguinte procedimento.

Primeiramente, consideremos a distribuição de probabilidade $P$, definida em 3.1, que descreve a incerteza sobre o genótipo do pai do demandado (ou do demandado), antes de serem observados genótipos de alguns filhos e da mãe do demandado, e o(s) alelo(s) de interesse - isto é, $P$ é a distribuição de probabilidade a priori para o genótipo do pai do demandado.

Agora, suponhamos que foram observados, independentemente. os genótipos da mãe do demandante, do demandante, da mãe do demandado e os genótipos de $s$ filhos do demandado, e sejam $\left(M_{1}, M_{2}\right),\left(F_{1}, F_{2}\right),\left(m_{1}, m_{2}\right)$ e u os genótipos observados, respectivamente. Consideremos $D_{\mathbf{u}}$ como o conjunto formado por todos os elementos $(x, y)_{q}$ onde $(x, y)$ é o genótipo observado em um dos filhos do demandado e $q$ representa o número de vezes que este genótipo foi observado nos $s$ filhos - isto é, $q$ representa o número de vezes que o genótipo $(x, y)$ ocorre no vetor $\mathbf{u}$.

Seguindo a metodologia proposta no capítulo 6, determinamos a distribuição de probabilidade a posteriori $P\left[\cdot \mid m_{X}\right]$ para o genótipo do demandado - uma vez que foi observado o genótipo $m_{X}$ na mãe do demandado. Esta distribuição de probabilidade é dada pela expressão

$$
P\left[g_{k} \mid m_{X}\right]=\sum_{j=1}^{N} V\left[g_{k} \mid\left(g_{j}, m_{X}\right)\right] P\left[g_{j}\right], \quad k=1, \cdots, N .
$$

onde $V\left[g_{k} \mid\left(g_{j}, m_{X}\right)\right]$ é a probabilidade condicional de que o genótipo $g_{k}$ provenha do cruzamento entre os genótipos $g_{j}$ e $m_{X}=\left(m_{1}, m_{2}\right)$, a qual pode ser determinada na tabela 3.1 (veja o capítulo 6 para maiores detalhes).

Assim, dispondo da distribuição de probabilidade a posteriori $P\left[\cdot \mid m_{X}\right]$ para o genótipo do demandado, após termos observado o genótipo $m_{X}=\left(m_{1}, m_{2}\right)$ na mãe do demandado - distribuição dada pela expressão 8.1 - usamos a informação fornecida pelos genótipos dos filhos do demandado e, com a metodologia proposta no capítulo 5 , obtemos a distribuição de probabilidade a posteriori $P\left[\cdot \mid D_{\mathbf{u}, m_{X}}\right]$ para o genótipo do demandado.

Em resumo, considerando a variável aleatória $X^{\prime}$ que denota o genótipo do demandado, e é $\mathcal{A}_{G_{L}}$ mensurável, $P$ como a medida de probabilidade definida sobre o espaço $\left(G_{L}, \mathcal{A}_{G_{L}}\right)$ 
definida na expressão 3.1 , a qual descreve a incerteza a priori sobre $X, m_{X}$ o genótipo observado na mãe do demandado e u o vetor dos genótipos observados nos filhos do demandado - representado no conjunto $D_{\mathbf{u}}$, obtemos o seguinte resultado.

Teorema 8.2.1 Se $m_{X}$ e u são obtidos ao observarmos independentemente a mãe es filhos do demandado, então a distribuição de probabilidade a posteriori $P\left[\cdot \mid D_{\mathbf{u}, m_{X}}\right]$ para $X$ é dada pela expressão

$$
P\left[g_{k} \mid D_{\mathbf{u}, m_{X}}\right]=\frac{v\left[D_{\mathbf{u}} \mid g_{k}\right]\left(\sum_{j=1}^{N} V\left[g_{k} \mid\left(g_{j}, m_{X}\right)\right] P\left[g_{j}\right]\right)}{\sum_{i=1}^{N}\left\{v\left[D_{\mathbf{u}} \mid g_{i}\right] \sum_{j=1}^{N} V\left[g_{i} \mid\left(g_{j}, m_{X}\right)\right] P\left[g_{j}\right]\right\}}, \quad k=1, \cdots, N,
$$

onde $V\left[\cdot \mid\left(g_{j}, m_{X}\right)\right], v\left[D_{\mathbf{u}} \mid g_{i}\right]$ e $P[\cdot]$ são dadas respectivamente pelas expressões da tabela $3.1,5.3$ e 3.1 .

\section{Demonstração}

Utilizando no teorema 5.2.1 a distribuição de probabilidade $P\left[\cdot \mid m_{X}\right]$ como a distribuição a priori para o genótipo do demandado - antes de serem observados os genótipos dos $s$ filhos do demandado - temos que a distribuição de probabilidade a posteriori $P\left[\cdot \mid D_{\mathbf{u}, m_{X}}\right]$ para o genótipo do demandado é dada pela expressão

$$
P\left[g_{k} \mid D_{\mathbf{u}, m_{X}}\right]=\frac{v\left[D_{\mathbf{u}} \mid g_{k}\right] P\left[g_{k} \mid m_{X}\right]}{\sum_{i=1}^{N} v\left[D_{\mathbf{u}} \mid g_{i}\right] P\left[g_{i} \mid m_{X}\right]}, \quad k=1, \cdots, N,
$$

onde a probabilidade condicional $v\left[D_{\mathbf{u}} \mid g_{i}\right]$ é definida pela expressão 5.3.

O resultado se segue ao substituirmos a expressão $\$ .1 \mathrm{em} \mathrm{8.3.}$

Na próxima seção, aplicaremos a metodologia aqui introduzida considerando todos os diferentes conjuntos $D_{\mathbf{u}, m X}$ que trazem informação sobre os genótipos observados na mãe e nos filhos do demandado. Para facilitar a apresentação dos resultados correspondentes aos conjuntos $D_{\mathbf{n}, m X}$ que determinam diferentes distribuições de probabilidade a posteriori para o genótipo do demandado, estes serão referenciados ao longo deste capítulo pelo código caso c.i.j a ser dado na primeira coluna da tabela 8.1 , onde c indica 
o capítulo, $\mathbf{i}$ indica o número de alelos diferentes que aparecem em $D_{\mathbf{u}}$ e $\mathbf{j}$ enumera as difer: ites associações com igual número de alelos.

Tabela 8.1 Dados relevantes ao observarmos a mãe e filhos do demandado.

caso genótipos observados
mãe filhos

8.1.1

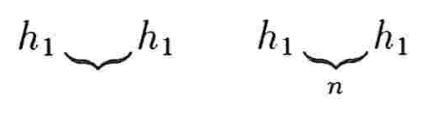

8.1 .2

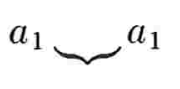

$h_{1} \underbrace{}_{n} h_{1}$

8.1.3

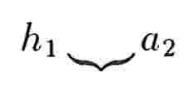

$h_{1} \underbrace{}_{n} h_{1}$

8.1 .4

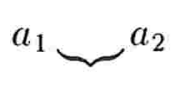

$h_{1} \underbrace{}_{n} h_{1}$

8.2.1

$h_{1} \underbrace{h_{1}}$

$h_{1} \underbrace{}_{n} h_{2}$

8.2.2

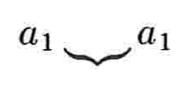

$h_{1} \underbrace{}_{n} h_{2}$

8.2.3

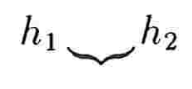

$h_{1} \underbrace{}_{n} h_{2}$

8.2.4

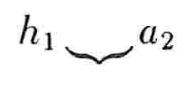

$h_{1} \underbrace{}_{n} h_{2}$

8.2 .5<smiles>[GeH3]C[GeH3]</smiles>

$h_{1} \underbrace{}_{n} h_{2}$

\subsection{Análise dos casos}

Nesta seção, aplicamos a metodologia desenvolvida na seção $\$ .2$ para determinar a distribuição de probabilidade a posteriori para o genótipo do demandado, considerando cada um dos casos relacionados na tabela 8.1 , exibida no final da seçào anterior. 
Além disso, pelos argumentos fornecidos na seção anterior, exibiremos apenas a probabilidade condicional $V_{0}[D]$ - ou $R V[D]$ quando possível - necessária ao cálculo da probabilidade a posteriori de paternidade. Quanto à outra probabilidade condicional $V_{1}[D]$, também necessária ao cálculo desta probabilidade a posteriori, será omitida por ser diretamente obtida da proposição 1.5.1.

Ao longo desta seção não tornaremos explícitos aqueles genótipos cujas probabilidades a posteriori sejam nulas.

\section{Caso 8.1.1}

Sejam $h_{1}, F_{1}$ e $F_{2}$ três alelos diferentes. Suponhamos que, ao considerarmos a mãe e $n$ filhos do demandado, independentemente, observamos em cada um deles o genótipo $\left(h_{1}, h_{1}\right)$ - isto é, $D_{\mathbf{u}}=\left\{\left(h_{1}, h_{1}\right)_{n}\right\}$ e $m_{X}=\left(h_{1}, h_{1}\right)$.

A distribuição de probabilidade a posteriori para o genótipo do demandado $P\left[\cdot \mid m_{X}\right]$, uma vez termos observado que o genótipo da sua mãe é $\left(h_{1}, h_{1}\right)$ - estabelecida na proposição 6.3.1 - e a probabilidade condicional $v\left[D_{\mathbf{u}} \mid g_{i}\right]$ de que os genótipos de $s$ filhos do demandado estejam representados no conjunto $D_{\mathbf{u}}$, dado que o genótipo do demandado é $g_{i}$, são dadas a seguir

$$
\begin{array}{rcl}
\text { genótipo }(\cdot) & P\left[\cdot \mid m_{X}\right] & v\left[D_{\mathbf{u}} \mid \cdot\right] \\
\left(h_{1}, h_{1}\right) & f_{h_{1}} & \frac{f_{h_{1}} H\left[n, f_{h_{1}}\right]}{2^{n-1}} \\
\left(h_{1}, F_{i}\right) & f_{F_{i}} & \frac{f_{h_{1}} H\left[n, f_{h_{1}}\right]}{2^{2 n-1}}, i=1,2 \\
\left(h_{1},(x x x)^{c}\right) & 1-f_{h_{1}}-\sum_{r=1}^{2} f_{F_{r}} & \frac{f_{h_{1}} H\left[n, f_{h_{1}}\right]}{2^{2 n-1}}
\end{array}
$$

Do teorema 8.2.1 e da expressão 8.4, deduzimos a distribuição de probabilidade $a$ posteriori para o genótipo do demandado $P\left[\cdot \mid D_{\mathbf{u}, m_{X}}\right]$, obtendo o seguinte resultado.

Proposição 8.3.1 A distribuição de probabilidade a posteriori para o genótipo do demandado $P\left[\cdot \mid D_{\mathbf{u}, m_{X}}\right]$, uma vez que em sua mãe e em $n$ de seus filhos foi observado o genótipo $\left(h_{1}, h_{1}\right)$ é a seguinte.

$$
\text { genótipo }(\cdot) \quad P\left[\cdot \mid D_{\mathbf{u}, m_{X}}\right]
$$




$$
\begin{aligned}
\left(h_{1}, h_{1}\right) & \frac{2^{n} f_{h_{1}}}{H\left[n+1, f_{h_{1}}\right]} \\
\left(h_{1}, F_{i}\right) & \frac{f_{F_{i}}}{H\left[n+1, f_{h_{1}}\right]}, \quad i=1,2 \\
\left(h_{1},(x x x)^{c}\right) & \frac{1-f_{h_{1}}-\sum_{i=1}^{2} f_{F_{i}}}{H\left[n+1, f_{h_{1}}\right]}
\end{aligned}
$$

Da expressão 8.5 obtemos a probabilidade condicional do demandante ter recebido do demandado o(s) alelo(s) de interesse após termos observado $D$ e, imediatamente, usando a proposição 1.5 .1 para determinar a probabilidade condicional $V_{1}[D]$, calculamos a razão $R V[D]$ para cada conjunto de alelos de interesse $I$, como podemos ver no seguinte corolário.

Corolário 8.3.1 Sob as condições da proposiçào 8.3.1, temos que a razâo de verossimilhanças $R V[D]$ e a probabilidade condicional $V_{0}[D]$, do demandante ter recebido do demandado o(s) alelo(s) de interesse após termos observado $D$, estão dadas a seguir

$$
\begin{array}{cll}
\multicolumn{1}{c}{I} & \multicolumn{1}{c}{V_{0}[D]} & \multicolumn{1}{c}{R V[D]} \\
h_{1} & \frac{H\left[n+2, f_{h_{1}}\right]}{2 H\left[n+1, f_{h_{1}}\right]} & \frac{2 f_{h_{1}} H\left[n+1, f_{h_{1}}\right]}{H\left[n+2, f_{h_{1}}\right]} \\
F_{i} & \frac{f_{F_{i}}}{2 H\left[n+1, f_{h_{1}}\right]} & 2 H\left[n+1, f_{h_{1}}\right], i=1,2 \\
h_{1} \in F_{i} & \frac{H\left[n+2, f_{h_{1}}\right]+f_{F_{i}}}{2 H\left[n+1, f_{h_{1}}\right]} & \frac{2\left(f_{h_{1}}+f_{F_{i}}\right) H\left[n+1, f_{h_{1}}\right]}{H\left[n+2, f_{h_{1}}\right]+f_{F_{i}}}, i=1,2 \\
F_{1} \in F_{2} & \frac{\sum_{i=1}^{2} f_{F_{i}}}{2 H\left[n+1, f_{h_{1}}\right]} & 2 H\left[n+1, f_{h_{1}}\right]
\end{array}
$$

\section{Caso 8.1.2}

Sejam $a_{1}, h_{1}, F_{1}$ e $F_{2}$ quatro alelos diferentes. Suponhamos que, ao considerarmos a mãe e $n$ filhos do demandado, independentemente, observamos, respectivamente, os genótipos $m_{X}=\left(a_{1}, a_{1}\right)$ e $D_{\mathbf{u}}=\left\{\left(h_{1}, h_{1}\right)_{n}\right\}$. 
Neste caso, a distribuição de probabilidade a posteriori para o genótipo do demandado $P\left[\cdot \mid m_{X}\right]$, uma vez termos observado que o genótipo da sua mãe é $\left(a_{1}, a_{1}\right)$ - estabelecida na proposição 6.3 .1 - e a probabilidade condicional $v\left[D_{\mathbf{u}} \mid g_{i}\right]$ de que os genótipos dos $s$ filhos do demandado estejam representados no conjunto $D_{\mathrm{u}}$, dado que o genótipo do demandado é $g_{i}$, são dadas a seguir

$\begin{array}{rcc}\text { genótipo }(\cdot) & P\left[\cdot \mid m_{X}\right] & v\left[D_{\mathbf{u}} \mid \cdot\right] \\ \left(a_{1}, a_{1}\right) & f_{a_{1}} & 0 \\ \left(a_{1}, h_{1}\right) & f_{h_{1}} & \frac{f_{h_{1}} H\left[n, f_{h_{1}}\right]}{2^{2 n-1}}, i=1,2 \\ \left(a_{1}, F_{i}\right) & f_{F_{i}} & 0, i=1,2 \\ \left(a_{1},(x x x x)^{c}\right) & 1-f_{a_{1}}-f_{h_{1}}-\sum_{r=1}^{2} f_{F_{r}} & 0\end{array}$

Imediatamente, do resultado anterior, obtemos que a distribuição de probabilidade $a$ posteriori para o genótipo do demandado $P\left[\cdot \mid D_{\mathbf{u}, m_{X}}\right]$, uma vez que em sua mãe foi observado o genótipo $\left(a_{1}, a_{1}\right)$ e em $n$ de seus filhos foi observado o genótipo $\left(h_{1}, h_{1}\right)$, é dada pela seguinte expressão

$$
P\left[g_{i} \mid D_{\mathbf{u}, m_{X}}\right]= \begin{cases}1 & \text { se } g_{i}=\left(a_{1}, h_{1}\right) \\ 0 & \text { caso contrário }\end{cases}
$$

A razão de verossimilhança $R V[D]$ e a probabilidade condicional $V_{0}[D]$, que é obtida da expressão 8.7 , estão dadas na seguinte tabela.

Tabela 8.2 Probabilidade condicional $V_{0}[D]$ e razão de verossimilhanças $R V[D]$ - Caso 8.1.2

$$
\begin{array}{ccl}
I & V_{0}[D] & \multicolumn{1}{c}{R V[D]} \\
a_{1} & 1 / 2 & 2 f_{a_{1}} \\
h_{1} & 1 / 2 & 2 f_{h_{1}} \\
a_{1} \text { е } h_{1} & 1 & f_{a_{1}}+f_{h_{1}} \\
a_{1} \text { е } F_{i} & 1 / 2 & 2\left(f_{a_{1}}+f_{F_{i}}\right) i=1,2 \\
h_{1} \text { е } F_{i} & 1 / 2 & 2\left(f_{h_{1}}+f_{F_{1}}\right) i=1,2
\end{array}
$$




\section{Caso 8.1.3}

Sejam $a_{2}, h_{1}, F_{1}$ e $F_{2}$ quatro alelos diferentes. Suponhamos que. ao considerarmos a mãe e $n$ filhos do demandado, independentemente, observamos respectivamente os genótipos $m_{X}=\left(h_{1}, a_{2}\right)$ e $D_{\mathbf{u}}=\left\{\left(h_{1}, h_{1}\right)_{n}\right\}$.

A distribuição de probabilidade a posteriori para o genótipo do demandado $P\left[\cdot \mid m_{X}\right]$, estabelecida na proposição 6.3 .2 - e a probabilidade condicional $v\left[D_{\mathbf{u}} \mid g_{i}\right]$ sào dados por

$$
\begin{array}{rcl}
\text { genótipo }(\cdot) & P\left[\cdot \mid m_{X}\right] & v\left[D_{\mathbf{u}} \mid \cdot\right] \\
\left(h_{1}, h_{1}\right) & \frac{f_{h_{1}}}{2} & \frac{f_{h_{1}} H\left[n, f_{h_{1}}\right]}{2^{n-1}} \\
\left(h_{1}, a_{2}\right) & \frac{f_{h_{1}}+f_{a_{2}}}{2} & \frac{f_{h_{1}} H\left[n, f_{h_{1}}\right]}{2^{2 n-1}} \\
\left(h_{1}, F_{i}\right) & \frac{f_{F_{i}}}{2} & \frac{f_{h_{1}} H\left[n, f_{h_{1}}\right]}{2^{2 n-1}}, i=1,2 \\
\left(h_{1},(x x x x)^{c}\right) & \frac{1-f_{a_{2}}-f_{h_{1}}-\sum_{r=1}^{2} f_{F_{r}}}{2} & \frac{f_{h_{1}} H\left[n, f_{h_{1}}\right]}{2^{2 n-1}} \\
\left(a_{2}, a_{2}\right) & \frac{f_{a_{2}}}{2} & 0 \\
\left(a_{2}, F_{i}\right) & \frac{f_{F_{1}}}{2} & 0, i=1,2 \\
\left(a_{2},(x x x y)^{c}\right) & \frac{1-f_{a_{2}}-f_{h_{1}}-\sum_{r=1}^{2} f_{F_{r}}}{2} & 0
\end{array}
$$

A distribuição de probabilidade a posteriori para o genótipo do demandado $P\left[\cdot \mid D_{\mathbf{u}, m_{X}}\right]$ - obtida da expressào $\$ .8$ e do teorema $\$ .2 .1$ - é dada no seguinte resultado.

Proposição 8.3.2 Sob as condiçôes estabelecidas acima obtemos que a distribuição de probabilidade a posteriori para o genótipo do demandado $P\left[\cdot \mid D_{\mathbf{n}, m_{X}}\right]$, uma vez que o genótipo observado em sua mãe foi $\left(h_{1}, a_{2}\right) \in \mathrm{em} n$ de seus filhos foi observado o genótipo $\left(h_{1}, h_{1}\right)$, é a seguinte.

$$
\text { genótipo }(\cdot) \quad P\left[\cdot \mid D_{\mathbf{u}, m_{X}}\right]
$$




$$
\begin{aligned}
\left(h_{1}, h_{1}\right) & \frac{2^{n} f_{h_{1}}}{1+2^{n} f_{h_{1}}} \\
\left(h_{1}, a_{2}\right) & \frac{f_{h_{1}}+f_{a_{2}}}{1+2^{n} f_{h_{1}}} \\
\left(h_{1}, F_{i}\right) & \frac{f_{F_{i}}}{1+2^{n} f_{h_{1}}}, \quad i=1,2 \\
\left(h_{1},(x x x x)^{c}\right) & \frac{1-f_{a_{2}}-f_{h_{1}}-\sum_{r=1}^{2} f_{F_{r}}}{1+2^{n} f_{h_{1}}}
\end{aligned}
$$

Para cada conjunto de alelos de interesse $I$ calculamos a razào $R V[D]$ e a probabilidade condicional do demandante ter recebido do demandado o(s) alelo(s) de interesse após termos observado $D$ - obtida da expressão 8.9 - como podemos ver no seguinte corolário.

Corolário 8.3.2 Sob as condições da proposição 8.3.2, temos que a razão de verossimilhanças $R V[D]$ e a probabilidade condicional $V_{0}[D]$, do demandante ter recebido do demandado o(s) alelo(s) de interesse após termos observado D, estão dadas a seguir

$$
\begin{aligned}
& \text { I } \\
& V_{0}[D] \\
& R V[D] \\
& h_{1} \quad \frac{1+2^{n+1} f_{h_{1}}}{2\left(1+2^{n} f_{h_{1}}\right)} \\
& \frac{2 f_{h_{1}}\left(1+2^{n} f_{h_{1}}\right)}{1+2^{n+1} f_{h_{1}}} \\
& a_{2} \quad \frac{f_{h_{1}}+f_{a_{2}}}{2\left(1+2^{n} f_{h_{1}}\right)} \\
& \operatorname{in} \frac{2 f_{a_{2}}\left(1+2^{n} f_{h_{1}}\right)}{f_{h_{1}}+f_{a_{2}}} \\
& F_{i} \quad \frac{f_{F_{i}}}{2\left(1+2^{n} f_{h_{1}}\right)} \\
& 2\left(1+2^{n} f_{h_{1}}\right), \quad i=1,2 \\
& h_{1} e a_{2} \quad \frac{1+\left(2^{n+1}+1\right) f_{h_{1}}+f_{a_{2}}}{2\left(1+2^{n} f_{h_{1}}\right)} \\
& \frac{2\left(f_{h_{1}}+f_{a_{2}}\right)\left(1+2^{n} f_{h_{1}}\right)}{1+\left(2^{n+1}+1\right) f_{h_{1}}+f_{a_{2}}} \\
& h_{1} \text { e } F_{i} \quad \frac{1+2^{n+1} f_{h_{1}}+f_{F_{i}}}{2\left(1+2^{n} f_{h_{1}}\right)} \\
& \frac{2\left(f_{h_{1}}+f_{F_{i}}\right)\left(1+2^{n} f_{h_{1}}\right)}{1+2^{n+1} f_{h_{1}}+f_{F_{i}}}, i=1,2 \\
& a_{2} \text { e } F_{i} \quad \frac{f_{h_{1}}+f_{a_{2}}+f_{F_{i}}}{2\left(1+2^{n} f_{h_{1}}\right)} \\
& \frac{2\left(f_{h_{1}}+f_{F_{1}}\right)\left(1+2^{n} f_{h_{1}}\right)}{f_{h_{1}}+f_{a_{2}}+f_{F_{i}}}, \quad i=1,2 \\
& F_{1} \text { e } F_{2} \quad \frac{\sum_{i=1}^{2} f_{F_{i}}}{2\left(1+2^{n} f_{h_{1}}\right)} \\
& 2\left(1+2^{n} f_{h_{1}}\right)
\end{aligned}
$$




\section{Caso 8.1.4}

Consideremos os seguintes cinco alelos $h_{1}$ e $a_{i}, F_{i}, \quad i=1,2$, diferentes.

Suponhamos que, ao considerarmos $n$ filhos do demandado, independentemente, observamos em cada um deles o genótipo $\left(h_{1}, h_{1}\right)$ - isto é, $D_{\mathbf{u}}=\left\{\left(h_{1}, h_{1}\right)_{n}\right\}$. Se na mãe do demandado observamos o genótipo $\left(a_{1}, a_{2}\right)$, obtemos que a distribuição de probabilidade a posteriori para o genótipo do demandado $P\left[\cdot \mid m_{X}\right]$, - estabelecida na proposiçào 6.3 .2 - e a probabilidade condicional $v\left[D_{\mathbf{u}} \mid g_{i}\right]$ são:

$\begin{array}{rcc}\text { genótipo }(\cdot) & P\left[\cdot \mid m_{X}\right] & v\left[D_{\mathbf{u}} \mid \cdot\right] \\ \left(a_{i}, a_{i}\right) & \frac{f_{a_{i}}}{2} & 0, i=1,2 \\ \left(a_{1}, a_{2}\right) & \frac{f_{a_{1}}+f_{a_{2}}}{2} & 0 \\ \left(a_{i}, h_{1}\right) & \frac{f_{h_{1}}}{2} & \frac{f_{h_{1}} H\left[n, f_{h_{1}}\right]}{2^{2 n-1}} \\ \left(a_{i}, F_{j}\right) & \frac{f_{F_{j}}}{2} & 0, i, j=1,2 \\ \left(a_{i},(x x x x)^{c}\right) & \frac{1-f_{h_{1}}-\sum_{r=1}^{2}\left(f_{a_{r}}+f_{F_{r}}\right)}{2} & 0, i=1,2\end{array}$

Do resultado anterior obtemos, imediatamente, que a distribuição de probabilidade $a$ posteriori para o genótipo do demandado $P\left[\cdot \mid D_{\mathbf{u}, m_{X}}\right]$, uma vez que em sua mãe foi observado o genótipo $m_{X}=\left(a_{1}, a_{2}\right)$ e em $n$ de seus filhos foi observado o genótipo $\left(h_{1}, h_{1}\right)$, é a seguinte.

$$
\begin{aligned}
\text { genótipo }(\cdot) & P\left[\cdot \mid D_{\mathbf{u}, m_{X}}\right] \\
\left(h_{1}, a_{1}\right) & 1 / 2 \\
\left(h_{1}, a_{2}\right) & 1 / 2
\end{aligned}
$$

A razão de verossimilhança $R V[D]$ e a probabilidade condicional $V_{0}[D]$, que é obtida da expressão 8.11, estão dadas na seguinte tabela. 
Tabela 8.3 Probabilidade condicional $V_{0}[D]$ e razão de verossimilhanças $R V[D]$ - Caso 8.1 .4

$$
\begin{array}{ccl}
I & V_{0}[D] & \multicolumn{1}{c}{R V[D]} \\
a_{i} & 1 / 4 & 4 f_{a_{i}}, \quad i=1,2 \\
h_{1} & 1 / 2 & 2 f_{h_{1}} \\
a_{i} \text { е } h_{1} & 3 / 4 & 4\left(f_{a_{i}}+f_{h_{1}}\right) / 3 i=1,2 \\
a_{1} \text { е } a_{2} & 1 / 2 & 2\left(f_{a_{1}}+f_{a_{2}}\right) \\
a_{i} \text { е } F_{j} & 1 / 4 & 4\left(f_{a_{i}}+f_{F_{j}}\right) i, j=1.2 \\
h_{1} \text { е } F_{j} & 1 / 2 & 2\left(f_{h_{1}}+f_{F_{j}}\right) j=1,2
\end{array}
$$

Caso 8.2.1 Sejam $h_{i}, F_{i}, i=1,2$, quatro alelos diferentes.

Suponhamos que, ao considerarmos a mãe e $n$ filhos do demandado, independentemente, observamos o genótipo $\left(h_{1}, h_{1}\right)$ na mãe e em cada um dos filhos o genótipo $\left(h_{1}, h_{2}\right)$ - isto é, $D_{\mathbf{u}}=\left\{\left(h_{1}, h_{2}\right)_{n}\right\}$.

A distribuição de probabilidade a posteriori para o genótipo do demandado $P\left[\cdot \mid m_{X}\right]$, - estabelecida na proposição 6.3.1 - e a probabilidade condicional $v\left[D_{\mathbf{u}} \mid g_{i}\right]$ são dadas a seguir.

$$
\begin{array}{rcl}
\text { genótipo }(\cdot) & P\left[\cdot \mid m_{X}\right] & v\left[D_{\mathbf{u}} \mid \cdot\right] \\
\left(h_{1}, h_{1}\right) & f_{h_{1}} & \frac{f_{h_{2}} H\left[n, f_{h_{2}}\right]}{2^{n-1}} \\
\left(h_{1}, h_{2}\right) & f_{h_{2}} & \frac{\left(\sum_{k=1}^{2} H\left[n, f_{h_{k}}\right]-1\right) \sum_{k=1}^{2} f_{h_{k}}}{2^{2 n-1}} \\
\left(h_{1}, F_{i}\right) & f_{F_{i}} & \frac{f_{h_{2}} H\left[n, f_{h_{2}}\right]}{2^{2 n-1}}, i=1,2 \\
\left(h_{1},(x x x x)^{c}\right) & 1-\sum_{r=1}^{2}\left(f_{h_{r}}+f_{F_{r}}\right) & \frac{f_{h_{2}} H\left[n, f_{h_{2}}\right]}{2^{2 n-1}}
\end{array}
$$


Considerando a função $u=u\left[n, f_{h_{1}}, f_{h_{2}}\right]$ definida por

$$
u\left[n, f_{h_{1}}, f_{h_{2}}\right]=\left(2^{n-1}-1\right) f_{h_{1}} \sum_{k=1}^{2} f_{h_{k}}+\left(1+2^{n} f_{h_{1}}\right) H\left[n, f_{h_{2}}\right],
$$

a expressão 8.12 e o teorema 8.2 .1 , obtemos a distribuição de probabilidade a posteriori para o genótipo do demandado $P\left[\cdot \mid D_{\mathbf{u}, m_{X}}\right]$, dada no seguinte resultado.

Proposição 8.3.3 Sob as condiçôes estabelecidas acima obtemos que a distribuiçâo de probabilidade a posteriori para o genótipo do demandado $P\left[\cdot \mid D_{\mathbf{u}, m_{X}}\right]$, uma vez que o genótipo observado em sua mãe foi $\left(h_{1}, h_{1}\right)$ e em $n$ de seus filhos foi observado o genótipo $\left(h_{1}, h_{2}\right)$, é a seguinte.

$$
\begin{aligned}
\text { genótipo (.) } & P\left[\cdot \mid D_{\mathbf{u}, m_{X}}\right] \\
\left(h_{1}, h_{1}\right) & \frac{2^{n} f_{h_{1}} H\left[n, f_{h_{2}}\right]}{u\left[n, f_{h_{1}}, f_{h_{2}}\right]} \\
\left(h_{1}, h_{2}\right) & \frac{\left(\sum_{k=1}^{2} H\left[n, f_{h_{k}}\right]-1\right) \sum_{k=1}^{2} f_{h_{k}}}{u\left[n, f_{h_{1}}, f_{h_{2}}\right]} \\
\left(h_{1}, F_{i}\right) & \frac{f_{F_{i}} H\left[n, f_{h_{2}}\right]}{u\left[n, f_{h_{1}}, f_{h_{2}}\right]}, i=1,2 \\
\left(h_{1},(x x x x)^{c}\right) & \frac{H\left[n, f_{h_{2}}\right]\left(1-\sum_{r=1}^{2}\left(f_{h_{r}}+f_{F_{r}}\right)\right.}{u\left[n, f_{h_{1}}, f_{h_{2}}\right]}
\end{aligned}
$$

Do resultado anterior obtemos:

Corolário 8.3.3 Sob as condições da proposiçâo 8.3.3, temos que a razão de verossimilhanças $R V[D]$ e a probabilidade condicional $V_{0}[D]$, do demandante ter recebido do demandado o(s) alelo(s) de interesse após termos observado D, estão dadas a seguir

$$
\begin{array}{ccc}
I & V_{0}[D] & R V[D] \\
h_{i} & \frac{w_{i}\left[n, f_{h_{1}}, f_{h_{2}}\right]}{2 u\left[n, f_{h_{1}}, f_{h_{2}}\right]} & \frac{2 f_{h_{1}} u\left[n, f_{h_{1}}, f_{h_{2}}\right]}{w_{i}\left[n, f_{h_{1}}, f_{h_{2}}\right]}, i=1,2
\end{array}
$$




$$
\begin{array}{lll}
\multicolumn{1}{c}{F_{i}} & \frac{f_{F_{i}} H\left[n, f_{h_{2}}\right]}{2 u\left[n, f_{h_{1}}, f_{h_{2}}\right]} & \frac{2 u\left[n, f_{h_{1}}, f_{h_{2}}\right]}{H\left[n, f_{h_{2}}\right]}, i=1,2 \\
h_{1} \text { e } h_{2} & \frac{w_{3}\left[n, f_{h_{1}}, f_{h_{2}}\right]}{2 u\left[n, f_{h_{1}}, f_{h_{2}}\right]} & \frac{2\left(f_{h_{1}}+f_{a_{2}}\right) u\left[n, f_{h_{1}}, f_{h_{2}}\right]}{w_{3}\left[n, f_{h_{1}}, f_{h_{2}}\right]} \\
h_{i} \text { e } F_{j} & \frac{w_{i j}\left[n, f_{h_{1}}, f_{h_{2}}, f_{F_{j}}\right]}{2 u\left[n, f_{h_{1}}, f_{h_{2}}\right]} & \frac{2\left(f_{h_{i}}+f_{F_{3}}\right) u\left[n, f_{h_{1}}, f_{h_{2}}\right]}{w_{i j}\left[n, f_{h_{1}}, f_{h_{2}}, f_{F_{3}}\right]}, i, j=1,2 \\
F_{1} e F_{2} & \frac{H\left[n, f_{h_{2}}\right] \sum_{i=1}^{2} f_{F_{1}}}{2 u\left[n, f_{h_{1}}, f_{h_{2}}\right]} & \frac{2 u\left[n, f_{h_{1}}, f_{h_{2}}\right]}{H\left[n, f_{h_{2}}\right]},
\end{array}
$$

onde para $i=1,2,3$ e $j=1,2$ as funções $w_{i}=w_{i}\left[n, f_{h_{1}}, f_{h_{2}}\right]$ e $w_{i j}=w_{i j}\left[n, f_{h_{1}}, f_{h_{2}}, f_{F_{j}}\right]$ são dadas pelas seguines expressões.

$$
\begin{aligned}
& w_{1}=\left(2^{n-1}-1\right) f_{h_{1}} \sum_{k=1}^{2} f_{h_{k}}+\left(1+2^{n+1} f_{h_{1}}\right) H\left[n, f_{h_{2}}\right] \\
& w_{2}=\left(\sum_{k=1}^{2} H\left[n, f_{h_{k}}\right]-1\right) \sum_{k=1}^{2} f_{h_{k}} \\
& w_{3}=2\left(2^{n-1}-1\right) f_{h_{1}} \sum_{k=1}^{2} f_{h_{k}}+\left(1+\left(2^{n+1}+1\right) f_{h_{1}}+f_{h_{2}}\right) H\left[n, f_{h_{2}}\right] \\
& w_{1 j}=\left(2^{n-1}-1\right) f_{h_{1}} \sum_{k=1}^{2} f_{h_{k}}+\left(1+2^{n+1} f_{h_{1}}+f_{F_{j}}\right) H\left[n, f_{h_{2}}\right], j=1,2 \\
& w_{2 j}=\left(\sum_{k=1}^{2} H\left[n, f_{h_{k}}\right]-1\right) \sum_{k=1}^{2} f_{h_{k}}+f_{F_{j}} H\left[n, f_{h_{2}}\right], j=1,2
\end{aligned}
$$

\section{Caso 8.2.2}

Consideremos os seguintes cinco alelos $a_{1}$ e $h_{i}, F_{i}, i=1,2$, diferentes.

Suponhamos que, ao considerarmos $n$ filhos do demandado, independentemente, observamos em cada um deles o genótipo $\left(h_{1}, h_{2}\right)$ - isto é, $D_{\mathbf{u}}=\left\{\left(h_{1}, h_{2}\right)_{n}\right\}$. Se na mãe do demandado observamos o genótipo $\left(a_{1}, a_{1}\right)$, obtemos que a distribuição de probabilidade a posteriori para o genótipo do demandado $P\left[\cdot \mid m_{X}\right]$, - estabelecida na proposição 6.3 .1

- e a probabilidade condicional $v\left[D_{\mathbf{u}} \mid g_{i}\right]$ são: 


$$
\begin{array}{rcc}
\text { genótipo }(\cdot) & P\left[\cdot \mid m_{X}\right] & v\left[D_{\mathbf{u}} \mid \cdot\right] \\
\left(a_{1}, a_{1}\right) & f_{v_{1}} & 0 \\
\left(a_{1}, h_{i}\right) & f_{h_{i}} & \frac{f_{h_{\sigma(i)}} H\left[n, f_{h_{\sigma(i)}}\right]}{2^{2 n-1}}, i=1,2 \\
\left(a_{1}, F_{i}\right) & 0, i=1,2 \\
\left(a_{1},(x x x x x)^{c}\right) & 1-f_{a_{1}}-\sum_{r=1}^{2}\left(f_{h_{r}}+f_{F_{r}}\right) & 0
\end{array}
$$

Desse resultado, calculamos, imediatamente, a distribuição de probabilidade a posteriori para o genótipo do demandado $P\left[\cdot \mid D_{\mathbf{u}, m_{X}}\right]$, uma vez que em sua mãe foi observado o genótipo $m_{X}=\left(a_{1}, a_{1}\right)$ e em $n$ de seus filhos foi observado o genótipo $\left(h_{1}, h_{2}\right)$, sendo a distribuição

$$
\begin{array}{rc}
\text { genótipo }(\cdot) & P\left[\cdot \mid \mathbf{u}, m_{X}\right] \\
\left(a_{1}, h_{i}\right) & \frac{H\left[n, f_{h_{\sigma(i)}}\right]}{\sum_{k=1}^{2} H\left[n, f_{h_{k}}\right]}, \quad i=1,2
\end{array}
$$

A probabilidade condicional $V_{0}[D]$, que é obtida da expressão 8.16 e a razão de verossimilhança $R V[D]$ estão dadas na seguinte tabela.

Tabela 8.4 Probabilidade condicional $V_{0}[D]$ e razão de verossimilhanças $R V[D]$ - Caso 8.2.2

$$
\begin{array}{cll}
\multicolumn{1}{c}{I} & V_{0}[D] & \multicolumn{1}{c}{R V[D]} \\
a_{1} & 1 / 2 & 2 f_{a_{1}} \\
h_{i} & \frac{H\left[n, f_{h_{\sigma(i)}}\right]}{2 \sum_{k=1}^{2} H\left[n, f_{h_{k}}\right]} & \frac{2 f_{h_{i}} \sum_{k=1}^{2} H\left[n, f_{h_{k}}\right]}{H\left[n, f_{h_{\sigma(i)}}\right]}, i=1,2 \\
a_{1} \text { e } h_{i} & \frac{H\left[n, f_{h_{i}}\right]+2 H\left[n, f_{h_{\sigma(i)}}\right]}{2 \sum_{k=1}^{2} H\left[n, f_{h_{k}}\right]} & \frac{2\left(f_{a_{1}}+f_{h_{i}}\right) \sum_{k=1}^{2} H\left[n, f_{h_{k}}\right]}{H\left[n, f_{h_{i}}\right]+2 H\left[n, f_{h_{\sigma(i)}}\right]}, i=1,2 \\
a_{1} \text { e } F_{i} & 1 / 2 & 2\left(f_{a_{1}}+f_{F_{i}}\right), i=1,2
\end{array}
$$




$$
h_{i} \text { e } F_{j} \quad \frac{H\left[n, f_{h_{\sigma(i)}}\right]}{2 \sum_{k=1}^{2} H\left[n, f_{h_{k}}\right]} \quad \frac{2\left(f_{h_{i}}+f_{F_{j}}\right) \sum_{k=1}^{2} H\left[n, f_{h_{k}}\right]}{H\left[n, f_{h_{\sigma(i)}}\right]}, i, j=1,2
$$

\section{Caso 8.2.3}

Sejam $h_{1}, h_{2}, F_{1}$ e $F_{2}$ quatro diferentes e suponhamos que, ao considerarmos a mãe do demandado e $n$ filhos do demandado, independentemente, observamos em cada um deles o genótipo $\left(h_{1}, h_{2}\right)$ - isto é, $m_{X}=\left(h_{1}, h_{2}\right)$ e $D_{\mathbf{u}}=\left\{\left(h_{1}, h_{2}\right)_{n}\right\}$.

A probabilidade condicional $v\left[D_{\mathbf{u}} \mid g_{i}\right]$ e a distribuição de probabilidade a posteriori para o genótipo do demandado $P\left[\cdot \mid m_{X}\right]$, - estabelecida na proposição 6.3 .2 - são dadas a seguir.

$$
\begin{array}{ccl}
\text { genótipo }(\cdot) & P\left[\cdot \mid m_{X}\right] & v\left[D_{\mathbf{u}} \mid \cdot\right] \\
\left(h_{i}, h_{i}\right) & f_{h_{i}} / 2 & \frac{f_{h_{\sigma(i)}} H\left[n, f_{h_{\sigma(i)}}\right]}{2^{n-1}}, i=1,2 \\
\left(h_{1}, h_{2}\right) & \sum_{k=1}^{2} f_{h_{k}} / 2 & \frac{\left(\sum_{k=1}^{2} H\left[n, f_{h_{k}}\right]-1\right) \sum_{k=1}^{2} f_{h_{k}}}{2^{2 n-1}} \\
\left(h_{i}, F_{j}\right) & f_{F_{j}} / 2 & \frac{f_{h_{\sigma(i)}} H\left[n, f_{h_{\sigma(i)}}\right]}{2^{2 n-1}}, i, j=1,2 \\
\left(h_{i},(x x x x)^{c}\right) & \left(1-\sum_{k=1}^{2}\left(f_{h_{k}}+f_{F_{k}}\right)\right) / 2 & \frac{f_{h_{\sigma(i)}} H\left[n, f_{h_{\sigma(i)}}\right]}{2^{2 n-1}}, i, j=1,2
\end{array}
$$

Ao considerarmos a função $u=u\left[n, f_{h_{1}}, f_{h_{2}}\right]$ definida por

$$
u=\sum_{k=1}^{2} f_{h_{k}} H\left[n, f_{h_{k}}\right]+2\left(2^{n}+\left(2^{2 n-2}-1\right) \sum_{k=1}^{2} f_{h_{k}}\right) \prod_{k=1}^{2} f_{h_{k}},
$$

o teorema 8.2 .1 e a expressão 8.17 , deduzimos a distribuição de probabilidade a posteriori para o genótipo do demandado $P\left[\cdot \mid D_{\mathbf{u}, m_{X}}\right]$. dada no seguinte resultado.

Proposição 8.3.4 Sob as condiçôes tstabelecidas acima obtemos que a distribuição de probabilidade a posteriori para o genótipo do demandado $P\left[\cdot \mid D_{\mathbf{u}, m_{X}}\right]$, uma vez que o 
genótipo observado em sua mãe e em $n$ de seus filhos foi $\left(h_{1}, h_{2}\right)$, é a seguinte.

$$
\begin{aligned}
\text { genótipo }(\cdot) & P\left[\cdot \mid D_{\mathbf{u}, m_{X}}\right] \\
\left(h_{i}, h_{i}\right) & \frac{2^{n} H\left[n, f_{h_{\sigma(i)}}\right] \prod_{k=1}^{2} f_{h_{k}}}{u\left[n, f_{h_{1}}, f_{h_{2}}\right]}, i=1,2 \\
\left(h_{1}, h_{2}\right) & \frac{\left(\sum_{k=1}^{2} H\left[n, f_{h_{k}}\right]-1\right)\left(\sum_{k=1}^{2} f_{h_{k}}\right)^{2}}{u\left[n, f_{h_{1}}, f_{h_{2}}\right]} \\
\left(h_{i}, F_{j}\right) & \frac{f_{h_{\sigma(i)}} f_{F_{j}} H\left[n, f_{h_{\sigma(i)}}\right]}{u\left[n, f_{h_{1}}, f_{h_{2}}\right]}, i, j=1,2 \\
\left(h_{i},(x x x x)^{c}\right) & \frac{H\left[n, f_{h_{\sigma(i)}}\right]\left(1-\sum_{k=1}^{2}\left(f_{h_{k}}+f_{F_{k}}\right)\right)}{u\left[n, f_{h_{1}}, f_{h_{2}}\right]}
\end{aligned}
$$

Como conseqüência do resultado anterior surge naturalmente o seguinte corolário.

Corolário 8.3.4 Sob as condições da proposição 8.3.4, temos que a razão de verossimilhanças $R V[D]$ e a probabilidade condicional $V_{0}[D]$, do demandante ter recebido do demandado o(s) alelo(s) de interesse após termos observado $D$, estão dadas a seguir

$$
\begin{aligned}
& \text { I } \\
& V_{0}[D] \\
& R V[D] \\
& h_{i} \quad \frac{w_{i}\left[n, f_{h_{1}}, f_{h_{2}}\right]}{2 u\left[n, f_{h_{1}}, f_{h_{2}}\right]} \\
& \frac{2 f_{h_{i}} u\left[n, f_{h_{1}}, f_{h_{2}}\right]}{w_{i}\left[n, f_{h_{1}}, f_{h_{2}}\right]}, i=1,2 \\
& F_{i} \quad \frac{f_{F_{i}} \sum_{k=1}^{2} f_{h_{k}} H\left[n, f_{h_{k}}\right]}{2 u\left[n, f_{h_{1}}, f_{h_{2}}\right]} \\
& \frac{2 u\left[n, f_{h_{1}}, f_{h_{2}}\right]}{\sum_{k=1}^{2} f_{h_{k}} H\left[n, f_{h_{k}}\right]}, \quad i=1,2 \\
& h_{1} e h_{2} \quad \frac{\sum_{k=1}^{2} w_{k}\left[n, f_{h_{1}}, f_{h_{2}}\right]}{2 u\left[n, f_{h_{1}}, f_{h_{2}}\right]} \\
& \frac{2 \sum_{k=1}^{2} f_{h_{k}} u\left[n, f_{h_{1}}, f_{h_{2}}\right]}{\sum_{k=1}^{2} w_{k}\left[n, f_{h_{1}}, f_{h_{2}}\right]} \\
& h_{i} \text { e } F_{j} \quad \frac{w_{i j}\left[n, f_{h_{1}}, f_{h_{2}}, f_{F_{j}}\right]}{2 u\left[n, f_{h_{1}}, f_{h_{2}}\right]} \\
& \frac{2\left(f_{h_{i}}+f_{F_{3}}\right) u\left[n, f_{h_{1}}, f_{h_{2}}\right]}{w_{i j}\left[n, f_{h_{1}}, f_{h_{2}}, f_{F_{j}}\right]}, i, j=1,2 \\
& F_{1} \text { e } F_{2} \quad \frac{\sum_{k=1}^{2} f_{h_{k}} H\left[n, f_{h_{k}}\right]}{2 u\left[n, f_{h_{1}}, f_{h_{2}}\right]} \sum_{k=1}^{2} f_{F_{k}} \frac{2 u\left[n, f_{h_{1}}, f_{h_{2}}\right]}{\sum_{k=1}^{2} f_{h_{k}} H\left[n, f_{h_{k}}\right]},
\end{aligned}
$$


onde para $i, j=1,2$ as funções $w_{i}=w_{i}\left[n, f_{h_{1}}, f_{h_{2}}\right]$ e $w_{i j}=w_{i j}\left[n, f_{h_{1}}, f_{h_{2}}, f_{F_{j}}\right]$ são dadas pelas seguines expressões.

$$
\begin{aligned}
w_{i}= & \left(1+\left(2^{n+1}-1\right) f_{h_{i}}-f_{h_{\sigma(i)}}\right) f_{h_{\sigma(i)}} H\left[n, f_{h_{\sigma(i)}}\right] \\
& +\left(\sum_{k=1}^{2} H\left[n, f_{h_{k}}\right]-1\right)\left(\sum_{k=1}^{2} f_{h_{k}}\right)^{2} \\
w_{i j}= & f_{h_{i}}\left\{\left(2^{n-1}-1\right)\left(\sum_{k=1}^{2} f_{h_{k}}\right)^{2}+f_{F_{j}} H\left[n, f_{h_{i}}\right]\right\} \\
& +H\left[n, f_{h_{\sigma(i)}}\right]\left\{f_{h_{i}}^{2}+f_{h_{\sigma(i)}}\left(1+f_{F_{j}}+\left(2^{n+1}+1\right) f_{h_{i}}\right)\right\}, i, j=1,2
\end{aligned}
$$

Caso 8.2.4 Consideremos cinco alelos diferentes $a_{2}$ e $h_{i}, F_{i}, i=1,2$. Suponhamos que foram observados a mãe e $n$ filhos do demandado, independentemente, encontrando nos $n$ filhos o genótipo $\left(h_{1}, h_{2}\right)$ e na mãe do demandado o genótipo $\left(h_{1}, a_{2}\right)$ - isto é, $D_{\mathbf{u}}=\left\{\left(h_{1}, h_{2}\right)_{n}\right\}$ e $m_{X}=\left(h_{1}, a_{2}\right)$.

A distribuição de probabilidade a posteriori para o genótipo do demandado $P\left[\cdot \mid m_{X}\right]$ e a probabilidade condicional $v\left[D_{\mathbf{u}} \mid g_{i}\right]$ são dadas a seguir.

$$
\begin{array}{ccl}
\text { genótipo }(\cdot) & P\left[\cdot \mid m_{X}\right] & v\left[D_{\mathbf{u}} \mid \cdot\right] \\
\left(h_{1}, h_{1}\right) & f_{h_{1}} / 2 & \frac{f_{h_{2}} H\left[n, f_{h_{2}}\right]}{2^{n-1}} \\
\left(h_{1}, a_{2}\right) & \left(f_{a_{2}}+f_{h_{1}}\right) / 2 & \frac{f_{h_{2}} H\left[n, f_{h_{2}}\right]}{2^{2 n-1}} \\
\left(h_{1}, h_{2}\right) & f_{h_{2}} / 2 & \frac{\sum_{k=1}^{2} H\left[n, f_{h_{k}}\right]-1}{2^{2 n-1}} \sum_{k=1}^{2} f_{h_{k}} \\
\left(h_{1}, F_{j}\right) & f_{F_{j}} / 2 & \frac{f_{h_{2}} H\left[n, f_{h_{2}}\right]}{2^{2 n-1}}, j=1,2 \\
\left(h_{1},(x x x x x)^{c}\right) & \left(1-f_{a_{2}}-\sum_{k=1}^{2}\left(f_{h_{k}}+f_{F_{k}}\right)\right) / 2 & \frac{f_{h_{2}} H\left[n, f_{h_{2}}\right]}{2^{2 n-1}}, j=1,2 \\
\left(a_{2}, a_{2}\right) & f_{a_{2}} / 2 & 0
\end{array}
$$




$$
\begin{array}{rcc}
\left(a_{2}, h_{2}\right) & f_{h_{2}} / 2 & \frac{f_{h_{1}} H\left[n, f_{h_{1}}\right]}{2^{2 n-1}} \\
\left(a_{2}, F_{j}\right) & f_{F_{j}} / 2 & 0, j=1,2 \\
\left(a_{2},(x x x x x)^{c}\right) & \left(1-f_{a_{2}}-\sum_{k=1}^{2}\left(f_{h_{k}}+f_{F_{k}}\right)\right) / 2 & 0
\end{array}
$$

Seja $u=u\left[n, f_{h_{1}}, f_{h_{2}}\right]$ a função definida por

$$
u=2\left(2^{n-1}-1\right) f_{h_{1}}^{2}+\left(1+\left(2^{n}+2\right) f_{h_{1}}\right) H\left[n, f_{h_{2}}\right] .
$$

Do teorema 8.2.1 e da expressão 8.20, obtemos que a distribuição de probabilidade $a$ posteriori para o genótipo do demandado $P\left[\cdot \mid D_{\mathbf{u}, m_{X}}\right]$, é dada no seguinte resultado.

Proposição 8.3.5 Sob as condições estabelecidas acima obtemos que a distribuição de probabilidade a posteriori para o genótipo do demandado $P\left[\cdot \mid D_{\mathbf{u}, m_{X}}\right]$, uma vez que em sua mãe foi observado o genótipo $m_{X}=\left(h_{1}, a_{2}\right)$ e em $n$ de seus filhos o genótipo observado foi $\left(h_{1}, h_{2}\right)$ é a seguinte.

$$
\begin{array}{cl}
\text { genótipo (·) } & P\left[\cdot \mid D_{\mathbf{u}, m_{X}}\right] \\
\left(h_{1}, h_{1}\right) & \frac{2^{n} f_{h_{1}} H\left[n, f_{h_{2}}\right]}{u\left[n, f_{h_{1}}, f_{h_{2}}\right]} \\
\left(h_{1}, a_{2}\right) & \frac{\left(f_{h_{1}}+f_{a_{2}}\right) H\left[n, f_{h_{2}}\right]}{u\left[n, f_{h_{1}}, f_{h_{2}}\right]} \\
\left(h_{1}, h_{2}\right) & \frac{\left(\sum_{k=1}^{2} H\left[n, f_{h_{k}}\right]-1\right) \sum_{k=1}^{2} f_{h_{k}}}{u\left[n, f_{h_{1}}, f_{h_{2}}\right]} \\
\left(h_{1}, F_{j}\right) & \frac{f_{F_{j}} H\left[n, f_{h_{2}}\right]}{u\left[n, f_{h_{1}}, f_{h_{2}}\right]}, j=1,2 \\
\left.h_{1},(x x x x)^{c}\right) & \frac{H\left[n, f_{h_{2}}\right]\left(1-f_{a_{2}}-\sum_{k=1}^{2}\left(f_{h_{k}}+f_{F_{k}}\right)\right.}{u\left[n, f_{h_{1}}, f_{h_{2}}\right]} \\
\left(h_{2}, a_{2}\right) & \frac{f_{h_{1}} H\left[n, f_{h_{1}}\right]}{u\left[n, f_{h_{1}}, f_{h_{2}}\right]}
\end{array}
$$


Do resultado anterior obtemos:

Corolário 8.3.5 Sob as condições da proposição 8.3.5, temos que a razão de verossimilhanças $R V[D]$ e a probabilidade condicional $V_{0}[D]$, do demandante ter recebido do demandado o(s) alelo(s) de interesse após termos observado D, tstão dadas a seguir

$$
\begin{array}{cll}
\multicolumn{1}{c}{\begin{array}{c}
I \\
h_{i}
\end{array}} & \frac{w_{i}\left[n, f_{h_{1}}, f_{h_{2}}\right]}{2 u\left[n, f_{h_{1}}, f_{h_{2}}\right]} & \frac{2 f_{h_{i}} u\left[n, f_{h_{1}}, f_{h_{2}}\right]}{w_{i}\left[n, f_{h_{1}}, f_{h_{2}}\right]}, i=1,2 \\
a_{2} & \frac{w_{3}\left[n, f_{h_{1}}, f_{h_{2}}\right]}{2 u\left[n, f_{h_{1}}, f_{h_{2}}\right]} & \frac{2 f_{a_{2}} u\left[n, f_{h_{1}}, f_{h_{2}}\right]}{w_{3}\left[n, f_{h_{1}}, f_{h_{2}}\right]} \\
F_{i} & \frac{f_{F_{i}} H\left[n, f_{h_{2}}\right]}{2 u\left[n, f_{h_{1}}, f_{h_{2}}\right]} & \frac{2 u\left[n, f_{h_{1}}, f_{h_{2}}\right]}{H\left[n, f_{h_{2}}\right]}, i=1,2 \\
h_{1} \text { e } h_{2} & \frac{\sum_{k=1}^{2} w_{k}\left[n, f_{h_{1}}, f_{h_{2}}\right]}{2 u\left[n, f_{h_{1}}, f_{h_{2}}\right]} & \frac{2 \sum_{k=1}^{2} f_{h_{k}} u\left[n, f_{h_{1}}, f_{h_{2}}\right]}{\sum_{k=1}^{2} w_{k}\left[n, f_{h_{1}}, f_{h_{2}}\right]} \\
h_{i} \text { e } a_{2} & \frac{w_{3+i}\left[n, f_{h_{1}}, f_{h_{2}}\right]}{2 u\left[n, f_{h_{1}}, f_{h_{2}}\right]} & \frac{2\left(f_{h_{i}}+f_{a_{2}}\right) u\left[n, f_{h_{1}}, f_{h_{2}}\right]}{w_{3+i}\left[n, f_{h_{1}}, f_{h_{2}}\right]}, i=1,2 \\
h_{i} \text { e } F_{j} & \frac{w_{i j}\left[n, f_{h_{1}}, f_{h_{2}}, f_{F_{j}}\right]}{2 u\left[n, f_{h_{1}}, f_{h_{2}}\right]} & \frac{2\left(f_{h_{i}}+f_{F_{j}}\right) u\left[n, f_{h_{1}}, f_{h_{2}}\right]}{w_{i j}\left[n, f_{h_{1}}, f_{h_{2}}, f_{F_{j}}\right]}, i, j=1,2 \\
a_{2} \text { e } F_{j} & \frac{f_{F_{j}} H\left[n, f_{h_{2}}\right]+w_{3}}{2 u\left[n, f_{h_{1}}, f_{h_{2}}\right]} & \frac{2\left(f_{a_{2}}+f_{F_{j}}\right) u\left[n, f_{h_{1}}, f_{h_{2}}\right]}{f_{F_{j}} H\left[n, f_{h_{2}}\right]+w_{3}}, j=1,2 \\
F_{1} \text { e } F_{2} & \frac{H\left[n, f_{h_{2}}\right] \sum_{k=1}^{2} f_{F_{k}}}{2 u\left[n, f_{h_{1}}, f_{h_{2}}\right]} & \frac{2 u\left[n, f_{h_{1}}, f_{h_{2}}\right]}{H\left[n, f_{h_{2}}\right]},
\end{array}
$$

onde as funções $w_{r}=w_{r}\left[n, f_{h_{1}}, f_{h_{2}}\right]$ para $i=1, \cdots, 5$ e $w_{i j}=w_{i j}\left[n, f_{h_{1}}, f_{h_{2}}, f_{F_{j}}\right]$ para $i, j=1,2$ são dadas pelas seguintes expressões.

$$
\begin{aligned}
& w_{1}=\left(1+\left(2^{n+1}+1\right) f_{h_{1}}\right) H\left[n, f_{h_{2}}\right]+\left(2^{n-1}-1\right) f_{h_{1}} \sum_{k=1}^{2} f_{h_{k}} \\
& w_{2}=\left(2 f_{h_{1}}+f_{h_{2}}\right) H\left[n, f_{h_{1}}\right]+\left(2^{n-1}-1\right) f_{h_{2}} \sum_{k=1}^{2} f_{h_{k}}
\end{aligned}
$$




$$
\begin{aligned}
& w_{3}=f_{h_{1}} \sum_{k=1}^{2} H\left[n, f_{h_{k}}\right]+f_{a_{2}} H\left[n, f_{h_{2}}\right] \\
& w_{4}=\left(1+f_{a_{2}}+\left(2^{n+1}+1\right) f_{h_{1}}\right) H\left[n, f_{h_{2}}\right]+f_{h_{1}}\left(\sum_{k=1}^{2} H\left[n, f_{h_{k}}\right]+\left(2^{n-1}-1\right) \sum_{k=1}^{2} f_{h_{k}}\right) \\
& w_{5}=\left(3 f_{h_{1}}+f_{h_{2}}\right) H\left[n, f_{h_{1}}\right]+\left(2^{n-1}-1\right) f_{h_{2}} \sum_{k=1}^{2} f_{h_{k}}+\left(f_{a_{2}}+f_{h_{1}}\right) H\left[n, f_{h_{2}}\right] \\
& w_{1 j}=\left(1+f_{F_{j}}+\left(2^{n+1}+1\right) f_{h_{1}}\right) H\left[n, f_{h_{2}}\right]+\left(2^{n-1}-1\right) f_{h_{1}} \sum_{k=1}^{2} f_{h_{k}}, j=1,2 \\
& w_{2 j}=\left(2 f_{h_{1}}+f_{h_{2}}\right) H\left[n, f_{h_{1}}\right]++f_{F_{j}} H\left[n, f_{h_{2}}\right]+\left(2^{n-1}-1\right) f_{h_{2}} \sum_{k=1}^{2} f_{h_{k}}, j=1,2
\end{aligned}
$$

Caso 8.2.5 Sejam $a_{i}, h_{i}$ e $F_{i}, i=1,2$ seis alelos diferentes. Suponhamos que foram observados a mãe e $n$ filhos do demandado, independentemente, encontrando nos $n$ filhos o genótipo $\left(h_{1}, h_{2}\right)$ e na mãe do demandado o genótipo $\left(a_{1}, a_{2}\right)$ - isto é, $D_{\mathbf{u}}=\left\{\left(h_{1}, h_{2}\right)_{n}\right\}$ e $m_{X}=\left(a_{1}, a_{2}\right)$.

A probabilidade condicional $v\left[D_{\mathbf{u}} \mid g_{i}\right]$ e a distribuição de probabilidade a posteriori para o genótipo do demandado $P\left[\cdot \mid m_{X}\right]$ - estabelecida na proposição 6.3 .2 - são dadas a seguir.

$$
\begin{array}{ccc}
\text { genótipo }(\cdot) & P\left[\cdot \mid m_{X}\right] & v\left[D_{\mathbf{u}} \mid \cdot\right] \\
\left(a_{i}, a_{i}\right) & f_{a_{i}} / 2 & 0, i=1,2 \\
\left(a_{1}, a_{2}\right) & \sum_{k=1}^{2} f_{a_{k}} / 2 & 0 \\
\left(a_{i}, h_{j}\right) & f_{h_{\jmath}} / 2 & \frac{f_{h_{\sigma(\jmath)}} H\left[n, f_{h_{\sigma(j)}}\right]}{2^{2 n-1}}, i, j=1,2 \\
\left(a_{i}, F_{j}\right) & f_{F_{j}} / 2 & 0, i, j=1,2 \\
\left(a_{i},(x x x x x)^{c}\right) & \left(1-\sum_{k=1}^{2}\left(f_{a_{k}}+f_{h_{k}}+f_{F_{k}}\right)\right) / 2 & 0, i=1,2
\end{array}
$$

Do resultado anterior e do teorema 8.2 .1 obtemos a distribuição de probabilidade $a$ posteriori para o genótipo do demandado $P\left[\cdot \mid D_{\mathbf{u}, m_{X}}\right]$. dada no seguinte resultado. 
Proposição 8.3.6 Sob as condições estabelecidas acima obtemos que a distribuição de probabilidade a posteriori para o genótipo do demandado $P\left[\cdot \mid D_{\mathbf{u}, m_{X}}\right]$, uma vez que em sua mãe foi observado o genótipo $m_{X}=\left(a_{1}, a_{2}\right)$ e em $n$ de seus filhos o genótipo observado foi $\left(h_{1}, h_{2}\right)$, é a seguinte.

$$
\begin{aligned}
\text { genótipo }(\cdot) & P\left[\cdot \mid D_{\mathbf{u}, m_{X}}\right] \\
\left(a_{i}, h_{j}\right) & \frac{H\left[n, f_{h_{\sigma(\jmath)}}\right]}{2 \sum_{k=1}^{2} H\left[n, f_{h_{k}}\right]}, i, j=1,2
\end{aligned}
$$

A razão de verossimilhanças $R V[D]$ e a probabilidade condicional $V_{0}[D]$ - obtida do resultado anterior - são explicitadas no seguinte resultado.

Corolário 8.3.6 Sob as condiçôes da proposição 8.3.6, temos que a razâo de verossimilhanças $R V[D]$ e a probabilidade condicional $V_{0}[D]$, do demandante ter recebido do demandado o(s) alelo(s) de interesse após termos observado $D$, estâo dadas a seguir

$$
\begin{array}{ccl}
I & V_{0}[D] & R V[D] \\
a_{i} & 1 / 4 & 4 f_{a_{i}}, i=1,2 \\
h_{i} & 1 / 4 & 4 f_{h_{i}}, i=1,2 \\
a_{1} \text { e } a_{2} & 1 / 2 & 2 \sum_{k=1}^{2} f_{a_{k}} \\
& & 2 \sum_{k=1}^{2} f_{h_{k}} \\
h_{1} \text { e } h_{2} & 1 / 2 & 2\left(f_{a_{i}}+f_{h_{j}}\right), i, j=1,2 \\
a_{i} \text { e } h_{j} & 1 / 2 & 4\left(f_{a_{i}}+f_{F_{j}}\right), i, j=1,2 \\
a_{i} \text { e } F_{j} & 1 / 4 & 2\left(f_{h_{i}}+f_{F_{j}}\right), i, j=1,2 . \\
h_{i} \text { e } F_{j} & 1 / 2 &
\end{array}
$$

Para finalizar a apresentação de resultados - mesmo que com o próximo conjunto de parentes do demandado nao ficam esgotadas todas as possibilidades - no capítulo 9 apresentaremos, a análise necessária para determinar a probabilidade a posteriori de paternidade quando está disponível a informação genotípica de alguns irmãos e de alguns filhos do demandado. Vamos admitir que os irmãos têm os mesmos pais e os filhos do demandado foram engendrados com a mesma mulher. 


\section{Capítulo 9}

\section{Análise para irmãos e filhos do demandado}

\subsection{Introdução}

Neste capítulo, apresentamos, detalhadamente, a metodologia proposta para determinar a distribuição de probabilidade a posteriori para o genótipo do demandado, uma vez que foi observada uma determinada estrutura genotípica em alguns de seus irmãos e em alguns de seus filhos. Esta distribuição de probabilidade a posteriori é a base para determinar a probabilidade de paternidade após terem sido observados os genótipos dos irmãos e dos filhos do demandado, da mãe do demandante e do próprio demandante isto é, a probabilidade a posteriori de paternidade - cujo método de cálculo foi exibido na seção 1.5 .

Admitiremos que os irmãos do demandado têm os mesmos pais e os filhos do demandado foram engendrados na mesma mulher.

Na seção 9.3, utilizamos a metodologia desenvolvida na seção anterior para calcular tanto a distribuição de probabilidade a posteriori para o genótipo do demandado quanto a razão entre as verossimilhanças do demandado não ser o pai do demandante e do demandado ser o pai do demandante, para cada um dos possiveis casos determinados pelos dados referentes aos genótipos dos irmãos e dos filhos do demandado. Estes dois 
elementos sào fundamentais no cálculo da probabilidade a posteriori de paternidade, a qual é obtida substituindo os valores encontrados aqui para estes elementos na expressão 1.8 ou 1.9 .

Devido aos inúmeros casos que se apresentam quando consideramos todas as possíveis relações entre os alelos que possuam os irmãos do demandado (veja capítulo 3) e, as relações entre os alelos dos filhos do demandado (veja capítulo 5), por motivos de espaço, mostraremos somente os resultados dos casos onde tanto nos irmãos quanto nos filhos do demandado é observado um mesmo genótipo, mas o genótipo observado nos irmãos pode ser diferente ao genótipo observado nos filhos.

\subsection{Descrição geral da metodologia}

Sejam $\mathcal{B}_{L},\left(G_{L}, \mathcal{A}_{G_{L}}\right), Z$ e $P[\cdot]$ como definidos na seção 3.2. Suponhamos que estejam disponíveis dados do demandante e de sua mãe, além de dados referentes a alguns irmãos e a alguns filhos do demandado. Suporemos ainda que o demandado e seus irmãos têm os mesmos pais e os filhos do demandado foram engendrados em uma mesma mulher. Isto é, a árvore genealógica que estudaremos apresenta a seguinte estrutura:

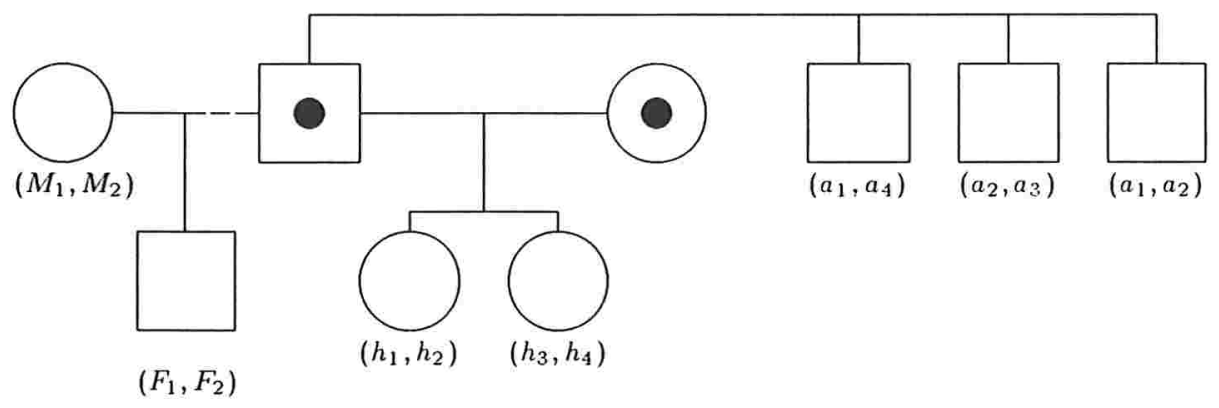

Árvore genealógica correspondente ao caso irmãos e filhos do demandado

Sejam $M, F$ e $X$ variáveis aleatórias $\mathcal{A}_{G_{L}}$ mensuráveis que denotam respectivamente os genótipos da mãe do demandante, do demandante e do demandado. Consideremos $U_{1} \mathrm{e}$ $U_{2}$ como sendo os vetores aleatórios dos genótipos dos irmãos e dos filhos do demandado, respectivamente, constituídos por componentes $\mathcal{A}_{G_{L}}$ mensuráveis.

Se os valores observados de $M, F, U_{1}$ e $U_{2}$ são respectivamente $\left(M_{1}, M_{2}\right),\left(F_{1}, F_{2}\right), \mathbf{u}_{1}$, e 
$\mathrm{u}_{2}$, o conjunto dos dados $D$ correspondente a este experimento é formado por

$$
D=\left\{\left(M_{1}, M_{2}\right),\left(F_{1}, F_{2}\right), \mathrm{u}_{1}, \mathrm{u}_{2}\right\} .
$$

Inicialmente, determinaremos a distribuição de probabilidade para o genótipo do demandado, após observar os genótipos de seus irmàos, de seus filhos e o(s) alelo(s) de interesse - isto é, obteremos a distribuição de probabilidade a posteriori $P[\cdot \mid D]$ da variável aleatória $X$. Para determinarmos esta distribuição de probabilidade propomos o seguinte procedimento.

Suponhamos que foram observados independentemente o genótipo da mãe do demandante, do demandante e os genótipos de $s_{1}$ irmãos e $s_{2}$ filhos do demandado, e sejam $\left(M_{1}, M_{2}\right),\left(F_{1}, F_{2}\right), \mathbf{u}_{1}$ e $\mathbf{u}_{2}$ os genótipos observados. respectivamente. Sejam $D_{\mathbf{u}_{1}}$ e $D_{\mathbf{u}_{2}}$ como os conjuntos definidos nos capítulos 2 e 4 , representando os genótipos observados nos $s_{1}$ irmãos e nos $s_{2}$ filhos, respectivamente.

Seguindo a metodologia proposta no capítulo 3, primeiramente, consideremos sobre o espaço mensurável $\left(G_{L}, \mathcal{A}_{G_{L}}\right)$ a medida de probabilidade $P\left[\cdot \mid D_{\mathbf{u}_{1}}\right]$, definida pela expressão 3.6, que descreve a incerteza para o genótipo do demandado, após que foram observados $s_{1}$ dos seus irmãos e antes de serem observados os genótipos de alguns filhos do demandado.

Dessa forma, a distribuição de probabilidade a posteriori para o genótipo do demandado $P\left[\cdot \mid D_{\mathbf{u}_{1}}\right]$, é considerada como a distribuiçào de probabilidade a priori para o genótipo do demandado - antes da observação dos genótipos de $s_{2}$ filhos do demandado. Imediatamente, ao utilizarmos a informação fornecida pela observação de $s_{2}$ filhos do demandado, usando a metodologia descrita no capítulo 5 , obtemos a distribuição de probabilidade a posteriori para o genótipo do demandado $P\left[\cdot \mid D_{\mathbf{u}_{1}}, D_{\mathbf{u}_{2}}\right]$.

Portanto, para cada $i=1, \cdots, N$, devemos calcular a probabilidade condicional $v\left[D_{\mathbf{u}_{2}} \mid g_{i}\right]$ de que os genótipos de $s_{2}$ irmãos, filhos dos mesmos pais, estejam representados no conjunto $D_{\mathbf{u}_{2}}$ dado que o genótipo de um de seus pais é $g_{i}$. A probabilidade condicional $v\left[D_{\mathbf{u}_{2}} \mid g_{i}\right]$ - já definida no capítulo 4 , é dada pela expressão

$$
v\left[D_{\mathbf{u}_{\mathbf{2}}} \mid g_{i}\right]=\sum_{j=1}^{N}\left(V\left[D_{\mathbf{u}_{2}} \mid\left(g_{i}, g_{j}\right)\right] P\left[g_{j}\right]\right),
$$

onde $P[\cdot]$ é a distribuição de probabilidade definida em 3.1 . 
O próximo passo é a atualização da distribuição de probabilidade a priori $P\left[\cdot \mid D_{\mathbf{u}_{1}}\right]$. Para isto usamos a informação obtida da observaçào dos filhos do demandado, a qual é traduzida no conjunto $D_{\mathbf{u}_{2}}$ e utilizamos o Teorema de Bayes como mecanismo de atualização de probabilidade.

Seja

$$
\delta=\sum_{i=1}^{N}\left(v\left[D_{\mathbf{u}_{2}} \mid g_{i}\right] P\left[g_{i} \mid D_{\mathbf{u}_{1}}\right]\right)
$$

Das expressões 5.4 e 9.1 obtemos que a distribuição de probabilidade a posteriori $P\left[\cdot \mid D_{\mathbf{u}_{1}}, D_{\mathbf{u}_{2}}\right]$, após serem observados $D_{\mathbf{u}_{1}}$ e $D_{\mathbf{u}_{2}}$. é

$$
\begin{aligned}
P\left[g_{k} \mid D_{\mathbf{u}_{1}}, D_{\mathbf{u}_{2}}\right] & =\frac{v\left[D_{\mathbf{u}_{2}} \mid g_{k}\right] P\left[g_{k} \mid D_{\mathbf{u}_{1}}\right]}{\delta} \\
& =\frac{v\left[D_{\mathbf{u}_{2}} \mid g_{k}\right] P\left[g_{k} \mid D_{\mathbf{u}_{1}}\right]}{\sum_{j=1}^{N} v\left[D_{\mathbf{u}_{2}} \mid g_{j}\right] P\left[g_{j} \mid D_{\mathbf{u}_{1}}\right]}, \quad k=1, \cdots, N .
\end{aligned}
$$

Em resumo, considerando a variável aleatória $X$ que denota o genótipo do demandado, e é $\mathcal{A}_{G_{L}}$ mensurável, $P$ como a medida de probabilidade definida sobre o espaço $\left(G_{L}, \mathcal{A}_{G_{L}}\right)$ definida na expressão 3.1 , a qual descreve a incerteza a priori sobre $\mathrm{X}, \mathbf{u}_{1} \mathrm{e}_{2}$ os vetores dos genótipos observados nos irmãos e filhos do demandado, representados nos conjuntos $D_{\mathbf{u}_{1}}$ e $D_{\mathbf{u}_{2}}$, respectivamente, provamos o seguinte resultado.

Teorema 9.2.1 Se $\mathbf{u}_{1}$ e $\mathbf{u}_{2}$ são obtidos ao observarmos independentemente $s_{1}$ irmãos $e s_{2}$ filhos do demandado, respectivamente, então a distribuição de probabilidade a posteriori $P\left[\cdot \mid D_{\mathbf{u}_{1}}, D_{\mathbf{u}_{2}}\right]$ para $X$ é dada pela expressâo

$$
P\left[g_{k} \mid D_{\mathbf{u}_{1}}, D_{\mathbf{u}_{2}}\right]=\frac{v\left[D_{\mathbf{u}_{2}} \mid g_{k}\right] P\left[g_{k} \mid D_{\mathbf{u}_{1}}\right]}{\sum_{j=1}^{N} v\left[D_{\mathbf{u}_{2}} \mid g_{j}\right] P\left[g_{j} \mid D_{\mathbf{u}_{1}}\right]}, \quad k=1, \cdots, N .
$$

onde $v\left[D_{\mathbf{u}_{2}} \mid \cdot\right]$ e $P\left[\cdot \mid D_{\mathbf{u}_{1}}\right]$ são dadas respectivamente pelas expressões 5.2 e 3.6 .

$\mathrm{Na}$ próxima seção, aplicaremos a metodologia introduzida aqui considerando todos os diferentes conjuntos $D_{\mathbf{u}_{1}}$ e $D_{\mathbf{n}_{2}}$ que trazem informação sobre os genótipos observados nos irmãos e nos filhos do demandado. Para facilitar a apresentação dos resultados 
correspondentes aos conjuntos $D_{\mathbf{u}_{1}}$ e $D_{\mathbf{u}_{2}}$ que determinam diferentes distribuições de probabilidade a posteriori para o genótipo do demandado, estes serão referenciados ao longo deste capítulo pelo código caso c.i.j.k a ser dado na primeira coluna da tabela 9.1, onde $\mathbf{c}$ indica o capítulo, i indica o número de alelos diferentes que aparecem em $D_{\mathbf{u}_{1}}$, j indica o número de alelos diferentes que aparecem em $D_{\mathbf{u}_{\mathbf{2}}}$ e $\mathrm{k}$ enumera as diferentes associações com igual número de alelos.

Tabela 9.1 Dados relevantes ao observarmos irmãos e filhos do demandado.

caso genótipos observados irmãos filhos

9.1.1.1<smiles>[13CH3][13CH3]</smiles><smiles>[13CH3]C[13CH3]</smiles>

9.1.1.2<smiles></smiles>

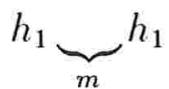

9.1.2.1<smiles></smiles><smiles>[13CH3][13CH3]</smiles>

9.1.2.2<smiles></smiles>

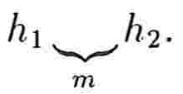

9.2.1.1<smiles>[GeH2]=C[TeH]</smiles><smiles></smiles>

9.2.1.2<smiles>[GeH2]=C[TeH2]</smiles><smiles>[123I]C=[125I]</smiles>

9.2.2.1<smiles>[CaH][CaH]</smiles><smiles></smiles>

9.2.2.2<smiles>[14CH3][14CH3]</smiles><smiles>[13CH3][13CH3]</smiles>

9.2.2.3<smiles>[13CH3][14CH3]</smiles>

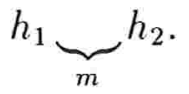




\subsection{Análise dos casos}

Nesta seção, aplicamos a metodologia desenvolvida na seção 9.2 para determinar a distribuição de probabilidade a posteriori para o genótipo do demandado, considerando cada um dos casos relacionados na tabela 9.1, exibida no final da seção anterior. Além disso, pelos argumentos fornecidos no capítulo 1, exibiremos apenas a probabilidade condicional $V_{0}[D]$ - ou $R V[D]$ quando possível - necessária ao cálculo da probabilidade a posteriori de paternidade. Quanto à outra probabilidade condicional $V_{1}[D]$, também necessária ao cálculo desta probabilidade a posteriori, será omitida por ser diretamente obtida da proposição 1.5.1.

Ao longo desta seção não tornaremos explícitos aqueles genótipos cujas probabilidades a posteriori sejam nulas.

\section{Caso 9.1.1.1}

Sejam $a_{1}, F_{1}$ e $F_{2}$ três alelos diferentes. Suponhamos que, ao considerarmos $n$ irmãos e $m$ filhos do demandado, independentemente, observamos em cada um deles o genótipo $\left(a_{1}, a_{1}\right)$ - isto é, $D_{\mathbf{u}_{1}}=\left\{\left(a_{1}, a_{1}\right)_{n}\right\}$ e $D_{\mathbf{u}_{2}}=\left\{\left(a_{1}, a_{1}\right)_{m}\right\}$

Da análise realizada nos casos 3.1.1 e 5.1.1 temos que a distribuição de probabilidade $a$ posteriori para o genótipo do demandado $P\left[\cdot \mid D_{\mathbf{u}_{1}}\right]$, uma vez que em $n$ de seus irmãos foi observado o genótipo $\left(a_{1}, a_{1}\right)$ e a probabilidade condicional $v\left[D_{\mathbf{u}_{2}} \mid \cdot\right]$ são dadas por

$$
\begin{array}{rlc}
\text { genótipo }(\cdot) & P\left[\cdot \mid D_{\mathbf{u}_{1}}\right] & v\left[D_{\mathbf{u}_{2}} \mid \cdot\right] \\
\left(a_{1}, a_{1}\right) & \frac{H^{2}\left[n+1, f_{a_{1}}\right]}{4 H^{2}\left[n, f_{a_{1}}\right]} & \frac{f_{a_{1}} H\left[m, f_{a_{1}}\right]}{2^{m-1}} \\
\left(a_{1}, F_{i}\right) & \frac{2 f_{F_{i}} H\left[n+1, f_{a_{1}}\right]}{4 H^{2}\left[n, f_{a_{1}}\right]}, i=1,2 & \frac{f_{a_{1}} H\left[m, f_{a_{1}}\right]}{2^{2 m-1}} \\
\left(a_{1},(x x x)^{c}\right) & \frac{2\left(1-f_{a_{1}}-\sum_{i=1}^{2} f_{F_{i}}\right) H\left[n+1, f_{a_{1}}\right]}{4 H^{2}\left[n, f_{a_{1}}\right]} & \frac{f_{a_{1}} H\left[m, f_{a_{1}}\right]}{2^{2 m-1}} \\
\left(F_{i}, F_{i}\right) & \frac{f_{F_{i}}^{2}}{4 H^{2}\left[n, f_{a_{1}}\right]}, i=1,2 & 0
\end{array}
$$




$$
\begin{array}{rlr}
\left(F_{1}, F_{2}\right) & \frac{2 \prod_{j=1}^{2} f_{F_{j}}}{4 H^{2}\left[n, f_{a_{1}}\right]} & 0 \\
\left(F_{i},(x x x)^{c}\right) & \frac{2 f_{F_{i}}\left(1-f_{a_{1}}-\sum_{j=1}^{2} f_{F_{j}}\right)}{4 H^{2}\left[n, f_{a_{1}}\right]}, i=1,2 & 0 \\
\left((x x x)^{c},(x x x)^{c}\right) & \frac{\left(1-f_{a_{1}}-\sum_{j=1}^{2} f_{F_{j}}\right)^{2}}{4 H^{2}\left[n, f_{a_{1}}\right]}
\end{array}
$$

Assim, para obtermos a distribuição $P\left[\cdot \mid D_{\mathbf{u}_{1}}, D_{\mathbf{u}_{2}}\right]$ é necessário apenas calcular o valor de $\delta$ definido na expressão 9.1. Para o caso que consideramos aqui, $\delta$ torna-se

$$
\delta=\frac{f_{a_{1}} H\left[n+1, f_{a_{1}}\right] H\left[m, f_{a_{1}}\right]}{2^{2 m} H^{2}\left[n, f_{a_{1}}\right]} u\left[n, m, f_{a_{1}}\right],
$$

onde $u\left[n, m, f_{a_{1}}\right]$ é dada por

$$
u\left[n, m, f_{a_{1}}\right]=1-f_{a_{1}}+2^{m-1} H\left[n+1, f_{a_{1}}\right]
$$

e a distribuição de probabilidade a posteriori para o genótipo do demandado $P\left[\cdot \mid D_{\mathbf{u}_{1}}, D_{\mathbf{u}_{2}}\right]$ é apresentada no seguinte resultado.

Proposição 9.3.1 A distribuição de probabilidade a posteriori para o genótipo do demandado $P\left[\cdot \mid D_{\mathbf{u}_{1}}, D_{\mathbf{u}_{2}}\right]$, uma vez que em $n$ de seus irmãos e em $m$ de seus filhos foi observado o genótipo $\left(a_{1}, a_{1}\right)$ é a seguinte.

$$
\begin{aligned}
\text { genótipo }(\cdot) & P\left[\cdot \mid D_{\mathbf{u}_{1}}, D_{\mathbf{u}_{2}}\right] \\
\left(a_{1}, a_{1}\right) & \frac{2^{m-1} H\left[n+1, f_{a_{1}}\right]}{u\left[n, m, f_{a_{1}}\right]} \\
\left(a_{1}, F_{i}\right) & \frac{f_{F_{i}}}{u\left[n, m, f_{a_{1}}\right]}, \quad i=1,2 \\
\left(a_{1},(x x x)^{c}\right) & \frac{1-f_{a_{1}}-\sum_{i=1}^{2} f_{F_{i}}}{u\left[n, m, f_{a_{1}}\right]}
\end{aligned}
$$

onde $u\left[n, m, f_{a_{1}}\right]$ é dada pela expressão 9.4 . 
Da distribuição de probabilidade a posteriori para o genótipo do demandado - dada neste caso pela expressão 9.5- obtemos a probabilidade condicional do demandante ter recebido do demandado o(s) alelo(s) de interesse após termos observado $D$ e, imediatamente, a razão de verossimilhanças $R V[D]$ para cada conjunto de alelos de interesse $I$, como podemos ver no seguinte corolário.

Corolário 9.3.1 Sob as condições da proposição 9.3.1, temos que a razão de verossimilhanças $R V[D]$ e a probabilidade condicional $V_{0}[D]$, do demandante ter recebido do demandado o(s) alelo(s) de interesse após termos observado D, estão dadas a seguir

$$
\begin{aligned}
& I \quad V_{0}[D] \quad R V[D] \\
& a_{1} \quad \frac{v_{1}\left[n . m, f_{a_{1}}\right]}{2 u\left[n . m, f_{a_{1}}\right]} \quad \frac{\left.2 f_{a_{1}}\right] u\left[n, m, f_{a_{1}}\right]}{v_{1}\left[n . m, f_{a_{1}}\right]} \\
& F_{i} \quad \frac{f_{F_{i}}}{2 u\left[n . m, f_{a_{1}}\right]} \quad 2 u\left[n, m, f_{a_{1}}\right], i=1,2 \\
& a_{1} \text { e } F_{i} \quad \frac{v_{1}\left[n . m, f_{a_{1}}\right]+f_{F_{i}}}{2 u\left[n, m, f_{a_{1}}\right]} \quad \frac{2\left(f_{a_{1}}+f_{F_{i}}\right) u\left[n, m, f_{a_{1}}\right]}{v_{1}\left[n, m, f_{a_{1}}\right]+f_{F_{i}}}, i=1,2 \\
& F_{1} e F_{2} \quad \frac{\sum_{i=1}^{2} f_{F_{i}}}{2 u\left[n, m, f_{a_{1}}\right]}, \quad 2 u\left[n, m, f_{a_{1}}\right]
\end{aligned}
$$

onde $v_{1}\left[n, m, f_{a_{1}}\right]=1-f_{a_{1}}+2^{m} H\left[n+1, f_{a_{1}}\right]$ e u[n, m, $\left.f_{a_{1}}\right]$ é dada pela expressâo 9.4.

\section{Caso 9.1.1.2}

Sejam $a_{1}, h_{1}, F_{1}$ e $F_{2}$ quatro alelos diferentes. Suponhamos que, ao considerarmos $n$ irmãos e $m$ filhos do demandado, independentemente, observamos em cada um dos irmãos o genótipo $\left(a_{1}, a_{1}\right)$ e em cada um dos filhos o genótipo $\left(h_{1}, h_{1}\right)$ - isto é, $D_{\mathbf{u}_{1}}=$ $\left\{\left(a_{1}, a_{1}\right)_{n}\right\}$ e $D_{\mathbf{u}_{2}}=\left\{\left(h_{1}, h_{1}\right)_{m}\right\}$.

Do caso 3.1.1 temos que a distribuição de probabilidade a posteriori $P\left[\cdot \mid D_{\mathbf{u}_{1}}\right]$ para o genótipo do demandado, uma vez foi observado o genótipo $\left(a_{1}, a_{1}\right)$ em $n$ de seus irmãos é dada por

$$
\text { genótipo } \quad P\left[\cdot \mid D_{\mathbf{u}_{1}}\right]
$$




$$
\begin{aligned}
\left(a_{1}, a_{1}\right) & H^{2}\left[n+1, f_{a_{1}}\right] /\left(4 H^{2}\left[n, f_{a_{1}}\right]\right) \\
\left(a_{1}, h_{1}\right) & 2 f_{h_{1}} H\left[n+1, f_{a_{1}}\right] /\left(4 H^{2}\left[n, f_{a_{1}}\right]\right) \\
\left(a_{1}, F_{j}\right) & 2 f_{F_{j}} H\left[n+1, f_{a_{1}}\right] /\left(4 H^{2}\left[n, f_{a_{1}}\right]\right), j=1,2 \\
\left(a_{1},(x x x x)^{c}\right) & 2 H\left[n+1, f_{a_{1}}\right]\left(1-f_{a_{1}}-f_{h_{1}}-\sum_{k=1}^{2} f_{F_{k}}\right) /\left(4 H^{2}\left[n, f_{a_{1}}\right]\right) \\
\left(h_{1}, h_{1}\right) & f_{h_{1}}^{2} /\left(4 H^{2}\left[n, f_{a_{1}}\right]\right) \\
\left(h_{1}, F_{j}\right) & 2 f_{h_{1}} f_{F_{j}} /\left(4 H^{2}\left[n, f_{a_{1}}\right]\right), j=1,2 \\
\left(h_{1},(x x x x)^{c}\right) & 2 f_{h_{1}}\left(1-f_{a_{1}}-f_{h_{1}}-\sum_{k=1}^{2} f_{F_{k}}\right) /\left(4 H^{2}\left[n, f_{a_{1}}\right]\right) \\
\left(F_{j}, F_{j}\right) & f_{F_{j}}^{2} /\left(4 H^{2}\left[n, f_{a_{1}}\right]\right), j=1,2 \\
\left(F_{1}, F_{2}\right) & 2 f_{F_{1}} f_{F_{2}} /\left(4 H^{2}\left[n, f_{a_{1}}\right]\right) \\
\left(F_{j},(x x x x)^{c}\right) & 2 f_{F_{j}}\left(1-f_{a_{1}}-f_{h_{1}}-\sum_{k=1}^{2} f_{F_{k}}\right) /\left(4 H^{2}\left[n, f_{a_{1}}\right]\right), j=1,2 \\
\left((x x x x)^{c},(x x x x)^{c}\right) & \left(1-f_{a_{1}}-f_{h_{1}}-\sum_{k=1}^{2} f_{F_{k}}\right)^{2} /\left(4 H^{2}\left[n, f_{a_{1}}\right]\right)
\end{aligned}
$$

Para este caso particular, a probabilidade condicional $v\left[D_{\mathbf{u}_{2}} \mid \cdot\right]$ é dada por

$$
\begin{aligned}
\text { genótipo } & v\left[D_{\mathbf{u}_{2}} \mid \cdot\right] \\
\left(h_{1}, h_{1}\right) & \frac{f_{h_{1}} H\left[m, f_{h_{1}}\right]}{2^{m-1}} \\
\left(h_{1}, h\right) & \frac{f_{h_{1}} H\left[m, f_{h_{1}}\right]}{2^{2 m-1}} \text { se } h \neq h_{1} \\
(x, y) & 0 \quad \text { se } x, y \neq h_{1}
\end{aligned}
$$

e o valor de $\delta$, definido pela expressão 9.1 , torna-se

$$
\delta=\frac{f_{h_{1}}^{2} H\left[m, f_{h_{1}}\right]}{2^{2 m} H^{2}\left[n, f_{a_{1}}\right]} u\left[n, m, f_{a_{1}}, f_{h_{1}}\right]
$$

onde $u\left[n, m, f_{a_{1}}, f_{h_{1}}\right]$ é a função definida pela expressão

$$
u\left[n, m, f_{a_{1}}, f_{h_{1}}\right]=2 H\left[n, f_{a_{1}}\right]+H\left[m, f_{h_{1}}\right]-1 .
$$


Das expressões 9.7, 9.8 e 9.9, obtemos a distribuição de probabilidade a posteriori para o genótipo do demandado $P\left[\cdot \mid D_{\mathbf{u}_{1}}, D_{\mathbf{u}_{2}}\right]$. a qual é apresentada no seguinte resultado.

Proposição 9.3.2 A distribuiçâo de probabilidade a posteriori para o genótipo do demandado $P\left[\cdot \mid D_{\mathbf{u}_{1}}, D_{\mathbf{u}_{2}}\right]$, uma vez que foram observados, respectivamente, os genótipos $\left(a_{1}, a_{1}\right)$ e $\left(h_{1}, h_{1}\right)$ em $n$ de seus irmãos $\epsilon$ em $m$ de seus filhos é a seguinte.

$$
\begin{aligned}
\text { genótipo }(\cdot) & P\left[\cdot \mid D_{\mathbf{u}_{1}}, D_{\mathbf{u}_{2}}\right] \\
\left(a_{1}, h_{1}\right) & \frac{H\left[n+1, f_{a_{1}}\right]}{u\left[n, m, f_{a_{1}}, f_{h_{1}}\right]} \\
\left(h_{1}, h_{1}\right) & \frac{2^{m-1} f_{h_{1}}}{u\left[n, m, f_{a_{1}}, f_{h_{1}}\right]} \\
\left(h_{1}, F_{i}\right) & \frac{f_{F_{i}}}{u\left[n, m, f_{a_{1}}, f_{h_{1}}\right]}, i=1,2 \\
\left(h_{1},(x x x)^{c}\right) & \frac{1-f_{a_{1}}-f_{h_{1}}-\sum_{k=1}^{2} f_{F_{k}}}{u\left[n, m, f_{a_{1}}, f_{h_{1}}\right]},
\end{aligned}
$$

onde $u\left[n, m, f_{a_{1}}, f_{h_{1}}\right]$ é dada pela expressão 9.10 .

A razão de verossimilhança $R V[D]$ e a probabilidade condicional $V_{0}[D]$, que é obtida da proposição 9.3.2, estão dadas no seguinte corolário.

Corolário 9.3.2 Sob as condiçôes da proposição 9.3.2, temos que a razão de verossimilhanças $R V[D]$ e a probabilidade condicional $V_{0}[D]$, do demandante ter recebido do demandado o(s) alelo(s) de interesse após termos observado $D$, estão dadas a seguir

$$
\begin{array}{lll}
I & V_{0}[D] & R V[D] \\
a_{1} & \frac{H\left[n+1, f_{a_{1}}\right]}{2 u\left[n, m, f_{a_{1}}, f_{h_{1}}\right]} & \frac{2 f_{a_{1}} u\left[n, m, f_{a_{1}}, f_{h_{1}}\right]}{H\left[n+1, f_{a_{1}}\right]} \\
h_{1} & \frac{v_{1}\left[n, m, f_{a_{1}}, f_{h_{1}}\right]}{2 u\left[n, m, f_{a_{1}}, f_{h_{1}}\right]} & \frac{2 f_{h_{1}} u\left[n, m, f_{a_{1}}, f_{h_{1}}\right]}{v_{1}\left[n, m, f_{a_{1}}\right]} \\
F_{i} & \frac{f_{F_{i}}}{2 u\left[n, m, f_{a_{1}}, f_{h_{1}}\right]} & 2 u\left[n, m, f_{a_{1}}, f_{h_{1}}\right], \quad i=1,2
\end{array}
$$




$$
\begin{array}{lll}
a_{1} \text { e } h_{1} & \frac{v_{2}\left[n, m, f_{a_{1}}, f_{h_{1}}\right]}{2 u\left[n, m, f_{a_{1}}, f_{h_{1}}\right]} & \frac{2\left(f_{a_{1}}+f_{h_{1}}\right) u\left[n, m, f_{a_{1}}, f_{h_{1}}\right]}{v_{2}\left[n, m, f_{a_{1}}, f_{h_{1}}\right]} \\
a_{1} \text { e } F_{i} & \frac{H\left[n+1, f_{a_{1}}\right]+f_{F_{i}}}{2 u\left[n, m, f_{a_{1}}, f_{h_{1}}\right]} & \frac{2\left(f_{a_{1}}+f_{F_{i}}\right) u\left[n, m, f_{a_{1}}, f_{h_{1}}\right]}{H\left[n+1, f_{a_{1}}\right]+f_{F_{i}}}, ; i=1,2 \\
h_{1} \text { e } F_{i} & \frac{v_{1}\left[n, m, f_{a_{1}}, f_{h_{1}}\right]+f_{F_{i}}}{2 u\left[n, m, f_{a_{1}}, f_{h_{1}}\right]} & \frac{2\left(f_{h_{1}}+f_{F_{i}}\right) u\left[n, m, f_{a_{1}}, f_{h_{1}}\right]}{v_{1}\left[n, m, f_{a_{1}}, f_{h_{1}}\right]+f_{F_{i}}}, ; i=1,2 \\
F_{1} e F_{2} & \frac{\sum_{i=1}^{2} f_{F_{i}}}{2 u\left[n, m, f_{a_{1}}, f_{h_{1}}\right]}, & 2 u\left[n, m, f_{a_{1}}, f_{h_{1}}\right]
\end{array}
$$

onde $v_{1}\left[n, m, f_{a_{1}}, f_{h_{1}}\right]=2 H\left[n, f_{a_{1}}\right]+\left(2^{m}-1\right) f_{h_{1}}$ e u[n.m, $\left.f_{a_{1}}, f_{h_{1}}\right]$ é dada pela expressão 9.10 .

\section{Caso 9.1.2.1}

Sejam $a_{1}, h_{1}, F_{1}$ e $F_{2}$ quatro alelos diferentes. Suponhamos que, ao considerarmos $n$ irmãos e $m$ filhos do demandado, independentemente, observamos em cada um dos irmãos o genótipo $\left(a_{1}, a_{1}\right)$ e em cada um dos filhos o genótipo $\left(a_{1}, h_{1}\right)$ - isto é, $D_{\mathbf{u}_{1}}=$ $\left\{\left(a_{1}, a_{1}\right)_{n}\right\}$ e $D_{\mathbf{u}_{2}}=\left\{\left(a_{1}, h_{1}\right)_{m}\right\}$.

A distribuição de probabilidade a posteriori $P\left[\cdot \mid D_{\mathbf{u}_{1}}\right]$ para o genótipo do demandado, uma vez foi observado o genótipo $\left(a_{1}, a_{1}\right)$ em $n$ de seus irmãos é dada por 9.7. Supondo que $a_{1}=h_{2}$, obtemos que a probabilidade condicional $v\left[D_{\mathbf{u}_{2}} \mid \cdot\right]$ é dada por

$$
\begin{aligned}
\text { genótipo } & v\left[D_{\mathbf{u}_{\mathbf{2}}} \mid \cdot\right] \\
\left(h_{i}, h_{i}\right) & \frac{f_{h_{\sigma(i)}} H\left[m, f_{h_{\sigma(i)}}\right]}{2^{m-1}}, i=1,2 \\
\left(h_{1}, h_{2}\right) & \frac{\left(\sum_{k=1}^{2} H\left[m, f_{h_{k}}\right]-1\right) \sum_{k=1}^{2} f_{h_{k}}}{2^{2 m-1}} \\
\left(h_{i}, h\right) & \frac{f_{h_{\sigma(i)}} H\left[m, f_{h_{\sigma(i)}}\right]}{2^{2 m-1}} \text { se } h \neq h_{j}, i, j=1,2 \\
(x, y) & 0 \text { se } x \neq h_{i} \text { e } y \neq h_{j} \text { para } i, j=1,2 .
\end{aligned}
$$

O valor de $\delta$, definido pela expressão 9.1 , é obtido das expressões 9.7 e 9.12 tornando-se

$$
\delta=\frac{f_{h_{1}}}{2^{2 m} H^{2}\left[n, f_{a_{1}}\right]} u\left[n, m, f_{a_{1}}, f_{h_{1}}\right]
$$


onde $u\left[n, m, f_{a_{1}}, f_{h_{1}}\right]$ é dada por

$$
\begin{aligned}
u\left[n, m, f_{a_{1}}, f_{h_{1}}\right]= & \left(1+2^{m-1} H\left[n+1, f_{a_{1}}\right]\right) H\left[n+1, f_{a_{1}}\right] H\left[m, f_{h_{1}}\right] \\
& +\left(2^{m-1}-1\right) f_{a_{1}}\left(f_{a_{1}}+f_{h_{1}}\right) H\left[n+1, f_{a_{1}}\right] \\
& +f_{a_{1}} H\left[m, f_{a_{1}}\right]\left(H\left[m, f_{h_{1}}\right]-f_{a_{1}}\right)
\end{aligned}
$$

A distribuição de probabilidade a posteriori para o genótipo do demandado $P\left[\cdot \mid D_{\mathbf{u}_{1}}, D_{\mathbf{u}_{2}}\right]$, é apresentada no seguinte resultado.

Proposição 9.3.3 A distribuição de probabilidade a posteriori para o genótipo do demandado $P\left[\cdot \mid D_{\mathbf{u}_{1}}, D_{\mathbf{u}_{2}}\right]$, uma vez que foram observados, respectivamente, os genótipos $\left(a_{1}, a_{1}\right)$ e $\left(a_{1}, h_{1}\right)$, em $n$ de seus irmãos e em $m$ de seus filhos, é a seguinte.

$$
\begin{aligned}
\text { genótipo }(\cdot) & P\left[(\cdot) \mid D_{\mathbf{u}_{1}}, D_{\mathbf{u}_{2}}\right] \\
\left(a_{1}, a_{1}\right) & \frac{2^{m-1} H^{2}\left[n+1, f_{a_{1}}\right] H\left[m, f_{h_{1}}\right]}{u\left[n \cdot m, f_{a_{1}}, f_{h_{1}}\right]} \\
\left(a_{1}, h_{1}\right) & \frac{H\left[n+1, f_{a_{1}}\right]\left(f_{a_{1}}+f_{h_{1}}\right)\left(H\left[m, f_{a_{1}}\right]+\left(2^{m-1}-1\right) f_{h_{1}}\right)}{u\left[n, m, f_{a_{1}}, f_{h_{1}}\right]} \\
\left(a_{1}, F_{i}\right) & \frac{f_{F_{i}} H\left[n+1, f_{a_{1}}\right] H\left[m, f_{h_{1}}\right]}{u\left[n, m, f_{a_{1}}, f_{h_{1}}\right]}, i=1,2 \\
\left(a_{1},(x x x x)^{c}\right) & \frac{H\left[n+1, f_{a_{1}}\right] H\left[m, f_{h_{1}}\right]\left(1-f_{a_{1}}-f_{h_{1}}-\sum_{j=1}^{2} f_{F_{j}}\right)}{u\left[n, m, f_{a_{1}}, f_{h_{1}}\right]} \\
\left(h_{1}, h_{1}\right) & \frac{2^{m-1} f_{a_{1}} f_{h_{1}} H\left[m, f_{a_{1}}\right]}{u\left[n, m, f_{a_{1}}, f_{h_{1}}\right]} \\
\left(h_{1}, F_{i}\right) & \frac{f_{F_{1}} f_{a_{1}} H\left[m, f_{a_{1}}\right]}{u\left[n, m, f_{a_{1}}, f_{h_{1}}\right]}, i=1,2 \\
\left(h_{1},(x x x x)^{c}\right) & \frac{f_{a_{1}} H\left[m, f_{a_{1}}\right]\left(1-f_{a_{1}}-f_{h_{1}}-\sum_{j=1}^{2} f_{F_{j}}\right)}{u\left[n, m, f_{a_{1}}, f_{h_{1}}\right]}
\end{aligned}
$$

onde $u\left[n, m, f_{a_{1}}, f_{h_{1}}\right]$ é dada pela expressão 9.14. 
A razão de verossimilhança $R V[D]$ e a probabilidade condicional $V_{0}[D]$, que é obtida da proposição 9.3.3, estão dadas no seguinte corolário.

Corolário 9.3.3 Sob as condiçôes da proposição 9.3.3, temos que a razão de verossimilhanças $R V[D]$ e a probabilidade condicional $\mathrm{V}_{0}[D]$, do demandante ter recebido do demandado o(s) alelo(s) de interesse após termos observado $D$, estão dadas a seguir

$$
\begin{array}{cll}
\multicolumn{1}{c}{I} & V_{0}[D] & \multicolumn{1}{c}{R V[D]} \\
a_{1} & \frac{v_{1}\left[n, m, f_{a_{1}}, f_{h_{1}}\right]}{2 u\left[n, m, f_{a_{1}}, f_{h_{1}}\right]} & \frac{2 f_{a_{1}} u\left[n, m, f_{a_{1}}, f_{h_{1}}\right]}{v_{1}\left[n, m, f_{a_{1}}, f_{h_{1}}\right]} \\
h_{1} & \frac{v_{2}\left[n, m, f_{a_{1}}, f_{h_{1}}\right]}{2 u\left[n, m, f_{a_{1}}, f_{h_{1}}\right]} & \frac{2 f_{h_{1}} u\left[n, m, f_{a_{1}}, f_{h_{1}}\right]}{v_{2}\left[n, m, f_{a_{1}}, f_{h_{1}}\right]} \\
F_{i} & \frac{f_{F_{i}} v_{3}\left[n, m, f_{a_{1}}, f_{h_{1}}\right]}{2 u\left[n, m, f_{a_{1}}, f_{h_{1}}\right]} & \frac{2 u\left[n, m, f_{a_{1}}, f_{h_{1}}\right]}{v_{3}\left[n, m, f_{a_{1}}, f_{h_{1}}\right]}, i=1,2 \\
a_{1} \text { e } h_{1} & \frac{v_{2}+H\left[n+1, f_{a_{1}}\right] v_{1}}{2 u\left[n, m, f_{a_{1}}, f_{h_{1}}\right]} & \frac{2\left(f_{a_{1}}+f_{h_{1}}\right) u\left[n, m, f_{a_{1}}, f_{h_{1}}\right]}{v_{2}+H\left[n+1, f_{a_{1}}\right] v_{1}} \\
a_{1} \text { e } F_{i} & \frac{H\left[n+1, f_{a_{1}}\right] v_{1}+f_{F_{i}} v_{2}}{2 u\left[n, m, f_{a_{1}}, f_{h_{1}}\right]} & \frac{2\left(f_{a_{1}}+f_{F_{i}}\right) u\left[n, m, f_{a_{1}}, f_{h_{1}}\right]}{H\left[n+1, f_{a_{1}}\right] v_{1}+f_{F_{i}} v_{2}}, i=1,2 \\
h_{1} \text { e } F_{i} & \frac{w_{i}\left[n, m, f_{a_{1}}, f_{h_{1}}, f_{F_{i}}\right]}{2 u\left[n, m, f_{a_{1}}, f_{h_{1}}\right]} & \frac{2\left(f_{h_{1}}+f_{F_{i}}\right) u\left[n, m, f_{a_{1}}, f_{h_{1}}\right]}{w_{i}\left[n, m, f_{a_{1}}, f_{h_{1}}, f_{F_{i}}\right]}, i=1,2 \\
F_{1} \text { e } F_{2} & \frac{v_{3}\left[n, m, f_{a_{1}}, f_{h_{1}}\right] \sum_{i=1}^{2} f_{F_{i}}}{2 u\left[n, m, f_{a_{1}}, f_{h_{1}}\right]} & \frac{2 u\left[n . m, f_{a_{1}}, f_{h_{1}}\right]}{v_{3}\left[n, m, f_{a_{1}}, f_{h_{1}}\right]},
\end{array}
$$

onde para $j=1,2,3$ e $i=1,2$ as funções $v_{j}=v_{j}\left[n, m, f_{a_{1}}, f_{h_{1}}\right]$ e $w_{i}=w_{i}\left[n, m, f_{a_{1}}, f_{h_{1}}, f_{F_{i}}\right]$ são dadas pelas seguintes expressões

$$
\begin{aligned}
v_{1}= & H\left[n+1, f_{a_{1}}\right]\left\{\left(2^{m-1}-1\right) f_{a_{1}}\left(f_{a_{1}}+f_{h_{1}}\right)+\left(1+2^{m} H\left[n+1, f_{a_{1}}\right]\right) H\left[m, f_{h_{1}}\right]\right\} \\
v_{2}= & 2 f_{a_{1}} H\left[m, f_{a_{1}}\right]\left\{H\left[n, f_{a_{1}}\right]+\left(2^{m-1}+2^{n-1}-1\right) f_{h_{1}}\right\} \\
& +f_{h_{1}}\left\{H\left[m, f_{a_{1}}\right]+\left(2^{m-1}-1\right)\left(f_{a_{1}}+f_{h_{1}}\right) H\left[n+1, f_{a_{1}}\right]\right\} \\
v_{3}= & H\left[n+1, f_{a_{1}}\right] H\left[m, f_{h_{1}}\right]+f_{a_{1}} H\left[m, f_{a_{1}}\right] \\
w_{i}= & H\left[n+1, f_{a_{1}}\right]\left\{\left(2^{m-1}-1\right) f_{h_{1}}\left(f_{a_{1}}+f_{h_{1}}\right)+f_{F_{i}} H\left[m, f_{h_{1}}\right]\right\} \\
& +H\left[m, f_{a_{1}}\right]\left\{f_{h_{1}}+f_{a_{1}}\left(f_{F_{1}}+2 H\left[n, f_{a_{1}}\right]+2\left(2^{m-1}+2^{n-1}-1\right) f_{h_{1}}\right)\right\}, i=1,2
\end{aligned}
$$




\section{Caso 9.1.2.2}

Sejam $a_{1}, h_{1}, h_{2}, F_{1}$ e $F_{2}$ cinco alelos diferentes. Suponhamos que, ao considerarmos $n$ irmãos e $m$ filhos do demandado. independentemente, observamos em cada um dos irmãos o genótipo $\left(a_{1}, a_{1}\right)$ e em cada um dos filhos o genótipo $\left(h_{1}, h_{2}\right)$ - isto é, $D_{\mathbf{u}_{1}}=$ $\left\{\left(a_{1}, a_{1}\right)_{n}\right\}$ e $D_{\mathbf{u}_{2}}=\left\{\left(h_{1}, h_{2}\right)_{m}\right\}$.

Do caso 3.1 .1 , obtemos que a distribuição de probabilidade a posteriori $P\left[\cdot \mid D_{\mathbf{u}_{1}}\right]$ para o genótipo do demandado, uma vez foi observado o genótipo $\left(a_{1}, a_{1}\right)$ em $n$ de seus irmãos é dada por

$$
\begin{aligned}
\text { genótipo } & P\left[\cdot \mid D_{\mathbf{u}_{1}}\right] \\
\left(a_{1}, a_{1}\right) & H^{2}\left[n+1, f_{a_{1}}\right] /\left(4 H^{2}\left[n, f_{a_{1}}\right]\right) \\
\left(a_{1}, h_{j}\right) & 2 f_{h_{j}} H\left[n+1, f_{a_{1}}\right] /\left(4 H^{2}\left[n, f_{a_{1}}\right]\right), j=1,2 \\
\left(a_{1}, F_{j}\right) & 2 f_{F_{j}} H\left[n+1, f_{a_{1}}\right] /\left(4 H^{2}\left[n, f_{a_{1}}\right]\right), j=1,2 \\
\left(a_{1},(x x x x x)^{c}\right) & 2 H\left[n+1, f_{a_{1}}\right]\left(1-f_{a_{1}}-\sum_{k=1}^{2}\left(f_{h_{k}}+f_{F_{k}}\right)\right) /\left(4 H^{2}\left[n, f_{a_{1}}\right]\right) \\
\left(h_{j}, h_{j}\right) & f_{h_{j}}^{2} /\left(4 H^{2}\left[n, f_{a_{1}}\right]\right), j=1,2 \\
\left(h_{j}, F_{i}\right) & 2 f_{h_{j}} f_{F_{i}} /\left(4 H^{2}\left[n, f_{a_{1}}\right]\right), i, j=1,2 \\
\left(h_{j},(x x x x)^{c}\right) & 2 f_{h_{j}}\left(1-f_{a_{1}}-\sum_{k=1}^{2}\left(f_{h_{k}}+f_{F_{k}}\right)\right) /\left(4 H^{2}\left[n, f_{a_{1}}\right]\right), j=1,2 \\
\left(F_{j}, F_{j}\right) & f_{F_{j}}^{2} /\left(4 H^{2}\left[n, f_{a_{1}}\right]\right), j=1,2 \\
\left(F_{1}, F_{2}\right) & 2 f_{F_{1}} f_{F_{2}} /\left(4 H^{2}\left[n, f_{a_{1}}\right]\right) \\
\left(F_{j},(x x x x)^{c}\right) & 2 f_{F_{j}}\left(1-f_{a_{1}}-\sum_{k=1}^{2}\left(f_{h_{k}}+f_{F_{k}}\right)\right) /\left(4 H^{2}\left[n, f_{a_{1}}\right]\right), j=1,2 \\
\left.(x x x x)^{c},(x x x x)^{c}\right) & \left(1-f_{a_{1}}-\sum_{k=1}^{2}\left(f_{h_{k}}+f_{F_{k}}\right)\right)^{2} /\left(4 H^{2}\left[n, f_{a_{1}}\right]\right) \\
& (x)
\end{aligned}
$$

Para este caso particular, a probabilidade condicional $v\left[D_{\mathbf{u}_{2}} \mid \cdot\right]$ é dada pela expressão 
9.12 e o valor de $\delta$, definido pela expressão 9.1 , torna-se

$$
\delta=\frac{f_{h_{1}} f_{h_{2}}}{2^{2 m} H^{2}\left[n, f_{a_{1}}\right]} u\left[n, m, f_{a_{1}}, f_{h_{1}}, f_{h_{2}}\right]
$$

onde $u=u\left[n, m, f_{a_{1}}, f_{h_{1}}, f_{h_{2}}\right]$ é dada por

$$
u=\sum_{i=1}^{2}\left\{H\left[m, f_{h_{i}}\right]\left(2 H\left[n, f_{a_{1}}\right]+2^{m-1} f_{h_{\sigma(i)}}\right)-f_{h_{i}}\right\}
$$

Das expressões 9.16, 9.12 e 9.17, obtemos a distribuição de probabilidade a posteriori para o genótipo do demandado $P\left[\cdot \mid D_{\mathbf{u}_{1}}, D_{\mathbf{u}_{2}}\right]$, a qual é apresentada no seguinte resultado.

Proposição 9.3.4 A distribuição de probabilidade a posteriori para o genótipo do demandado $P\left[\cdot \mid D_{\mathbf{u}_{1}}, D_{\mathbf{u}_{2}}\right]$, uma vez que foram observados, respectivamente, os genótipos $\left(a_{1}, a_{1}\right)$ e $\left(h_{1}, h_{2}\right)$ em $n$ de seus irmãos e em $m$ de seus filhos é a seguinte.

$$
\begin{aligned}
\text { genótipo }(\cdot) & P\left[\cdot \mid D_{\mathbf{u}_{1}}, D_{\mathbf{u}_{2}}\right] \\
\left(a_{1}, h_{i}\right) & \frac{H\left[n+1, f_{a_{1}}\right] H\left[m, f_{h_{\sigma(i)}}\right]}{u\left[n, m, f_{a_{1}}, f_{h_{1}}, f_{h_{2}}\right]}, i=1,2 \\
\left(h_{i}, h_{i}\right) & \frac{2^{m-1} f_{h_{i}} H\left[m, f_{h_{\sigma(i)}}\right]}{u\left[n, m, f_{a_{1}}, f_{h_{1}}, f_{h_{2}}\right]}, i=1,2 \\
\left(h_{1}, h_{2}\right) & \frac{\left(f_{h_{1}}+f_{h_{2}}\right)\left(H\left[m, f_{h_{1}}\right]+\left(2^{m-1}-1\right) f_{h_{2}}\right)}{u\left[n, m, f_{a_{1}}, f_{h_{1}}, f_{h_{2}}\right]} \\
\left(h_{i}, F_{j}\right) & \frac{f_{F_{j}} H\left[m, f_{h_{\sigma(i)}}\right]}{u\left[n, m, f_{a_{1}}, f_{h_{1}}, f_{h_{2}}\right]}, i, j=1,2 \\
\left(h_{i},(x x x x)^{c}\right) & \frac{H\left[m, f_{h_{\sigma(i)}}\right)\left(1-f_{a_{1}}-\sum_{k=1}^{2}\left(f_{F_{k}}+f_{h_{k}}\right)\right)}{u\left[n, m, f_{a_{1}}, f_{h_{1}}, f_{h_{2}}\right]}, i=1,2
\end{aligned}
$$

onde $u\left[n, m, f_{a_{1}}, f_{h_{1}}, f_{h_{2}}\right]$ é dada pela expressão 9.18 .

A razão de verossimilhança $R V[D]$ e a probabilidade condicional $V_{0}[D]$, que é obtida da proposição 9.3.4, estão dadas no seguinte corolário. 
Corolário 9.3.4 Sob as condições da proposição 9.3.4, temos que a razão de verossimilhanças $R V[D]$ e a probabilidade condicional $\mathrm{V}_{0}[D]$, do demandante ter recebido do demandado o(s) alelo(s) de interesse após termos observado D, estão dadas a seguir

$$
\begin{aligned}
& V_{0}[D] \\
& R V[D] \\
& a_{1} \quad \frac{H\left[n+1, f_{a_{1}}\right] \sum_{k=1}^{2} H\left[m, f_{h_{k}}\right]}{2 u\left[n, m, f_{a_{1}}, f_{h_{1}}, f_{h_{2}}\right]} \quad \frac{2 f_{a_{1}} u\left[n, m, f_{a_{1}}, f_{h_{1}}, f_{h_{2}}\right]}{H\left[n+1, f_{a_{1}}\right] \sum_{k=1}^{2} H\left[m, f_{h_{k}}\right]} \\
& h_{i} \quad \frac{v_{i}\left[n, m, f_{a_{1}}, f_{h_{1}}, f_{h_{2}}\right]}{2 u\left[n, m, f_{a_{1}}, f_{h_{1}}, f_{h_{2}}\right]} \quad \frac{2 f_{h_{i}} u\left[n, m, f_{a_{1}}, f_{h_{1}}, f_{h_{2}}\right]}{v_{i}\left[n, m, f_{a_{1}}, f_{h_{1}}, f_{h_{2}}\right]}, i=1,2 \\
& F_{i} \quad \frac{f_{F_{i}} \sum_{k=1}^{2} H\left[m, f_{h_{k}}\right]}{2 u\left[n, m, f_{a_{1}}, f_{h_{1}}, f_{h_{2}}\right]} \quad \frac{2 u\left[n, m \cdot f_{a_{1}}, f_{h_{1}}, f_{h_{2}}\right]}{\sum_{k=1}^{2} H\left[m, f_{h_{k}}\right]}, i=1,2 \\
& a_{1} e h_{i} \quad \frac{v_{1 i}\left[n, m, f_{a_{1}}, f_{h_{1}}, f_{h_{2}}\right]}{2 u\left[n, m, f_{a_{1}}, f_{h_{1}}, f_{h_{2}}\right]} \\
& a_{1} \text { e } F_{i} \quad \frac{v_{2 i}\left[n, m, f_{a_{1}}, f_{h_{1}}, f_{h_{2}}\right]}{2 u\left[n, m, f_{a_{1}}, f_{h_{1}}, f_{h_{2}}\right]} \\
& h_{1} \text { e } h_{2} \quad \frac{z\left[n, m, f_{a_{1}}, f_{h_{1}}, f_{h_{2}}\right]}{2 u\left[n, m, f_{a_{1}}, f_{h_{1}}, f_{h_{2}}\right]} \\
& h_{i} \text { e } F_{j} \quad \frac{w_{i j}\left[n, m, f_{a_{1}}, f_{h_{1}}, f_{h_{2}}, f_{F_{3}}\right]}{2 u\left[n, m, f_{a_{1}}, f_{h_{1}}, f_{h_{2}}\right]} \quad \frac{2\left(f_{h_{i}}+f_{F_{j}}\right) u\left[n, m, f_{a_{1}}, f_{h_{1}}, f_{h_{2}}\right]}{w_{i j}\left[n . m, f_{a_{1}}, f_{h_{1}}, f_{h_{2}}, f_{F_{j}}\right]}, ; i, j=1,2 \\
& F_{1} \text { e } F_{2} \quad \frac{\sum_{k=1}^{2} H\left[m, f_{h_{k}}\right] \sum_{i=1}^{2} f_{F_{i}}}{2 u\left[n, m, f_{a_{1}}, f_{h_{1}}, f_{h_{2}}\right]} \quad \frac{2 u\left[n, m, f_{a_{1}}, f_{h_{1}}, f_{h_{2}}\right]}{\sum_{k=1}^{2} H\left[m, f_{h_{k}}\right]},
\end{aligned}
$$

onde as funções

$$
\begin{aligned}
v_{i} & =v_{i}\left[n, m, f_{a_{1}}, f_{h_{1}}, f_{h_{2}}\right], i=1,2 \\
v_{i j} & =v_{i j}\left[n, m, f_{a_{1}}, f_{h_{1}}, f_{h_{2}}\right], \quad i, j=1,2 \\
w_{i j} & =w_{i j}\left[n, m, f_{a_{1}}, f_{h_{1}}, f_{h_{2}}\right], \quad i, j=1,2 \\
z & =z\left[n, m, f_{a_{1}}, f_{h_{1}}, f_{h_{2}}\right]
\end{aligned}
$$

são dadas pelas seguintes expressões

$$
z=2\left(2^{m}\left(2^{m-1}-1\right) \prod_{k=1}^{2} f_{h_{k}}+H\left[n, f_{a_{1}}\right] \sum_{k=1}^{2} H\left[m, f_{h_{k}}\right]\right.
$$




$$
\begin{aligned}
& \left.+\left\{\left(2^{m-1}-1\right)+\sum_{k=1}^{2} H\left[m, f_{h_{k}}\right]\right\} \sum_{k=1}^{2} f_{h_{k}}\right) \\
v_{i}= & 2 H\left[m, f_{h_{\sigma(i)}}\right]\left(H\left[n, f_{a_{1}}\right]+2^{m-1} f_{h_{i}}\right) \\
& +\left(2^{m-1}-1\right) f_{h_{i}} \sum_{k=1}^{2} f_{h_{k}}, i=1,2 \\
v_{1 j}= & H\left[m, f_{h_{\sigma(\jmath)}}\right]\left(1-f_{a_{1}}+2^{m} f_{h_{\jmath}}\right)+2 H\left[n+1, f_{a_{1}}\right] \sum_{k=1}^{2} H\left[m, f_{h_{k}}\right] \\
& +\left(2^{m-1}-1\right) f_{h_{1}} \sum_{k=1}^{2} f_{h_{k}}, j=1,2 \\
v_{2 j}= & \left(H\left[n+1, f_{a_{1}}\right]+f_{F_{j}}\right) \sum_{k=1}^{2} H\left[m, f_{h_{k}}\right], j=1,2 \\
w_{i j}= & H\left[m, f_{h_{\sigma(i)}}\right]\left\{2 H\left[n, f_{a_{1}}\right]+2^{m} f_{h_{i}}+f_{F_{j}}\right\}+f_{F_{j}} \\
& +\left(2^{m-1}-1\right) f_{h_{i}}\left(f_{h_{1}}+f_{h_{2}}+f_{F_{j}}\right) . \quad i, j=1,2
\end{aligned}
$$

\section{Caso 9.2.1.1}

Sejam $a_{1}, a_{2}, F_{1}$ e $F_{2}$ quatro alelos diferentes. Suponhamos que, ao considerarmos $n$ irmãos e $m$ filhos do demandado, independentemente, observamos em cada um dos irmãos o genótipo $\left(a_{1}, a_{2}\right)$ e em cada um dos filhos o genótipo $\left(a_{1}, a_{1}\right)$ - isto é, $D_{\mathbf{u}_{1}}=$ $\left\{\left(a_{1}, a_{2}\right)_{n}\right\}$ e $D_{\mathbf{u}_{2}}=\left\{\left(a_{1}, a_{1}\right)_{m}\right\}$.

Do caso 3.2 .2 , obtemos que a distribuição de probabilidade a posteriori $P\left[\cdot \mid D_{\mathbf{u}_{1}}\right]$ para o genótipo do demandado, uma vez foi observado o genótipo $\left(a_{1}, a_{2}\right)$ em $n$ de seus irmãos é dada por

$$
\begin{aligned}
\text { genótipo } & P\left[\cdot \mid D_{\mathbf{u}_{1}}\right] \\
\left(a_{i}, a_{i}\right) & f_{a_{i}}\left\{\left(2^{n}-1\right) f_{a_{i}}+H\left[n, f_{a_{\sigma(2)}}\right]\right\} / 4 d, i=1,2 \\
\left(a_{1}, a_{2}\right) & \left\{1+\left(2^{n}-1\right)\left(f_{a_{1}}+f_{a_{2}}+2^{n} f_{a_{1}}, f_{a_{2}}\right)\right\} / 4 d \\
\left(a_{i}, F_{j}\right) & f_{F_{j}}\left(1+2^{n} f_{a_{i}}\right) / 4 d, i, j=1,2 \\
\left(a_{i},(x x x x)^{c}\right) & \left(1+2^{n} f_{a_{1}}\right)\left(1-\sum_{k=1}^{2}\left(f_{a_{k}}+f_{F_{k}}\right)\right) / 4 d, \quad i=1,2
\end{aligned}
$$




$$
\begin{aligned}
\left(F_{i}, F_{i}\right) & f_{F_{i}}^{2} / 4 d, i=1,2 \\
\left(F_{1}, F_{2}\right) & 2 f_{F_{1}} f_{F_{2}} / 4 d \\
\left(F_{i},(x x x x)^{c}\right) & 2 f_{F_{i}}\left(1-\sum_{k=1}^{2}\left(f_{a_{k}}+f_{F_{k}}\right)\right) / 4 d, \quad i=1,2 \\
\left((x x x x)^{c},(x x x x)^{c}\right) & \left(1-\sum_{k=1}^{2}\left(f_{a_{k}}+f_{F_{k}}\right)\right)^{2} / 4 d,
\end{aligned}
$$

sendo $d=d\left[n, f_{a_{1}}, f_{a_{2}}\right]$ a função definida pela expressão

$$
d=1+\left(2^{n-1}-1\right)\left(f_{a_{1}}+f_{a_{2}}+2^{n-1} f_{a_{1}} f_{a_{2}}\right)
$$

Substituindo $h_{1}$ por $a_{1}$ na expressão $9 . S$, obtemos a probabilidade condicional $v\left[D_{\mathbf{u}_{2}} \mid \cdot\right]$ para este caso.

O valor de $\delta$, definido pela expressão 9.1 , é

$$
\delta=\frac{f_{a_{1}} H\left[m, f_{a_{1}}\right]}{2^{2 m} d\left[n, f_{a_{1}}, f_{a_{2}}\right]} u\left[n . m, f_{a_{1}}, f_{a_{2}}\right]
$$

onde $u=u\left[n, m, f_{a_{1}}, f_{a_{2}}\right]$ é dada por

$$
\begin{aligned}
u= & f_{a_{1}}\left\{\left(2^{m+n-1}-2^{m-1}-2^{n-1}\right) f_{a_{1}}-1\right\} \\
& +\left\{1+\left(2^{m-1}+2^{n}\right) f_{a_{1}}\right\} H\left[n, f_{a_{2}}\right]
\end{aligned}
$$

Das expressões $9.20,9.8$ (substituindo $h_{1}$ por $a_{1}$ ) e 9.22 , obtemos a distribuição de probabilidade a posteriori para o genótipo do demandado $P\left[\cdot \mid D_{\mathbf{u}_{1}}, D_{\mathbf{u}_{2}}\right]$, a qual é apresentada no seguinte resultado.

Proposição 9.3.5 A distribuiçâo de probabilidade a posteriori para o genótipo do demandado $P\left[\cdot \mid D_{\mathbf{u}_{1}}, D_{\mathbf{u}_{2}}\right]$, uma vez que foram observados, respectivamente, os genótipos $\left(a_{1}, a_{2}\right)$ e $\left(a_{1}, a_{1}\right)$ em $n$ de seus irmãos e em $m$ de seus filhos é a seguinte.

$$
\begin{array}{rc}
\text { genótipo }(\cdot) & P\left[\cdot \mid D_{\mathbf{u}_{1}}, D_{\mathbf{u}_{2}}\right] \\
\left(a_{1}, a_{1}\right) & \frac{2^{m} f_{a_{1}}\left\{\left(2^{n}-1\right) f_{a_{1}}+H\left[n, f_{a_{2}}\right]\right\}}{2 u\left[n, m, f_{a_{1}}, f_{a_{2}}\right]}
\end{array}
$$




$$
\begin{aligned}
\left(a_{1}, a_{2}\right) & \frac{1+\left(2^{n}-1\right)\left(f_{a_{1}}+f_{a_{2}}+2^{n} f_{a_{1}} f_{a_{2}}\right)}{2 u\left[n, m, f_{a_{1}}, f_{a_{2}}\right]} \\
\left(a_{1}, F_{i}\right) & \frac{f_{F_{i}}\left(1+2^{n} f_{a_{1}}\right)}{2 u\left[n, m, f_{a_{1}}, f_{a_{2}}\right]}, \quad i=1,2 \\
\left(a_{1},(x x x x)^{c}\right) & \frac{\left(1+2^{n} f_{a_{1}}\right)\left(1-\sum_{k=1}^{2}\left(f_{a_{k}}+f_{F_{k}}\right)\right)}{2 u\left[n, m, f_{a_{1}}, f_{a_{2}}\right]}
\end{aligned}
$$

onde $u\left[n, m, f_{a_{1}}, f_{a_{2}}\right]$ é dada pela expressâo 9.23.

A razão de verossimilhança $R V[D]$ e a probabilidade condicional $V_{0}[D]$, que é obtida da proposição 9.3.5, estão dadas no seguinte corolário.

Corolário 9.3.5 Sob as condições da proposição 9.3.5, temos que a razão de verossimilhanças $R V[D]$ e a probabilidade condicional $V_{0}[D]$, do demandante ter recebido do demandado o(s) alelo(s) de interesse após termos observado $D$, estão dadas a seguir

$$
\begin{array}{cll}
\multicolumn{1}{c}{I} & V_{0}[D] & R V[D] \\
a_{i} & \frac{v_{i}\left[n, m, f_{a_{1}}, f_{a_{2}}\right]}{4 u\left[n, m, f_{a_{1}}, f_{a_{2}}\right]} & \frac{4 f_{a_{i}} u\left[n, m, f_{a_{1}}, f_{a_{2}}\right]}{v_{i}\left[n, m, f_{a_{1}}, f_{a_{2}}\right]}, i=1,2 \\
F_{i} & \frac{f_{F_{i}}\left(1+2^{n} f_{a_{1}}\right)}{4 u\left[n, m, f_{a_{1}}, f_{a_{2}}\right]} & \frac{4 u\left[n, m, f_{a_{1}}, f_{a_{2}}\right]}{1+2^{n} f_{a_{1}}}, i=1,2 \\
a_{1} \text { e } a_{2} & \frac{\sum_{i=1}^{2} v_{i}\left[n, m, f_{a_{1}}, f_{a_{2}}\right]}{4 u\left[n, m, f_{a_{1}}, f_{a_{2}}\right]} & \frac{4\left(f_{a_{1}}+f_{a_{2}}\right) u\left[n, m, f_{a_{1}}, f_{a_{2}}\right]}{\sum_{i=1}^{2} v_{i}\left[n, m, f_{a_{1}}, f_{a_{2}}\right]} \\
a_{i} \text { e } F_{j} & \frac{w_{i j}\left[n, m, f_{a_{1}}, f_{a_{2}}, f_{F_{j}}\right]}{4 u\left[n, m, f_{a_{1}}, f_{a_{2}}\right]} & \frac{4\left(f_{a_{i}}+f_{F_{j}}\right) u\left[n, m, f_{a_{1}}, f_{a_{2}}\right]}{w_{i j}\left[n, m, f_{a_{1}}, f_{a_{2}}, f_{F_{j}}\right]}, i, j=1,2 \\
F_{1} \text { e } F_{2} & \frac{\left(1+2^{n} f_{a_{1}}\right) \sum_{i=1}^{2} f_{F_{i}}}{4 u\left[n, m, f_{a_{1}}, f_{a_{2}}\right]} & \frac{4 u\left[n, m, f_{a_{1}}, f_{a_{2}}\right]}{1+2^{n} f_{a_{1}}}
\end{array}
$$

onde para $i, j=1,2$ as funções $v_{i}=v_{i}\left[n, m, f_{a_{1}}, f_{a_{2}}\right]$ e $w_{i j}=w_{i j}\left[n, m, f_{a_{1}}, f_{a_{2}}\right]$ são dadas por

$$
\begin{aligned}
v_{1} & =2\left(f_{a_{1}}\left\{\left(2^{m+n}-2^{m}-2^{n-1}\right) f_{a_{1}}-1\right\}+\left\{1+\left(2^{m}+2^{n}\right) f_{a_{1}}\right\} H\left[n, f_{a_{2}}\right]\right) \\
v_{2} & =1+\left(2^{n}-1\right)\left(f_{a_{1}}+f_{a_{2}}+2^{n} f_{a_{1}} f_{a_{2}}\right) \\
w_{i j} & =v_{i}\left[n, m, f_{a_{1}}, f_{a_{2}}\right]+f_{F_{j}}\left(1+2^{n} f_{a_{1}}\right), \quad i, j=1,2 .
\end{aligned}
$$




\section{Caso 9.2.1.2}

Sejam $a_{1}, a_{2}, h_{1}, F_{1}$ e $F_{2}$ cinco alelos diferentes. Suponhamos que, ao considerarmos $n$ irmãos e $m$ filhos do demandado, independentemente, observamos em cada um dos irmãos o genótipo $\left(a_{1}, a_{2}\right)$ e em cada um dos filhos o genótipo $\left(h_{1}, h_{1}\right)$ - isto é, $D_{\mathbf{u}_{1}}=$ $\left\{\left(a_{1}, a_{2}\right)_{n}\right\}$ e $D_{\mathbf{u}_{2}}=\left\{\left(h_{1}, h_{1}\right)_{m}\right\}$.

A distribuição de probabilidade a posteriori $P\left[\cdot \mid D_{\mathbf{u}_{1}}\right]$ para o genótipo do demandado, uma vez foi observado o genótipo $\left(a_{1}, a_{2}\right)$ em $n$ de seus irmãos é dada por

$$
\begin{aligned}
\text { genótipo } & P\left[\cdot \mid D_{\mathbf{u}_{1}}\right] \\
\left(a_{i}, a_{i}\right) & f_{a_{i}}\left\{\left(2^{n}-1\right) f_{a_{1}}+H\left[n, f_{a_{\sigma(i)}}\right]\right\} / 4 d, i=1,2 \\
\left(a_{1}, a_{2}\right) & \left\{1+\left(2^{n}-1\right)\left(f_{a_{1}}+f_{a_{2}}+2^{n} f_{a_{1}} f_{a_{2}}\right)\right\} / 4 d \\
\left(a_{i}, F_{j}\right) & f_{F_{j}}\left(1+2^{n} f_{a_{1}}\right) / 4 d, i, j=1,2 \\
\left(a_{i}, h_{1}\right) & f_{h_{1}}\left(1+2^{n} f_{a_{1}}\right) / 4 d, i=1,2 \\
\left(a_{i},(x x x x)^{c}\right) & \left(1+2^{n} f_{a_{i}}\right)\left(1-f_{h_{1}}-\sum_{k=1}^{2}\left(f_{a_{k}}+f_{F_{k}}\right)\right) / 4 d, \quad i=1,2 \\
\left(F_{i}, F_{i}\right) & f_{F_{i}}^{2} / 4 d, i=1,2 \\
\left(F_{1}, F_{2}\right) & 2 f_{F_{1}} f_{F_{2}} / 4 d \\
\left(F_{i}, h_{1}\right) & 2 f_{F_{i}} f_{h_{1}} / 4 d, i=1,2 \\
\left(F_{i},(x x x x)^{c}\right) & 2 f_{F_{i}}\left(1-f_{h_{1}}-\sum_{k=1}^{2}\left(f_{a_{k}}+f_{F_{k}}\right)\right) / 4 d, \quad i=1,2 \\
\left(h_{1}, h_{1}\right) & f_{h_{1}}^{2} / 4 d \\
\left(h_{1},(x x x x x)^{c}\right) & 2 f_{h_{1}}\left(1-f_{h_{1}}-\sum_{k=1}^{2}\left(f_{a_{k}}+f_{F_{k}}\right)\right) / 4 d \\
& \left(1-f_{h_{1}}-\sum_{k=1}^{2}\left(f_{a_{k}}+f_{F_{k}}\right)\right)^{2} / 4 d,
\end{aligned}
$$

sendo $d=d\left[n, f_{a_{1}}, f_{a_{2}}\right]$ a função definida pela expressão 9.21 .

Neste caso particular, a probabilidade condicional $v\left[D_{\mathbf{u}_{2}} \mid \cdot\right]$ é dada por 9.8 e o valor de 
$\delta$, definido pela expressão 9.1 , torna-se

$$
\delta=\frac{f_{h_{1}}^{2} H\left[m, f_{h_{1}}\right]}{2^{2 m} d\left[n, f_{a_{1}}, f_{a_{2}}\right]} u\left[n, m, f_{a_{1}}, f_{a_{2}}, f_{h_{1}}\right]
$$

onde $u=u\left[n, m, f_{a_{1}}, f_{a_{2}}, f_{h_{1}}\right]$ é a função dada por

$$
u=H\left[m, f_{h_{1}}\right]-1+\sum_{i=1}^{2} H\left[n, f_{a_{i}}\right]
$$

Das expressões $9.25,9.8$ e 9.26, obtemos a distribuição de probabilidade a posteriori para o genótipo do demandado $P\left[\cdot \mid D_{\mathbf{u}_{1}}, D_{\mathbf{u}_{2}}\right]$ a qual é apresentada no seguinte resultado.

Proposição 9.3.6 A distribuição de probabilidade a posteriori para o genótipo do demandado $P\left[\cdot \mid D_{\mathbf{u}_{1}}, D_{\mathbf{u}_{2}}\right]$, uma vez que foram observados, respectivamente, os genótipos $\left(a_{1}, a_{2}\right)$ e $\left(h_{1}, h_{1}\right)$ em $n$ de seus irmãos e em $m$ de seus filhos é a seguinte.

$$
\begin{aligned}
\text { genótipo }(\cdot) & P\left[\cdot \mid D_{\mathbf{u}_{1}}, D_{\mathbf{u}_{2}}\right] \\
\left(h_{1}, h_{1}\right) & \frac{2^{m} f_{h_{1}}}{2 u\left[n, m, f_{a_{1}}, f_{a_{2}}, f_{h_{1}}\right]} \\
\left(h_{1}, a_{i}\right) & \frac{1+2^{n} f_{a_{i}}}{2 u\left[n, m, f_{a_{1}}, f_{a_{2}}, f_{h_{1}}\right]}, \quad i=1,2 \\
\left(h_{1}, F_{i}\right) & \frac{2 f_{F_{i}}}{2 u\left[n, m, f_{a_{1}}, f_{a_{2}}, f_{h_{1}}\right]}, \quad i=1,2 \\
\left(h_{1},(x x x x x)^{c}\right) & \frac{2\left(1-f_{h_{1}}-\sum_{k=1}^{2}\left(f_{a_{k}}+f_{F_{k}}\right)\right)}{2 u\left[n, m, f_{a_{1}}, f_{a_{2}}, f_{h_{1}}\right]}
\end{aligned}
$$

onde $u\left[n, m, f_{a_{1}}, f_{a_{2}}, f_{h_{1}}\right]$ é dada pela expressão 9.27.

A razão de verossimilhança $R V[D]$ e a probabilidade condicional $V_{0}[D]$, que é obtida da proposição 9.3.6, estão dadas no seguinte corolário.

Corolário 9.3.6 Sob as condiçoes da proposição 9.3.6, temos que a razão de verossimilhanças $R V[D]$ e a probabilidade condicional $V_{0}[D]$, do demandante ter recebido do 
demandado o(s) alelo(s) de interesse após termos observado $D$, estâo dadas a seguir

$$
\begin{aligned}
& V_{0}[D] \\
& R V[D] \\
& a_{i} \quad \frac{1+2^{n} f_{a_{i}}}{4 u\left[n, m, f_{a_{1}}, f_{a_{2}}, f_{h_{1}}\right]} \\
& \frac{4 f_{a_{i}} u\left[n, m, f_{a_{1}}, f_{a_{2}}, f_{h_{1}}\right]}{1+2^{n} f_{a_{i}}}, \quad i=1,2 \\
& h_{1} \quad \frac{z\left[n, m, f_{a_{1}}, f_{a_{2}}, f_{h_{1}}\right]}{2 u\left[n, m, f_{a_{1}}, f_{a_{2}}, f_{h_{1}}\right]} \\
& \frac{2 f_{h_{1}} u\left[n, m, f_{a_{1}}, f_{a_{2}}, f_{h_{1}}\right]}{z\left[n, m, f_{a_{1}}, f_{a_{2}}, f_{h_{1}}\right]} \\
& F_{i} \quad \frac{f_{F_{i}}}{2 u\left[n, m, f_{a_{1}}, f_{a_{2}}, f_{h_{1}}\right]} \\
& 2 u\left[n, m, f_{a_{1}}, f_{a_{2}}, f_{h_{1}}\right], \quad i=1,2 \\
& a_{i} e h_{1} \quad \frac{v_{i}\left[n, m, f_{a_{1}}, f_{a_{2}}, f_{h_{1}}\right]}{4 u\left[n, m, f_{a_{1}}, f_{a_{2}}, f_{h_{1}}\right]} \\
& \frac{4\left(f_{a_{i}}+f_{h_{1}}\right) u\left[n, m, f_{a_{1}}, f_{a_{2}}, f_{h_{1}}\right]}{v_{i}\left[n, m, f_{a_{1}}, f_{a_{2}}, f_{h_{1}}\right]}, \quad i=1,2 \\
& a_{1} \text { e } a_{2} \quad \frac{1+2^{n-1} \sum_{i=1}^{2} f_{a_{i}}}{2 u\left[n, m, f_{a_{1}}, f_{a_{2}}, f_{h_{1}}\right]} \\
& \frac{\left.2 \sum_{i=1}^{2} f_{a_{i}}\right) u\left[n, m, f_{a_{1}}, f_{a_{2}}, f_{h_{1}}\right]}{1+2^{n-1} \sum_{i=1}^{2} f_{a_{i}}} \\
& h_{1} e F_{j} \quad \frac{w_{j}\left[n, m, f_{a_{1}}, f_{a_{2}}, f_{h_{1}}, f_{F_{j}}\right]}{2 u\left[n, m, f_{a_{1}}, f_{a_{2}}, f_{h_{1}}\right]} \\
& \frac{2\left(f_{h_{1}}+f_{F_{j}}\right) u\left[n, m, f_{a_{1}}, f_{a_{2}}, f_{h_{1}}\right]}{w_{i j}\left[n, m, f_{a_{1}}, f_{a_{2}}, f_{h_{1}}, f_{F_{j}}\right]}, j=1,2 \\
& a_{i} e F_{j} \quad \frac{1+2^{n} f_{a_{i}}+2 f_{F_{j}}}{4 u\left[n, m, f_{a_{1}}, f_{a_{2}}, f_{h_{1}}\right]} \\
& \frac{4\left(f_{a_{i}}+f_{F_{j}}\right) u\left[n, m, f_{a_{1}}, f_{a_{2}}, f_{h_{1}}\right]}{1+2^{n} f_{a_{i}}+2 f_{F_{j}}}, i, j=1,2 \\
& F_{1} \text { e } F_{2} \quad \frac{\sum_{i=1}^{2} f_{F_{i}}}{2 u\left[n, m, f_{a_{1}}, f_{a_{2}}, f_{h_{1}}\right]} \\
& 2 u\left[n, m, f_{a_{1}}, f_{a_{2}}, f_{h_{1}}\right]
\end{aligned}
$$

onde as funções $v_{i}=v_{i}\left[n, m, f_{a_{1}}, f_{a_{2}}, f_{h_{1}}\right] \epsilon w_{i}=w_{i}\left[n, m, f_{a_{1}}, f_{a_{2}}, f_{h_{1}}, f_{F_{i}}\right]$ para $i=1,2 e$ $z=z\left[n, m, f_{a_{1}}, f_{a_{2}}, f_{h_{1}}\right]$ são dadas por

$$
\begin{aligned}
z & =H\left[m+1, f_{h_{1}}\right]-1+\sum_{k=1}^{2} H\left[n, f_{a_{k}}\right] \\
v_{i} & =1+2\left(H\left[n+1, f_{a_{i}}\right]+H\left[n, f_{a_{\sigma(i)}}\right]+\left(2^{m}-1\right) f_{h_{1}}\right), i=1,2 \\
w_{i} & =f_{F_{i}}-1+H\left[m+1, f_{h_{1}}\right]+\sum_{k=1}^{2} H\left[n, f_{a_{k}}\right], \quad i=1,2
\end{aligned}
$$

\section{Caso 9.2.2.1}

Sejam $a_{1}, a_{2}, F_{1}$ e $F_{2}$ quatro alelos diferentes. Suponhamos que, ao considerarmos $n$ 
irmãos e $m$ filhos do demandado, independentemente, observamos em cada um dos irmãos e dos filhos o genótipo $\left(a_{1}, a_{2}\right)$ - isto é, $D_{\mathbf{u}_{1}}=\left\{\left(a_{1}, a_{2}\right)_{n}\right\}$ e $D_{\mathbf{u}_{2}}=\left\{\left(a_{1}, a_{2}\right)_{m}\right\}$.

Nesta situação temos que a distribuição de probabilidade a posteriori $P\left[\cdot \mid D_{\mathbf{u}_{1}}\right]$ para o genótipo do demandado, uma vez foi observado o genótipo $\left(a_{1}, a_{2}\right)$ em $n$ de seus irmãos é dada por 9.20; além disso, a probabilidade condicional $v\left[D_{\mathbf{u}_{2}} \mid \cdot\right]$ é obtida ao substituirmos $h_{i}$ por $a_{i}$ na expressão 9.12 para $i=1,2$ e o valor de $\delta$, definido pela expressão 9.1 , é

$$
\delta=\frac{u\left[n, m, f_{a_{1}}, f_{a_{2}}\right]}{2^{2 m} d\left[n, f_{a_{1}}, f_{a_{2}}\right]}
$$

onde $u=u\left[n, m, f_{a_{1}}, f_{a_{2}}\right]$ é dada por

$$
\begin{aligned}
u= & \left(2^{m-1}-1\right) f_{a_{1}} f_{a_{2}}\left\{1+\left(2^{n}-1\right)\left(f_{a_{1}}+f_{a_{2}}+2^{n} f_{a_{1}} f_{a_{2}}\right)\right\} \\
& +\sum_{i=1}^{2} f_{a_{i}} H\left[m, f_{a_{i}}\right] u_{i}\left[n, m, f_{a_{1}}, f_{a_{2}}\right]
\end{aligned}
$$

e para $i=1,2$ a função $u_{i}=u_{i}\left[n, m, f_{a_{1}}, f_{a_{2}}\right]$ é

$$
\begin{aligned}
u_{i}= & H\left[n, f_{a_{i}}\right]+f_{a_{\sigma(i)}}\left\{\left(2^{m+n-1}-2^{n-1}-2^{m-1}\right) f_{a_{\sigma(i)}}-1\right\} \\
& +\left(2^{m-1}+2^{n}\right) f_{a_{\sigma(i)}} H\left[n, f_{a_{\sigma(i)}}, i=1,2\right.
\end{aligned}
$$

Das expressões 9.20, 9.12 e 9.29, obtemos a distribuição de probabilidade a posteriori para o genótipo do demandado $P\left[\cdot \mid D_{\mathbf{u}_{1}}, D_{\mathbf{u}_{2}}\right]$, apresentada no seguinte resultado.

Proposição 9.3.7 A distribuição de probabilidade a posteriori para o genótipo do demandado $P\left[\cdot \mid D_{\mathbf{u}_{1}}, D_{\mathbf{u}_{2}}\right]$, uma vez que foi observado o genótipo $\left(a_{1}, a_{2}\right)$ em $n$ de seus irmãos e em $m$ de seus filhos é a seguinte.

$$
\begin{aligned}
& \text { genótipo (.) } \\
& \qquad \begin{array}{cc}
\left(a_{i}, a_{i}\right) & 2^{m} f_{a_{i}} f_{a_{\sigma(i)}}\left\{\left(D_{\mathbf{u}_{1}}, D_{\mathbf{u}_{2}}\right]\right. \\
& \times H\left[m, f_{a_{\sigma(i)}}\right] / 2 u, \quad i=1,2 \\
\left(a_{1}, a_{2}\right) & \left\{1+\left(2^{n}-1\right)\left(f_{a_{i}}+H\left[n, f_{a_{\sigma(i)}}\right]\right\}\right.
\end{array}
\end{aligned}
$$




$$
\begin{gathered}
\times\left(\sum_{k=1}^{2} H\left[m, f_{a_{k}}\right]-1\right) / 2 u \\
\left(a_{i}, F_{j}\right) \quad f_{F_{j}}\left(1+2^{n} f_{a_{i}}\right) f_{a_{\sigma(i)}} H\left[m, f_{a_{\sigma(i)}}\right] / 2 u, \quad i, j=1,2 \\
\left(a_{i},(x x x x)^{c}\right) \quad\left(1+2^{n} f_{a_{i}}\right) f_{a_{\sigma(i)}} H\left[m, f_{a_{\sigma(i)}}\right]\left(1-\sum_{k=1}^{2}\left(f_{a_{k}}+f_{F_{k}}\right)\right) / 2 u, i=1,2
\end{gathered}
$$

onde a função $u=u\left[n, m, f_{a_{1}}, f_{a_{2}}\right]$ é dada pela expressão 9.30 .

A razão de verossimilhança $R V[D]$ e a probabilidade condicional $V_{0}[D]$, que é obtida da proposição 9.3.7, estão dadas no seguinte corolário.

Corolário 9.3.7 Sob as condiçôes da proposição 9.3.7, temos que a razão de verossimilhanças $R V[D]$ e a probabilidade condicional $V_{0}[D]$, do demandante ter recebido do demandado o(s) alelo(s) de interesse após termos observado D, estão dadas a seguir

$$
\begin{aligned}
& I \quad V_{0}[D] \\
& R V[D] \\
& a_{i} \quad \frac{v_{i}\left[n, m, f_{a_{1}}, f_{a_{2}}\right]}{4 u\left[n, m, f_{a_{1}}, f_{a_{2}}\right]} \\
& \frac{4 f_{a_{i}} u\left[n, m, f_{a_{1}}, f_{a_{2}}\right]}{v_{i}\left[n, m, f_{a_{1}}, f_{a_{2}}\right]}, \quad i=1,2 \\
& F_{i} \quad \frac{F_{i} w_{1}\left[n, m, f_{a_{1}}, f_{a_{2}}\right]}{4 u\left[n, m, f_{a_{1}}, f_{a_{2}}\right]} \\
& \frac{4 u\left[n, m, f_{a_{1}}, f_{a_{2}}\right]}{w_{1}\left[n, m, f_{a_{1}}, f_{a_{2}}\right]}, \quad i=1,2 \\
& \begin{array}{llll}
a_{1} & e & a_{2} & \frac{w_{2}\left[n, m, f_{a_{1}}, f_{a_{2}}\right]}{4 u\left[n, m, f_{a_{1}}, f_{a_{2}}\right]}
\end{array} \\
& \frac{4 \sum_{i=1}^{2} f_{a_{i}} u\left[n, m, f_{a_{1}}, f_{a_{2}}\right]}{w_{2}\left[n, m, f_{a_{1}}, f_{a_{2}}\right]} \\
& a_{i} \text { e } F_{j} \quad \frac{w_{i j}\left[n, m, f_{a_{1}}, f_{a_{2}}, f_{F_{j}}\right]}{4 u\left[n, m, f_{a_{1}}, f_{a_{2}}\right]} \\
& \frac{4\left(f_{a_{i}}+f_{F_{j}}\right) u\left[n, m, f_{a_{1}}, f_{a_{2}}\right]}{w_{i j}\left[n, m, f_{a_{1}}, f_{a_{2}}, f_{F_{j}}\right]}, \quad i, j=1,2 \\
& F_{1} e F_{2} \quad \frac{\sum_{i=1}^{2} f_{F_{i}} w_{1}\left[n, m, f_{a_{1}}, f_{a_{2}}\right]}{2 u\left[n, m, f_{a_{1}}, f_{a_{2}}\right]} \quad \frac{2 u\left[n, m, f_{a_{1}}, f_{a_{2}}\right]}{w_{1}\left[n, m, f_{a_{1}}, f_{a_{2}}\right]}
\end{aligned}
$$

onde para $i, j=1,2$ as funções $v_{i}=v_{i}\left[n, m, f_{a_{1}}, f_{a_{2}}\right], w_{i}=w_{i}\left[n, m, f_{a_{1}}, f_{a_{2}}\right]$ e $w_{i j}=$ $w_{i j}\left[n, m, f_{a_{1}}, f_{a_{2}}, f_{F_{j}}\right]$ são dadas por

$$
\begin{aligned}
v_{i}= & \left(2^{m-1}-1\right) f_{a_{i}}\left(f_{a_{i}}+f_{a_{\sigma(i)}}\right)\left\{1+\left(2^{n}-1\right)\left(f_{a_{1}}+f_{a_{2}}+2^{n} f_{a_{1}} f_{a_{2}}\right)\right\} \\
& +H\left[m, f_{a_{\sigma(i)}}\right] v_{i 1}\left[n, m, f_{a_{1}}, f_{a_{2}}\right], \quad i=1,2
\end{aligned}
$$




$$
\begin{aligned}
w_{1}= & \sum_{i=1}^{2}\left(1+2^{n} f_{a_{i}}\right) f_{a_{\sigma(i)}} H\left[m, f_{a_{\sigma(i)}}\right] \\
w_{2}= & \sum_{k=1}^{2} f_{a_{k}} H\left[m, f_{a_{k}}\right] W_{k}\left[n, m, f_{a_{1}}, f_{a_{2}}\right]+W_{3}\left[n, m, f_{a_{1}}, f_{a_{2}}\right] \\
w_{i j}= & \left\{1+\left(2^{n}-1\right)\left(f_{a_{1}}+f_{a_{2}}+2^{n} f_{a_{1}} f_{a_{2}}\right)\right\}\left(\sum_{r=1}^{2} H\left[m, f_{a_{r}}\right]-1\right) \sum_{r=1}^{2} f_{a_{r}} \\
& +2^{m+1} f_{a_{i}} f_{a_{\sigma(i)}} H\left[m, f_{a_{\sigma(i)}}\right]\left\{\left(2^{n}-1\right) f_{a_{i}}+H\left[n, f_{a_{\sigma(i)}}\right)\right\} \\
& +f_{a_{\sigma(i)}} H\left[m, f_{a_{\sigma(i)}}\right]\left(1-f_{a_{1}}-f_{a_{2}}+f_{F_{j}}\right)\left(1+2^{n} f_{a_{i}}\right) \\
& +\left(1+2^{n} f_{a_{\sigma(i)}}\right), f_{a_{i}} f_{F_{j}} H\left[m, f_{a_{i}}\right]
\end{aligned}
$$

sendo as funçôes $v_{i 1}=v_{i 1}\left[n, m, f_{a_{1}}, f_{a_{2}}\right]$ e $W_{k}=W_{k}\left[n, m, f_{a_{1}}, f_{a_{2}}\right]$ dadas por

$$
\begin{aligned}
v_{i 1}= & f_{a_{1}} f_{a_{2}}\left\{2^{m+1}+3\left(2^{n}-1\right)+\left(2^{n-1}-1\right)\left(2^{m+1}+2^{n+1}\right) \sum_{k=1}^{2} f_{a_{k}}\right\} \\
& +f_{a_{i}}\left\{1+f_{a_{i}}\left(2^{n}-1+2^{m+n} f_{a_{\sigma(i)}}\right)\right\}+2 f_{a_{\sigma(i)}} H\left[n, f_{a_{\sigma(i)}}\right], i=1,2 \\
W_{k}= & 2^{m+1} f_{a_{\sigma(k)}}\left\{\left(2^{n}-1\right) f_{a_{\sigma(k)}}+H\left[n, f_{a_{k}}\right]\right\} \\
& +\left(1-f_{a_{1}}-f_{a_{2}}\right)\left(1+2^{n} f_{a_{\sigma(k)}}\right), k=1,2 \\
W_{3}= & 2\left\{1+\left(2^{n}-1\right)\left(f_{a_{1}}+f_{a_{2}}+2^{n} f_{a_{1}} f_{a_{2}}\right)\right\}\left(\sum_{r=1}^{2} H\left[m, f_{a_{r}}\right]-1\right) \sum_{r=1}^{2} f_{a_{r}}
\end{aligned}
$$

\section{Caso 9.2.2.2}

Sejam $a_{1}, a_{2}, h_{1}, F_{1}$ e $F_{2}$ cinco alelos diferentes. Suponhamos que, ao considerarmos $n$ irmãos e $m$ filhos do demandado, independentemente, observamos em cada um dos irmãos o genótipo $\left(a_{1}, a_{2}\right)$ e em cada um dos filhos o genótipo $\left(a_{1}, h_{1}\right)$ - isto é, $D_{\mathbf{u}_{1}}=$ $\left\{\left(a_{1}, a_{2}\right)_{n}\right\}$ e $D_{\mathbf{u}_{2}}=\left\{\left(a_{1}, h_{1}\right)_{m}\right\}$.

Como no caso 9.2.1.2, temos que a distribuição de probabilidade a posteriori $P\left[\cdot \mid D_{\mathbf{u}_{\mathbf{1}}}\right]$ para o genótipo do demandado, uma vez foi observado o genótipo $\left(a_{1}, a_{2}\right)$ em $n$ de seus irmãos é dada por 9.25 .

Para este caso particular, a probabilidade condicional $v\left[D_{\mathbf{u}_{2}} \mid \cdot\right]$, é obtida ao substituir $a_{1}$ 
por $h_{2}$ na expressão 9.12. Portanto, o valor de $\delta$, definido pela expressão 9.1 , torna-se

$$
\delta=\frac{f_{h_{1}} u\left[n \cdot m, f_{a_{1}}, f_{a_{2}}, f_{h_{1}}\right]}{2^{2 m+1} d\left[n, f_{a_{1}}, f_{a_{2}}\right]}
$$

sendo $d\left[n, f_{a_{1}}, f_{a_{2}}\right]$ a função definida pela expressão 9.21 e $u=u\left[n, m, f_{a_{1}}, f_{a_{2}}, f_{h_{1}}\right]$ é a função dada por

$$
u=H\left[m, f_{h_{1}}\right] u_{1}+f_{a_{1}} H\left[m, f_{a_{1}}\right] u_{2}+u_{3},
$$

onde

$$
\begin{aligned}
& u_{1}=\left(2+\left(2^{m}+2^{n+1}\right) f_{a_{1}}\right) H\left[n, f_{a_{2}}\right]+\left(2^{m}\left(2^{n}-1\right) f_{a_{1}}-1\right) f_{a_{1}} \\
& u_{2}=1+2\left(2^{m-1}-1\right) f_{h_{1}}-2 f_{a_{1}}+2 H\left[n, f_{a_{2}}\right] \\
& u_{3}=\left(2^{m-1}-1\right)\left(1+2^{n} f_{a_{1}}\right)\left(f_{a_{1}}+f_{h_{1}}\right) f_{a_{1}}
\end{aligned}
$$

A distribuição de probabilidade a posteriori para o genótipo do demandado $P\left[\cdot \mid D_{\mathbf{u}_{1}}, D_{\mathbf{u}_{2}}\right]$, dada a seguir, é obtida das expressões $9.25,9.12$ e 9.32 .

Proposição 9.3.8 A distribuiçâo de probabilidade a posteriori para o genótipo do demandado $P\left[\cdot \mid D_{\mathbf{u}_{1}}, D_{\mathbf{u}_{2}}\right]$, uma vez que foram observados, respectivamente, os genótipos $\left(a_{1}, a_{2}\right)$ e $\left(a_{1}, h_{1}\right)$ em $n$ de seus irmãos e em $m$ de seus filhos é a seguinte.

$$
\begin{aligned}
& \text { genótipo }(\cdot) \quad P\left[\cdot \mid D_{\mathbf{u}_{1}}, D_{\mathbf{u}_{2}}\right] \\
& \left(a_{1}, a_{1}\right) \quad 2^{m} f_{a_{1}}\left\{\left(2^{n}-1\right) f_{a_{1}}+H\left[n, f_{a_{2}}\right]\right\} H\left[m, f_{h_{1}}\right] / u \\
& \left(a_{1}, a_{2}\right) \quad\left\{1+\left(2^{n}-1\right)\left(f_{a_{1}}+f_{a_{2}}+2^{n} f_{a_{1}} f_{a_{2}}\right)\right\} H\left[m, f_{h_{1}}\right] / u \\
& \left(a_{1}, h_{1}\right) \quad\left(1+2^{n} f_{a_{1}}\right)\left(f_{a_{1}}+f_{h_{1}}\right)\left(H\left[m, f_{a_{1}}\right]+\left(2^{m-1}-1\right) f_{h_{1}}\right) / u \\
& \left(a_{1}, F_{j}\right) \quad\left(1+2^{n} f_{a_{1}}\right) H\left[m, f_{h_{1}}\right] f_{F_{j}} / u, j=1,2 \\
& \left(a_{1},(x x x x x)^{c}\right) \quad\left(1+2^{n} f_{a_{1}}\right) H\left[m, f_{h_{1}}\right]\left(1-f_{h_{1}}-\sum_{k=1}^{2}\left(f_{a_{k}}+f_{F_{k}}\right)\right) / u \\
& \left(a_{2}, h_{1}\right) \quad\left(1+2^{n} f_{a_{2}}\right) f_{a_{1}} H\left[m, f_{a_{1}}\right] / u \\
& \left(h_{1}, h_{1}\right) \quad 2^{m} f_{h_{1}} f_{a_{1}} H\left[m, f_{a_{1}}\right] / u \\
& \left(h_{1}, F_{j}\right) \quad 2 f_{F_{j}} f_{a_{1}} H\left[m, f_{a_{1}}\right] / u, j=1,2 \\
& \left(h_{1},(x x x x x)^{c}\right) \quad 2 H\left[m, f_{a_{1}}\right] f_{a_{1}}\left(1-f_{h_{1}}-\sum_{k=1}^{2}\left(f_{a_{k}}+f_{F_{k}}\right)\right) / u
\end{aligned}
$$

onde $u=u\left[n, m, f_{a_{1}}, f_{a_{2}}, f_{h_{1}}\right]$ é dada pela expressão 9.33 . 
A razào de verossimilhança $R V[D]$ e a probabilidade condicional $V_{0}[D]$, que é obtida da. proposição 9.3.8, estão dadas no seguinte corolário.

Corolário 9.3.8 Sob as condições da proposição 9.3.8, temos que a razão de verossimilhanças $R V[D] \in$ a probabilidade condicional $V_{0}[D]$, do demandante ter recebido do demandado o(s) alelo(s) de interesse após termos observado D, estão dadas a seguir

$$
\begin{aligned}
& V_{0}[D] \\
& R V[D] \\
& a_{i} \quad \frac{v_{i}\left[n, m, f_{a_{1}}, f_{a_{2}}, f_{h_{1}}\right]}{2 u\left[n, m, f_{a_{1}}, f_{a_{2}}, f_{h_{1}}\right]} \quad \frac{2 f_{a_{i}} u\left[n . m, f_{a_{1}}, f_{a_{2}}, f_{h_{1}}\right]}{v_{i}\left[n, m, f_{a_{1}}, f_{a_{2}}, f_{h_{1}}\right]}, i=1,2 \\
& h_{1} \quad \frac{v_{3}\left[n, m, f_{a_{1}}, f_{a_{2}}, f_{h_{1}}\right]}{2 u\left[n, m, f_{a_{1}}, f_{a_{2}}, f_{h_{1}}\right]} \quad \frac{2 f_{h_{1}} u\left[n, m, f_{a_{1}}, f_{a_{2}}, f_{h_{1}}\right]}{v_{3}\left[n, m, f_{a_{1}}, f_{a_{2}}, f_{h_{1}}\right]} \\
& F_{i} \quad \frac{f_{F_{i}} v_{4}\left[n, m, f_{a_{1}}, f_{a_{2}}, f_{h_{1}}\right]}{2 u\left[n, m, f_{a_{1}}, f_{a_{2}}, f_{h_{1}}\right]} \quad \frac{2 u\left[n, m, f_{a_{1}}, f_{a_{2}}, f_{h_{1}}\right]}{v_{4}\left[n, m, f_{a_{1}}, f_{a_{2}}, f_{h_{1}}\right]}, i=1,2 \\
& a_{1} \text { e } a_{2} \quad \frac{v_{5}\left[n, m, f_{a_{1}}, f_{a_{2}}, f_{h_{1}}\right]}{2 u\left[n, m, f_{a_{1}}, f_{a_{2}}, f_{h_{1}}\right]} \quad \frac{\left.2 \sum_{i=1}^{2} f_{a_{i}}\right) u\left[n, m, f_{a_{1}}, f_{a_{2}}, f_{h_{1}}\right]}{v_{5}\left[n, m, f_{a_{1}}, f_{a_{2}}, f_{h_{1}}\right]} \\
& a_{i} \text { e } h_{1} \quad \frac{v_{5+i}\left[n, m, f_{a_{1}}, f_{a_{2}}, f_{h_{1}}\right]}{2 u\left[n, m, f_{a_{1}}, f_{a_{2}}, f_{h_{1}}\right]} \quad \frac{2\left(f_{a_{i}}+f_{h_{1}}\right) u\left[n, m, f_{a_{1}}, f_{a_{2}}, f_{h_{1}}\right]}{v_{5+i}\left[n, m, f_{a_{1}}, f_{a_{2}}, f_{h_{1}}\right]}, i=1,2 \\
& h_{1} e F_{j} \quad \frac{w_{j}\left[n, m, f_{a_{1}}, f_{a_{2}}, f_{h_{1}}, f_{F_{j}}\right]}{2 u\left[n, m, f_{a_{1}}, f_{a_{2}}, f_{h_{1}}\right]} \quad \frac{2\left(f_{h_{1}}+f_{F_{j}}\right) u\left[n, m, f_{a_{1}}, f_{a_{2}}, f_{h_{1}}\right]}{w_{j}\left[n, m, f_{a_{1}}, f_{a_{2}}, f_{h_{1}}, f_{F_{j}}\right]}, j=1,2 \\
& a_{i} \text { e } F_{j} \quad \frac{w_{i j}\left[n, m, f_{a_{1}}, f_{a_{2}}, f_{h_{1}}, f_{F_{j}}\right]}{2 u\left[n, m, f_{a_{1}}, f_{a_{2}}, f_{h_{1}}\right]} \quad \frac{2\left(f_{a_{i}}+f_{F_{j}}\right) u\left[n, m, f_{a_{1}}, f_{a_{2}}, f_{h_{1}}\right]}{w_{i j}\left[n, m, f_{a_{1}}, f_{a_{2}}, f_{h_{1}}, f_{F_{j}}\right]}, i, j=1,2 \\
& F_{1} e F_{2} \quad \frac{v_{4}\left[n, m, f_{a_{1}}, f_{a_{2}}, f_{h_{1}}\right] \sum_{i=1}^{2} f_{F_{i}}}{2 u\left[n, m, f_{a_{1}}, f_{a_{2}}, f_{h_{1}}\right]} \quad \frac{2 u\left[n, m, f_{a_{1}}, f_{a_{2}}, f_{h_{1}}\right]}{v_{4}\left[n, m, f_{a_{1}}, f_{a_{2}}, f_{h_{1}}\right]}
\end{aligned}
$$

onde para $i=1, \cdots, 7$ as funções $v_{i}=v_{i}\left[n . m, f_{a_{1}}, f_{a_{2}}, f_{h_{1}}\right]$ são dadas por

$$
\begin{aligned}
v_{1}= & \left(2+\left(2^{m+1}+2^{n+1}\right) f_{a_{1}}\right) H\left[n, f_{a_{2}}\right] H\left[m, f_{h_{1}}\right] \\
& +\left(2^{m-1}-1\right)\left(1+2^{n} f_{a_{1}}\right)\left(f_{a_{1}}+f_{h_{1}}\right) f_{a_{1}} \\
& +\left(2^{m+1}\left(2^{n}-1\right) f_{a_{1}}-1\right) f_{a_{1}} H\left[m, f_{h_{1}}\right]
\end{aligned}
$$




$$
\begin{aligned}
& v_{2}=H\left[m, f_{h_{1}}\right]\left\{1+\left(2^{n}-1\right)\left(f_{a_{1}}+f_{a_{2}}+2^{n} f_{a_{1}} f_{a_{2}}\right)\right\} \\
& +\left(1+2^{n} f_{a_{2}}\right) f_{a_{1}} H\left[m, f_{a_{1}}\right] \\
& v_{3}=2 f_{a_{1}} H\left[m, f_{a_{1}}\right]\left(\sum_{k=1}^{2} H\left[n, f_{a_{k}}\right]+H\left[m+1, f_{h_{1}}\right]-1\right) \\
& +f_{h_{1}}\left(1+2^{n} f_{a_{1}}\right)\left\{1+\left(2^{m-1}-1\right)\left(2 f_{a_{1}}+f_{h_{1}}\right)\right\} \\
& v_{4}=\left(1+2^{n} f_{a_{1}}\right) H\left[m, f_{h_{1}}\right]+2 f_{a_{1}} H\left[m, f_{a_{1}}\right] \\
& v_{5}=\left(1+2^{n} f_{a_{1}}\right)\left\{H\left[m, f_{h_{1}}\right]\left(1-f_{a_{2}}\right)+\left(f_{a_{1}}+f_{h_{1}}\right)\left(H\left[m, f_{a_{1}}\right]-1\right)\right\} \\
& +2 H\left[m, f_{h_{1}}\right]\left\{1+\left(2^{n}-1\right)\left(f_{a_{2}}\left(1+2^{n} f_{a_{1}}\right)+f_{a_{1}}\left(1+2^{m} f_{a_{1}}\right)\right)\right. \\
& \left.+2^{m} f_{a_{1}} H\left[n, f_{a_{2}}\right]\right\}+\left(1+2^{n} f_{a_{2}}\right) f_{a_{1}} H\left[m, f_{a_{1}}\right] \\
& v_{6}=2 f_{a_{1}} H\left[m, f_{a_{1}}\right]\left(\sum_{k=1}^{2} H\left[n, f_{a_{k}}\right]+H\left[m+1, f_{h_{1}}\right]-1\right) \\
& +H\left[m, f_{h_{1}}\right]\left\{1+\left(2^{n}-1\right)\left(f_{a_{1}}+f_{a_{2}}+2^{n} f_{a_{1}} f_{a_{2}}\right)\right. \\
& \left.+2^{m+1} f_{a_{1}}\left(\left(2^{n}-1\right) f_{a_{1}}+H\left[n, f_{a_{2}}\right]\right)\right\}+2 H\left[n, f_{a_{2}}\right]-f_{h_{1}} \\
& +2 f_{a_{1}}\left(\left(2^{n}+2^{m}\right) H\left[n, f_{a_{2}}\right]-2^{n-1} f_{h_{1}}-1\right) \\
& +\left(2^{m+n+1}-2^{m+1}-2^{n}\right) f_{a_{1}}^{2} \\
& v_{7}=2 f_{a_{1}} H\left[m, f_{a_{1}}\right]\left\{2+\left(2^{n}-1\right) f_{a_{2}}+\left(2^{m}-1\right) f_{h_{1}}-f_{a_{1}}\right\} \\
& +\left(1+2^{n} f_{a_{1}}\right)\left(f_{a_{1}}+f_{h_{1}}\right)\left(H\left[m, f_{a_{1}}\right]+\left(2^{m-1}-1\right) f_{h_{1}}\right) \\
& +H\left[m, f_{h_{1}}\right]\left\{1+\left(2^{n}-1\right)\left(f_{a_{1}}+f_{a_{2}}+2^{n} f_{a_{1}} f_{a_{2}}\right)\right\}
\end{aligned}
$$

e para $i, j=1,2$ as funções $w_{j}=w_{j}\left[n, m, f_{a_{1}}, f_{a_{2}}, f_{h_{1}}, f_{F_{j}}\right]$ e $w_{i j}=w_{i j}\left[n, m, f_{a_{1}}, f_{a_{2}}, f_{h_{1}}, f_{F_{j}}\right]$ sâo

$$
\begin{aligned}
w_{j}= & \left(1+2^{n} f_{a_{1}}\right)\left\{\left(f_{a_{1}}+f_{h_{1}}\right)\left(H\left[m, f_{a_{1}}\right]+\left(2^{m-1}-1\right) f_{h_{1}}\right)+f_{F_{j}} H\left[m, f_{h_{1}}\right]\right\} \\
& +f_{a_{1}} H\left[m, f_{a_{1}}\right]\left\{1+2 H\left[n, f_{a_{2}}\right]+2\left(2^{m}-1\right) f_{h_{1}}+2 f_{F_{j}}-2 f_{a_{1}}\right\} \\
w_{1 j}= & \left(1+2^{n} f_{a_{1}}\right)\left(f_{a_{1}}+f_{h_{1}}\right)\left(H\left[m, f_{a_{1}}\right]+\left(2^{m-1}-1\right) f_{h_{1}}\right)+2 f_{F_{J}} f_{a_{1}} H\left[m, f_{a_{1}}\right] \\
& +H\left[m, f_{h_{1}}\right]\left\{1+\left(2^{n}-1\right)\left(f_{a_{1}}+f_{a_{2}}+2^{n} f_{a_{1}} f_{a_{2}}\right)\right.
\end{aligned}
$$




$$
\begin{aligned}
& +\left(1-f_{a_{1}}-f_{a_{2}}-f_{h_{1}}+f_{F_{j}}\right)\left(1+2^{n} f_{a_{1}}\right) \\
& \left.+2^{m+1} f_{a_{1}}\left(\left(2^{n}-1\right) f_{a_{1}}+H\left[n, f_{a_{2}}\right]\right)\right\} \\
w_{2 j}= & \left.H\left[m, f_{h_{1}}\right]\left\{1+\left(2^{n}-1\right)\left(f_{a_{1}}+f_{a_{2}}+2^{n} f_{a_{1}} f_{a_{2}}\right)+\left(1+2^{n} f_{a_{1}}\right) f_{F_{j}}\right)\right\} \\
& +f_{a_{1}} H\left[m, f_{a_{1}}\right]\left(1+2^{n} f_{a_{2}}+2 f_{F_{j}}\right) .
\end{aligned}
$$

\section{Caso 9.2.2.3}

Sejam $a_{1}, a_{2}, h_{1}, h_{2}, F_{1}$ e $F_{2}$ seis alelos diferentes. Suponhamos que, ao considerarmos $n$ irmãos e $m$ filhos do demandado, independentemente, observamos em cada um dos irmãos o genótipo $\left(a_{1}, a_{2}\right)$ e em cada um dos filhos o genótipo $\left(h_{1}, h_{2}\right)$ - isto é, $D_{\mathbf{u}_{1}}=$ $\left\{\left(a_{1}, a_{2}\right)_{n}\right\}$ e $D_{\mathbf{u}_{2}}=\left\{\left(h_{1}, h_{2}\right)_{m}\right\}$.

A distribuição de probabilidade a posteriori $P\left[\cdot \mid D_{\mathbf{u}_{1}}\right]$ para o genótipo do demandado, uma vez foi observado o genótipo $\left(a_{1}, a_{2}\right)$ em $n$ de seus irmãos é dada por

$$
\begin{aligned}
\text { genótipo } & \multicolumn{1}{c}{P\left[\cdot \mid D_{\mathbf{u}_{1}}\right]} \\
\left(a_{i}, a_{i}\right) & f_{a_{i}}\left\{\left(2^{n}-1\right) f_{a_{i}}+H\left[n, f_{a_{\sigma(i}}\right]\right\} / 4 d, i=1,2 \\
\left(a_{1}, a_{2}\right) & \left\{1+\left(2^{n}-1\right)\left(f_{a_{1}}+f_{a_{2}}+2^{n} f_{a_{1}} f_{a_{2}}\right)\right\} / 4 d \\
\left(a_{i}, F_{j}\right) & f_{F_{j}}\left(1+2^{n} f_{a_{i}}\right) / 4 d, i, j=1,2 \\
\left(a_{i}, h_{j}\right) & f_{h_{\jmath}}\left(1+2^{n} f_{a_{i}}\right) / 4 d, i, j=1,2 \\
\left(a_{i},(x x x x x)^{c}\right) & \left(1+2^{n} f_{a_{i}}\right)\left(1-\sum_{k=1}^{2}\left(f_{a_{k}}+f_{h_{k}}+f_{F_{k}}\right)\right) / 4 d, \quad i=1,2 \\
\left(F_{i}, F_{i}\right) & f_{F_{i}}^{2} / 4 d, i=1,2 \\
\left(F_{1}, F_{2}\right) & 2 f_{F_{1}} f_{F_{2}} / 4 d \\
\left(F_{i}, h_{j}\right) & 2 f_{F_{1}} f_{h_{j}} / 4 d, i, j=1,2 \\
\left(F_{i},(x x x x x)^{c}\right) & 2 f_{F_{i}}\left(1-\sum_{k=1}^{2}\left(f_{a_{k}}+f_{h_{k}}+f_{F_{k}}\right)\right) / 4 d, \quad i=1,2 \\
\left(h_{i}, h_{i}\right) & f_{h_{i}}^{2} / 4 d \\
\left(h_{1}, h_{2}\right) & 2 f_{h_{1}} f_{h_{2}} / 4 d
\end{aligned}
$$




$$
\begin{aligned}
\left(h_{i},(x x x x x x)^{c}\right) & 2 f_{h_{1}}\left(1-\sum_{k=1}^{2}\left(f_{a_{k}}+f_{h_{k}}+f_{F_{k}}\right)\right) / 4 d \\
\left((x x x x x)^{c},(x x x x x)^{c}\right) & \left(1-\sum_{k=1}^{2}\left(f_{a_{k}}+f_{h_{k}}+f_{F_{k}}\right)\right)^{2} / 4 d,
\end{aligned}
$$

sendo $d=d\left[n, f_{a_{1}}, f_{a_{2}}\right]$ a função definida pela expressão 9.21 .

Neste caso, a probabilidade condicional $v\left[D_{\mathbf{u}_{2}} \mid \cdot\right]$ é dada por 9.12 e o valor de $\delta$, definido pela expressão 9.1 , torna-se

$$
\delta=\frac{f_{h_{1}} f_{h_{2}} u\left[n, m, f_{a_{1}}, f_{a_{2}}, f_{h_{1}}, f_{h_{2}}\right]}{2^{2 m} d\left[n, f_{a_{1}}, f_{a_{2}}\right]}
$$

sendo $d\left[n, f_{a_{1}}, f_{a_{2}}\right]$ a função definida pela expressão 9.21 e $u=u\left[n, m, f_{a_{1}}, f_{a_{2}}, f_{h_{1}}, f_{h_{2}}\right]$ é a função dada por

$$
u=\left(2^{m-1}-1\right)\left(f_{h_{1}}+f_{h_{2}}\right) f_{h_{1}}+\sum_{k=1}^{2} u_{k} H\left[m, f_{h_{k}}\right]
$$

onde

$$
\begin{aligned}
& u_{1}=H\left[m, f_{h_{2}}\right]-f_{h_{1}}-1+\sum_{k=1}^{2} H\left[n, f_{a_{k}}\right] \\
& u_{2}=2^{m-1} f_{h_{1}}+\sum_{k=1}^{2} H\left[n, f_{a_{k}}\right]
\end{aligned}
$$

Das expressões $9.35,9.12$ e 9.36 , obtemos a distribuição de probabilidade a posteriori para o genótipo do demandado $P\left[\cdot \mid D_{\mathbf{u}_{1}}, D_{\mathbf{u}_{2}}\right]$, a qual é apresentada no seguinte resultado.

Proposição 9.3.9 A distribuição de probabilidade a posteriori para o genótipo do demandado $P\left[\cdot \mid D_{\mathbf{u}_{1}}, D_{\mathbf{u}_{2}}\right]$, uma vez que foram observados, respectivamente, os genótipos $\left(a_{1}, a_{2}\right)$ e $\left(h_{1}, h_{2}\right)$ em $n$ de seus irmãos e em $m$ de seus filhos é a seguinte.

$$
\begin{array}{cc}
\text { genótipo }(\cdot) & P\left[\cdot \mid D_{\mathbf{u}_{1}}, D_{\mathbf{u}_{2}}\right] \\
\left(h_{i}, h_{i}\right) & 2^{m} f_{h_{i}} H\left[m, f_{h_{\sigma(\ell)}}\right] /(2 u), i=1,2 \\
\left(h_{1}, h_{2}\right) & 2\left(\sum_{k=1}^{2} H\left[m, f_{h_{k}}\right]-1\right) \sum_{k=1}^{2} f_{h_{k}} /(2 u)
\end{array}
$$




$$
\begin{aligned}
\left(h_{i}, a_{j}\right) & \left(1+2^{n} f_{a_{\jmath}}\right) H\left[m, f_{h_{\sigma(i)}}\right] /(2 u), i, j=1,2 \\
\left(h_{i}, F_{j}\right) & 2 f_{F_{j}} H\left[m, f_{h_{\sigma(i)}}\right] /(2 u), i, j=1,2 \\
\left(h_{i},(x x x x x x)^{c}\right) & 2 H\left[m, f_{h_{\sigma(i)}}\right]\left(1-\sum_{k=1}^{2}\left(f_{a_{k}}+f_{h_{k}}+f_{F_{k}}\right)\right) /(2 u), i=1,2
\end{aligned}
$$

onde $u=u\left[n, m, f_{a_{1}}, f_{a_{2}}, f_{h_{1}}, f_{h_{2}}\right]$ é dada pela expressão 9.37.

A razão de verossimilhança $R V[D]$ e a probabilidade condicional $V_{0}[D]$, que é obtida da proposição 9.3 .9 , estão dadas no seguinte corolário.

Corolário 9.3.9 Sob as condições da proposição 9.3.9, temos que a razão de verossimilhanças $R V[D]$ e a probabilidade condicional $V_{0}[D]$, do demandante ter recebido do demandado o(s) alelo(s) de interesse após termos observado $D$, estão dadas a seguir

$$
\begin{aligned}
& \text { I } \\
& V_{0}[D] \\
& R V[D] \\
& a_{i} \quad \frac{\left(1+2^{n} f_{a_{i}}\right) \sum_{k=1}^{2} H\left[m, f_{h_{k}}\right]}{2 u} \\
& \frac{2 f_{a_{i}} u}{\left(1+2^{n} f_{a_{i}}\right) \sum_{k=1}^{2} H\left[m, f_{h_{k}}\right]}, \quad i=1,2 \\
& h_{i} \quad \frac{w_{i}}{2 u} \\
& \frac{2 f_{h_{i}} u}{w_{i}}, \quad i=1,2 \\
& F_{i} \quad \frac{f_{F_{i}} \sum_{k=1}^{2} H\left[m, f_{h_{k}}\right]}{2 u} \\
& \frac{2 u}{\sum_{k=1}^{2} H\left[m, f_{h_{k}}\right]}, \quad i=1,2 \\
& a_{1} \text { e } a_{2} \quad \frac{\left(1+2^{n-1} \sum_{k=1}^{2} f_{a_{k}}\right) \sum_{k=1}^{2} H\left[m, f_{h_{k}}\right]}{2 u} \\
& \frac{2 u \sum_{i=1}^{2} f_{a_{i}}}{\left(1+2^{n-1} \sum_{k=1}^{2} f_{a_{k}}\right) \sum_{k=1}^{2} H\left[m, f_{h_{k}}\right]} \\
& h_{1} \text { e } h_{2} \\
& \frac{w_{3}}{2 u} \\
& \frac{2 u \sum_{i=1}^{2} f_{h_{i}}}{w_{3}} \\
& a_{i} e h_{j} \quad \frac{v_{i j}}{2 u} \\
& \frac{2\left(f_{a_{i}}+f_{h_{j}}\right) u}{v_{i j}}, \quad i, j=1,2 \\
& a_{i} e F_{j} \\
& \frac{z_{i j}}{4 u} \\
& \frac{4\left(f_{a_{i}}+f_{F_{j}}\right) u}{z_{i j}}, \quad i, j=1,2 \\
& h_{i} e F_{j} \\
& \frac{w_{i j}}{2 u} \\
& \frac{2\left(f_{h_{i}}+f_{F_{j}}\right) u}{w_{i j}}, \quad i, j=1,2
\end{aligned}
$$


$F_{1}$ e $F_{2} \quad \frac{\sum_{k=1}^{2} H\left[m, f_{h_{k}}\right] \sum_{i=1}^{2} f_{F_{i}}}{2 u} \quad \frac{2 u}{\sum_{k=1}^{2} H\left[m, f_{h_{k}}\right]}$,

onde as funçôes $w_{i}=w_{i}\left[n, m, f_{a_{1}}, f_{a_{2}}, f_{h_{1}}, f_{h_{2}}\right]$ para $i=1,2,3, v_{i j}=v_{i j}\left[n, m, f_{a_{1}}, f_{a_{2}}, f_{h_{1}}, f_{h_{2}}\right]$, $w_{i j}=w_{i j}\left[n, m, f_{a_{1}}, f_{a_{2}}, f_{h_{1}}, f_{h_{2}}, f_{F_{1}}, f_{F_{2}}\right] e \tilde{\sim}_{i j}=\tilde{z}_{i j}\left[n, m, f_{a_{1}}, f_{a_{2}}, f_{h_{1}}, f_{h_{2}}, f_{F_{1}}, f_{F_{2}}\right]$ para $i, j=1,2$ são dadas por

$$
\begin{aligned}
w_{i}= & H\left[m, f_{h_{\sigma(i)}}\right]\left(2^{m} f_{h_{i}}+\sum_{k=1}^{2} H\left[n, f_{a_{k}}\right]\right) \\
& +\left(2^{m-1}-1\right) f_{h_{i}} \sum_{k=1}^{2} f_{h_{k}}, i=1,2 \\
w_{3}= & \left(2^{m-1}-1\right)\left(\sum_{k=1}^{2} f_{h_{k}}\right)^{2}+2^{m} \sum_{k=1}^{2} f_{h_{k}} H\left[m, f_{h_{\sigma(k)}}\right] \\
& +\left(\sum_{k=1}^{2} H\left[n, f_{a_{k}}\right]\right)\left(\sum_{k=1}^{2} H\left[m, f_{h_{k}}\right]\right) \\
v_{i j}= & H\left[m, f_{h_{\sigma(\jmath)}}\right]\left(2^{m} f_{h_{j}}+\sum_{k=1}^{2} H\left[n, f_{a_{k}}\right]\right) \\
& +\left(2^{m-1}-1\right) f_{h_{j}} \sum_{k=1}^{2} f_{h_{k}}+\left(1+2^{n} f_{a_{i}}\right) \sum_{k=1}^{2} H\left[m, f_{h_{k}}\right], i, j=1,2 \\
z_{i j}= & \left(1+2^{n} f_{a_{i}}+2 f_{F_{j}}\right) \sum_{k=1}^{2} H\left[m, f_{h_{k}}\right], i, j=1,2 \\
& +\left(2^{m-1}-1\right) f_{h_{i}} \sum_{k=1}^{2} f_{h_{k}}+f f_{F} \sum_{k=1}^{2} H\left[m, f_{h_{k}}\right] \\
w_{i j}= & H\left[m, f_{h_{\sigma(i)}}\right]\left(2^{m} f_{h_{i}}+\sum_{k=1}^{2} H\left[n, f_{a_{k}}\right]\right) \\
&
\end{aligned}
$$

No póximo capítulo, apresentaremos o conceito de informação esperada de um experimento, do qual faremos uso para estabelecer uma ordem de preferência entre os experimentos considerados nos capítulos 3 a 9 . 


\section{Capítulo 10}

\section{Ordem de preferência entre parentes do demandado}

\subsection{Introdução}

Em diferentes circunstâncias pode acontecer que, por razões econômicas ou físicas, nao seja possível efetuar a análise do DNA de alguns dos parentes do demandado e portanto é importante dispôr de critérios para fazer uma "boa" escolha sobre qual ou quais dos parentes são mais adequados para analisarmos. É natural pensar que quando a incerteza a priori sobre se o demandado é ou não é o pai do demandante está muito próxima da incerteza a posteriori sobre o mesmo fato, após ter realizado um experimento $Y$, então o experimento $Y$ pode considerar-se que traz pouca informação para o nosso problema. Isto sugere que devemos considerar funções que meçam a proximidade entre duas distribuições, neste caso entre a distribuição de probabilidade a priori de paternidade e a distribuição de probabilidade a posteriori de paternidade.

Quando, na determinação dos perfis do DNA, são usados vários locos em um experimento particular, é de interesse conhecer em quais daqueles locos esperamos que se apresente uma maior diferença entre as probabilidades a priori e a posteriori de paternidade. Esse conhecimento é de grande utilidade para estabelecer regras, a respeito de quantos e quais locos devem ser analisados em um determinado experimento. 
Os aspectos acima mencionados sào considerados, em nosso problema, através de duas medidas de informação, amplamente utilizadas na literatura sobre informação e comparação de experimentos: a médida de informação de Kullback-Leibler e a distância de variação total, cujas definições são apresentadas na seção 10.2 .

Na seção 10.3, exibimos o método de cálculo da informação esperada em cada um dos experimentos considerados nos capítulos 3 a 9, quando os conjuntos de parentes do demandado são, respectivamente, um irmão, um filho e sua mãe, um filho, a mãe do demandado, a mãe e um irmão, um filho e a mãe do demandado e finalmente, um irmão e um filho do demandado.

Utilizando o banco de dados do laboratório Genomic, calculamos a informação esperada em cada um dos experimentos acima mencionados, para cada uma das medidas de informação aqui consideradas e para alguns dos locos, cujos dados estão disponíveis. Comparações entre a informação média, fornecida em cada experimento, nos diferentes locos, são apresentadas na seção 10.4. Na seção 10.5, exibimos a relação de ordem - estabelecida para os experimentos aqui considerados - em termos da informação esperada.

Os programas de computador, para calcular a informação esperada em cada experimento, estão escritos em Pascal e, as figuras exibidas, foram elaboradas com o software Splus.

\subsection{Medidas de informação}

A entropia, conceito que foi considerado por Shannon sob o ponto de vista da teoria da comunicação, é definida como uma medida da incerteza de um experimento aleatório. Desenvolvendo esta idéia de entropia, Kullback (1959) introduz o conceito de entropia relativa - como uma medida da distância entre duas distribuições de probabilidade. A entropia relativa, também é conhecida na literatura pelos nomes de número de informação de Kullback-Leibler, divergência em informação ou ganho de informação.

Uma caracterização axiomática da entropia e suas propriedades pode ser vista, por exemplo, em Khinchin (1957), Ash (1967) e Ihara (1993). Smith e Bernardo (1994) consideram, em detalhes, a entropia relativa, utilizando-a para definir a informação esperada de um experimento aleatório. Baseándonos nessa definição, consideramos, também, a informação esperada de um experimento no caso que, a distância entre as distribuições de probabilidade seja dada pela distância de variação total. 
Outros pontos de vista e definições, a respeito da informação fornecida por um experimento podem ver-se, por exemplo, em Blackwell e Girshick (1954), Lindley (1956), DeGroot (1962), Goel e DeGroot (1979), Bernardo (1979), e Berger (1980).

Apresentamos, a seguir, as definições das medidas de informação de Kullback-Leibler e de variação total, junto com a definição de informação de um conjunto de dados e a. informação esperada de um experimento, fazendo énfase sobre os aspeitos particulares que são motivo de análise neste trabalho.

\section{Definição 10.2.1 Número de informação de Kullback-Leibler}

Sejam $P$ e $Q$ duas distribuições de probabilidade definidas sobre o espaço mensurável $(W, \mathcal{A})$. O número de informação de Kullback - Leibler de $Q$ com respeito a $P$, denotado $K[Q, P]$, é dado pela expressão

$$
K[Q, P]= \begin{cases}\int \log \left[\frac{d Q}{d P}\right] d Q & \text { se } Q \prec P, \\ \infty & \text { se } Q \nprec P,\end{cases}
$$

onde $Q \prec P$ significa que a distribuição $Q$ é absolutamente contínua com respeito à distribuição $P$ - isto é, se para cada $A$ em $\mathcal{A}$ tal que $P[A]=0$ temos que $Q[A]=0$.

No caso que $W$ seja um conjunto finito, sem perda de generalidade podemos supor que $P[\{i\}]>0$ para cada $i \in W$ e, neste caso, o número de informação de Kullback-Leibler é dado por

$$
K[Q, P]=\sum_{i \in W} Q[\{i\}] \log \left[\frac{Q[\{i\}]}{P[\{i\}]}\right],
$$

onde o caso $0 \log [0]$ é definido como zero.

Suponhamos que $W$ é constituído por dois elementos, dizemos $W=\{0,1\}, \mathcal{A}=\mathcal{A}_{W}$, sendo $P[\cdot]$ e $Q[\cdot]$, respectivamente, a distribuição de probabilidade a priori de paternidade $\pi[\cdot]$ e a distribuição de probabilidade a posteriori de paternidade $\pi[\cdot \mid D]$, onde $D$ é o conjunto de dados associado ao experimento de observar, independentemente, em um loco particular, o genótipo da mãe do demandante, do demandante e alguns parentes do demandado. Para este caso particular, o número de informação de Kullback - Leibler da distribuição de probabilidade a posteriori de paternidade, com respeito à distribuição 
de probabilidade a priori de paternidade, torna-se

$$
K[P, Q]=\sum_{j=0}^{1} \frac{\pi[\theta=j] V_{j}[D]}{V_{1}[D]+\pi_{0}\left(V_{0}[D]-V_{1}[D]\right)} \log \left[\frac{V_{j}[D]}{V_{1}[D]+\pi_{0}\left(V_{0}[D]-V_{1}[D]\right)}\right](1
$$

onde $\pi_{0}=\pi[\theta=0]$ e $V_{j}[D]$ para $j=0,1$, é a probabilidade condicional definida no capítulo 1.

O resultado anterior pode ser escrito como se mostra a seguir, sempre que a probabilidade condicional $V_{0}[D]$ seja positiva.

$$
K[P, Q]=\left(1-\pi_{0}\right) \frac{R V[D] \log [R V[D]]}{Z[R V[D], \pi[\theta=0]]}-\log \left[Z\left[R V[D], \pi_{0}\right]\right]
$$

sendo $Z\left[R V[D], \pi_{0}\right]$ a expressão definida por

$$
Z\left[R V[D], \pi_{0}\right]=R V[D]+\pi_{0}(1-R V[D])
$$

\section{Definição 10.2.2 Distância de variação total}

Sejam $P$ e $Q$ duas distribuições de probabilidade definidas sobre o espaço mensurável $(W, \mathcal{A})$. A distância de variação total entre as distribuições $Q$ e $P$, denotada $|Q-P|$, é definida pela expressão

$$
|Q-P|=\sup \{|Q[B]-P[B]|: B \in \mathcal{A}\}
$$

A demonstração de algumas propriedades da distância de variação total pode ser vista em Diaconis e Freedman (1987).

Suponhamos, como antes, que $P[\cdot]$ e $Q[\cdot]$ são, respectivamente, a distribuição de probabilidade a priori de paternidade $\pi[\cdot]$ e a distribuição de probabilidade a posteriori de paternidade $\pi[\cdot \mid D]$. Para este caso, a distância de variação total entre as distribuições 
de probabilidade a posteriori e a priori de paternidade, é dada pela seguinte expressão

$$
\begin{aligned}
|Q-P| & =\left|\pi_{0}-\frac{\pi_{0} V_{0}[D]}{\sum_{j=0}^{1} V_{j}[D] \pi[\theta=j]}\right| \\
& =\pi_{0}\left|1-\frac{V_{0}[D]}{V_{1}[D]+\pi_{0}\left(V_{0}[D]-V_{1}[D]\right)}\right| .
\end{aligned}
$$

No caso que a probabilidade condicional $V_{0}[D]$ seja positiva. a expressão $10 . \bar{t}$ torna-se

$$
|Q-P|=\pi_{0}\left|1-\frac{1}{Z\left[R V[D], \pi_{0}\right]}\right|,
$$

onde $Z\left[R V[D], \pi_{0}\right]$ é como definido em 10.5 .

As definições de informação dos dados e informação esperada de um experimento, dadas em Bernardo e Smith (1994), quando a medida de "distância" entre uma distribuição a priori $P[\cdot]$ e a distribuição a posteriori $P[\cdot \mid D]$ - obtida após da observação de $D$ é o número de informação de Kullback-Leibler, sugerem definições semelhantes para qualquer outra medida de "distância" entre essas distribuições de probabilidade.

\section{Definição 10.2.3 Informação dos dados}

Seja $Y$ o experimento consistente em observar, independentemente, em um dado loco, o genótipo da mãe do demandante, do demandante e alguns parentes do demandado.

Suponhamos que $W$ é constituído por dois elementos, dizemos $W=\{0,1\} \cdot \mathcal{A}=\mathcal{A}_{W}$ e sejam $P[\cdot]$ e $Q[\cdot]$, respectivamente, a distribuição de probabilidade a priori de paternidade $\pi[\cdot]$ e a distribuição de probabilidade a posteriori de paternidade $\pi[\cdot \mid D]$, onde $D$ é o conjunto de dados associado ao experimento $Y$.

Se a distância entre a distribuição de probabilidade a posteriori de paternidade e a distribuição de probabilidade a priori de paternidade, é dada por $N[\pi[\cdot \mid D] . \pi[\cdot]]$, então esta quantidade é chamada de informação fornecida pelos dados $D$.

\section{Definição 10.2.4 Informação esperada de um experimento}

Sob as condiçòes dadas acima, a informaçào esperada, fornecida pelo experimento $Y$, denotada $I E_{N}\left[Y^{\prime} \mid \pi[\cdot]\right]$, é definida por 


$$
I E_{N}[Y \mid \pi[\cdot]]=\sum_{i} P\left[D_{i}\right] N\left[\pi\left[\cdot \mid D_{i}\right], \pi[\cdot]\right],
$$

onde $D_{i}$ percorre o conjunto de todos os possíveis resultados do experimento $Y$ e os $D_{i}$ ocorrem com probabilidades $P\left[D_{i}\right]$.

\subsection{Cálculo da informação esperada de um experi- mento}

Da expressão 10.9 temos que, para calcular a informação esperada de um experimento $Y$, precisamos da probabilidade de todos seus possíveis resultados. O método de cálculo, para o problema que estamos aqui considerando, é exibido a seguir.

Seja $D$ um resultado qualquer do experimento $Y$. A probabilidade do resultado $D, P[D]$, é dada pela seguinte expressão

$$
\begin{aligned}
P[D] & =\sum_{j=0}^{1} P[D \mid \theta=j] \pi[\theta=j] \\
& =\sum_{j=0}^{1} P\left[M=\left(M_{1}, M_{2}\right), F=\left(F_{1}, F_{2}\right), U=\mathbf{u} \mid \theta=j\right] \pi[\theta=j] \\
& =\sum_{j=0}^{1} V_{j}[D] P\left[M=\left(M_{1}, M_{2}\right), U=\mathbf{u} \mid \theta=j\right] \pi[\theta=j] \\
& =P\left[M=\left(M_{1}, M_{2}\right)\right] P[U=\mathbf{u}]\left(V_{1}[D]+\left(V_{0}[D]-V_{1}[D]\right) \pi_{0}\right),
\end{aligned}
$$

onde as probabilidades condicionais $V_{0}[D]$ e $V_{1}[D]$ são dadas, respectivamente, pelas expressões 1.6 e 1.7 .

Se a probabilidade $V_{0}[D]$ é positiva, a probabilidade do resultado $D$ é dada por

$$
P[D]=P\left[M=\left(M_{1}, M_{2}\right)\right] P[U=\mathbf{u}] V_{0}[D] Z\left[R V[D], \pi_{0}\right],
$$

onde $Z\left[R V[D], \pi_{0}\right]$ é dado pela expressão 10.5 . 
Consideremos os seguintes cinco experimentos em um dado loco. O experimento $Y_{i}$ para $i=1, \cdots, 5$ consiste em determinar o genótipo da màe do demandante, do demandante e dos seguintes parentes do demandado: para

$\begin{array}{clc}\text { Exper. } & \text { Parentes do demandado } & \text { Abreviação }^{1} \\ Y_{1} & \text { um irmão } & \text { irm } \\ Y_{2} & \text { um pai e um irmão } & \text { mair } \\ Y_{3} & \text { um pai e um filho } & \text { mafi } \\ Y_{4} & \text { a esposa e um filho } & \text { esfi } \\ Y_{5} & \text { um irmão e um filho } & \text { irfi }\end{array}$

Para cada experimento $Y_{i}, i=1, \cdots, 5$, exibiremos a seguir o valor da contribuição de um dado resultado, na informação esperada desse experimento.

1. Dos resultados exibidos nos capítulos 3,5 e 6 , obtemos que se observamos somente um irmão, ou um filho, ou um dos pais do demandado e se estes indivíduos possuem o mesmo genótipo, então, as correspondentes probabilidades condicionais $V_{0}[D]$ tomam o mesmo valor e, conseqëntemente, as razões de verossimilhança $R V[D]$ são iguais. Além disto, nos três casos, a probabilidade $P[U=\mathrm{u}]$ é igual. Logo, a informação esperada a realizar qualquer um destes experimentos é sempre a mesma.

Suponhamos que ao observarmos, independentemente, a mãe do demandante, o demandante e um irmão do demandado obtevemos o seguinte resultado:

$$
M_{1}=M_{2}=F_{1}=F_{2}=a_{1}, a_{1} \neq a_{2}
$$

Como o resultado 10.3 está incluido no caso 3.2 .2 , basta substituir $n$ por 1 , no corolário 3.3.2, para obter a probabilidade condicional $V_{0}[D]$. dada neste caso por $V_{0}[D]=(1+$ $\left.2 f_{a_{1}}\right) / 4$. Assim, a probabilidade deste resultado é

$$
\begin{aligned}
P[D] & =\frac{1}{2} f_{a_{1}}^{2} 2 f_{a_{1}} f_{a_{2}} \frac{1+2 f_{a_{1}}}{4} Z\left[R V[D], \pi_{0}\right] \\
& =\frac{1}{4} f_{a_{1}}^{3} f_{a_{2}}\left(1+2 f_{a_{1}}\right) Z\left[R V[D], \pi_{0}\right],
\end{aligned}
$$

onde $R V[D]=4 f_{a_{1}} /\left(1+2 f_{a_{1}}\right)$ e $Z\left[R V[D], \pi_{0}\right]$ é dado pela expressão 10.5 . 
Como os alelos $a_{1}$ e $a_{2}$ podem ser qualquer um dos alelos no loco em consideração, obtemos que, a contribuição - na informação esperada deste experimento - de todos os possíveis resultados como em 10.3 é dada por

$$
T_{1}=\frac{1}{4} \sum_{i=1}^{c} \sum_{j \neq i} f_{b_{i}}^{3}\left(1+2 f_{b_{i}}\right) f_{b}, Z\left[R V\left[D_{i}\right], \pi_{0}\right] N\left[\pi\left[\cdot \mid D_{i}\right], \pi[\cdot]\right],
$$

onde $N\left[\pi\left[\cdot \mid D_{i}\right], \pi[\cdot]\right]$ é o valor da informação do conjunto de dados $D_{i}$, obtido ao substituirmos $R V[D]$ por $R V\left[D_{i}\right]$ na correspondente medida de informação e

$$
R V\left[D_{i}\right]=\frac{4 f_{b_{i}}}{1+2 f_{b_{i}}}, \quad i=1, \cdots, c
$$

$O$ valor total da informação esperada do experimento $Y_{1}$, é obtida em forma semelhante ao exemplo acima, ao considerarmos todos os possiveis resultados nos casos 3.1.1 e 3.2.2.

2. Suponhamos que ao observarmos, independentemente, a mãe do demandante, o demandante, um irmão e a mãe do demandado obtevemos o seguinte resultado:

$$
M_{1}=M_{2}=F_{1}=F_{2} \quad v_{1}=v_{2}=a_{1}, a_{1} \neq a_{2}
$$

Este resultado está incluido no caso 7.2 .2 parte i). Se, no corolário 7.3.4, substituimos $n$ por 1 obtemos que $V_{0}[D]=f_{F_{1}} / 4$.

Neste caso é necessário calcular a probabilidade de que a mãe do demandado tenha o genótipo $\left(a_{1}, a_{1}\right)$ e seu filho - o irmão do demandado - possua o genótipo $\left(a_{1}, a_{2}\right)$. Esta probabilidade é dada por $P[U=\mathrm{u}]=f_{a_{1}}^{2} f_{a_{2}}$.

Assim, a probabilidade deste resultado é

$$
\begin{aligned}
P[D] & =f_{F_{1}}^{2} f_{a_{1}}^{2} f_{a_{2}} \frac{f_{F_{1}}}{4} Z\left[R V[D], \pi_{0}\right] \\
& =\frac{1}{4} f_{a_{1}}^{2} f_{a_{2}} f_{F_{1}}^{3} Z\left[R V[D], \pi_{0}\right],
\end{aligned}
$$

onde $R V[D]=4$ e $Z\left[R V[D], \pi_{0}\right]$ é dado pela expressão 10.5 . 
Como os três alelos diferentes $F_{1}, a_{1}$ e $a_{2}$, podem ser qualquer um dos alelos no loco em consideração, obtemos que, a contribuição - na informação esperada deste experimento - de todos os possiveis resultados como em 10.3 é dada por

$$
T_{2}=\frac{1}{4} \sum_{i=1}^{c} \sum_{\substack{j, k \neq i \\ k \neq j}} f_{b_{i}}^{3} f_{b_{j}}^{2} f_{b_{k}} Z\left[R V\left[D_{i}\right], \pi_{0}\right] N\left[\pi\left[\cdot \mid D_{i}\right], \pi[\cdot]\right]
$$

onde $N\left[\pi\left[\cdot \mid D_{i}\right], \pi[\cdot]\right]$ é o valor da informação do conjunto de dados $D_{i}$, obtido ao substituirmos $R V[D]$ por $R V\left[D_{i}\right]$ na correspondente medida de informação e $R V\left[D_{i}\right]=4, \quad i=$ $1, \cdots, c$.

$\mathrm{O}$ valor total da informação esperada do experimento $Y_{2}$, é obtida em forma semelhante ao exemplo acima, ao considerarmos todos os possíveis resultados nos casos 7.1.1 e 7.2.2.

3. Suponhamos que ao observarmos, independentemente, a màe do demandante, o demandante, um filho e a mãe do demandado obtevemos o seguinte resultado:

$$
M_{1}=M_{2}=F_{1}=F_{2}=v_{1}=v_{2}=h_{1}, h_{1} \neq h_{2}
$$

Este resultado está incluido no caso 8.2.1. Se, no corolário 8.3.3, substituimos $n$ por 1 obtemos que

$$
V_{0}[D]=\frac{1+4 f_{h_{1}}}{2\left(1+2 f_{h_{1}}\right.}
$$

Neste caso é necessário calcular a probabilidade de que a mãe do demandado tenha o genótipo $\left(h_{1}, h_{1}\right)$ e seu neto - o filho do demandado - possua o genótipo $\left(h_{1}, h_{2}\right)$. Esta probabilidade é dada por

$$
P[U=\mathbf{u}]=f_{h_{1}}^{2} \frac{f_{h_{2}}\left(1+2 f_{h_{1}}\right)}{2} .
$$

Assim, a probabilidade deste resultado é

$$
\begin{aligned}
P[D] & =f_{h_{1}}^{2} f_{h_{1}}^{2} \frac{f_{h_{2}}\left(1+2 f_{h_{1}}\right)}{2} \frac{1+4 f_{h_{1}}}{2\left(1+2 f_{h_{1}}\right.} Z\left[R V[D], \pi_{0}\right] \\
& =\frac{1}{4} \int_{h_{1}}^{4} \int_{h_{2}}\left(1+4 f_{h_{1}}\right) Z\left[R V[D], \pi_{0}\right],
\end{aligned}
$$


onde

$$
R V[D]=\frac{2 f_{h_{1}}\left(1+2 f_{h_{1}}\right.}{1+4 f_{h_{1}}}
$$

e $Z\left[R V[D], \pi_{0}\right]$ é dado pela expressão 10.5 .

Como os dois alelos diferentes $h_{1}$ e $h_{2}$, podem ser qualquer um dos alelos no loco em consideração, obtemos que, a contribuição - na informação esperada deste experimento - de todos os possíveis resultados como em 10.3 é dada por

$$
T_{3}=\frac{1}{4} \sum_{i=1}^{c} \sum_{j \neq i} f_{b_{i}}^{4} f_{b_{j}}\left(1+4 f_{b_{i}}\right) Z\left[R V\left[D_{i}\right], \pi_{0}\right] N\left[\pi\left[\cdot \mid D_{i}\right], \pi[\cdot]\right]
$$

onde $N\left[\pi\left[\cdot \mid D_{i}\right], \pi[\cdot]\right]$ é o valor da informação do conjunto de dados $D_{i}$, obtido ao substituirmos $R V[D]$ por $R V\left[D_{i}\right]$ na correspondente medida de informação e

$$
R V\left[D_{i}\right]=\frac{2 f_{b_{i}}\left(1+2 f_{b_{i}}\right.}{1+4 f_{b_{i}}}, \quad i=1, \cdots, c .
$$

O valor total da informação esperada do experimento $Y_{3}$, é obtida em forma semelhante ao exemplo acima, ao considerarmos todos os possíveis resultados nos casos 8.1.1 - 8.2.5.

4. Suponhamos que ao observarmos, independentemente, a mãe do demandante, o demandante, um filho e a esposa do demandado obtevemos o seguinte resultado:

$$
M_{1}=M_{2}=F_{1}=F_{2}=m_{1}=m_{2}=h_{1}, \quad h_{1} \neq h_{2}
$$

Este resultado está incluido no caso 4.2.2 parte ii. Se, no corolário 4.3.3, substituimos $n$ por 1 obtemos que $V_{0}[D]=f_{h_{1}} / 2$.

Neste caso é necessário calcular a probabilidade de que a esposa do demandado tenha o genótipo $\left(h_{1}, h_{1}\right)$ e seu filho - o filho do demandado - possua o genótipo $\left(h_{1}, h_{2}\right)$. Esta probabilidade é dada por $P[U=\mathbf{u}]=f_{h_{1}}^{2} f_{h_{2}}$.

Portanto, a probabilidade deste resultado é

$$
P[D]=f_{h_{1}}^{2} f_{h_{1}}^{2} f_{h_{2}} \frac{f_{h_{1}}}{2} Z\left[R V[D], \pi_{0}\right]
$$




$$
=\frac{1}{2} f_{h_{1}}^{5} f_{h_{2}} Z\left[R V[D], \pi_{0}\right]
$$

onde $R V[D]=2$ e $Z\left[R V[D], \pi_{0}\right]$ é dado pela expressão 10.5 .

Como os dois alelos diferentes $h_{1}$ e $h_{2}$, podem ser qualquer um dos alelos no loco em consideração, obtemos que, a contribuição - na informação esperada deste experimento - de todos os possíveis resultados como em 10.3 é dada por

$$
T_{4}=\frac{1}{2} \sum_{i=1}^{c} \sum_{j \neq i} f_{b_{i}}^{5} f_{b_{j}} Z\left[R V\left[D_{i}\right], \pi_{0}\right] N\left[\pi\left[\cdot \mid D_{i}\right], \pi[\cdot]\right],
$$

onde $N\left[\pi\left[\cdot \mid D_{i}\right], \pi[\cdot]\right]$ é o valor da informação do conjunto de dados $D_{i}$, obtido ao substituirmos $R V[D]$ por $R V\left[D_{i}\right]$ na correspondente medida de informação e $R V\left[D_{i}\right]=2, \quad i=$ $1, \cdots, c$.

$\mathrm{O}$ valor total da informação esperada do experimento $Y_{4}$, é obtida em forma semelhante ao exemplo acima, ao considerarmos todos os possiveis resultados nos casos 4.1.1 e 4.2.2.

5. Finalmente, consideremos que ao observarmos. independentemente, a mãe do demandante, o demandante, um irmão e um filho do demandado obtevemos o seguinte resultado:

$$
M_{1}=M_{2}=F_{1} \neq F_{2}=a_{1}=a_{2} \neq h_{1}=h_{2}
$$

O resultado está incluido no caso 9.1.1.2. Se, no corolário 9.3.2, substituimos $n$ por 1 obtemos que $V_{0}[D]=\left(1+f_{a_{1}}\right) / 4$.

Neste caso é necessário calcular a probabilidade de que o irmão do demandado tenha o genótipo $\left(a_{1}, a_{1}\right)$ e o filho do demandado possua o genótipo $\left(h_{1}, h_{1}\right)$. Esta probabilidade é dada por $P[U=\mathbf{u}]=f_{a_{1}}^{2} f_{h_{1}}^{2} / 2$.

Portanto, a probabilidade deste resultado é

$$
\begin{aligned}
P[D] & =f_{M_{1}}^{2} f_{a_{1}}^{2} \frac{f_{h_{1}}^{2}}{2} \frac{1+f_{a_{1}}}{4} Z\left[R V[D], \pi_{0}\right] \\
& =\frac{1}{8} f_{a_{1}}^{2} f_{h_{1}}^{2} f_{M_{1}}^{2}\left(1+f_{a_{1}}\right) Z\left[R V[D], \pi_{0}\right] .
\end{aligned}
$$


onde $R V[D]=4 f_{a_{1}} /\left(1+f_{a_{1}}\right)$ e $Z\left[R V[D], \pi_{0}\right]$ é dado pela expressão 10.5 .

Como os três alelos diferentes $M_{1}, a_{1}$ e $h_{1}$, podem ser qualquer um dos alelos no loco em consideração, obtemos que, a contribuição - na informação esperada deste experimento - de todos os possíveis resultados como em 10.3 é dada por

$$
T_{5}=\frac{1}{8} \sum_{i=1}^{c} \sum_{j, k \neq i} f_{b_{i}}^{2}\left(1+f_{b_{i}}\right) f_{b_{j}}^{2} f_{b_{k}}^{2} Z\left[R V\left[D_{i}\right], \pi_{0}\right] N\left[\pi\left[\cdot \mid D_{i}\right], \pi[\cdot]\right],
$$

onde $N\left[\pi\left[\cdot \mid D_{i}\right], \pi[\cdot]\right]$ é o valor da informação do conjunto de dados $D_{i}$, obtido ao substituirmos $R V[D]$ por $R V\left[D_{i}\right]$ na correspondente medida de informação e

$$
R V\left[D_{i}\right]=\frac{4 f_{b_{i}}}{1+f_{b_{i}}} i=1, \cdots, c .
$$

$O$ valor total da informação esperada do experimento $Y_{5}$, é obtida em forma semelhante ao exemplo acima, ao considerarmos todos os possíveis resultados nos casos 9.1.1.1 9.2.2.3.

Na próxima seção, exibiremos algumas gráficas onde se apresenta a informação esperada, por experimento, nos diferentes locos.

\subsection{Informação esperada, por experimento, nos di- ferentes locos}

As freqüências dos alelos, nos correspondentes locos, foram obtidas do banco de dados da empresa Genomic (Whittle (1998)). Apresentamos, a seguir, os nomes dos locos e o número de alelos - com freqüência não-nula - nessa base de dados. 
Nome do loco Abreviação ${ }^{2}$ No. de alelos

$\begin{array}{lcc}\text { D14S297 } & \text { D14 } & 5 \\ \text { D13S764 } & \text { D13 } & 6 \\ \text { FES } & \text { FES } & 10 \\ \text { DiS820 } & \text { D7S } & 10 \\ \text { Vwf1 } & \text { Vwf } & 13 \\ 32027 & 320 & 14 \\ 28912 & 289 & 15 \\ \text { D5S815 } & \text { D5S } & 17 \\ \text { F13A1 } & \text { F13 } & 18 \\ \text { DSS306 } & \text { DSS } & 23\end{array}$

Nas seguintes figuras exibimos a informação esperada, obtida nos diferentes locos e para cada um dos experimentos considerados na seção 10.3 .
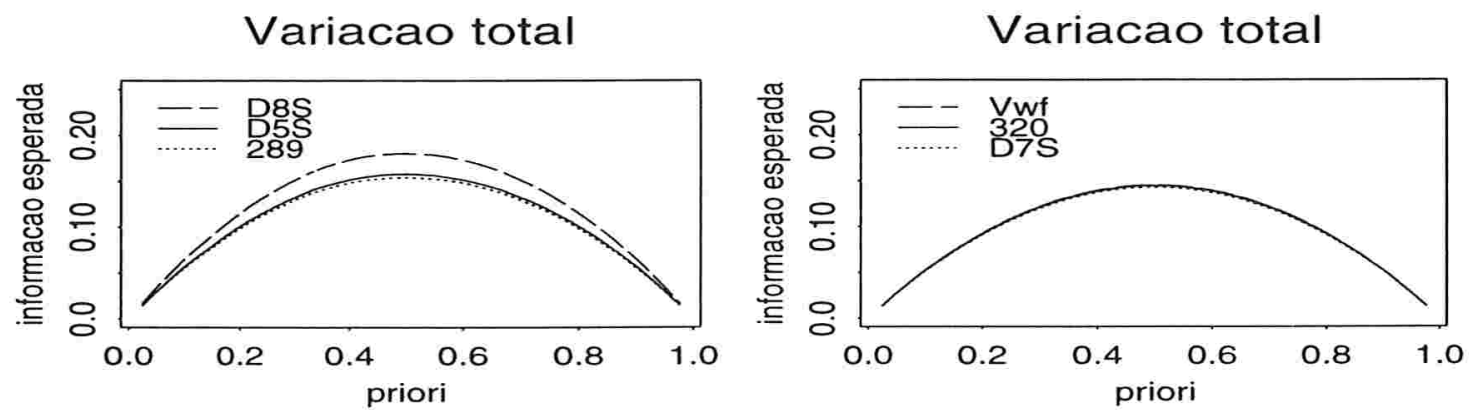

Variacao total
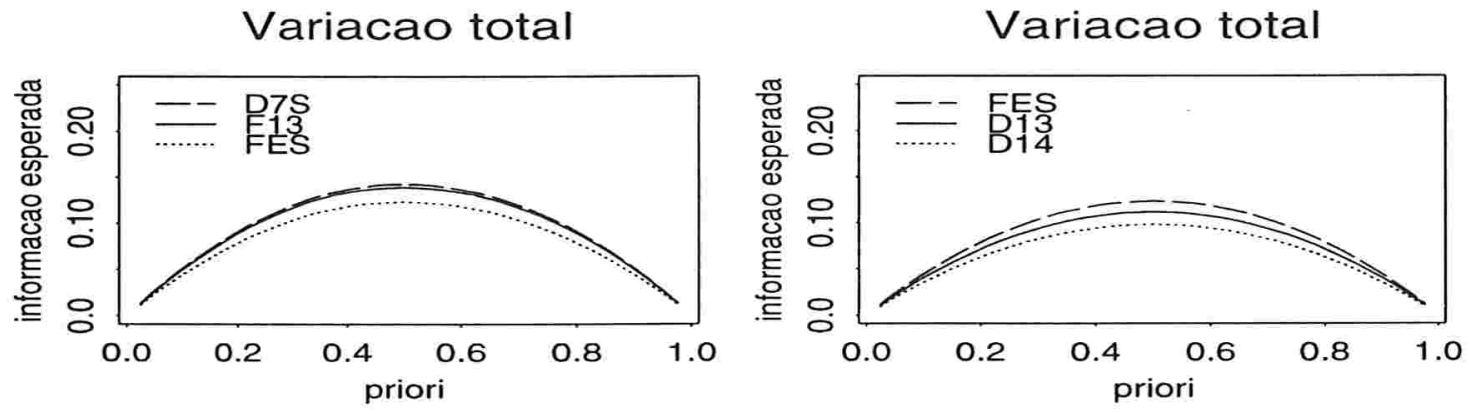

Figura 10.1: Informação esperada - um irmão do demandado 

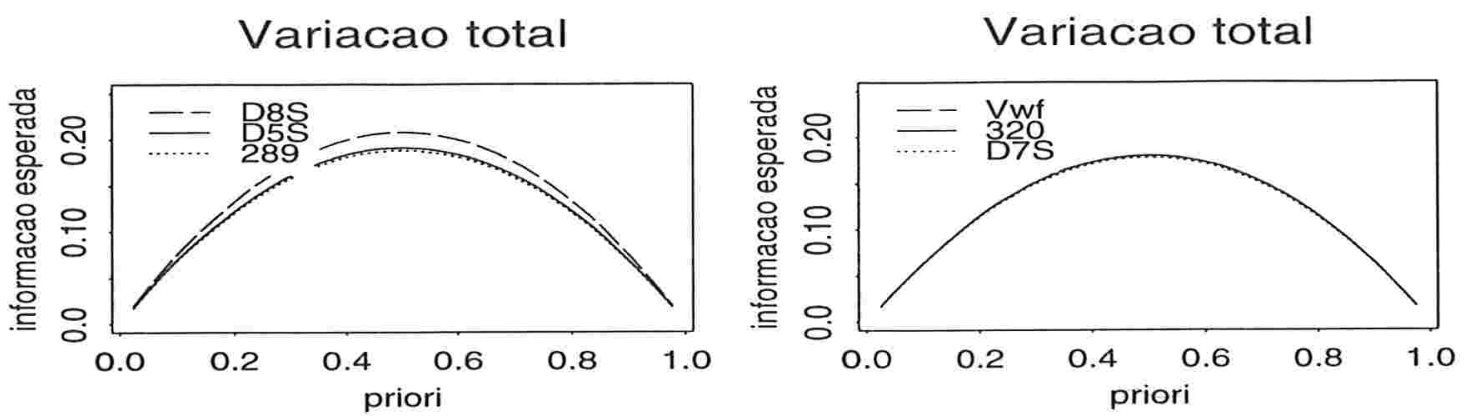

Variacao total

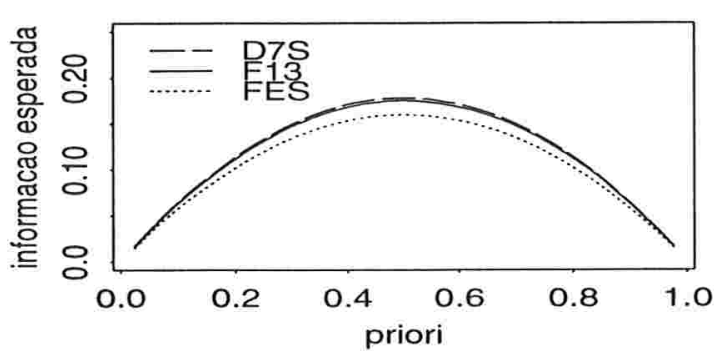

Variacao total

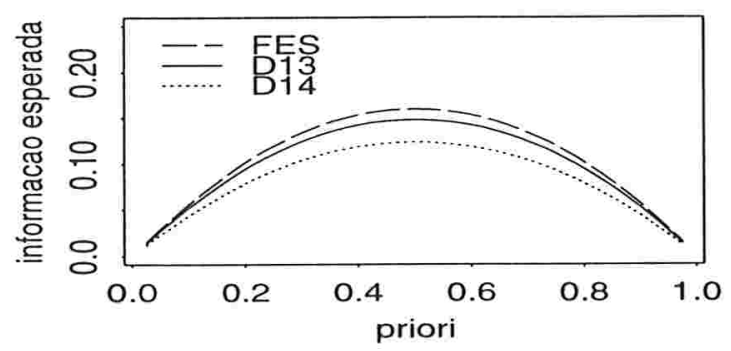

Figura 10.2: Informação esperada - um filho e a esposa do demandado
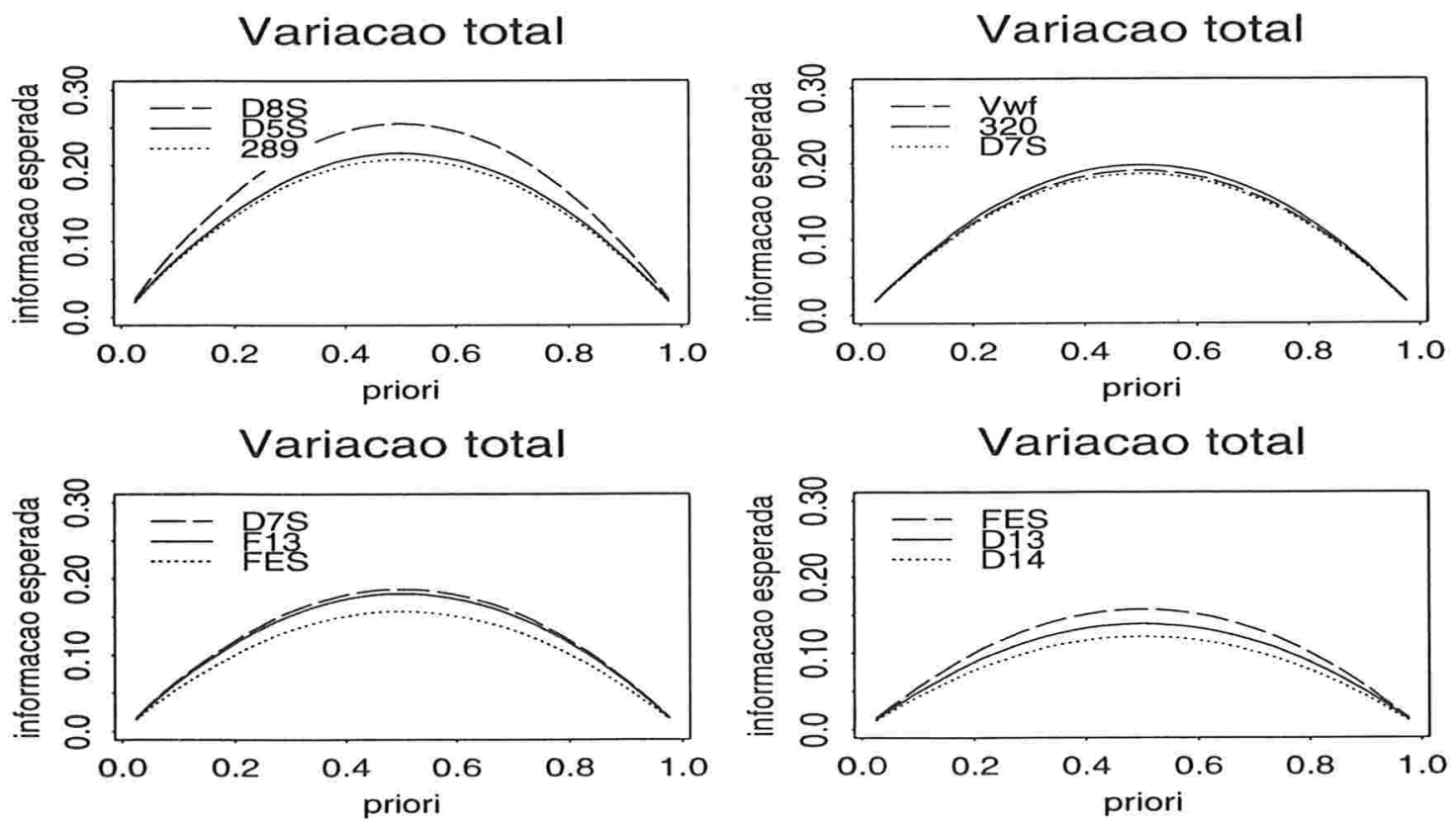

Figura 10.3: Informação esperada - um irmão e a mãe do demandado 

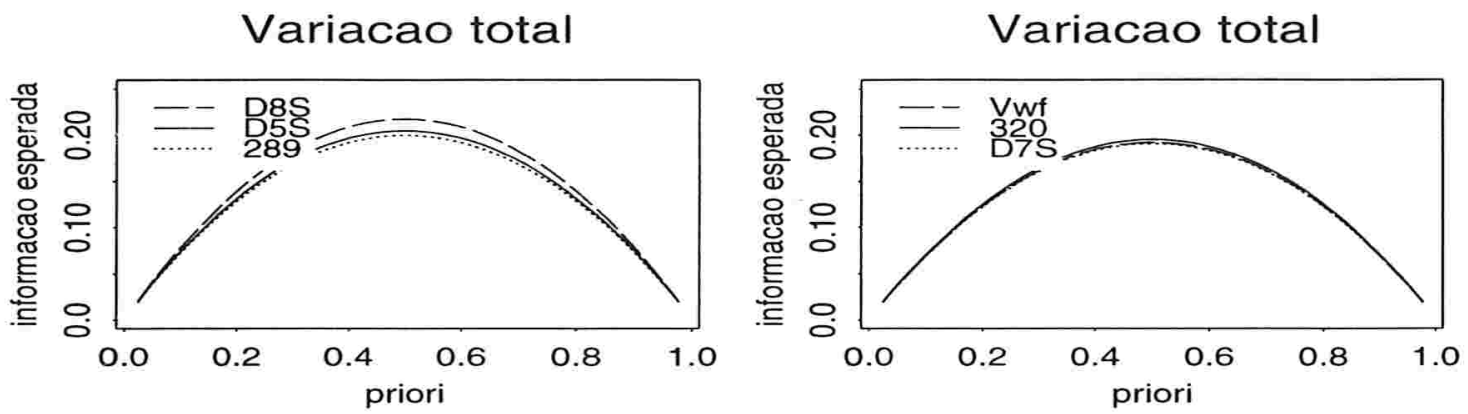

Variacao total

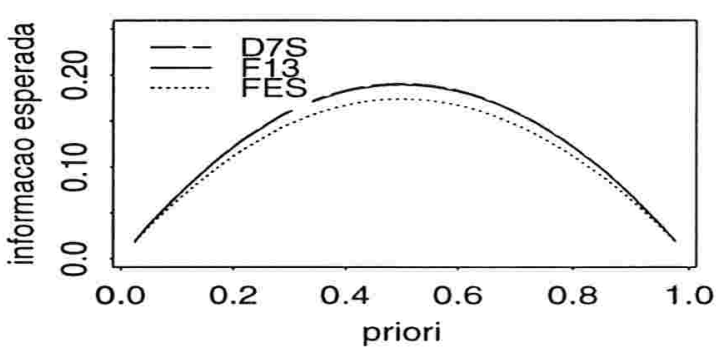

Variacao total

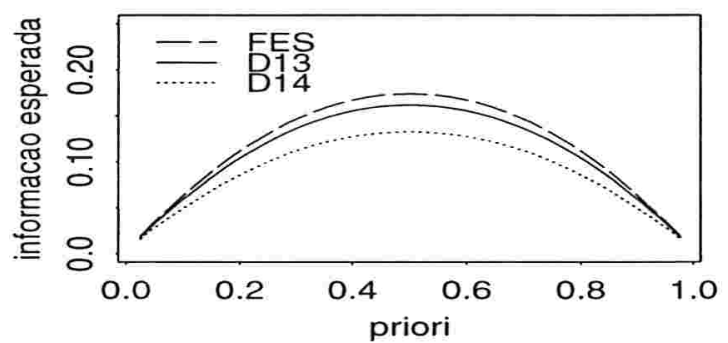

Figura 10.4: Informação esperada - um filho e a mãe do demandado
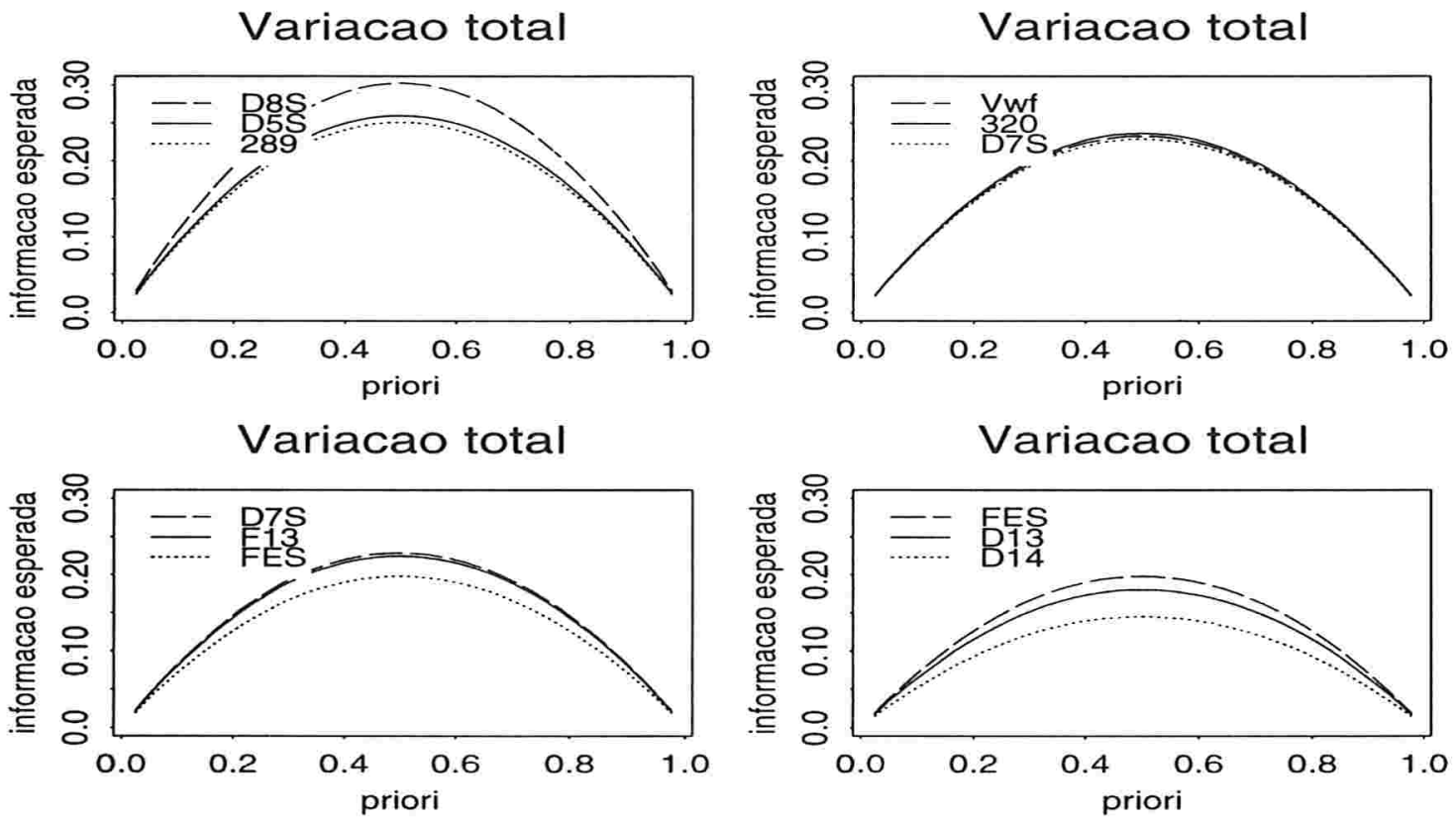

Figura 10.5: Informação esperada - um irmào e um filho do demandado 
Da observaçào das figuras 10.1-10.5 podemos afirmar que, independentemente do experimento, a maior informação esperada - em ordem decrescente - é atingida nos locos DSS306, D5S815, 28912 e 32027; enquanto que, a menor informação esperada é alcanzada nos locos FES, D13S764 e D14S297. Já no caso dos locos 32027, Vwf1, DiS820 e F13A1, a informação esperada é muito parecida.

As afirmações feitas anteriormente, são igualmente válidas tanto para a médida de variação total, quanto para o número de informação de Kullback-Leibler.

Na próxima seção, exibiremos algumas figuras onde se apresenta a informação esperada, por loco, nos diferentes experimentos.

\subsection{Informação esperada, por loco, nos diferentes experimentos}

A informação esperada, para os diferentes experimentos, em alguns dos locos considerados na seção anterior, é exibida a seguir. 

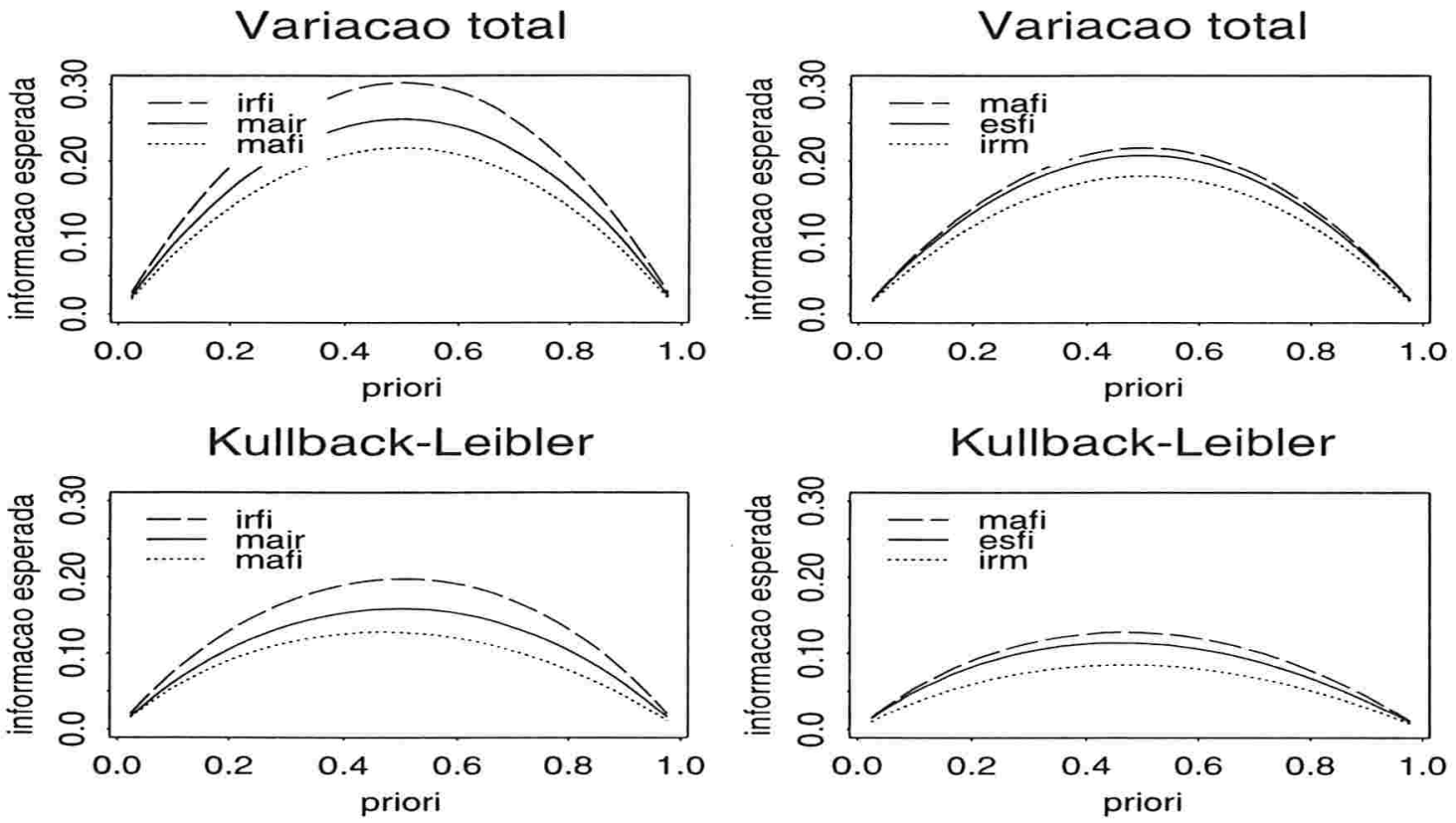

Figura 10.6: Informação esperada - Loco DSS306
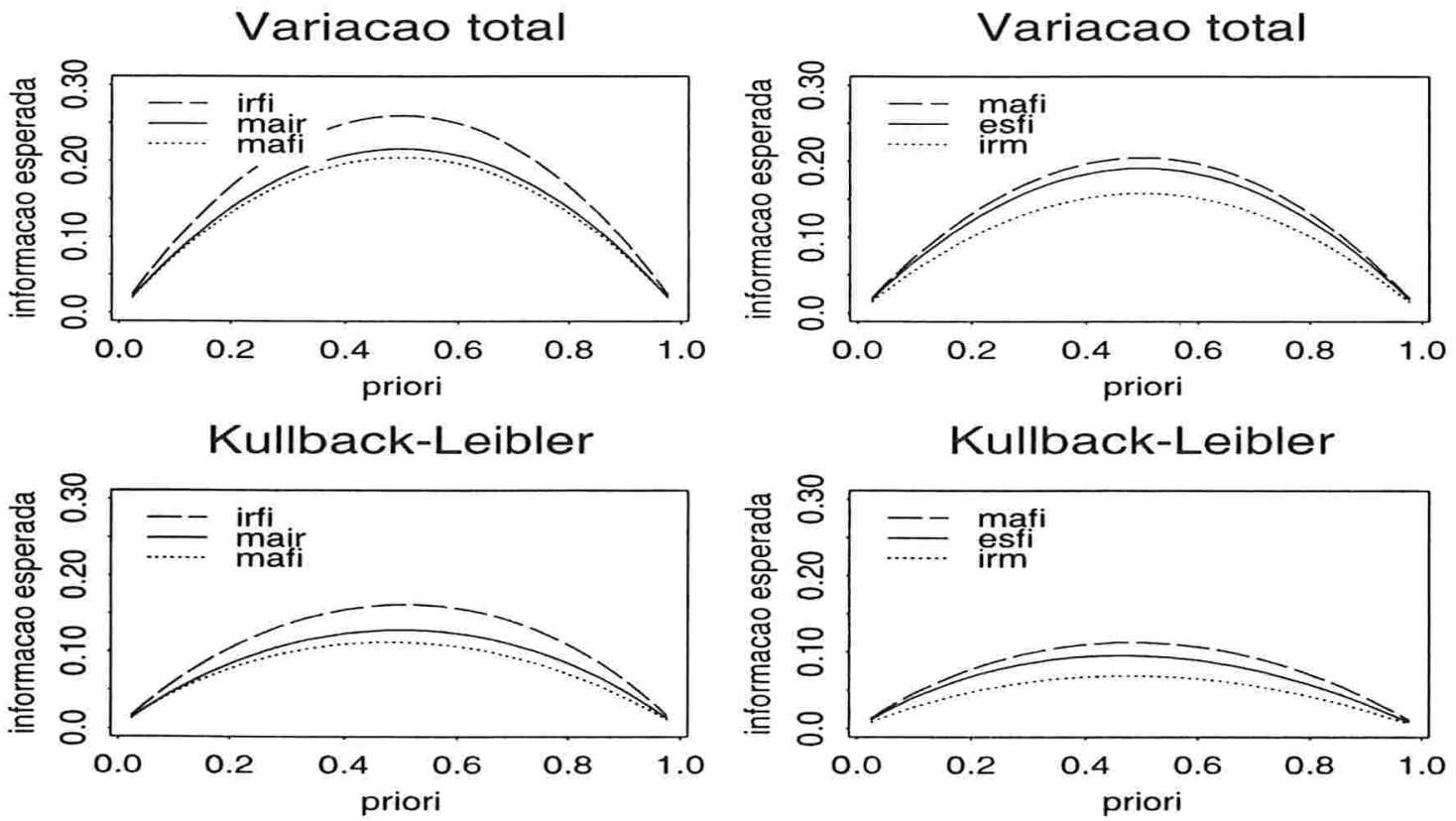

Figura 10.7: Informação esperada - Loco D5S815 

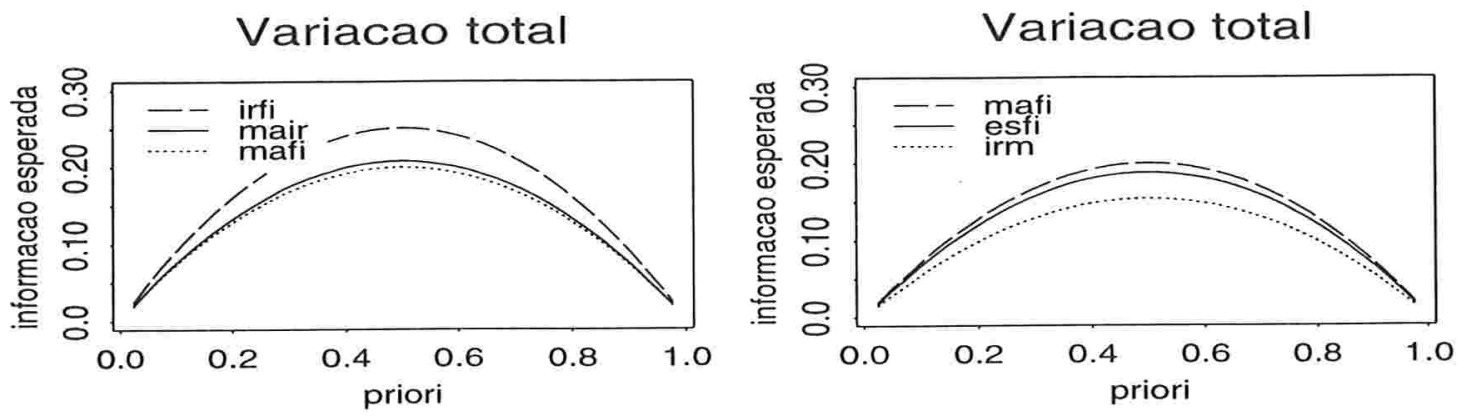

Kullback-Leibler

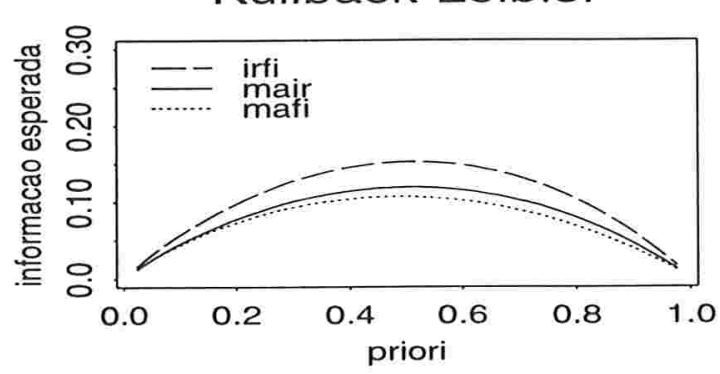

Kullback-Leibler

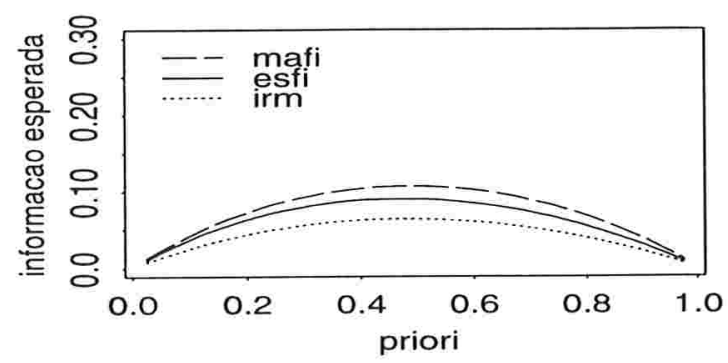

Figura 10.8: Informação esperada - Loco 28912
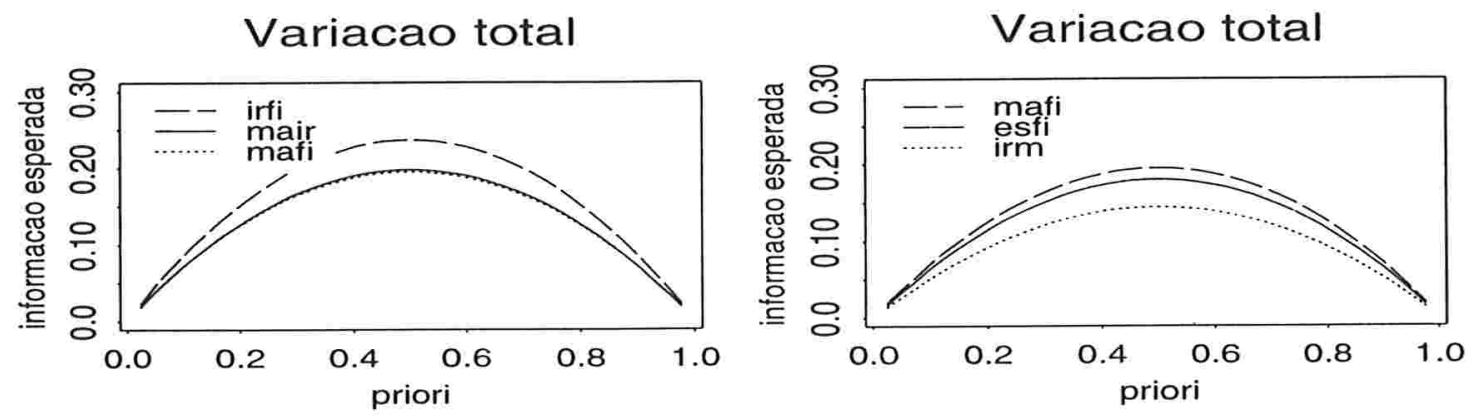

Kullback-Leibler
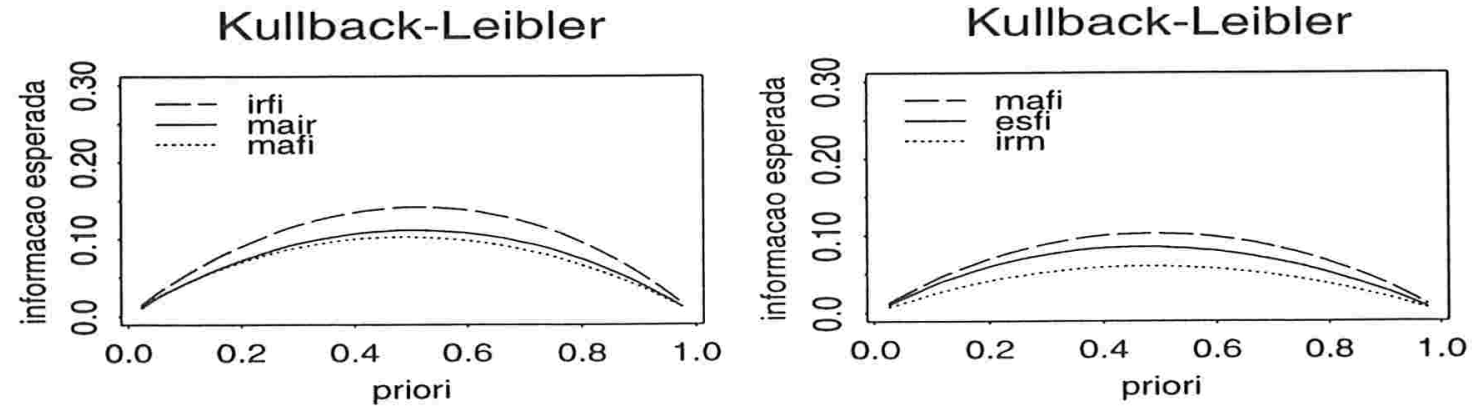

Figura 10.9: Informação esperada - Loco 32027 

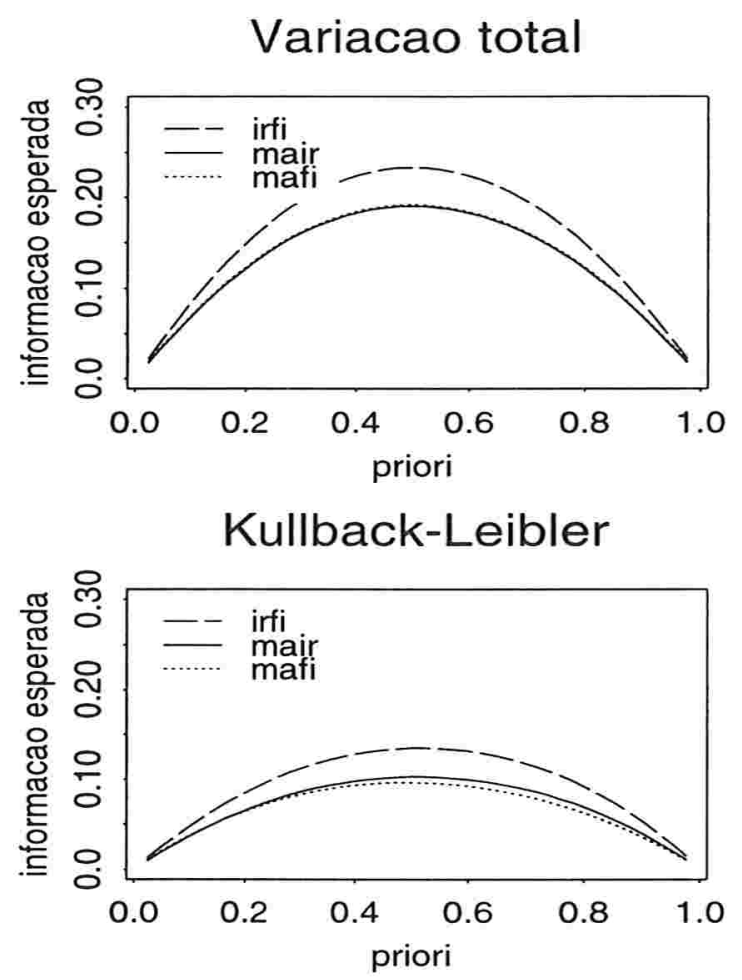
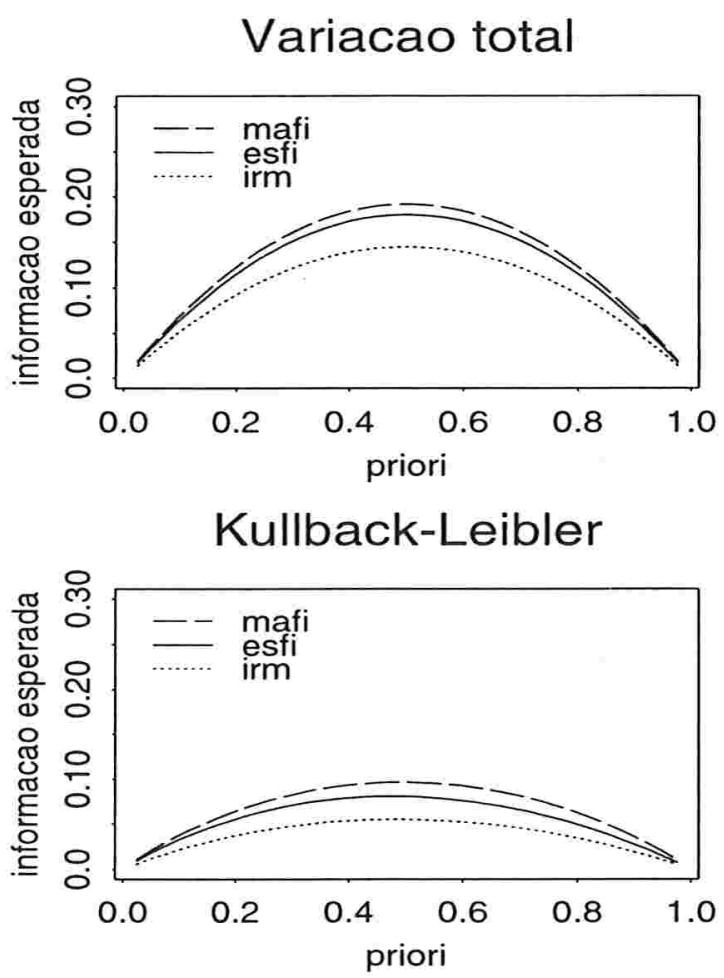

Figura 10.10: Informação esperada - Loco Vwf1

Da observação das figuras $10.6-10.10$ podemos afirmar que, independentemente do loco em consideração, o experimento com maior informação esperada é $Y_{5}$, isto é, quando se observa um irmão e um filho do demandado. Os experimentos com menor informação esperada, em ordem decrescente, são: observar um filho e a esposa do demandado $\left(Y_{4}\right)$ e observar um irmão do demandado $\left(Y_{1}\right)$. Além disso, os experimentos, observar a mãe e um irmão do demandado e observar a mãe e um filho do demandado, apresentam informação esperada muito parecida - qualquer que seja a medida de informação utilizada. 


\section{Conclusões}

No capítulo 2 conseguimos caracterizar, em detalhes, para os casos de dois alelos e de alelos múltiplos, o teste exato não condicional para a hipótese de equilíbrio populacional de Hardy-Weinberg, quando considerada em um sistema monogênico, autossômico e codominante em uma população pan-mítica.

Para contornar as dificuldades de tipo computacional, que se apresentam no teste exato para o caso de alelos múltiplos, definimos um procedimento seqüêncial para testar a hipótese de equilíbrio, usando-se dos resultados 2.4.2 e 2.4.3.

O fato de poder identificar os alelos, nos locos STR, sem erro de medição (veja, Hammond et al. (1994), Gill e Evett (1995) e Foreman et al. (1997)), permite definir processos metodológicos para calcular exatamente a probabilidade de paternidade, quando os perfis do DNA são obtidos desses locos.

Como visto nos capítulos 3 a 9, sob as condições estabelecidas em cada caso, propomos uma metodologia para determinar a distribuição de probabilidade a posteriori para o genótipo do demandado e, conseqüentemente, para calcular a probabilidade de paternidade, quando observamos o perfil de DNA da mãe do demandante, do demandante e de alguns parentes do demandado.

Além disso, quando comparados os resultados obtidos nos casos 3.1.1 - 3.4.2 com os resultados dos casos 5.1.1 - $\mathbf{5 . 4 . 2}$, provamos que ao analisarmos $s$ irmãos ou $s$ filhos do demandado, se o conjunto determinado pelos genótipos observados nos irmãos é igual ao conjunto determinado pelos genótipos observados nos filhos, então as inferências que podemos fazer - a respeito da probabilidade de paternidade do demandado, também são iguais. Este resultado é igualmente válido quando em um irmão. um filho e um dos pais do demandado os genótipos observados são iguais. 
Finalmente, estabelecimos uma ordem de preferência entre os experimentos considerados nos capítulos 3 a 9. A partir da informaçào esperada, calculada para cada um dos experimentos mencionados, nos locos 28912, 32027, D5S815, D7S820, DSS306, D13S764, D14S297, F13A1, FES e Vwf1, determinamos que o experimento "mais informativo" é, observar um irmão e um filho do demandado. Os experimentos com menor informação esperada, em ordem decrescente, são: observar um filho e a esposa do demandado e observar um irmão do demandado. Além disso, os experimentos, observar a mãe e um irmão do demandado e observar a mãe e um filho do demandado, apresentam informação esperada muito parecida. 


\section{Referências Bibliográficas}

Ash, Robert (1967) Information Theory. John Wiley \& Sons, New York.

Belin, T.; Gjertson, D. \& Hu, M. (1997) Summarizing DNA Evidence When Relatives are Possible Suspects. Journal of the American Statistical Association, Vol. 92, No. 438, pp. 706-716.

Berger, James O. (1980) Statistical Decision Theory. Foundations, concepts, and Methods. Springer Verlag, New York.

Bernardo, José (1979) Expected information as expected utility. The Annals of Statistics, Vol. 7, No. 3, pp. 686-690.

Berry, D. (1991) Inferences using DNA profiling in forensic identification and paternity cases. Statistical Science, Vol. 6, No. 2, pp. $175-205$

Berry, D.; Evett, I. \& Pinchin. R. (1992) Statistical Inference in Crime Investigations Using Deoxyribonucleic Acid Profiling. Journal of the Royal Statisical Society, Serie C, Vol. 41, pp. $499-531$.

Blackwell D. \& Girshick, M. A. (1954) Theory of Games and Statistical Decisions. John Wiley \& Sons, New York.

Busque, L.; Desmarais, D.; Provost, S.; Schumm, J.; Zhong, Y. \& Chakraborty, R. (1997) Analysis of Allele Distribution for Six Short Tandem Repeat Loci in the French Canadian Population of Quebec. Journal of Forensic Sciences, 42(6), pp. 1147-1153.

Cavalli-Sforza, L.L. \& Bodmer, W. F. (1971) The Genetics of Human Populations. Freeman, San Francisco.

Courant, R. \& John, F. (1974) Introduction to CALCULUS AND ANALYSIS. Vol. 2, John Wiley \& Sons, Nova York. 
Curnow, R. N. \& Sharon Wheeler (1993) Probabilities of Incorrect Decisions in Paternity Cases using Multilocus Deoxyribonucleic Acid Probes. Journal of the Royal Statisical Society, Serie A, Vol. 156, parte 2, pp. $207-223$.

DeGroot, M. H. (1962) Uncertainty, information and sequential experiments. Annals Mathematical Statistics, 43, pp. 1428-1440.

Deka, R.; Jin, L.; Shriver, M.; Yu, L.; DeCroo, S.; Hundrieser, J.; Bunker, C.; Ferrel, R. e Chakraborty, R. (1995) Population genetics of dinucleotide $(d C-d A)_{n} .(d G-$ $d T)_{n}$ polymorphisms in world populations. American Journal of Human Genetics, 56, pp. $461-474$.

Devlin, B.; Risch, N. \& Roeder, K. (1992) Forensic inference from DNA fingerprints. Journal of the American Statistical Association, Vol 87, No. 418, pp. 337-350.

Diaconis, P. \& Freedman, D. (1987) A dozen de Finetti results in search of theory. Ann. Inst. H. Poincaré. Prob. Statist., 23, pp. 397-423.

Dickey, J. M. \& Lientz, B. P. (1970) The weighted likelihood ratio, sharp hypotheses about chances, the order of a Markov chain. Annals Mathematical Statistics, 41, pp. 214-266.

Emigh, J. M. \& Lientz, B. P. (1980) A comparison of tests for Hardy-Weinberg equilibrium. Biometrics, 36, 627-642.

Evett, I. W. (1992) Evaluating DNA Profiles in the Case Where the Defense Is: It Was My Brother. Journal of the Forensic Science Society, 32, pp. 5-14.

Evett, I.; Gill, P.; Scranage, J. \& Weir, B. (1996) Establishing the Robustness of Short Tandem - Repeat Statistics for Forensic Applications. American Journal of Human Genetics, 58, pp. 389-407.

Farah, Solange B. (1997) DNA Segredos 8 Mistérios. São Paulo, Sarvier.

Foreman, L.; Smith, A. \& Evett, I. (1997) Bayesian Analysis of DNA Profiling Data in Forensic Identification Applications. Journal Royal Statisical Society, Serie A, Vol. 160, parte 3, pp. $429-469$.

Geisser, S. \& Johnson, W. (1992) Testing Hardy - Weinberg Equilibrium on Allelic Data from VNTR Loci. American Journal of Human Genetics, 51, pp. 1084-1088.

Gill, P. et al. (1994) Identification of the remains of the Romanov Family by DNA analysis. Nat. Genetic, 6, pp. 130-135. 
Gill, P. \& Evett, IW. (1995) Population Genetics of short tandem repeat (STR) loci. Genética, 96, pp. 69-87.

Gjertson, D.; Mickey, M.; Hopfield, J.; Takenouchi, T. \& Terasaki, P. (1988) Calculation of Probability of Paternity Using DNA Sequences. American Journal of Human Genetics, 43, pp. 860-869.

Goel, P. K. \& Morris H. DeGroot (1979) Comparison of Experiments and Information Measures. The Annals of Statistics, Vol. 7, No. 5, pp. 1066 - 1077.

Goldgar, D. \& Thompson, E. (1988) Bayesian Interval Estimation of Genetic Relationships: Application to Paternity Testing. American Journal of Human Genetics, 42, pp. 135-142.

Gunel, E. \& Wearden, S. (1995) Bayesian estimation and testing of gene frequencies. Theo. Appl. Genet., 91, pp. 534-543.

Guo, S. \& Thompson, E. (1992) Performing the exact test for Hardy-Weinberg proportion for multiple alleles. Biometrics, 48, 361-372.

Hammmond, H.; Jin, L.; Caskey, C. \& Chakraborty, R. (1994) Evaluation of 13 Short Tandem Repeat Loci for use in personal identification applications. American Journal of Human Genetics, 55, pp. 175-189.

Hernández, J. L. \& B. S. Weir (1989) A disequilibrium coefficient approach to Hardy Weinberg testing. Biometrics, 45, 53-70.

Hochberg, Yosef \& Tamhane, A. (1987) Multiple comparison procedures. John Wiley and Sons, New York.

Ihara, Shunsuke (1993) Information Theory for Continuous Systems. World Scientific $\mathrm{Pu}$. Co., Singapure.

Irony, T. Z. \& Pereira, C. A. de B. (1995) Bayesian Hypothesis Test: Using surface integrals to distribute prior information among hypothesis. Resenhas Vol. 2, Instituto de Matemática e Estatística, USP, São Paulo.

Jeffreys, A. J.; Turner, M. \& Debenham, P. (1991) The efficient of multilocus DNA fingerprint probes for individualization and establishment of family relationships, determined from extensive casework. American Journal of Human Genetics, 48, pp. $824-840$.

Khinchin, A. I. (1957) Mathematical Foundations of Information Theory. Dover, Nova York. 
Kullback, S. (1959) Information Theory and Statistics. Wiley, Nova York.

Lange, Kenneth (1995) Applications of the Dirichlet distribution to forensic match probabilities. Genética, 96, pp. 107-117.

Lazzeroni, L. C. \& Lange, K. (1997) Markov chains for Monte Carlo tests of genetic equilibrium in multidimensional contingency tables. The Annals of Statistics, Vol. 27, No. 1, $138-168$.

Levene, Howard (1949) On a matching problem arising in genetics. Annals of Mathematical Statistics, 20, 91-94.

Lindley, D. V. (1956) On a measure of the information provided by an experiment. Annals Mathematical Statistics, 27, 986-1005.

Maiste, P. J. (1993) Comparison of Statistical Tests for Independence at Genetic Loci with many Alleles. Tese de doutorado, North Carolina State University, Raleigh, NC.

Pavan, C. \& Da Cunha, B. (1966) Elementos de GENÉTICA. Companhia Editora Nacional, Editôra da Universidade de São Paulo, São Paulo.

Pena, Sérgio D.J \& Ranajit Chakraborty (1994) Paternity testing in the DNA era. Reviews, Vol. 10, No. 6, pp. $204-209$.

Pereira, C. A. de B. (1985) Teste de hipóteses definidas em espaços de diferentes dimensões: visâo Bayesiana $\epsilon$ interpretação Clássica. Tese de livre docente, São Paulo, Instituto de Matemática e Estatística, USP.

Pereira, C. A. de B. \& Wechsler. S. (1993) On the concept of P-value. Revista Brasileira de Probabilidade e Estatística, Vol. 7, No. 2, pp. 159-177.

Robertson, B. \& G. A. Vignaux (1995) INTERPRETING EVIDENCE Evaluating Forensic Science in the Courtroom. Chichester, John Wiley \& Sons.

Roeder, Kathryn (1994) DNA fingerprinting: a review of the controversy. Statistical Science, Vol. 9, No. 2, pp. 222-278.

Singer, J.; Peres, C. \& Harle. C'. (1996) Performance of Wald's Test for the HardyWeinberg Equilibrium with fixed Sample Sizes. Brazilian Journal of Probability and Statistics, Vol 10, No. 1, pp. 59-68.

Smith, A. \& Bernardo, J. (1994) Bayesian Theory. John Wiley, Nova York. 
Weir, Bruce (1996) Genetic Data Analysis II. Sinauer Associates, Inc., Sunderland. Whittle, Martin (1997) Correspondência pessoal. São Paulo.

Whittle, Martin (1998) Base de dados - correspondência pessoal. São Paulo. 